UNIVERSIDADE DE SÃO PAULO ESCOLA DE ENGENHARIA DE SÃO CARLOS DEPARTAMENTO DE ESTRUTURAS

\title{
CARREGAMENTO CRÍTICO DE INSTABILIDADE GERAL DE PILARES DE SEÇÃO COMPOSTA VARIÁVEL, DE EDIFÍCIOS INDUSTRIAIS METÁLICOS
}

JOÃO ALBERTO VENEGAS REQUENA

TESE APRESENTADA À ESCOLA DE ENGENHARIA DE SÃO CARLOS, DA UNIVERSIDADE DE SÃO PAULO, COMO PARTE DOS REQUISITOS PARA OBTENÇÃO DO TÍTULO DE DOUTOR EM ENGENHARIA DE ESTRUTURAS

ORIENTADOR:

Prof. Dr. TIOETURO YAGUI

SÃO CARLOS, AGOSTO DE 1995 


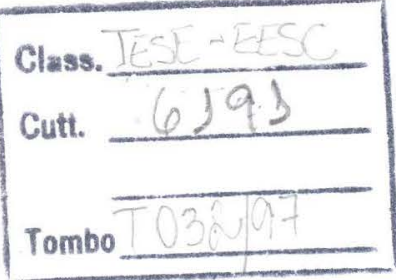

st 0746972

Venegas Requena, João Alberto

V554c Carregamento crítico de instabilitade geral de pilares de seção composta variável, de edifícios industriais metálicos.

-- São Carlos, SP., 1995.

$122 \mathrm{p}$.

Tese (Doutorado) - Escola de Engenharia de São

Carlos - Universidade de São Paulo, 1995.

Orientador: Prof. Dr. Tioeturo Yagui

1. Edificios industriais. 2. Estruturas metálicas

I. Título. 
Dedicado a

Terê. 


\section{AGRADECIMENTO}

Ao Prof. Dr. Tioeturo Yagui pela orientação $e$ ajuda no desenvolvimento deste trabalho.

Ao Prof. Dr. José Luiz Fernandes de Arruda Serra pela contribuição efetiva no desenvolvimento deste trabalho.

Aos colegas, professores e funcionários do Departamento de Construção Civil, da Faculdade de Engenharia Civil da Universidade Estadual de Campinas (UNICAMP), pelo apoio e incentivo.

Ao setor de Edição de Textos pelos desenhos e em especial a Fábio Roberto Eleutério e Alessandra Simões pelo apoio na digitação e impressão final deste trabalho. 


\section{SUMÁRIO}

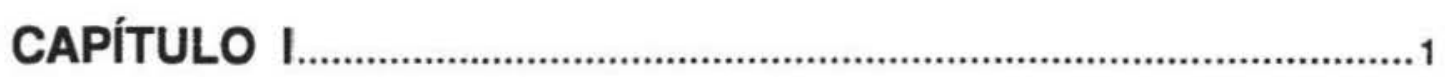

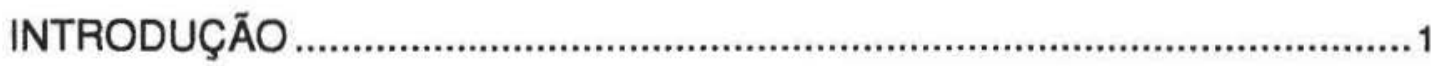

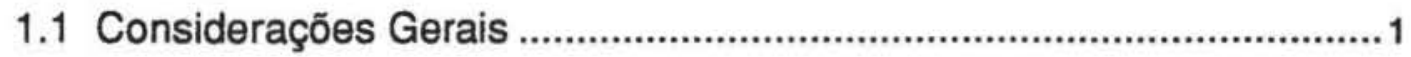

1.2 Situação do Problema...........................................................................

1.3 O Presente Trabalho........................................................................... 17

CAPÍTULO II 19

CARREGAMENTO CRÍTICO DE INSTABILIDADE ELÁSTICA POR FLEXÃO, DE PILARES dE SEÇÃO COMPOSTA VARIÁVEL, DE EDIFÍCIOS INDUSTRIAIS METÁLICOS ……............................................... 19

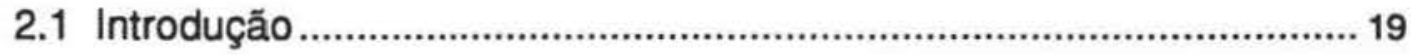

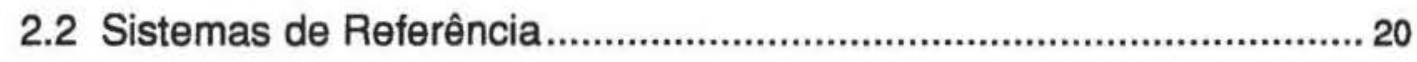

2.2.1 Sistema de Referência Global de Eixos para a Estrutura do

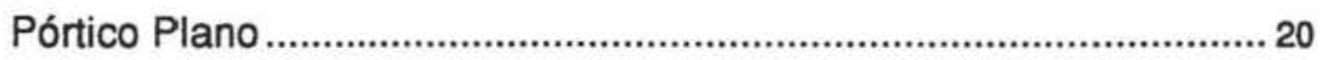

2.2.2 Sistema de Referência Local de Eixos para o Elemento de

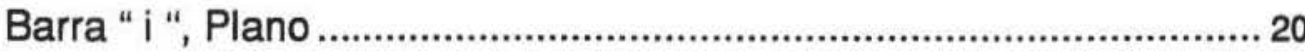

2.3 Matriz de Rigidez do Elemento de Barra ............................................ 21

2.3.1 Formulação da Matriz de Rigidez do Elemento de Barra Considerando o Efeito da Força Axial ....................................... 22

2.4 Matriz de Rigidez da Estrutura Formada por Elementos de Barra ...... 29

2.5 Cálculo dos Esforços e Deslocamentos da Estrutura, em Teoria de Primeira e Segunda Ordem .................................................................... 32

2.6 Processo Iterativo com Aproximações Sucessivas............................... 32 
2.7 Verificação da Estabilidade da Estrutura Submetida a um Determinado Carregamento.

2.8 Carregamento Crítico de Instabilidade, do Pórtico Plano do Edifício Industrial

CAPÍTULO III 42

CARREGAMENTO CRÍTICO DE INSTABILIDADE ELÁSTICA GERAL, DE PILARES DE SEÇÃO COMPOSTA VARIÁVEL, DE EDIFíCIOS INDUSTRIAIS METÁLICOS. 42

3.1 Introdução 42

3.2 Discretização dos Pilares de Seção Variável Compostos por Perfis Abertos e de Paredes Delgadas .................................................... 43

3.3 Hipóteses Adotadas no Processo ........................................................... 46

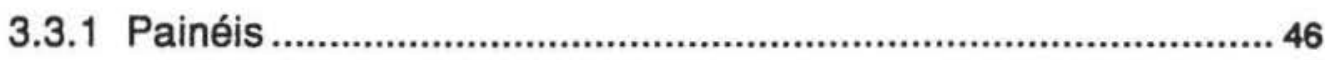

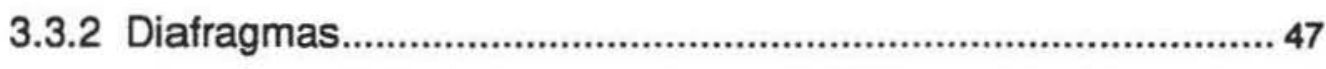

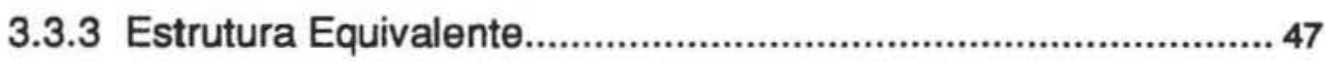

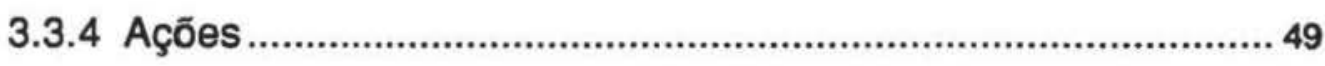

3.3.5 Vínculos Externos ....................................................................... 49

3.4 Sistemas de Referência....................................................................... 50

3.4.1 Sistema de Referência Global de Eixos para a Estrutura do Pórtico Transversal 50

3.4.2 Sistema de Referência Local de Eixos para o Elemento de Barra "i", da Trave 50

3.4.3 Sistema de Referência Local de Eixos para o Painel "j", do Pilar Discretizado 51

3.4.4 Sistema de Referência Local de Eixos para o Elemento "i" de Painel "j", do Pilar Discretizado

3.4.5 Sistema de Referência Local de Eixos para o Pilar Discretizado. 51

3.5 Matriz de Rigidez do Elemento de Painel 53 
3.6 Matriz de Rigidez do Pórtico Transversal

3.6.1 Contribuição dos elementos de painel do pilar da esquerda do pórtico transversal, denominado de "P1". 62

3.6.2 Contribuição dos elementos de barra que constituem a trave do pórtico transversal

3.6.3 Contribuição dos elementos de painel do pilar da direita do pórtico transversal, denominado de "P2" 72

3.6.4 Contribuição dos vínculos elásticos ............................................ 74

3.7 Determinação do carregamento crítico .................................................. 75

3.7.1 Cálculo dos esforços e deslocamentos ....................................... 75

3.7.2 Processo iterativo de aproximações sucessivas ......................... 75

3.7.3 Carregamento crítico de instabilidade geral................................75

CAPÍTULO IV 78

FLUXOGRAMA DAS PROGRAMAÇŌES PARA COMPUTADOR 78

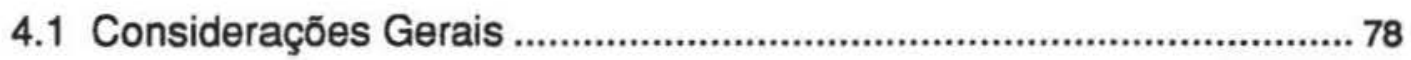

4.2 Fluxogramas Resumidos das Programações ...................................... 79

4.2.1 Carregamento crítico de instabilidade elástica por flexão de pórticos planos - programa Tipo I (PORTCRI7.FOR) ........ 79 4.2.2 Carregamento crítico de instabilidade geral, no regime elástico para estruturas com elementos discretizados e elementos de barra - programa tipo II (CARCRITF.FOR)

CAPÍTULO V 92

EXEMPLOS NUMÉRICOS E COMPARAÇÕES DE RESULTADOS 92

5.1 Introdução. 92

5.2 Exemplo Numérico 1. 93

5.3 Exemplo Numérico 2 100 
5.4 Exemplo Numérico 3

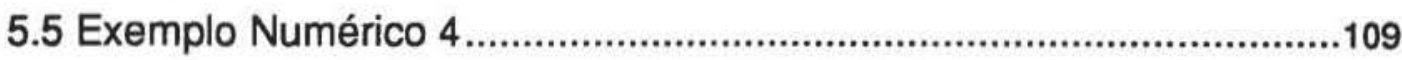

5.6 Exemplo Numérico 5 .........................................................................114

5.7 Exemplo Numérico 6 ...........................................................................117

CAPÍTULO VI....................................................................................124

CONCLUSÕES E CONSIDERAÇÕES FINAIS ............................................124

ANEXO A

ESTUDO DA DISTRIBUIÇĀO DE DIAFRAGMAS TRANSVERSAIS ............129

REFERÊNCIAS BIBLIOGRÁFICAS...............................................151 


\section{LISTA DE FIGURAS}

Figura l-1 Pórtico Transversal do Edificio Industrial com Ponte ROLANTE

Figura I-2 Sistema de Contraventamento Vertical de Pilar de PÓrtico TRANSVERSAL do EdifícIo IndUSTRIAL METÁlico........ 02

figura I-3 Pilares de Pórticos transversals de Edifícios INDUSTRIAIS........................................................................... 03

Figura I-4 Sistema de CONTRAVENTAMENTO do Banzo INFERIOR DAS TrAVES

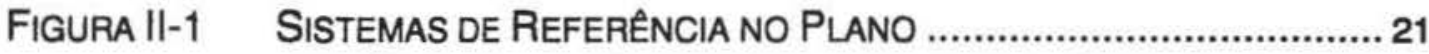

Figura ll-2 Elemento de Barra Plano no Estado Deslocado e DEFORMADO............................................................................. 22

Figura II-3 CoORdenadas Deslocamentos do Elemento de BARRA........ 24

Figura ll-4 Configuração Deformada do Elemento de Barra, $\operatorname{coM} \phi_{A}=1 \quad \theta \quad \phi_{B}=\Delta=$ zero $\ldots \ldots \ldots \ldots \ldots \ldots \ldots \ldots \ldots \ldots \ldots \ldots \ldots . .27$

Figura ll-5 Matriz de Rigidez da Barra Sujeita Às Funções de RIGIDEZ ............................................................................. 28

Figura ll-6 Submatriz de Transformação $[\mathrm{b}]_{i}$, de Ordem $6 \times \mathrm{N}$, do ELEMENTO DE BARRA

Figura III-1 Pilar com Variação brusca de Seção transversal do Tipo I, Utilizando Chapas Diafragmas nos Níveis A,.B E C.. 43

Figura III-2 Pilar Discretizado em Oito Painéis de Seis Tramos Cada UM. 
Figura III-3 A) Painel "J" de um Perfil, Representando Uma Parede, FORMADA POR SEIS EleMENTOS. B)PÓRTICO EQUIVALENTE à Parede, Formado por Vigas e Uma Coluna Central. C) ELEMENTO DE PAINEL

Figura III-4 Relações entre Comprimento e largura dos tramos do Pilar Central do Pórtico Equivalente ............................ 48

FIGURA III-5 SISTEMAS DE REFERÊNCIA. ...................................................... 52

Figura III-6 Modelo de Elemento de Painel e Sistema de COORDENADAS DESLOCAMENTOS............................................. 53

Figura III-7 Elemento de Painel na Posiçāo Deslocada e Deformada E O CORRESPONDENTE SISTEMA DE COORDENADAS DE BARRA .. 55

Figura III-8 Matriz de Rigidez do Elemento de Painel Sujeita às FunçóES DE RIGIDEZ, NAS COORDENADAS DO ELEMENTO dE BARRA. 57

Figura III-9 Matriz de Rigidez do Elemento de Painel. 60

FIGURA III-10 EXEMPLIFICAÇÃo DA NUMERAÇÃO DAS COORDENADAS Deslocamentos no Sistema Global do pórtico TRANSVERSAL

Figura III-11 Sistema de Orientação de Um Elemento de Painel "I", COINCIDENTE COM A ORIENTAÇÃo dO PAINEL "J"

Figura III-12 Coordenadas Deslocamentos do Primeiro Diafragma Transversal de UM Pilar Discretizado Formado por PAINÉIS.

Figura III-13 Submatriz de Transformação de Ordem $8 \times$ NT, OBtida DE PARTE DA MATRIZ DE TRANSFORMAÇĀO [T]

Figura III-14 Submatriz de Transformação de Ordem 6 x nt, Obtida DE PARTE da MATRIZ de TRANSFORMAÇĀo [B] 69

FIGURA V-1 ESTRUTURA DO EDIFICIO INDUSTRIAL ..........................................9 94

Figura V-2 Modelagem dos Pilares Isolados do Edificio Industrial

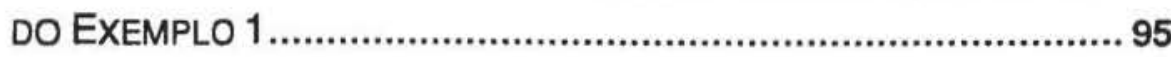

FIGURA V-3 ESTRUTURA DO EDIFÍCIO INDUSTRIAL ........................................101 
FiguRA V-4 MODELAGEM do PÓRTICO dO EXEMPLO 2

Figura V-5 A) Características Geométricas; B) Sistema de CoOrdenadas Deslocamentos e Posições dos DIAFRAGMAS PARA DISCRETIZAÇÃO …......................................107

Figura V-6 Modelagem da Viga em Balanço, Feita Pelo ANSYS...........110

Figura V-7 Vista Amplada da Viga em Balanço com AçÃo UNitária APLICADA NO CG DA SEÇÃO DA EXTREMIDADE LIVRE..................111

Figura V-8 Diagramas dos Resultados de "P $P_{C r} \times$ E" Para a Viga do Exemplo 4, Comparando o Programa Proposto com o Programa ANSYS

Figura V-9 Características Geométricas da Viga-Coluna...................114

FIGURA V-10 Modelos EstrutURAIS PARA ANÁLISE......................................118

Figura V-11 Características Geométricas das Seçōes Transversais E Sistema de CoORdenadas Locais para O EXEMPLO NUMÉRICO 6 


\section{LISTA DE TABELAS}

TABELA II-1 FunçÕES de Rigidez PARA BARRA COM INTERAÇÃo ENTRE FORÇA AXIAL; ForÇA CORTANTE E FLEXÃO.

TABela III-1 Funçóes de Rigidez para O Elemento de Painel Com INTERAÇÃo ENTRE FORÇA NORMAL; ForÇA CORTANTE; FLEXÃo E TORÇÃO.

tabela V-1 Valores dos Comprimentos Efetivos de flambagem OBTIDOS DO EXEMPLO NÚMERO 1 ................................................98

TABELA V-2 ComparaÇÃo entRe OS EfEITOS dos VínCULOS No PILAR...........103

TABela V-3 Resultados Comparativos "P ${ }_{C R}$ XE" do EXemplo 4 113 


\section{LISTA DE SIGLAS}

ABNT - Associação Brasileira de Normas Técnicas

AISC - American Institute of Steel Construction

AISE - Association of Iron and Steel Engineers

ASD - Allowable Stress Design

BISRA - British Iron and Steel Research Association

LRFD - Load and Resistance Factor Design

SSRC - Structural Stability Research Concil 


\section{LISTA DE SÍMBOLOS}

Ax - Área da seção transversal, do elemento de barra, do elemento de painel ou da seção transversal do pilar

$\mathrm{C}_{\mathrm{i}} \quad$ - Comprimentos dos espaços ou tramos, entre diafragmas transversais, dos painéis de um pilar discretizado

Cm - Coeficiente utilizado nas expressões de flexão-composta que considera a deslocabilidade da estrutura

CTV - Contraventamento

E - Módulo de elasticidade longitudinal

F - Ação concentrada

$\mathrm{F}_{\mathrm{a}} \quad$ - Tensão axial admissível do elemento de barra, considerando a esbeltez no plano de menor rigidez

F $\quad$ - Tensão de flexão admissível do elemento de barra, que pode considerar a possibilidade de instabilidade lateral por torção

$\mathrm{F}_{\text {e }} \quad$ - Tensão axial crítica de Euler, por flexão, do elemento

G - Módulo de elasticidade transversal

$\mathrm{H}_{\mathrm{i}} \quad$ - Alturas das partes superior e inferior do pilar de seção variável

IBC - Índice da barra " $\mathrm{i}$ " obtido com a força axial $\mathrm{P}_{\mathrm{i}}$, o mais próximo de $\mathrm{P}_{\mathrm{Ei}}$

Ir - Momento de inércia, em relação ao eixo " $Y$ ", do sistema de referência local de eixos, do elemento de barra, do elemento de painel ou do pilar 
Iz - Momento de inércia, em relação ao eixo " $z$ ", do sistema de referência local de eixos, do elemento de barra, do elemento de painel ou do pilar

$J_{1} \quad$ - Momento de inércia à torção

$J_{w} \quad-\quad$ Momento setorial de inércia

L - Comprimento de elemento ou vão livre

$M_{a} \quad$ - Momento fletor no ponto $A$, do elemento de barra

$M_{b} \quad$ - Momento fletor no ponto B, do elemento de barra

MxA - Momento torçor no ponto A, do elemento de barra

MxA - Momento torçor no ponto B, do elemento de barra

Np1 - Número total de coordenadas deslocamentos do pilar da esquerda, $\mathrm{nf}_{1} \times \mathrm{nd}$

P - Força axial, no elemento de barra, no elemento de painel ou na seção transversal do pilar. Ação concentrada aplicada

$\mathrm{P}_{\mathrm{Ci}}$ - Força axial no elemento de barra " $\mathrm{i}$ ", obtido das cargas constantes

$P_{E l} \quad$ - Força axial de Euler, no elemento de barra " $i$ "

$P_{i} \quad$ - Força axial no elemento de barra " $i$ " da estrutura com carregamento obtido com $\mathrm{W}=1$

$P_{C R}$ - Força axial crítica de instabilidade no elemento de barra " $i$ "

$\mathrm{P}_{\mathrm{Vi}_{\mathrm{i}}}$ - Força axial no elemento de barra " $\mathrm{i}$ ", obtido das cargas vivas

Q - Carga de içamento da ponte rolante

$\mathrm{S}_{\mathrm{ij}} \quad$ - Coeficientes da matriz de rigidez do elemento de barra, para linha " $i$ " e coluna " $j$ " 
TTR - Ação horizontal da ponte rolante, transversal ao edifício industrial

$T_{L} \quad$ - Ação horizontal da ponte rolante, longitudinal ao edifício industrial

TOL - Tolerância utilizada no processo computacional

$V_{a} \quad$ - Força cortante no ponto $A$, do elemento de barra

$V_{b} \quad$ - Força cortante no ponto $B$, do elemento de barra

W - Parâmetro de proporcionalidade das cargas vivas

WA - Limite inferior do parâmetro das cargas vivas

WB - Limite superior do parâmetro das cargas vivas

$W_{C R}$ - Parâmetro crítico que conduz ao carregamento crítico da estrutura

$\mathrm{W}_{\mathrm{E}} \quad$ - Parâmetro multiplicador das cargas vivas, para que a barra mais crítica atinja $P_{E}$, de Euler

$\mathrm{W}_{\text {MAX - }} \quad$ Parâmetro máximo multiplicador das cargas vivas que um pórtico pode suportar sem perder a estabilidade

$\{\mathrm{V}\} \quad=$ Vetor deslocamento da estrutura do pórtico transversal, de ordem $\mathrm{nt} \times 1$, nas coordenadas globais

$\left[A_{K}\right]_{1}^{i}$ - Matriz de rigidez do elemento genérico "i", do painel genérico "ju, no espaço " $\mathrm{C}_{\mathrm{i}}$ " entre diafragmas

[S] - Matriz de rigidez pórtico transversal, de ordem nt $x \mathrm{nt}$, nas coordenadas globais

$[T]_{\mathrm{i}}^{\mathrm{j}^{\top}}$ - $\quad$ Matriz transposta de $[\mathrm{T}]_{\mathrm{i}}^{\mathrm{l}}$

$[\mathrm{b}]_{i}^{\top} \quad$ - Matriz transposta de $[\mathrm{b}]_{\mathrm{i}}$

\{V\} - Vetor deslocamento da estrutura do pórtico transversal, de ordem $\mathrm{nt} \times 1$, nas coordenadas globais 
$\left\{d_{1}\right\}_{i}$ - Vetor deslocamento do elemento de painel "i", do pilar "P1", de ordem $8 \times 1$, nas coordenadas locais do elemento

$\left\{d_{2}\right\}_{i}$ - Vetor deslocamento do elemento de painel "i", do pilar "P2", de ordem $8 \times 1$, nas coordenadas locais do elemento

$\left\{d_{T R}\right\}_{i}$ - Vetor dos deslocamentos do elemento de barra " $i$ ", da trave, de ordem $6 \times 1$, nas coordenadas locais do elemento

$\{d\}_{i}^{i}$ - Vetor dos deslocamentos, do elemento "i" do painel "j"

$\{F\}_{i}^{i}$ - $\quad$ Vetor dos esforços, do elemento "i" do painel "j"

$\left[A_{K}\right]_{i}^{j}-\quad$ Matriz de rigidez do elemento genérico " $i$ " do painel genérico "j" no espaço " $\mathrm{C}_{i}$ " entre diafragmas

$[T]_{i}^{\top}$ - Matriz transposta de $[T]_{i}^{\mathrm{j}}$

$[T]_{i(8 \times n t)}^{j} \quad$ Submatriz de ordem $8 \times n$ nt, correspondente ao elemento "i" do painel "j", da matriz de transformação [T], que relaciona os deslocamentos da estrutura do pórtico transversal " $\mathrm{V}$ ", com os deslocamentos dos elementos de painel " $\mathrm{d}_{1}$ ", do pilar "P1"

$[T]_{i(8 \times n) t}^{j} \quad$ Submatriz de ordem $8 \times \mathrm{nt}$, Fig. III-13, correspondente ao elemento "i" do painel "j", da matriz de transformação [T], que relaciona os deslocamentos da estrutura do pórtico transversal " $V$ ", com os deslocamentos dos elementos " $d_{2}$ " de painel, do pilar "P2"

[b] - Matriz de transformação que relaciona os deslocamentos da estrutura com os deslocamentos dos elementos, de ordem $6 \mathrm{nb} \times \mathrm{n}$

[b]i - Submatriz de transformação, de ordem $6 \times \mathrm{n}$, correspondente ao elemento " $i$ ", da matriz de transformação [ $b$ ]

[D] - Matriz de rigidez diagonal genérica

[ L ] - Matriz de rigidez triangular inferior genérica 
[S ] - Matriz de rigidez genérica

[ $\left.\mathrm{S}_{\mathrm{KB}}\right]_{\mathrm{i}}$ - Matriz de rigidez do elemento de barra " $\mathrm{i}$ ", no sistema local de coordenadas, de ordem $6 \times 6$

[ $\mathrm{S}_{\mathrm{KG}}$ ] - Matriz de rigidez da estrutura, no sistema global de coordenadas, de ordem $n \times n$

[A $]$ - Matriz de rigidez do elemento de painel, de ordem $8 \times 8$, em suas coordenadas locais, Fig.III-9

[b] - Submatriz de ordem $6 \times \mathrm{nt}$, correspondente ao elemento "i", da matriz de transformação [b], que relaciona os deslocamentos da estrutura do pórtico transversal " $\mathrm{V}$ ", com os deslocamentos dos elementos de barra da trave " $\mathrm{d}_{\mathrm{TR}}$ "

[bp ] - Matriz de transformação, de ordem $8 \times 8$ que relaciona os deslocamentos das coordenadas do elemento de painel com os deslocamentos do elemento de barra

[S] - Matriz de rigidez da estrutura do pórtico transversal, de ordem $\mathrm{nt} \times \mathrm{nt}$, nas coordenadas globais

[S $S_{K}$ - Matriz de rigidez do elemento de painel de ordem $8 \times 8$, nas coordenadas do elemento de barra, Fig.III-8

$\left[\mathrm{S}_{\mathrm{KB}}\right]_{\mathrm{i}}$ - Matriz de rigidez do elemento genérico de barra "i", da trave do pórtico transversal, de ordem $6 \times 6$, nas coordenadas locais

\{A\} - Vetor das ações da estrutura, no sistema global de coordenadas, de ordem $\mathrm{n} \times 1$

\{D \} - Vetor dos deslocamentos da estrutura, no sistema global de coordenadas, de ordem $\mathrm{n} \times 1$

$\left\{D_{L}\right\}_{i}$ - Vetor dos deslocamentos do elemento de barra " $i$ ", no sistema local de coordenadas, de ordem $6 \times 1$

$\{\mathrm{F}\}_{\mathrm{i}}$ - Vetor dos esforços do elemento de barra " $\mathrm{i}$ ", no sistema local de coordenadas, de ordem $6 \times 1$ 
b - Largura de um painel

cf - Coeficiente de forma

c - Gabarito máximo de aproximação do carrinho da ponte rolante

$C_{i} \quad$ - Número do tramo ou espaço considerado entre dois diafragmas transversais, a numeração é sempre feita da base do pilar para o topo

$e_{i} \quad$ - Excentricidade de ação aplicada

$f_{a} \quad$ - Tensão axial atuante, no elemento de barra

$f_{a}^{\prime} \quad$ - $\quad$ Tensão axial atuante, no elemento de barra, acrescida da tensão de flexão atuante no plano de maior rigidez

$f_{b x} \quad$ - Tensão de flexão atuante, no elemento de barra, em relação ao eixo $x$ de maior inercia (plano do pórtico)

fby - Tensão de flexão atuante, no elemento de barra, em relação ao eixo y de menor inércia (plano perpendicular do pórtico)

i - Índice do número do elemento

io - Raio de giração polar em relação ao centro de torção

ji - Número do nó inicial do painel "j", ao nível do primeiro diafragma localizado na base do pilar, correspondente às coordenadas verticais

jk - Número do nó final do painel "j", ao nível do primeiro diafragma localizado na base do pilar, correspondente às coordenadas verticais

I - Comprimento do elemento

I $\quad$ - Distância à esquerda da carga de içamento da ponte rolante

Id - Distância à direita da carga de içamento da ponte rolante 
n - Número de coordenadas totais da estrutura formada por elementos de barra, no sistema global de coordenadas

nb - Número de elementos de barra, na trave

$n_{1}$ - Número de espaços(tramos) entre diafragmas, "nf $f_{1}-1$ ", em "P1"

$\mathrm{nc}_{2}$ - Número de espaços entre diafragmas, " $\mathrm{nf} \mathrm{f}_{2}$ - 1", em "P2"

ncf1 - Número da coordenada horizontal, Tipo 1, do diafragma considerado, no eixo global " $y_{G}$ "

ncml - Número da coordenada momento de extremidade da barra conectada ao pilar

nd - Número de coordenadas deslocamentos em cada diafragma transversal do pilar

$n e_{1} \quad$ - Número de elementos de painel em "P1", ne $e_{1}=n c_{1} \times n p_{1}$

$n e_{2} \quad$ - Número de elementos de painel em "P2", $n e_{2}=n c_{2} \times n p_{2}$

$\mathrm{nf}_{1} \quad$ - Número de diafragmas transversais, em "P1"

$\mathrm{nf}_{2} \quad$ - Número de diafragmas transversais, em "P2"

nj - Número do nó inicial "j" do elemento de barra "i"

nk - Número do nó final "k" do elemento de barra "i"

nml - Número de nós da trave conectados aos pilares do pórtico transversal

nnos - Número de nós da trave, do pórtico transversal

$\mathrm{np}_{1} \quad$ - Número de painéis do pilar "P1"

$\mathrm{np}_{2} \quad$ - Número de painéis do pilar "P2"

nt - Número total de coordenadas da estrutura do pórtico transversal, no sistema global 
ntab - Número de coordenadas deslocamentos acumuladas do pilar "P1" e da trave, excluindo as coordenadas do pilar "P2"
qw - $\quad$ Ação uniformemente distribuída
$t \quad$ - Espessura de um painel
$v_{D} \quad$ - Deslocamento do centro de torção da seção na direção do eixo $y$

$w_{D}$ - Deslocamento do centro de torção da seção na direção do eixo $z$

$x, y, z$ - Eixos cartesianos do sistema de referência local de um elemento de barra do pórtico plano

$\mathrm{X}_{G}, \mathrm{Y}_{G}, \mathrm{Z}_{\mathrm{G}} \quad$ Eixos cartesianos do sistema de referência global de uma estrutura

xi,yi,zi - Eixos cartesianos do sistema de referência local, de um elemento de barra "i" da trave

xij,yij,zij Eixos cartesianos do sistema de referência local, de um elemento "i" do painel "j" do pilar discretizado

xj,yj,zj - Eixos cartesianos do sistema de referência local, de um painel "j" do pilar discretizado

$\mathrm{x}_{\text {pil }}, \mathrm{Y}_{\text {pil }}, \mathrm{Z}_{\text {pil }} \quad$ Eixos cartesianos do sistema de referência local, de um pilar discretizado, do pórtico transversal

$\mathrm{x}_{\mathrm{S}}, \mathrm{y}_{\mathrm{S}}$ - Eixos paralelos aos eixos globais $\mathrm{x}_{G}, \mathrm{y}_{\mathrm{G}}$, com origem $\mathrm{O}_{\mathrm{S}}$ coincidente com a origem local da barra $O_{1}$

$\gamma \quad$ - Ângulo formado entre os eixos do sistema global e local de referência, para o plano $x y$

$\Delta \quad$ - Deslocamento relativo dos pontos $\mathrm{A}$ e B de extremidade de barra 
$\rho \quad$ - $\quad$ Relação entre as forças atuantes no elemento de barra e as forças de Euler no mesmo elemento

$\phi_{\mathrm{A}} \quad$ - Deslocamento angular no ponto A, do elemento de barra

$\phi_{B} \quad$ - Deslocamento angular no ponto $B$, do elemento de barra

$\sigma_{c} \quad$ - Tensão normal provocada pelas cargas constantes

$\sigma_{\max } \quad$ - Máxima tensão normal

$\sigma_{\mathrm{P}} \quad$ - Tensão limite de proporcionalidade do material

$\sigma_{\mathrm{V} 1} \quad$ - Tensão normal provocada pelas cargas vivas, com parâmetro unitário

$\phi x \quad$ - $\quad$ Rotação da seção em torno do centro de torção

$\phi_{X A}$ e $\phi_{X B} \quad$ Rotações de torção nas extremidades A e B 


\section{RESUMO}

Neste trabalho, é apresentado um processo de análise de estruturas de edifícios industriais metálicos, constituídas de pilares de seção composta, com variação brusca de seção ao nível de assentamento da viga de rolamento, e traves em treliça. $O$ processo tem como objetivo a determinação do carregamento crítico que produz a instabilidade elástica geral por flexão ou por flexo-torção, dos pilares supostos engastados na base e vinculados elasticamente na sua extremidade superior à trave do telhado. A estrutura é analisada pelo processo dos deslocamentos, empregando-se a técnica matricial com discretização de seção dos pilares, de modo que todo o pilar discretizado seja representado por uma estrutura tridimensional equivalente composta por barras. Esta análise é desenvolvida no regime elástico, em teoria de segunda ordem, computando as modificações nas condições de equilíbrio decorrentes do estado deslocado da estrutura. Como parte do desenvolvimento do trabalho, é analisado inicialmente os efeitos dos vínculos elásticos na parte superior dos pilares, os quais modificam os comprimentos efetivos de flambagem, considerando o pórtico transversal apenas com elementos de barra deformáveis por flexão em seu plano. Finalmente, é analisado o comportamento completo dos pilares integrados à estrutura do pórtico transversal, considerando-os discretizados e vinculados à trave do telhado. Obtém-se então o limite de estabilidade dos pilares tridimensionais, deformáveis por flexão ou por flexotorção. Fluxogramas das programaçőes são apresentados para facilitar o entendimento do processo. Exemplos numéricos são apresentados e seus resultados são comparados com os obtidos por outros autores e com os da aplicação de recomendações de normas técnicas. Os resultados mostram que a aplicação do processo proposto fornece parâmetros capazes de representar o comportamento real dos pilares, possibilitando dimensionamentos mais precisos.

Palavra-chave: edifícios industriais metálicos - estruturas - pilares de seção variável - instabilidade 


\section{ABSTRACT}

This thesis presents a process for analysis of steel industrial buildings, with stepped columns with sudden variation of section at the level of the crane runway girder and truss chords. The process aims at the determination of the global elastic, flexural or flexural-torsional, instability limit for columns with fully restrained rotations at the basis and elastically connected to the chord. The stiffness method is applied, using the matrix analysis technique with discretization of the column elements, resulting an equivalent three-dimensional structure. The analysis is developed in second order theory, in the elastic range, computing the changes in equilibrium due to the deformed shape of the structure. First, the effects of elastic connections at the tops of the columns are analyzed. These effects are responsible for changes in the effective buckling lengths, considering the transversal frame as beam elements deforming by bending in their own planes. Finally, an analysis is performed for the overall behavior of the whole transversal frame structure, with the discretized columns connected to the frame chord. The stability limit is obtained for the three-dimensional columns, which is deformable by bending or torsion-bending. Flowcharts are presented to help in the process understanding. Numerical examples are presented, comparing to results obtained by other researchers or to specifications from technical norms. Results show that the application of the proposed approach leads to parameters capable of representing the actual behavior of the columns, thus resulting in more efficient design.

Keywords: mill buildings - structures - stepped columns - stepped crane columns - instability 


\section{CAPÍtULO I}

\section{INTRODUÇÃO}

\subsection{CONSIDERAÇÕES GERAIS}

Serão designados de edifícios industriais, aqueles cujas estruturas são projetadas para abrigar máquinas e processar materiais que devido ao seu peso, necessitam das chamadas pontes rolantes para o seu deslocamento. Estas, por sua vez, são constituídas de estruturas rígidas que se movem por meio de motores elétricos, sobre vias de rolamento dispostas longitudinalmente ao edifício e apoiadas nas partes superiores dos pilares, em alturas compatíveis com os gabaritos das máquinas situadas no piso, de modo que as cargas quando transportadas por elas não colidam com essas máquinas.

Os edifícios industriais são geralmente de um só piso de um só vão e requerem estruturas com pouca deslocabilidade, principalmente sob as açōes das pontes rolantes. Estas características básicas podem ser encontradas nos edifícios industriais do tipo Shed e do tipo Duas Águas.

As estruturas metálicas dos edifícios industriais são compostas por pórticos transversais planos, constituídos de pilares e em geral, traves em treliça, ligados rigidamente entre si, exemplificado na Fig.l-1. Os elementos longitudinais, como vigas de rolamento, longarinas laterais e terças, ligam esses pórticos de modo que, juntamente com os contraventamentos convenientemente colocados, formem o sistema estrutural tridimensional estável. Os pilares ficam contraventados, no plano perpendicular ao dos pórticos transversais, pelo sistema vertical de contraventamentos, ilustrado na Fig.l-2. 


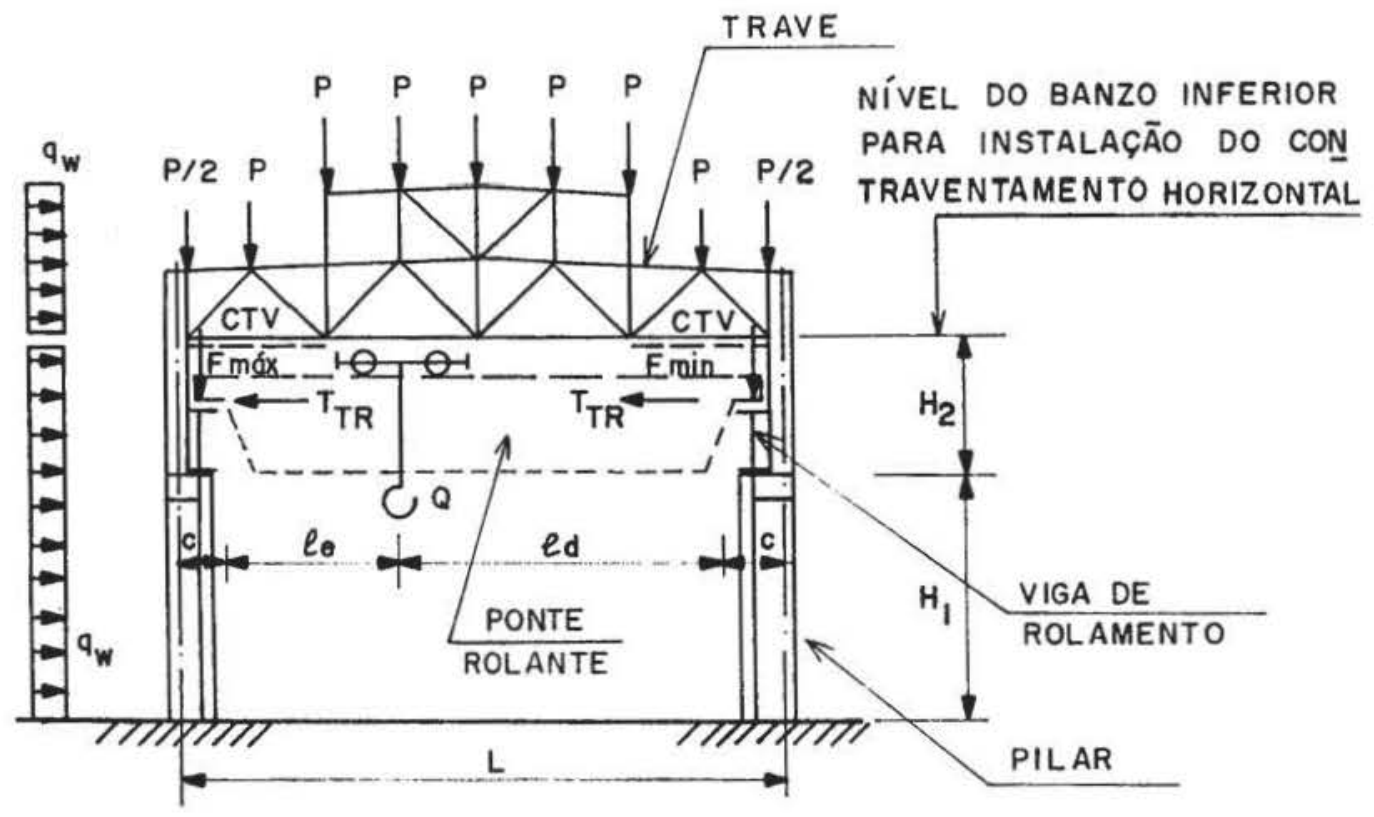

Figura I- 1 Pórtico Transversal do Edifício Industrial com Ponte Rolante (extraído da ref. 31 )

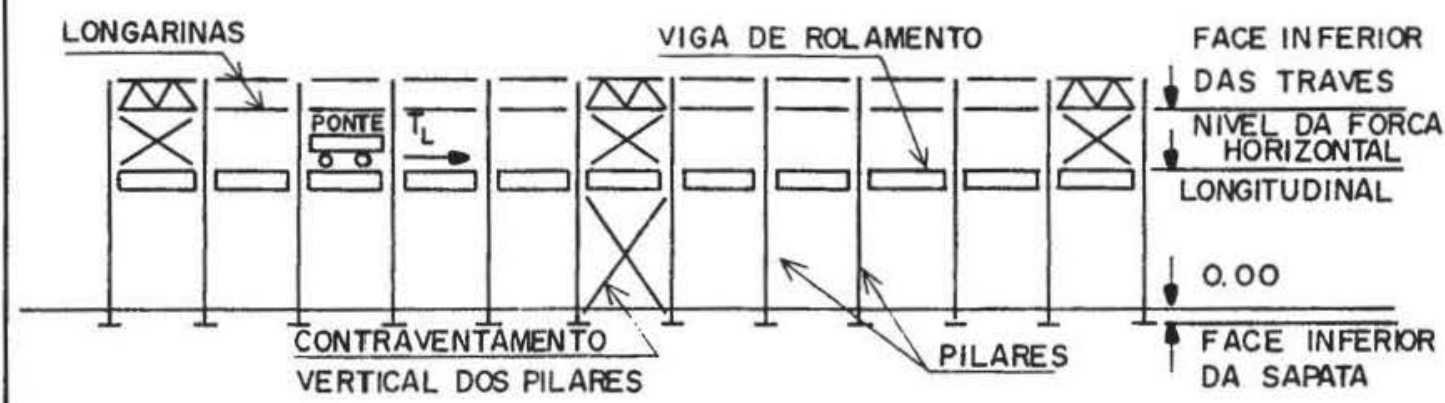

Figura I - 2 Sistema de Contraventamento Vertical de Pilar de Pórtico Transversal do Edifício Industrial Metálico 
Os pilares dos pórticos transversais são responsáveis pela rigidez da estrutura e, dependendo do carregamento, devem apresentar várias formas. Para estruturas com pontes rolantes leves, (capacidade de içamento inferior a $Q=10 t$ ), os pilares são geralmente constituídos de perfis prismáticos, em alma cheia e possuem consoles para a fixação das vigas de rolamento, Fig.l-3a.
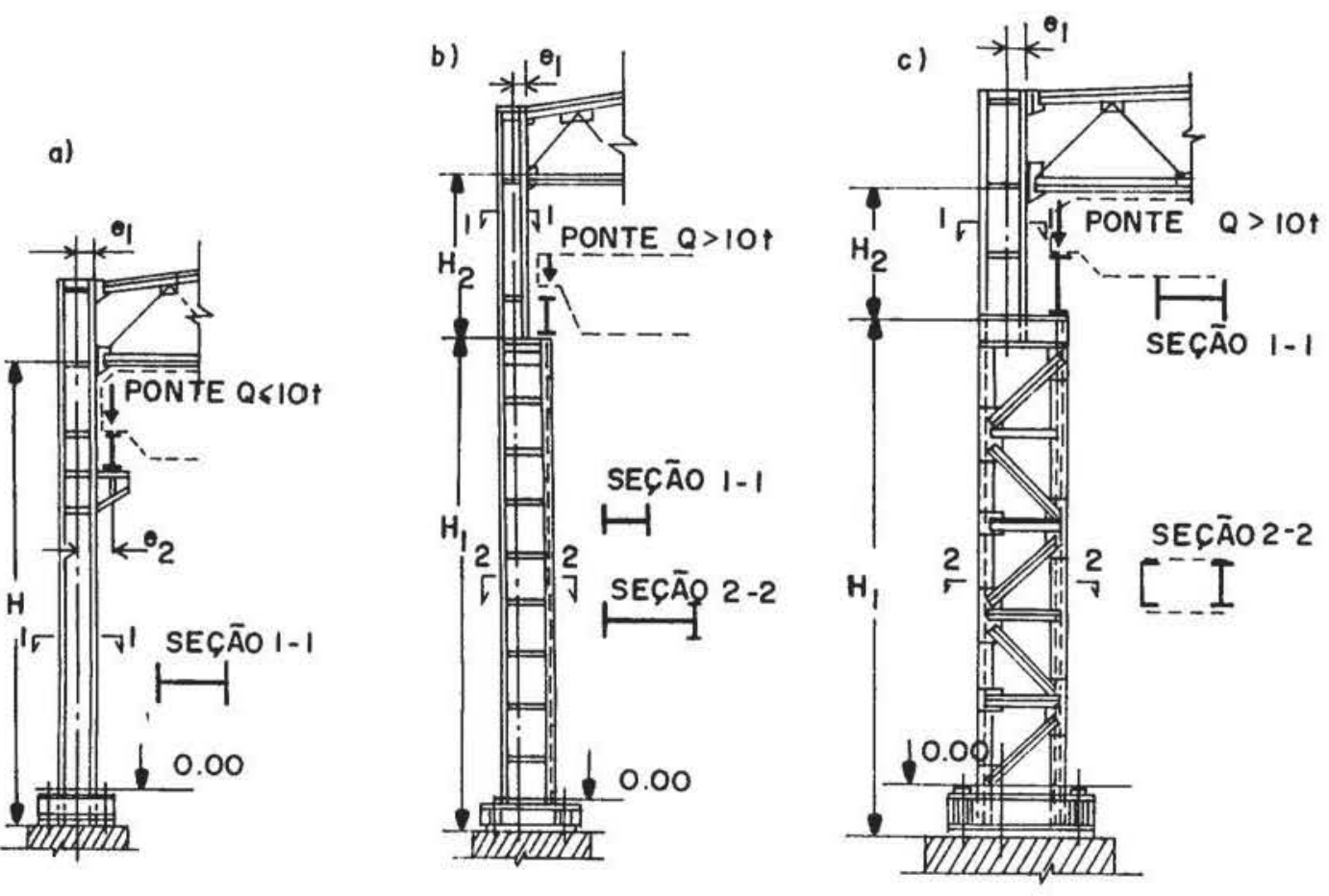

Figura I - 3 Pilares de Pórticos Transversais de Edifícios Industriais (extraído da ref. 31 )

Para estruturas conf pontes rolantes de maior capacidade $(Q>10 t)$, os pilares possuem um variação discreta de seção ao nível de assentamento da viga de rolamento. A parte superior do pilar deve resistir aos esforços provenientes da cobertura e a parte inferior do pilar deve resistir aos 
esforços combinados da ponte rolante e da cobertura. Desta forma, a rigidez da parte inferior do pilar deve ser bem maior que a rigidez da parte superior. Neste caso, costumam ser de dois tipos: a) com perfil em alma cheia do tipo I , na parte superior e treliça na parte inferior do pilar, Fig.l-3c; b) com perfil em alma cheia do tipo I, na parte superior e perfil em alma cheia composto de chapas na parte inferior do pilar, Fig.l-3b. Para este segundo tipo, a seção transversal da parte inferior do pilar deve ser composta de forma que a mesa interna, situada sob a viga de rolamento, deva concentrar maior área e rigidez em relação à mesa externa do pilar. Esta forma geométrica pode ser conseguida utilizando um perfil do tipo I de menor rigidez, na mesa externa do pilar e outro perfil do tipo I de maior rigidez, na mesa interna, ambos ligados por uma chapa que forma a alma da seção transversal do pilar. As vinculaçōes das bases dos pilares são adotadas dependendo do tipo de solo e da concepção estrutural pretendida, porém, são usualmente engastadas para garantir a rigidez necessária ao pórtico transversal, devido às ações verticais e horizontais contidas no plano do pórtico, provenientes da frenagem da ponte rolante.

As ações verticais proveniente da ponte rolante são transmitidas aos pilares do pórtico transversal " $F_{\max }$ e $F_{\text {min }}$ " através das vigas de rolamento. As ações horizontais transversais ao edifício industrial, resultantes da frenagem do carrinho " $\mathrm{TRR}_{\mathrm{TR}}$ ", são transmitidas pelos contraventamentos horizontais daquelas vigas aos mesmos pilares, agindo na direção do plano do pórtico. As ações horizontais longitudinais ao edifício industrial, resultantes da frenagem do carrinho "TL", são transmitidas pelos contraventamentos verticais dos pilares para as fundações. Para um determinado pórtico transversal, um pilar ficará com o carregamento vertical máximo " $\mathrm{F}_{\max }$ " quando $\mathrm{o}$ carrinho da ponte rolante estiver carregado e localizado o mais próximo possível dele. $O$ outro pilar ficará com a parcela restante bem menor " $F_{\min }$ ", Fig.l-1.

Além dos contraventamentos normais entre os banzos comprimidos das traves em treliça, situados entre os pórticos transversais, são geralmente utilizados também os contraventamentos horizontais ao nível dos banzos inferiores, dispostos em faixas longitudinais e transversais ao edifício industrial, formando uma espécie de chapa, Fig.l-4. Este tipo de contraventamento, tem a função de interligar os pórticos transversais de modo que todos eles fiquem solicitados quando ocorrer uma ação 
transversal, devido à frenagem da ponte rolante, atuando em um único pórtico.

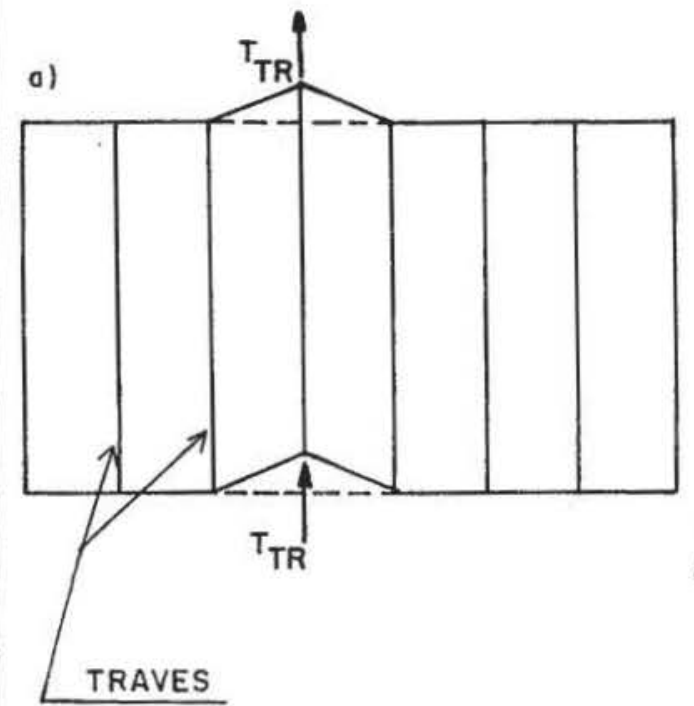

$\angle$ To CONTRAVENTAMENTO TRANSVERSAL NO BANZO INFERIOR

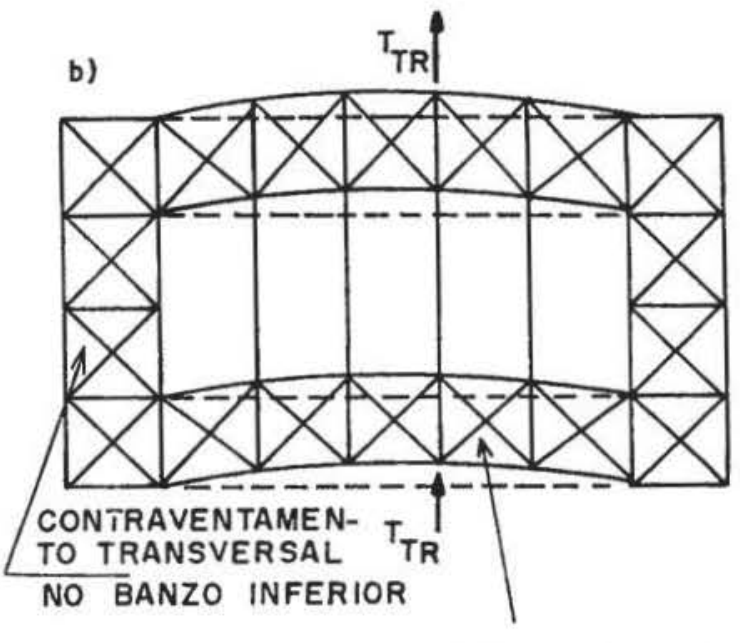

CONTRAVENTAMENTO LONGITUDINAL NO BANZO INFERIOR

Figura I - 4 Sistema de Contraventamento do Banzo Inferior das Traves (extraído da ref. 31 )

Os pilares dos edifícios industriais eram dimensionados, até recentemente, por processos semi-empíricos, com bases experimentais, com resultados pouco satisfatórios, sob o ponto de vista econômico. Um dos processos muito utilizado, é demonstrado no "Guide to Stability Design Criteria for Metal Strucutures" 6. Ele tem como base de cálculo as expressōes da "Specification for the Design, Fabrication and Erection of Steel Buildings" 1, AISC, com a utilização de tabelas do "Guide for the Design and Construction of Mill Buildings" 2 , AISE, para obtenção dos parâmetros de estabilidade. Este processo, apesar de ser adotado por muitos calculistas, pode conduzir a uma estrutura super dimensionada. 
Muitos fabricantes optaram por adotar suas próprias hipóteses de construção e seus próprios processos de dimensionamento de pilares, visto que são eles os principais responsáveis pelo consumo de aço na estrutura.

O principal motivo das divergências entre os calculistas, está na determinação dos comprimentcs efetivos de flambagem dos pilares de seção composta variável, no plano do pórtico. Estes pilares, além de possuírem variação discreta de seção e açōes diferenciadas ao longo do eixo, são ligados de modo contínuo à estrutura da cobertura, que é parte integrante do pórtico deslocável. Este fato causa a indeterminação do índice de esbeltez do pilar, complicando a resolução por métodos analíticos, a menos que se adotem hipóteses simplificadoras do comportamento real da estrutura.

As análises de estabilidade dos pilares, só contemplam o caso particular da instabilidade por flexão, ou seja, só consideram a flambagem elástica por flexão no plano do pórtico, também chamada de flambagem de Euler, com ações centradas e alinhadas, caracterizando problema de $1^{\underline{a}}$. espécie. Como os pilares são constituídos de perfis abertos, de chapas delgadas e com variação discreta de seção, a análise torna-se bem mais complexa, pois neste caso surgem os efeitos dos empenamentos não uniformes ao longo do eixo, forçando o surgimento de esforços de torçáo combinados ao de flexão. A análise completa do pilar abrange teorias mais complexas, como a de VLASSOV ${ }^{32}$, que possibilita 0 estudo da instabilidade geral, de barras de seções abertas de paredes delgadas, em sua forma tridimensional, incluindo os efeitos da flexo-torção.

Pretende-se, neste trabalho, analisar o carregamento crítico de instabilidade geral de pilares de seção composta por chapas delgadas, constituindo perfil aberto, com variação discreta de seção, com eixos longitudinais desalinhados. Neste carregamento, serão consideradas as ações transversais e axiais, assim como os efeitos do acoplamento rígido do pilar à trave em treliça, ou seja, analisando a instabilidade não mais como pilar isolado mas como elemento tridimensional integrante do pórtico deslocável, submetido ao carregamento global. 


\subsection{SITUAÇÃO DO PROBLEMA}

Até os anos ${ }^{50}$, poucos artigos foram oscritos e publicados, sobre os edifícios industriais com ponte rolante. Apesar do alto custo dessas estruturas e de serem muito utilizadas, pouco se estudou sobre 0 assunto, negligenciando o seu problema de otimização.

Os critérios de dimensionamento eram definidos pelas próprias indústrias de estruturas metálicas, através de estudos próprios e processos empíricos, baseados em normas não específicas. Seus resultados não eram divulgados nem discutidos.

Em 1941, a AISE (Association of Iron and Steel Engineers) fez uma investigação sobre 0 assunto, pois lançou dúvidas sobre as hipóteses adotadas na época. Revendo principalmente os critérios de dimensionamento da viga de rolamento e, em segundo lugar, dos pilares, concluiu que havia muita discordância entre os projetistas, principalmente com relação aos pilares dos edifícios industriais. Em muitos casos havia super dimensionamento e em outros casos havia falta de segurança na estrutura. Os critérios de verificação da estabilidade da estrutura tinham que ser discutidos e comprovados cientificamente.

Em 1955, a BISRA (British Iron and Steel Research Association) fez avaliaçōes sobre edifícios industriais com ponte rolante e concluiu que a AISE, entre outras associações, necessitava de maiores estudos para adotar procedimentos padronizados de cálculo completo sobre 0 assunto, pois ainda não havia surgido especificações e critérios satisfatórios.

As normas técnicas abordam o problema de elementos estruturais submetidos a esforços combinados, de compressão e de flexão, utilizando expressões de interação que apresentam no primeiro termo a influência da compressão centrada e no segundo termo a influência da flexão majorada do efeito de segunda ordem provocado pela compressão, no plano da flexão. O primeiro termo é geralmente analisado sob o aspecto de flambagem por flexão no plano de menor rigidez do elemento e o segundo termo é geralmente analisado sob o aspecto de flambagem lateral por torção. Os pilares dos edifícios industriais apresentam características próprias como variações discretas de seção, ações diferenciadas ao longo do eixo e são ligados de modo contínuo à estrutura de cobertura. Neste 
caso, provocando a difícil determinação dos comprimentos efetivos de flambagem em cada trecho dos pilares do pórtico para serem utilizadas nas expressões das normas.

Com tantas divergências e falta de publicações, MURRAY \& GRAHAM ${ }^{3}$, definiram em 1957, os aspectos gerais e hipóteses para o projeto completo de um edifício industrial de aço com ponte rolante, em uma tentativa de fornecer a todos os projetistas uma recomendação atualizada sobre o assunto. Estas recomendações são citadas por vários autores, até os dias de hoje, como manual básico do projeto. Entre as mais importantes, destaca-se a criação do contraventamento longitudinal ao nível do banzo inferior da trave de cobertura, interligando todos os pórticos transversais entre si. Desta forma, o topo do pilar carregado pela ponte rolante pode ser considerado indeslocável no plano do pórtico transversal, pois esse contraventamento pode proporcionar uma reação horizontal quando vinculado aos demais pórticos. Outra recomendação importante, foi a de análise isolada do pilar, como "free body". MURRAY 3 , definiu um princípio de projeto destes pilares, considerando em seu esquema estático, um engastamento na base e articulação-fixa no topo, no ponto médio do trecho de vinculação entre o pilar e a trave de cobertura. Este princípio foi definido apenas para ações gravitacionais e açōes provenientes da ponte rolante, sem as ações devidas ao vento. Nesse caso, foi desprezada a rigidez da ligação trave-pilar e o topo do pilar foi totalmente impedido de deslocar no plano do pórtico. Para MURRAY ${ }^{3}$, quando houvessem as açóes de vento, todos os pilares estariam sujeitos ao mesmo carregamento, portanto as hipóteses seriam alteradas, pois não haveria mais o efeito de travamento no plano dos banzos inferiores. Desta forma, o pilar passaria a ser considerado engastado na base e engastado-móvel no topo, admitindo rigidez infinita na ligação trave-pilar. Neste caso, a treliça de cobertura seria considerada como rígida, porém, permitindo o deslocamento horizontal do topo do pilar no plano do pórtico. Todo esse esforço, de MURRAY \& GRAHAM ${ }^{3}$, em criar hipóteses simplificadoras do problema, foi motivado pela falta de processos precisos para análise dos pilares, de seção composta variável, integrados ao pórtico.

Para HUANG 4-5, em 1968, os critérios definidos por MURRAY \& GRAHAM ${ }^{3}$, deram uma contribuição importante para definir a concepção e o dimensionamento de pilares dos edifícios industriais com ponte rolante, 
reforçando as hipóteses mais importantes: a) A relação entre os momentos de inércia, da trave de cobertura e da parte superior dos pilares, deve ser considerada infinita. Esta hipótese permite que a ligação trave-pilar seja considerada como engastamento, pois admite que a rigidez da trave seja sempre muito maior que a rigidez da parte superior do pilar. b) As bases dos pilares devem ser engastadas. Esta hipótese garante 0 aumento de rigidez do pilar para diminuir a deslocabilidade da estrutura. c) Para os carregamentos gravitacionais e de ponte rolante, os pilares devem ter vinculações trave-pilar do tipo articulado-fixo. Esta hipótese considera que o pilar carregado individualmente pela ponte rolante tenha um vínculo horizontal fixo agindo no topo do pilar proveniente do contraventamento longitudinal do banzo inferior que interliga todos os topos dos pilares impedindo o seu deslocamento. d) Para carregamentos devidos ao vento, os pilares devem ser considerados com vínculos engastado-móvel na ligação trave-pilar, ou seja, impedides contra rotação, porém livres para deslocarem no plano do pórtico. Esta hipótese admite que todos os pilares recebem as ações de vento simultaneamente, desta forma podendo deslocar lateralmente no plano do pórtico associando a primeira hipótese de engastamento na ligação trave-pilar. Todas estas hipóteses conservativas estão ligadas a hipótese de pilar isolado que admite a perda de estabilidade simultânea dos dois pilares do pórtico plano submetidos a carregamentos máximos. HUANG 4-5, inicialmente desenvolveu tabelas para solucionar um problema de reações do sistema indeterminado de pilares, para obtenção dos esforços. Em seguida, desenvolveu um processo de cálculo, somado de gráficos, para obtenção direta do índice de esbeltez dos pilares. Para o plano perpendicular ao do pórtico, os comprimentos de flambagem dos pilares foram definidos pelos contraventamentos, porém para o plano do pórtico, os comprimentos de flambagem dos pilares necessitaram de algumas variáveis e hipóteses simplificadoras do problema. Como o pilar tem uma variação discreta de seção ao nível de assentamento da viga de rolamento, a determinação do comprimento efetivo de flambagem é função não só das vinculações, como também das relações entre os comprimentos, os momentos de inércia e as ações aplicadas na parte superior e inferior do pilar. A principal hipótese adotada, portanto, foi de pilar isolado da estrutura, para possibilitar a determinação dos coeficientes de flambagem. Para isto, os pilares de um mesmo pórtico, foram admitidos com as mesmas seçōes e igualmente carregados, provocando a instabilidade simultânea do conjunto. 
Esta hipótese gera uma situação muito conservadora, pois na realidade, quando um pilar está com a máxima ação proveniente da ponte rolante, o outro pilar do mesmo pórtico está com a ação mínima. Conseqüentemente, com reservas de resistência, não ocorrendo a tendência de flambagem simultânea. HUANG $4-5$, resolveu ○ problema de instabilidade do pilar isolado através de soluções de equações diferenciais, pelo método do equilíbrio, desprezando a excentricidade entre a ação vertical de topo do pilar com a ação vertical ao nível da variação da seção, desprezando as demais ações. Considerando a flambagem elástica por flexão, no plano do pórtico, desprezou uma possível flambagem por flexo-torção, devido a simplicidade do processo. Os resultados foram limitados a apenas dois casos de vinculações de pilares.

Em 1972, ANDERSON \& WOODWARD 9 , publicaram equaçōes para a fácil e direta obtenção dos comprimentos efetivos de flambagem dos pilares de seção composta variável, dos pórticos dos edifícios industriais com ponte rolante, para serem utilizados nas expressões de interação da AISC 1, na verificação da estabilidade. As equações foram montadas baseadas na solução de cinco diferentes tipos de vinculações, possíveis de ocorrerem nos pilares. As equações diferenciais foram obtidas através do método do equilíbrio, da teoria da instabilidade, com as hipóteses de pilares isolados, adotados por HUANG 4-5. O processo considerou apenas a flambagem elástica por flexão, no plano do pórtico, trabalhando com duas ações verticais, de topo do pilar e ao nível da variação de seção, desprezando suas excentricidades. ANDERSON \& WOODWARD 9 , reconheceram as limitações do processo, viável estritamente sob as condições de vinculações perfeitas; módulo de elasticidade constante; ações verticais constantes em cada segmento; seções distintas e constantes; ações verticais de topo do pilar e ao nível da variação de seção, alinhadas; pilares considerados isolados; ações críticas consideradas simultâneas em ambos os pilares do pórtico plano, ( também chamada de carga crítica ). Neste trabalho, os comprimentos efetivos de flambagem foram recomendados para utilização na AISC 1, porém como o processo foi desenvolvido no regime elástico a utilização direta nas expressões da norma pode produzir resultados imprecisos quando aplicados no dimensionamento, no regime inelástico do pilar. 
Em 1976, MUKHANOV 31, publicou as hipóteses simplificadoras para tratar o problema de estabilidade dos pilares, dos edifícios industriais, contidos no plano do pórtico: a) Considera que o pórtico transversal está carregado somente com forças concentradas em seus nós. b) $\mathrm{O}$ pórtico de um só vão é analisado sob a influência da carga crítica sobre ambos os pilares, o que permite desprezar a influência da rigidez e do grau de carregamento do pilar vizinho, no mesmo pórtico. Desta forma, considera o pilar como uma barra isolada que está engastada em sua base e se desloca livremente no topo, ou ainda pode estar apoiada numa articulação na base e ligada rigidamente no topo. c) Nos pórticos de vários vãos, quando estes possuírem muita rigidez ou contarem com sistemas de contraventamentos longitudinais que ligam os topos dos pilares, considera-se que as cargas críticas não podem ser aplicadas simultaneamente a todos os pilares. Por isso, o apoio superior do pilar pode ser considerado indeslocável independente do tipo de ligação trave-pilar utilizada. Portanto, mesmo neste caso o pilar pode ser considerado como uma barra isolada com diversas fixações nas extremidades. MUKHANOV ${ }^{31}$, publicou algumas tabelas de comprimentos efetivos de flambagem para pilares prismáticos e para pilares com uma ou mais variações discretas de seção. Nos casos dos pilares com variações de seção os comprimentos efetivos de flambagem são fornecidos separadamente para cada tramo do pilar. As tabelas de MUKHANOV ${ }^{31}$, são extremamente limitadas pois só contemplam os casos de pilares com relação de momentos de inércia variando entre limites restritos e constatase que os valores dos comprimentos efetivos de flambagem para as partes superiores dos pilares estão freqüentemente abaixo dos valores fornecidos pelos demais autores, que utilizam as mesmas hipóteses. As expressőes diferenciais que regem 0 problema não foram apresentadas, impossibilitando a comparação com as já citadas expressões de ANDERSON \& WOODWARD ${ }^{9}$. Neste trabalho, também não foi citado os problemas de utilização dos comprimentos de flambagem, obtidos no regime elástico e aplicados diretamente nas expressões da norma soviética.

Em 1979, ocorreram duas importantes publicações. Uma através da AISE ${ }^{2}$, e outra através da AISC ${ }^{7}$. Estas publicaçōes, são consideradas como manuais de projeto de edifícios industriais com ponte rolante, utilizados até os dias de hoje. As hipóteses apresentadas foram as mesmas analisadas até o momento, sem nenhuma restrição em suas aplicações. Os 
pilares são tratados de forma isolada do restante da estrutura, com hipóteses simplificadoras. A determinação do comprimento efetivo de flambagem do pilar no plano do pórtico é fornecida diretamente em tabelas pela AISE 2 e utilizadas de acordo com a AISC ${ }^{7}$. FISHER ${ }^{11}$, no mesmo ano, discutiu a aplicação dos manuais apontando para 0 aspecto limitador das tabelas apresentadas, pois os comprimentos de flambagem são fornecidos apenas para a parte inferior dos pilares de seção variável, como também, são limitadas para relações entre ações, de topo e ao nível da variação de seção em 0.25 e analisadas para somente bases engastadas com articulação fixa no topo. Apesar de estar diante de atualizados manuais, FISHER 11 teve o bom senso de recomendar a utilização das equações de ANDERSON \& WOODWARD 9, por serem exatas e de fácil programação. Estas equações, além de não limitarem a aplicação, fornecem separadamente os comprimentos efetivos de flambagem das partes superior e inferior dos pilares de seção composta variável do edifício industrial com ponte rolante. Uma importante contribuição com base nas publicações da AISE 2 e da AISC ${ }^{7}$, consiste na verificação da resistência por flexão em ambos os eixos principais de inércia do pilar, bem como na resistência axial do pilar. Neste caso, a expressão de interação (1.1) que verifica a estabilidade do trecho inferior do pilar, recebe uma alteração no terceiro termo que verifica a influência da flexão majorada do efeito de segunda ordem provocado pela compressão, que ocorre no plano perpendicular ao do pórtico, provocado pela excentricidade do apoio da viga de rolamento no pilar. No terceiro termo, portanto, " $\boldsymbol{f}_{\mathbf{a}}$ " passa para " $\mathbf{f}_{\mathrm{a}}$ ' ", representando a tensão axial majorada da tensão de flexão provocada pelo momento no plano do pórtico, aplicado no centro de gravidade do perfil que representa a mesa interna do pilar situado sob a ação da viga de rolamento.

$$
\frac{f_{a}}{F_{a}}+\frac{C_{m x} f_{b x}}{\left(1-\frac{f_{a}}{F_{e x}^{\prime}}\right) F_{b x}}+\frac{C_{m y} f_{b y}}{\left(1-\frac{f_{a}^{\prime}}{F_{e y}^{\prime}}\right) F_{b y}} \leq 1.0
$$


Com o reconhecimento da eficiência do processo de ANDERSON \& WOODWARD 9, AGRAWAL \& STAFIEJ 12 completaram 0 trabalho desenvolvendo sete casos de vinculações dos pilares dos edifícios industriais com ponte rolante, incluindo bases articuladas, até então, não analisadas. Além de publicarem as equações e tabelas para os casos citados, desenvolveram programas para a fácil $\Theta$ imediata obtenção dos parâmetros de flambagem dos pilares isolados.

Apesar das divergências entre os projetistas, existia uma tendência de utilização de algumas publicações. WILLIAM ${ }^{13}$, também estudou 0 assunto, para programar e resolver os problemas encontrados nos pilares dos edifícios industriais com ponte rolante, sugerindo as hipóteses de MURRAY3 e HUANG ${ }^{4-5}$ para a solução do problema; AISC ${ }^{7}$ para o roteiro geral; AISE 2 para o processo de cálculo dos pilares; AISC ${ }^{1}$ para as expressões de dimensionamento e ANDERSON \& WOODWARD ${ }^{9} \mathrm{com}$ AGRAWAL \& STAFIEJ 12 para determinação do comprimento efetivo de flambagem. Esta tendência, persiste até os dias de hoje, no cotidiano dos escritórios de projetos de estruturas metálicas, como citado por BELLEI ${ }^{54}$ em publicação brasileira e citado por GALAMBOS ${ }^{6}$ em publicação internacional que divergiu apenas por recomendar as tabelas da AISE 2 ao invés das equações de ANDERSON \& WOODWARD ${ }^{9}$. Estes trabalhos fornecem os parâmetros de estabilidade compatíveis com as hipóteses adotadas pelas especificações técnicas existentes acarretando dimensionamentos muito conservadores.

Muitas pesquisas foram realizadas, a partir da obtenção dos parâmetros de estabilidade dos pilares dos edifícios industriais de aço com ponte rolante, porém, sempre analisando o pilar de maneira isolada do resto da estrutura. As chamadas "Stepped Columns" são verificadas separadamente, na parte superior do pilar e na parte inferior, usando o processo do comprimento efetivo de flambagem $\theta$ as fórmulas de interação da AISC ${ }^{49-50}$, com os esforços de compressão axial e flexão, válidos nos segmentos prismáticos. $O$ processo baseado no conceito de comprimento efetivo está implicitamente ligado ao conceito de instabilidade de $1^{\text {a }}$. espécie com problema de bifurcação e é possível entender qual situação é associada com o colapso do elemento estrutural, porém não é possível apreciar o efeito das imperfeições geométricas. As normas técnicas procuram resolver este problema introduzindo excentricidades casuais em 
suas expressões, o que seria equivalente a diminuir o limite de resistência nominal do pilar.

No atual estado da arte, FRASER ${ }^{16-18-19}$ publicou vários trabalhos mudando completamente a abordagem do problema, tanto para pilares prismáticos, dos edifícios industriais leves com ponte rolante, quanto para os pilares de seção composta variável, dos edifícios industriais pesados, ambos de aço. A principal mudança no conceito, está em analisar o pilar integrado ao pórtico, ou seja, não mais isolando-o do resto da estrutura. A rigidez da ligação trave-pilar é considerada no cálculo da estabilidade dos pilares, carregados de forma diferenciada, caracterizando comportamento de conjunto. Desta forma, o tratamento do problema passa para uma consideração real do comportamento do pórtico deslocável. Para análise de pilares prismáticos, o trabalho foi relativamente simples, porém, para pilares de seção composta variável, o trabalho foi bem mais complexo. FRASER 16$18-19$, recorreu à análise numérica do problema, utilizando o processo dos elementos finitos, reduzindo as hipóteses simplificadoras. Foram consideradas, no processo, apenas ações verticais, sem excentricidade, para obtenção da chamada carga crítica de flambagem elástica por flexão no plano do pórtico. Foram estudados pórticos de dois grupos: os com bases engastadas e os com bases articuladas. Em ambos os casos, o perfil utilizado na parte superior dos pilares foi o mesmo utilizado na viga de cobertura, de seção constante. FRASER 16-18-19 destacou os principais fatores que influenciam o comportamento dos pilares quando integrados ao pórtico contínuo: a) resistência à flambagem de cada pilar isolado; b) rotação da ligação trave-pilar, exercida pela rigidez da estrutura de cobertura. c) translação da ligação trave-pilar, efeito controlado pela ação do pilar menos carregado do pórtico. As hipóteses adotadas consideraram: a) pórticos com bases articuladas, desprezando a relação entre as ações verticais assim como as excentricidades envolvidas; b) pórticos com bases engastadas, desprezando apenas as excentricidades das ações verticais; c) os efeitos de rotação e translação da ligaçăo trave-pilar, foram considerados de forma isolada e posteriormente sobrepostas. Os resultados deste processo, em relação aos anteriores, mostraram um aumento no carregamento crítico do pilar analisado. O processo de FRASER 16-18-19, apresenta uma contribuição muito grande para otimizar o dimensionamento de pilares utilizando as expressões das normas técnicas atuais, porque 
conserva as hipóteses básicas dos autores anteriores e das próprias especificações técnicas e consegue levar em consideração a contribuição das rigidezes de todos os elementos constituintes do pórtico. Portanto, os comprimentos efetivos de flambagem fornecidos por este processo podem ser utilizados diretamente nas expressões das normas atuais com muita segurança. Mas, recomenda-se cautela na utilização desses parâmetros de estabilidade utilizados no regime inelástico do pilar, pois todos os trabalhos desenvolvidos até aqui utilizaram a hipótese de regime elástico do pilar.

Uma importante recomendação para utilização dos parâmetros de estabilidade, obtidos pelos processos citados, nas expressões das normas existentes, foi dada por WHITE \& HAJJAR 23 , alertando que no caso das normas que utilizam métodos dos estados limites, como 0 caso da LRFD 50 e da ABNT 51, não vale a superposição dos efeitos dos coeficientes de majoração das ações utilizadas no processo. Portanto, as combinações das açōes majoradas devem ser realizadas antes da obtenção dos parâmetros de estabilidade e de forma independente de cada situação real de trabalho da estrutura. Desta forma, a utilização das expressões das referidas normas estaria garantida sem incorreções.

Todos os processos apresentados até agora só trataram do caso particular da instabilidade conhecido por flambagem de Euler, admitindo as hipóteses de seçōes manterem-se planas após as deformações e atingidas as flambagens. Na realidade, os pilares dos edifícios industriais compostos por chapas delgadas e com variação discreta de seção, podem apresentar casos característicos de instabilidade geral por flexo-torção, como são previstos na teoria de VLASSOV 32.

Os casos de perfis abertos de seção delgada, foram estudados por diversos pesquisadores, mais recentemente por RACHID 37, PALERMO $\mathrm{Jr} .{ }^{39}$, MORI ${ }^{47}$, com base na teoria de VLASSOV ${ }^{32}$, considerando os efeitos dos empenamentos e bimomentos, no comportamento tridimensional das barras, porém sem considerar as deformações por força cortante e admitindo sempre o alinhamento do eixo longitudinal, pois, segundo as hipóteses adotadas, garantiriam a posição do centro de cisalhamento da seção em relação ao eixo longitudinal. Já é de conhecimento atual, que a posição do centro de cisalhamento da seção se altera ao longo do eixo longitudinal da barra, em certos casos de carregamento e de assimetria de seções. 
As Normas, AISC 1-49-50, AISE 2, ABNT 51, independentemente de considerarem os estados limites ou as tensões admissíveis, adotam as expressões de interação para resolver o problema da flexão composta, na verificação da estabilidade. No primeiro termo, só levam em consideração o efeito da flambagem por flexão, considerando a barra como elemento isolado. No segundo termo, é levado em consideração a perda de estabilidade lateral, por torção, causado pelo momento fletor agindo em perfil aberto com chapas delgadas. Apesar de admitir o momento constante ao longo do eixo longitudinal, é possível corrigir os efeitos da variação desse momento fletor $\theta$ das ações transversais aplicadas fora da posição do centro de cisalhamento, através do coeficiente " $\mathrm{Cm}$ ", como é demonstrado por CHEN 25.

Nenhum dos casos citados considera o desalinhamento dos eixos longitudinais, da parte superior e inferior dos pilares, que provocaria empenamentos em seções abertas de chapas delgadas, causando esforços adicionais de flexo-torção.

Vários trabalhos estấo sendo desenvolvidos no sentido de substituir as atuais expressões de interação utilizadas nas atuais normas técnicas, por processos que representem o comportamento de elementos estruturais, buscando informaçōes quanto a segurança da estrutura. Os limites de estabilidade foram, até o momento, desenvolvidos em teoria de segunda ordem que fornecem apenas o ponto limite de resistência da estrutura. FRUCHTENGARTEN ${ }^{55}$ e PIMENTA \& YOJO ${ }^{56}$, estudam o comportamento de elementos estruturais em teoria de terceira ordem, utilizando a não linearidade geometricamente exata, no intuito de obter o comportamento global da estrutura analisando-a quanto a segurança. FRUCHTENGARTEN 55 , apresentou um estudo de instabilidade de barras tridimensionais isoladas com seções transversais abertas e delgadas com o eixo longitudinal passando pelo centro de torção. Este eixo sempre foi apresentado constante em relação ao centro de torção da seção, nos exemplos apresentados. Não demonstrou a possibilidade de variação da posição do eixo longitudinal do elemento estrutural para o caso de variações bruscas de seção transversal. Os elementos eram sempre apresentados de forma isolada e não como pórtico formado por estes elementos. 


\subsection{O PRESENTE TRABALHO}

Para a obtenção de uma rigorosa compreensão do comportamento dos pilares de seção variável, associados ao pórtico transversal, serão realizadas duas etapas de análise.

Na primeira, serão pesquisados os efeitos da participação dos pilares, integrados ao pórtico transversal, considerando-os com variação discreta de seção, e a trave de cobertura em forma de treliça. Neste caso inicial, os elementos de barra serão admitidos planos e considerados deformáveis por flexão; por força cortante e por força axial.

Para isto, foi desenvolvido um programa de instabilidade elástica por flexão de pórtico plano, em teoria de segunda ordem, pelo processo dos deslocamentos com a técnica matricial, capaz de considerar os efeitos da força cortante nos elementos de barra; os efeitos da treliça de cobertura no topo de cada pilar e os efeitos da reserva de resistência de ambos os pilares integrados ao pórtico, com carregamento diferenciado, devido a posição da carga da ponte rolante. Será possível, também, visualizar os efeitos semelhantes aos dos vínculos elásticos no topo dos pilares, aumentando de forma considerável a rigidez contra a perda de estabilidade, no plano do pórtico.

$\mathrm{Na}$ segunda etapa, serão considerados os mesmos efeitos da etapa anterior, porém com pilares de seção composta variável constituídos por chapas delgadas formando seções abertas, considerados como estruturas tridimensionais. Nestes pilares, serão admitidas ações externas, agindo axialmente e transversalmente nas seções, coincidentes ou não com o centro de cisalhamento, em particular nas abas do perfil considerado. Neste caso, o pórtico transversal fica constituído por uma trave em treliça, deformável apenas no plano do pórtico, e dois pilares deformáveis por flexão; por força cortante; por força axial e por torção, tridimensionalmente.

Para este caso, foi desenvolvido um programa de instabilidade elástica geral de pilares considerados tridimensionais acoplados à trave de cobertura em forma de treliça, constituindo um pórtico transversal. $\mathrm{O}$ processo escolhido para obter o comportamento tridimensional do pilar do edifício industrial, com variação discreta de seção, considerando a seção transversal formada por perfil aberto de chapas delgadas, foi $\circ$ dos 
deslocamentos com a técnica matricial utilizando discretização de seção em elementos planos de pórticos. Este processo, desenvolvido por YAGUI17-3334, foi utilizado como base para o desenvolvimento do referido programa que tem como objetivo fornecer o carregamento crítico de instabilidade geral da estrutura, dando uma visão mais rigorosa do comportamento dos pilares integrados ao pórtico.

Para concluir a análise de instabilidade dos pilares de edifícios industriais, serão apresentados exemplos numéricos, com intuito de comparar os resultados fornecidos pelos dois processos do presente trabalho, com os fornecidos pelos processos convencionais ainda utilizados. Serão apresentados, também, exemplos numéricos comparando o processo desenvolvido neste trabalho, que utiliza a não linearidade geométrica em teoria de segunda ordem, e o programa ANSYS, que utiliza a não linearidade geometricamente exata. 


\section{CAPÍTULO ॥}

\section{CARREGAMENTO CRÍTICO DE INSTABILIDADE ELÁSTICA POR FLEXÃO, DE PILARES DE SEÇÃo COMPOSTA VARIÁVEL, DE EDIFÍCIOS INDUSTRIAIS METÁLICOS}

\subsection{INTRODUÇÃO}

A análise aqui apresentada prende-se apenas a estruturas planas constituídas de elementos de barra, deformáveis por flexão, por força axial e por força cortante, em seu plano.

O desenvolvimento matricial é feito com base no processo dos deslocamentos para estruturas, no regime elástico.

Cada pilar de seção composta variável será dividido em dois elementos de barra prismáticos $\theta$ ambos os pilares integrarão o pórtico transversal.

$\mathrm{Na}$ análise da instabilidade do pórtico é levada em conta a influência da força axial nos elementos de barra, caracterizada pelo efeito da não linearidade geométrica.

Os carregamentos serão admitidos variáveis, compostos por cargas vivas variando proporcionalmente a um parâmetro e cargas constantes permanecendo inalteradas.

O carregamento crítico da estrutura é alcançado quando ela deixa de ser estável em seu próprio plano, admitindo estável no plano perpendicular por vinculações adequadas.

A verificação da estabilidade é feita com base no processo dos deslocamentos, em que a matriz de rigidez de cada elemento de barra que relaciona as forças com os deslocamentos em seus vínculos externos sofrerá a influência da força axial para um determinado carregamento. 
Como as matrizes de rigidez dos elementos contribuirão para a montagem da matriz de rigidez da estrutura, que relaciona as ações nas coordenadas nodais da estrutura com os respectivos deslocamentos, sua matriz de rigidez também estará afetada pelo efeito da força axial. Portanto, pesquisase um carregamento crítico capaz de degenerar a rigidez da estrutura, através da singularização de sua matriz de rigidez.

O carregamento crítico de instabilidade dos pilares, será obtido através do comportamento do conjunto da estrutura do pórtico e não mais como elementos isolados.

\subsection{SISTEMAS DE REFERÊNCIA}

2.2.1 Sistema de Referência Global de Eixos para a Estrutura do Pórtico Plano.

Para referência da estrutura do pórtico, será adotado um sistema global, dextrorso, com eixos " $\mathrm{K}_{G}$ ", " $\mathrm{Y}_{G}$ ", " $\mathrm{Z}_{G}$ " e origem "O" num ponto qualquer. $O$ eixo " $_{\mathrm{G}}$ ", horizontal, será orientado da esquerda para a direita $e$ o eixo " $\mathrm{Y}_{\mathrm{G}}$ ", vertical, será orientado de baixo para cima, Fig.Il-1, definindo o plano da estrutura do pórtico.

2.2.2 Sistema de Referência Local de Eixos para o Elemento de Barra "i", Plano.

Para referência do elemento de barra "i", será adotado um sistema local, dextrorso, com eixos " $x$ ", " $y$ ", "z" e origem " $\mathrm{O}_{i}$ " no nó inicial "j" da barra "i", no centro de gravidade da barra. O eixo "x" será o próprio eixo da barra orientado do nó inicial "j" para o nó final "k". O eixo " $y$ " será orientado perpendicularmente ao eixo " $x$ " com início no nó "j" da barra. $O$ ângulo " $\gamma$ ", formado entre o eixo " $x_{G}$ ", global da estrutura e o eixo " $x$ ", local do elemento de barra, medido a partir do primeiro, em relação ao suposto eixo " $\mathrm{z}_{\mathrm{G}}$ ", define a relação entre os sistemas de referência global e local. Os eixos " $x_{s}$ " e " $y_{s}$ " são eixos paralelos aos eixos globais com origem " $\mathrm{O}_{s}$ " coincidente a origem do sistema local da barra "i", Fig.Il-1. 


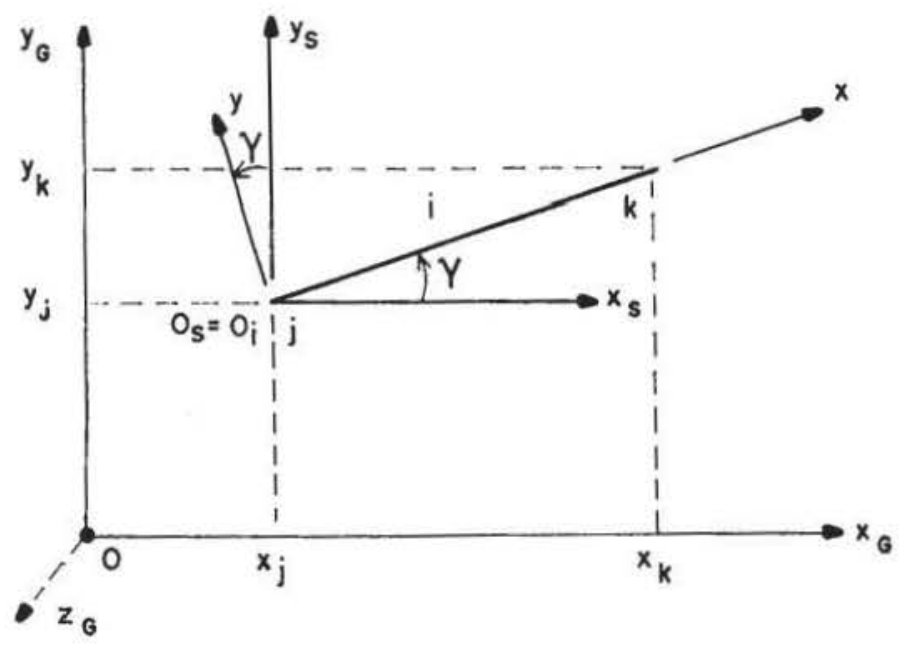

Figura II-1 Sistemas de Referência no Plano

\subsection{MATRIZ DE RIGIDEZ DO ELEMENTO DE BARRA}

A matriz de rigidez de um elemento de barra será definida em função de suas coordenadas locais e das deformaçőes admitidas em seu plano.

Para considerar as deformações nos elementos de barra admitindo as interações entre forças axiais e flexão, ou ainda entre forças axiais e força cortante, CHEN 25 e GERE-WEAVER 41, apresentaram as respectivas matrizes de rigidez, com as chamadas funções de rigidez (também chamadas de funçōes de estabilidade), capazes de considerar os efeitos da não linearidade geométrica, no cálculo dos deslocamentos da estrutura. Para considerar simultaneamente as três deformações, por força axial; por força cortante e por flexão na matriz de rigidez do elemento, YAGUI ${ }^{17-34} \mathrm{e}$ SERRA ${ }^{48}$ apresentaram novas funções de rigidez capazes de considerar os efeitos da não linearidade geométrica em teoria de $2^{\mathrm{a}}$ ordem, de forma mais completa.

Estas funções de rigidez que regem as deformações do elemento de barra no plano, considerando o efeito da força axial de forma mais completa, 
foram também adotados no presente trabalho, para deduzir as matrizes de rigidez dos elementos.

2.3.1 Formulação da Matriz de Rigidez do Elemento de Barra Considerando o Efeito da Força Axial

A matriz de rigidez do elemento de barra, será determinada em teoria de $2^{\mathrm{a}}$ ordem, com carga axial cêntrica aplicada em suas extremidades, exceto quando a força axial for nula, a matriz de rigidez do elemento de barra será determinada em teoria de $1^{\underline{a}}$ ordem.

Na Fig.ll-2 é esquematizado o estado deslocado e deformado da barra submetida aos esforços de extremidade do elemento.

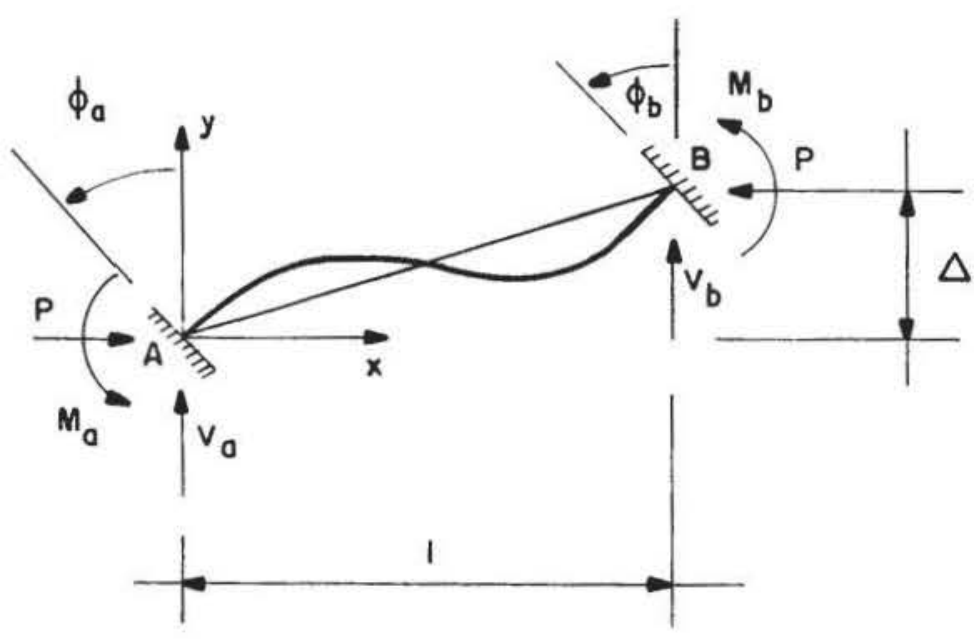

Figura II-2 Elemento de Barra Plano no Estado Deslocado e Deformado

As equações regentes do problema ficam definidas pelas equações diferenciais, em relação ao sistema de referência da barra:

$$
y^{\prime V}+\alpha^{2} y^{\prime \prime}=0 \quad \quad p / \text { "P" de compressão }
$$


com solução geral,

$$
\begin{aligned}
& y=C_{1} \operatorname{sen} \alpha x+C_{2} \cos \alpha x+C_{3} x+C_{4} \\
& y^{\prime v}-\alpha^{2} y^{\prime \prime}=0 \quad \quad \text { / "P" de tração }
\end{aligned}
$$

com solução geral,

$$
\begin{aligned}
& y=C_{1} \operatorname{senh} \alpha x+C_{2} \cosh \alpha x+C_{3} x+C_{4} \\
& y^{\text {IV }}=0 \quad \text { p/ "P" nula }
\end{aligned}
$$

com solução geral,

$$
y=C_{1} x^{3}+C_{2} x^{2}+C_{3} x+C_{4}
$$

onde,

$$
\begin{aligned}
& \alpha^{2}=\frac{P}{E I_{z} a} \\
& a=1-\frac{\text { cf } P}{A_{x} G}
\end{aligned}
$$

$\mathrm{P}$ = Força axial, no elemento de barra

$A_{x}=$ Área da seção transversal

$\mathrm{I}_{\mathrm{z}}$ = Momento de inércia, em relação ao eixo $\mathrm{z}$

$\mathrm{G}=$ Módulo de elasticidade transversal 


$$
\begin{aligned}
E & =\text { Módulo de elasticidade longitudinal } \\
\text { cf } & =\text { Coeficiente de forma } \\
\text { I } & =\text { Comprimento do elemento de barra }
\end{aligned}
$$

Através das soluçōes das equaçöes diferenciais citadas, pode-se obter as expressões dos esforços de extremidade do elemento de barra, permitindo calcular os coeficientes das matrizes de rigidez, em teorias tanto de primeira ordem $(P=0)$ quanto de segunda ordem $(P \neq 0)$, de um elemento de barra pertencente a um pórtico. No caso da teoria de segunda ordem é prevista a possibilidade da carga "P" ser de compressão ou tração. Esta matriz, segundo as coordenadas deslocamentos, Fig.II-3, é de ordem $6 \times 6$.

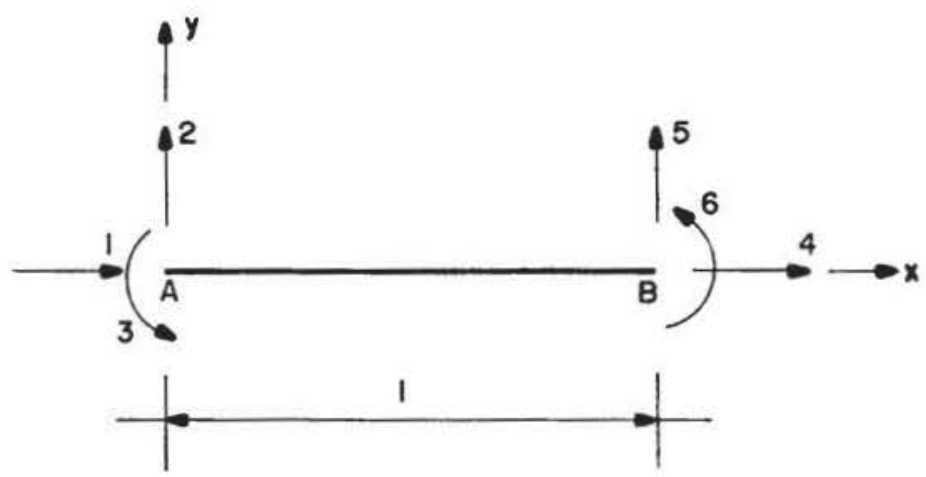

Figura II-3 Coordenadas Deslocamentos do Elemento de Barra

Para obter as expressões dos esforços de extremidade de barra, basta aplicar as condições de contorno nas expressões (2.2), (2.4) e (2.6) de cada caso considerado. Estas expressões são apresentadas adiante nos seus estados finais sem as deduções intermediárias, uma vez que já foram também realizadas por YAGUI ${ }^{17-34}$ e SERRA ${ }^{48}$, de forma semelhante: 
a) Para "P" de compressão

$$
\begin{aligned}
& \mathrm{M}_{\mathrm{A}}=\mathrm{El}_{\mathrm{Z}} \alpha\left(\frac{\mathrm{a} \alpha(1-\cos \alpha \mathrm{l}) \Delta+(\operatorname{sen} \alpha \mathrm{l}-\mathrm{a \alpha l} \cos \alpha \mathrm{l}) \phi_{\mathrm{A}}+(\mathrm{a} \alpha \mathrm{l}-\operatorname{sen} \alpha \mathrm{l}) \phi_{\mathrm{B}}}{2-2 \cos \alpha \mathrm{l}-\mathrm{a} \alpha \mathrm{sen} \alpha \mathrm{l}}\right) \\
& \mathrm{M}_{\mathrm{B}}=\mathrm{El}_{\mathrm{Z}} \alpha\left(\frac{\mathrm{a} \alpha(1-\cos \alpha \mathrm{l}) \Delta+(\mathrm{a} \alpha \mathrm{l}-\operatorname{sen} \alpha \mathrm{l}) \phi_{\mathrm{A}}+(\operatorname{sen} \alpha \mathrm{l}-\mathrm{a} \alpha \mathrm{l} \cos \alpha \mathrm{l}) \phi_{\mathrm{B}}}{2-2 \cos \alpha \mathrm{l}-\mathrm{a \alpha l} \operatorname{sen} \alpha \mathrm{l}}\right) \\
& \mathrm{V}_{\mathrm{A}}=\mathrm{EI}_{\mathrm{Z}} \mathrm{a} \alpha^{2}\left(\frac{\mathrm{a} \alpha(\operatorname{sen} \alpha \mathrm{l}) \Delta+(1-\cos \alpha \mathrm{l})\left(\phi_{\mathrm{A}}+\phi_{\mathrm{B}}\right)}{2-2 \cos \alpha \mathrm{l}-\mathrm{a} \alpha \mathrm{sen} \alpha \mathrm{l}}\right)
\end{aligned}
$$

b) Para "P" de tração

$$
M_{A}=E_{Z} \alpha\left(\frac{a \alpha(\cosh \alpha l-1) \Delta+(a \alpha l \cosh \alpha l-\operatorname{senh} \alpha l) \phi_{A}+(\operatorname{senh} \alpha l-a \alpha l) \phi_{B}}{2-2 \cosh \alpha l+a \alpha l \operatorname{senh} \alpha l}\right)
$$

$$
M_{B}=E I_{Z} \alpha\left(\frac{a \alpha(\cosh \alpha l-1) \Delta+(\operatorname{senh} \alpha l-a \alpha l) \phi_{A}+(a \alpha l \cosh \alpha l-\operatorname{senh} \alpha l) \phi_{B}}{2-2 \cosh \alpha l+a \alpha l \operatorname{senh} \alpha l}\right)
$$

$$
V_{A}=E I_{Z} a \alpha^{2}\left(\frac{a \alpha(\operatorname{senh} \alpha l) \Delta+(\cosh \alpha l-1)\left(\phi_{A}+\phi_{B}\right)}{2-2 \cosh \alpha l+a \alpha l \operatorname{senh} \alpha l}\right)
$$


26

c) Para "P" nulo

$$
\mathrm{M}_{\mathrm{A}}=\frac{6 \mathrm{El}_{\mathrm{Z}} \Delta}{\mathrm{l}^{2}(1+2 \mathrm{~g})}+\frac{2 \mathrm{El}_{\mathrm{Z}}(2-\mathrm{g}) \phi_{\mathrm{A}}}{\mathrm{l}(1+2 \mathrm{~g})}+\frac{2 \mathrm{El}_{\mathrm{Z}}(1-\mathrm{g}) \phi_{\mathrm{B}}}{\mathrm{l}(1+2 \mathrm{~g})}
$$

$M_{B}=\frac{6 \mathrm{El}_{Z} \Delta}{\mathrm{I}^{2}(1+2 \mathrm{~g})}+\frac{2 \mathrm{El}_{\mathrm{Z}}(1-\mathrm{g}) \phi_{\mathrm{A}}}{\mathrm{I}(1+2 \mathrm{~g})}+\frac{2 \mathrm{El}_{\mathrm{Z}}(2+\mathrm{g}) \phi_{\mathrm{B}}}{\mathrm{I}(1+2 \mathrm{~g})}$

$V_{A}=\frac{12 \mathrm{El}_{Z} \Delta}{\mathrm{I}^{3}(1+2 \mathrm{~g})}+\frac{6 \mathrm{El}_{\mathrm{Z}}\left(\phi_{\mathrm{A}}+\phi_{\mathrm{B}}\right)}{\mathrm{I}^{2}(1+2 \mathrm{~g})}$

onde,

$$
g=\frac{6 c f E I_{z}}{G A_{x} I^{2}}
$$

Com as expressões dos esforços de extremidade de barra, conhecidos, pode-se obter a matriz de rigidez de cada elemento de ordem $6 \times 6$, bastando para isto, impor um por vez, deslocamentos unitários segundo cada uma das coordenadas numeradas na Fig.II-3, mantendo-se fixas as demais coordenadas e obtendo seus esforços, para que mantenham a configuração deformada, em equilíbrio. Por exemplo, para "P" de compressão com $\phi_{\mathrm{A}}=1 ; \phi_{\mathrm{B}}=\Delta=$ zero, Fig.Il-4, obtém-se a terceira coluna da referida matriz, com:

$$
\begin{aligned}
& S_{33}=\frac{\alpha(\operatorname{sen} \alpha|-a \alpha| \cos \alpha \mid) E l_{z}}{2(1-\cos \alpha \mid) a \alpha|\operatorname{sen} \alpha|} \\
& S_{63}=\frac{\alpha(a \alpha|-\operatorname{sen} \alpha|) E l_{z}}{2(1-\cos \alpha \mid)-a \alpha|\operatorname{sen} \alpha|}
\end{aligned}
$$




$$
\begin{aligned}
& S_{23}=-S_{53}=\frac{a \alpha^{2}(1-\cos \alpha I) E l_{z}}{2(1-\cos \alpha I)-a \alpha I \operatorname{sen} \alpha I} \\
& S_{13}=-S_{43}=\text { zero }
\end{aligned}
$$

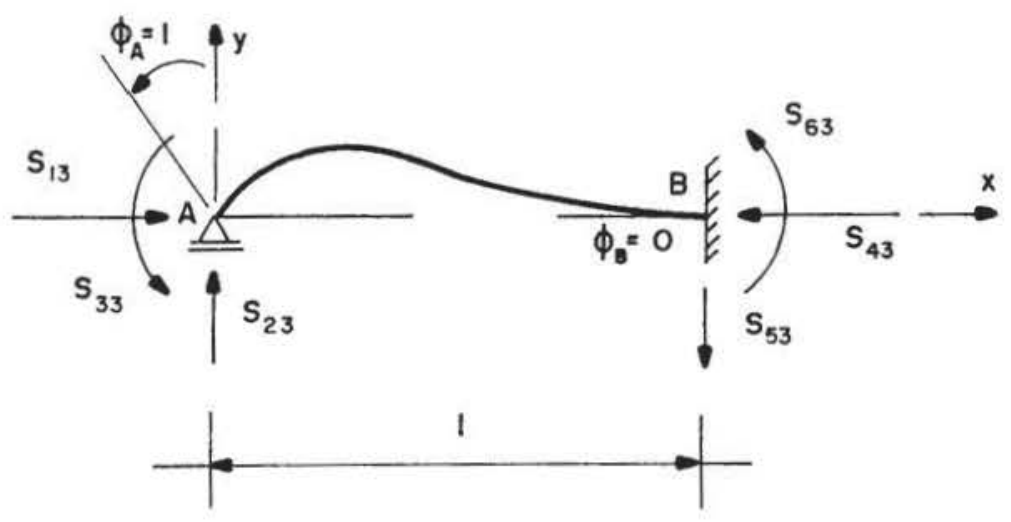

Figura II-4 Configuração Deformada do Elemento de Barra, com $\phi_{\mathrm{A}}=1$ e $\phi_{\mathrm{B}}=\Delta=$ zero

Fazendo para as demais colunas da matriz com $P<0$, pode-se obter a matriz de ordem $6 \times 6$.

Analogamente para o caso de $P>0$ e $P=0$, obtém-se as outras duas matrizes de rigidez, também de ordem $6 \times 6$.

Para facilitar a utilização das matrizes, é montado a seguir, um esquema de matriz de rigidez do elemento de barra com seus termos representados por fatores que podem ser alterados conforme a condição de influência da força cortante ou sob a variação da força axial, como será mostrado na Fig.II-5 e Tab.Il-1. 


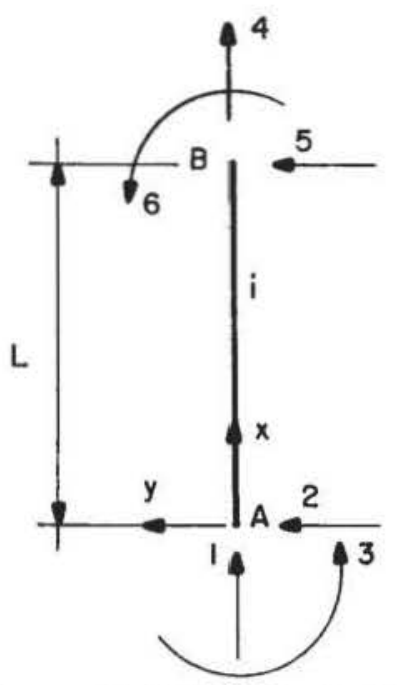

$$
\mathrm{S}_{\mathrm{KB}}=\left[\begin{array}{cccccc}
\mathrm{S}_{1} & 0 & 0 & -\mathrm{S}_{1} & 0 & 0 \\
0 & \mathrm{~S}_{2} & \mathrm{~S}_{3} & 0 & -\mathrm{S}_{2} & \mathrm{~S}_{3} \\
0 & \mathrm{~S}_{3} & \mathrm{~S}_{4} & 0 & -\mathrm{S}_{3} & \mathrm{~S}_{5} \\
-\mathrm{S}_{1} & 0 & 0 & \mathrm{~S}_{1} & 0 & 0 \\
0 & -\mathrm{S}_{2} & -\mathrm{S}_{3} & 0 & \mathrm{~S}_{2} & -\mathrm{S}_{3} \\
0 & \mathrm{~S}_{3} & \mathrm{~S}_{5} & 0 & -\mathrm{S}_{3} & \mathrm{~S}_{4}
\end{array}\right]
$$

Figura II-5 Matriz de Rigidez da Barra Sujeita às Funções de Rigidez

\begin{tabular}{|c|c|c|c|}
\hline $\mathbf{S} \backslash \mathbf{P}$ & Compressão $(\mathrm{P}<0)$ & $(\mathrm{P}=0)$ & Tração $(P>0)$ \\
\hline s1 & $\frac{E A_{x}}{L}$ & $\frac{E A_{x}}{L}$ & $\frac{E A_{x}}{L}$ \\
\hline $\mathbf{s} 2$ & $\frac{\mathrm{EI}_{\mathrm{z}}\left(\mathrm{a}_{1}\right)^{2} \varepsilon^{3} \operatorname{sen} \varepsilon}{\mathrm{L}^{3} \phi_{\mathrm{c}}}$ & $\frac{12 \mathrm{El}_{2}}{\mathrm{~L}^{3}(1+2 \mathrm{~g})}$ & $\frac{E I_{z}\left(a_{2}\right)^{2} \varepsilon^{3} \operatorname{senh} \varepsilon}{L^{3} \phi_{1}}$ \\
\hline S3 & $\frac{E \mathrm{I}_{z} a_{1} \varepsilon^{2}(1-\cos \varepsilon)}{L^{2} \phi_{c}}$ & $\frac{6 \mathrm{El}_{2}}{\mathrm{~L}^{2}(1+2 \mathrm{~g})}$ & $\frac{E \mathrm{I}_{2} \mathrm{a}_{2} \varepsilon^{2}(\cosh \varepsilon-1)}{L^{2} \phi_{t}}$ \\
\hline S4 & $\frac{E \mathrm{El}_{\mathrm{z}} \varepsilon\left(\operatorname{sen} \varepsilon-\mathrm{a}_{1} \varepsilon \cos \varepsilon\right)}{\mathrm{L} \phi_{\mathrm{c}}}$ & $\frac{2 \mathrm{El}_{\mathrm{z}}(2+\mathrm{g})}{\mathrm{L}(1+2 \mathrm{~g})}$ & $\frac{E \mathrm{E}_{2} \varepsilon\left(\mathrm{a}_{2} \varepsilon \cosh \varepsilon-\operatorname{senh} \varepsilon\right)}{L \phi_{1}}$ \\
\hline S5 & $\frac{E \mathrm{I}_{\mathrm{z}} \varepsilon\left(\mathrm{a}_{1} \varepsilon-\operatorname{sen} \varepsilon\right)}{\mathrm{L} \phi_{\mathrm{c}}}$ & $\frac{2 \mathrm{El}_{2}(1-\mathrm{g})}{\mathrm{L}(1+2 \mathrm{~g})}$ & $\frac{E \mathrm{I}_{\mathrm{z}} \varepsilon\left(\operatorname{senh} \varepsilon-\mathrm{a}_{2} \varepsilon\right)}{\mathrm{L} \phi_{\mathrm{t}}}$ \\
\hline & $\begin{array}{c}2-2 \cos \varepsilon-a_{1} \varepsilon \operatorname{sen} \varepsilon \\
a_{1}=1-\frac{c f \cdot|P|}{G \cdot A_{x}} \\
\alpha=\sqrt{\frac{|P|}{\left(a_{1} E I_{z}\right)}}\end{array}$ & $\begin{array}{c}\mathrm{g}=\frac{6 \mathrm{cf} E \mathrm{I}_{2}}{\mathrm{GA}_{\mathrm{X}} \mathrm{L}^{2}} \\
\varepsilon=\alpha \mathrm{L}\end{array}$ & $\begin{array}{c}\phi_{1}=2-2 \cosh \varepsilon+a_{2} \varepsilon \operatorname{senh} \varepsilon \\
a_{2}=1+\frac{\text { cf. } P}{G \cdot A_{x}} \\
\alpha=\sqrt{\frac{P}{\left(a_{2} E I_{z}\right)}}\end{array}$ \\
\hline
\end{tabular}


A matriz de rigidez de um elemento de barra $\left[\mathrm{S}_{\mathrm{KB}}\right]_{\mathrm{i}}$, relaciona o vetor, dos seus esforços $\{F\}_{i}$, com o vetor dos seus deslocamentos $\left\{D_{L}\right\}_{i}$, nas coordenadas locais do elemento, Fig.ll-5. Portanto, a formulação matricial para o i-ésimo elemento da estrutura, fica:

$$
\{F\}_{i_{(6 \times 1)}}=\left[S_{\mathrm{KB}}\right]_{(6 \times 6)}\left\{D_{\mathrm{L}}\right\}_{((6 \times 1)}
$$

\subsection{MATRIZ DE RIGIDEZ DA ESTRUTURA FORMADA POR ELEMENTOS DE BARRA}

A matriz de rigidez da estrutura $\left[\mathrm{S}_{\mathrm{KG}}\right]$, relaciona o vetor das ações $\{A\}$, com o vetor dos deslocamentos $\{D\}$, nas " $n$ " coordenadas do sistema global:

$$
\{A\}_{(n \times 1)}=\left[S_{K G}\right]_{(n \times n)}\{D\}_{(n \times 1)}
$$

A matriz de rigidez da estrutura $\left[\mathrm{S}_{\mathrm{KG}}\right]$ pode ser obtida através da contribuição dos elementos de barra (WEAVER ${ }^{42}$, RUBISTEIN ${ }^{40}$ ):

$$
\left[S_{k G}\right]_{(n \times n)}=\sum_{i=1}^{n b}[b]_{i(n \times 6)}^{\top}\left[S_{k B}\right]_{i(6 \times 6)}[b]_{i(6 \times n)}
$$

onde,

n = número total de coordenadas da estrutura formada apenas por elementos de barra, no sistema global

$\mathrm{nb} \quad=$ número de elementos de barra

[b] $]_{\mathrm{i}}=$ submatriz de ordem $6 \times \mathrm{n}$, correspondente ao elemento " $\mathrm{i}$ ", da matriz de transformação [b] de ordem $6 n b \times n$, que relaciona 
os deslocamentos da estrutura com os deslocamentos dos elementos, (estrutura desmontada ):

$\left\{\begin{array}{c}\left\{D_{L}\right\}_{1} \\ \left\{D_{L}\right\}_{2} \\ \vdots \\ \left\{D_{L}\right\}_{n b}\end{array}\right\}_{(6 n b \times 1)}=\left[\begin{array}{c}{[b]_{1}} \\ {[b]_{2}} \\ \vdots \\ {[b]_{n b}}\end{array}\right]_{(6 n b \times n)} \cdot\{D\}_{(n \times 1)}$

$\left[\mathrm{S}_{\mathrm{KB}}\right]_{\mathrm{i}}=$ matriz de rigidez do elemento "i", de ordem $6 \times 6$, nas coordenadas locais

$\left[\mathrm{S}_{\mathrm{KG}}\right]=$ matriz de rigidez da estrutura, de ordem $n \times n$, nas coordenadas globais

$\{D\}=$ Vetor dos deslocamentos da estrutura, no sistema global de coordenadas, de ordem $\mathrm{n} \times 1$

$\left\{D_{L}\right\}_{i}=$ Vetor dos deslocamentos do elemento de barra " $i$ ", no sistema local de coordenadas, de ordem $6 \times 1$

A Fig. II-6, mostra a submatriz $[\mathrm{b}]_{\text {, }}$ de ordem $6 \times \mathrm{n}$, do elemento de barra " $i$ ". A primeira linha de $[b]_{1}$ corresponde a $6 \times(i-1)+1$ linha da matriz de rigidez [b], sucessivamente até a sexta linha da matriz $[b]_{i}$ correspondente a $6 \times(\mathrm{i}-1)+6$ linha da matriz de rigidez [b]. A coluna $1 \mathrm{ji}$ de [b], corresponde a coluna $3 \mathrm{nj}-2$ de [b]; a coluna 2ji de [b], corresponde a coluna $3 \mathrm{nj}$ - 1 de [b]; a coluna $3 \mathrm{ji}$ de [b] corresponde a coluna 3 nj de [b]; a coluna $4 \mathrm{ki}$ de [b]; corresponde a coluna $3 \mathrm{nk}$ - 2 de [b]; a coluna $5 \mathrm{ki}$ de $[\mathrm{b}]_{\mathrm{i}}$ corresponde a coluna $3 \mathrm{nk}$ - 1 de [b] e a coluna 6 ki corresponde a coluna $3 \mathrm{nk}$ de [b].

Onde,

$\mathrm{i}=$ número da barra

$\mathrm{nj} \quad=$ número do nó inicial da barra 
nk = número do nó final da barra

$\mathrm{n} \quad=$ número total de coordenadas, no sistema global

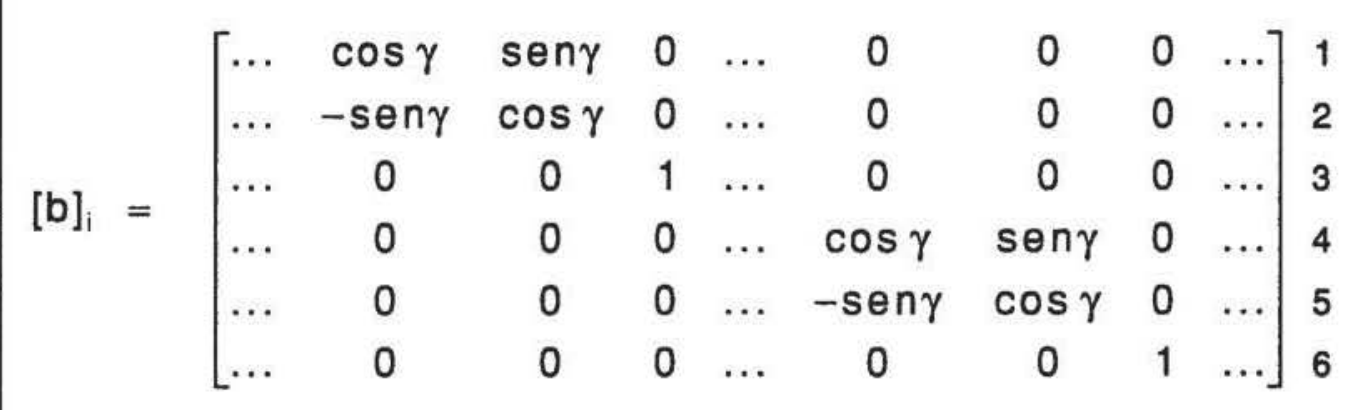

$\begin{array}{llllllllll}\ldots & 1 \mathrm{ji} & 2 \mathrm{ji} & 3 \mathrm{ji} & \ldots & 4 \mathrm{ki} & 5 \mathrm{ki} & 6 \mathrm{ki} & \ldots\end{array}$

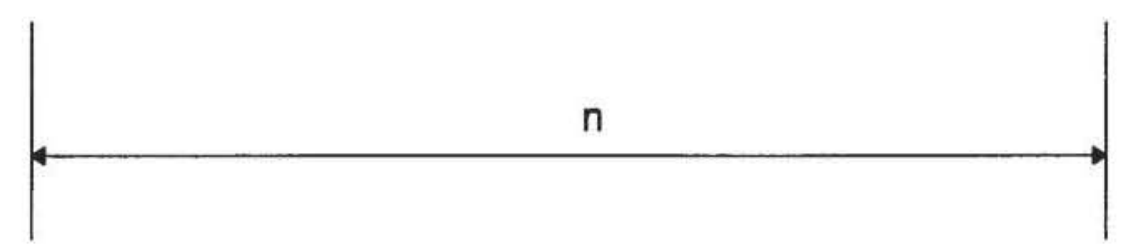

Figura II-6 Submatriz de Transformação $[\mathrm{b}]$, de Ordem $6 \times \mathrm{n}$, do Elemento de Barra

Como a matriz de rigidez da estrutura [ $\mathrm{S}_{\mathrm{KG}}$ ] é obtida através das contribuições das matrizes de rigidez dos elementos de barra que em regime de $2^{a}$ ordem são funções das forças axiais, a matriz de rigidez [ $\left.\mathrm{S}_{\mathrm{KG}}\right]$ dependerá do carregamento da estrutura. 


\subsection{CÁLCULO DOS ESFORÇOS E DESLOCAMENTOS DA ESTRUTURA, EM TEORIA DE PRIMEIRA E SEGUNDA ORDEM}

As formulações matriciais, mostradas nas expressões (2.20) e (2.21), permitem determinar os deslocamentos nas coordenadas do sistema global e os esforços nos elementos de barra nas suas coordenadas locais, a partir das ações nas coordenadas do sistema global. A análise da estrutura em regime de primeira ordem é realizada através de um sistema de equações lineares de solução direta; porém, a análise da estrutura em regime de segunda ordem, depende de um sistema de equações não lineares, em termos de forças axiais "P". Neste caso, como elas são incógnitas, é inviável a sua solução direta.

Para resolver o problema, de obtenção dos esforços e deslocamentos na estrutura submetida a um carregamento em regime de segunda ordem, será adotado processo iterativo com aproximações sucessivas.

\subsection{PROCESSO ITERATIVO COM APROXIMAÇÕES SUCESSIVAS}

A técnica utilizada é a da iteração direta, que consiste em uma sucessão de atualizações da matriz de rigidez da estrutura, através de estimativas de deslocamentos, até se atingir a configuração deformada de equilíbrio, mediante tolerância adotada.

Inicialmente será desprezada a influência da força axial no cálculo das matrizes de rigidez dos elementos de barra que contribuirão para a montagem da matriz de rigidez da estrutura, em regime de primeira ordem. Com o carregamento imposto e a matriz de rigidez do sistema serão determinados os deslocamentos da estrutura. Com estes deslocamentos serão determinados os deslocamentos nos elementos de barra. Finalmente, com estes deslocamentos serão determinadas as forças axiais "P".

Com os valores, iniciais, das forças axiais "P" obtidas em regime de primeira ordem, é iniciado o processo iterativo para determinar a matriz de rigidez com termos não lineares, em regime de segunda ordem. Com estas 
forças axiais, recalcula-se a matriz de rigidez do sistema com seus coeficientes afetados por estas forças utilizando as funções de rigidez. Com o mesmo procedimento anterior recalculam-se os novos deslocamentos da estrutura e as novas forças axiais "P", nos elementos de barra, submetidos ao mesmo carregamento anterior. Com os novos valores, o processo é repetido, mantendo o carregamento e assim sucessivamente a iteração é processada até que na n-ésima vez, o vetor deslocamento $\left\{D_{n}\right\}$ seja praticamente coincidente com $\left\{D_{n-1}\right\}$ da (n-1)-ésima aproximação.

Como o processo é iterativo, ele só termina quando ocorre a convergência dos deslocamentos para valores definitivos em cada etapa. Para agilizar o processo, é necessário definir uma tolerância para as interações. Neste caso, foi adotada a expressão:

$$
\left|\frac{\left\{D_{n}\right\}-\left\{D_{n-1}\right\}}{\left\{D_{n}\right\}}\right| \leq \text { TOL }
$$

onde,

$\left\{D_{n}\right\}=$ vetor deslocamento na n-ésima iteração

$\left\{D_{n-1}\right\}=$ vetor deslocamento da (n-1)-ésima iteração

$\mathrm{TOL}=$ tolerância adotada

Apesar da tolerância, recomendada por alguns pesquisadores, ser um valor fixo de $10^{-3}$, o presente trabalho recomenda instalar no programa uma entrada interativa para facilitar alterações que se fazem necessárias na determinação de algumas estruturas, próximas do limite de estabilidade, devido à dificuldade de convergência no processo em termos de precisão e tempo de computação.

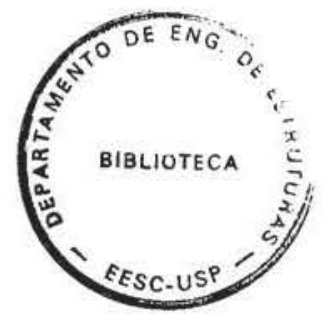




\subsection{VERIFICAÇÃO DA ESTABILIDADE DA ESTRUTURA SUBMETIDA A UM DETERMINADO CARREGAMENTO}

Uma estrutura será considerada estável sob um certo carregamento se sua matriz de rigidez for definida positiva(40-43-52), ou seja, todos os seus autovalores são positivos. Portanto, seu produto que é o determinante da matriz de rigidez também será positivo e conseqüentemente a matriz de rigidez será dita não singular.

Se a matriz é definida positiva, é possível exprimí-la através de uma transformação linear sobre as linhas e colunas, correspondente a uma mudança de base, na forma de uma matriz diagonal ainda positiva(43) (52).

Os autovalores dessa matriz de rigidez diagonalizada, de ordem nxn, são em número de " $n$ " e correspondem exatamente aos termos da diagonal. A cada autovalor negativo ou nulo corresponde um modo de flambagem. Desta forma, para um carregamento definido, o número de elementos negativos ou nulos na diagonal é igual ao número de graus de liberdade que tem o modo de flambagem para esse carregamento. No trabalho de ANTUNES ${ }^{35}$, a transformação linear foi orientada pelo método de Gauss, por pivotamento, visando zerar os elementos abaixo da diagonal. Neste processo, o pivotamento pode ser interrompido ao constatar a existência do primeiro elemento negativo ou nulo na diagonal, o que já detectaria a existência de flambagem com pelo menos um grau de liberdade, caracterizando a instabilidade da estrutura. Este processo também foi utilizado por FIGUEIREDO 36 comparando-o com 0 processo de decomposição das matrizes definidas positivas pelo método de Cholesky, viabilizando suas utilizações com muita eficiência. Porém, segundo JENNINGS 43 e GOLUB ${ }^{52}$, para verificar se uma matriz é definida positiva, basta tentar decompô-la por Cholesky, pois é uma condição necessária e suficiente, demonstrada por ambos. Como o processo é muito simples de ser programado, foi o utilizado neste trabalho. Portanto, a verificação da estabilidade da estrutura submetida a um determinado carregamento passa pela verificação da matriz da estrutura, ser ou não definida positiva $e$ conseqüentemente ser possível decompô-la por Cholesky. A estabilidade da estrutura será verificada, portanto, no instante da decomposição de sua matriz de rigidez. Ao detectar um termo negativo ou nulo na diagonal, 
durante a decomposição da matriz através da fatoração $\mathrm{LDL}^{\top}$, com "L" representando a matriz triangular inferior (com " 1 " na diagonal) e " $D$ " a matriz diagonal, o processo pode ser interrompido. Alternativamente, a fatoração da matriz pode ser feita através de $\tilde{L} \tilde{L}^{\top}$ com " $\tilde{L}$ " representando a matriz triangular inferior com $\tilde{L}=L D^{1 / 2}$. Portanto, para uma matriz de rigidez "S", simétrica e definida positiva ela pode ser decomposta como segue:

$$
\begin{aligned}
& {[S]=[L][D][L]^{\top}=[\tilde{L}][\tilde{L}]^{\top}} \\
& \tilde{L}=L D^{1 / 2}
\end{aligned}
$$

Para cada carregamento, a matriz de rigidez é calculada buscando a sua convergência, em regime de $2^{2}$ ordem e com isso a sua estabilização. 0 valor de seu determinante será inferior àquele do determinante correspondente à matriz de rigidez em que os coeficientes não estão afetados pela força axial predominantemente de compressão e em conseqüência disto, os deslocamentos resultantes serăo maiores. Os deslocamentos resultantes da matriz de rigidez em regime de primeira ordem serão inferiores aos deslocamentos resultantes da matriz de rigidez em regime de $2^{a}$ ordem, 0 que é o mesmo que dizer matriz de rigidez considerando a não linearidade geométrica, logo, alterando o carregamento em acréscimos sucessivos as forças axiais resultantes serão majoradas. A medida que aquelas forças axiais de compressão forem aumentando em conseqüência da mudança crescente do carregamento da estrutura, o valor do determinante correspondente à nova matriz de rigidez irá diminuindo e os deslocamentos resultantes no sistema irão aumentando, até que atingido o carregamento crítico, o valor do determinante correspondente à matriz de rigidez, será nulo e os deslocamentos resultarão indeterminados. 0 processo é valido, naturalmente, para problemas tanto de primeira quanto de segunda espécie e a pesquisa da estabilidade da estrutura poderá ser realizada com facilidade. 


\subsection{CARREGAMENTO CRÍTICO DE INSTABILIDADE, DO PÓRTICO PLANO DO EDIFÍCIO INDUSTRIAL}

A determinação do carregamento crítico para a estrutura do pórtico, submetida às ações permanentes e às ações variáveis de vento e ponte rolante, será considerada através de dois carregamentos distintos: o primeiro carregamento composto pelas ações cujas intensidades serão mantidas constantes, como por exemplo, as permanentes em conjunto com o vento, chamado de cargas constantes, e o segundo carregamento cujas intensidades serão afetadas por um parâmetro de proporcionalidade "W", chamado de cargas vivas, como por exemplo açōes da ponte rolante. Após a definição dos carregamentos, a busca do parâmetro crítico " $\mathrm{W}_{\mathrm{cr}}$ " que conduzirá ao carregamento total crítico da estrutura ficará restrito à análise do parâmetro "W".

Inicialmente a matriz de rigidez é calculada em regime de primeira ordem, com os coeficientes não afetados pelos efeitos das forças axiais. Com esta matriz de rigidez, são calculados os esforços internos, em especial as forças axiais nas barras, através das cargas constantes e das cargas vivas multiplicadas pelo parâmetro $\mathrm{W}=1$.

Em seguida, é calculado o parâmetro "W" que iniciará o processo de carregamentos e verificações de instabilidade da estrutura. A determinação de "W" inicial será feita através das seguinte etapas:

a) Com o valor do parâmetro "W" unitário, procura-se a barra "i" com força axial "P", a mais próxima possível da flambagem de Euler, correspondente ao máximo valor de " $\rho "$.

$$
\begin{aligned}
& \rho=\frac{P_{i}}{P_{E i}} \\
& P_{E i}=\frac{\pi^{2} E_{i} l_{Z i}}{L_{i}^{2}}
\end{aligned}
$$




$$
\begin{aligned}
& P_{i}=P_{c i}+W P_{v i} \\
& \rho_{\text {max }}=\left(\frac{P_{c i}+P_{v i}}{P_{E i}}\right)_{\text {max }} \Rightarrow I B C
\end{aligned}
$$

onde,

$P_{i}=$ Força axial da barra "i", com carregamento total com $\mathrm{W}=1$

$\mathrm{P}_{\mathrm{vi}}=$ Força axial da barra "i", obtida das cargas vivas

$\mathrm{P}_{\mathrm{Ei}}=$ Força axial da barra "i", obtida da expressão de Euler

$P_{c i}=$ Força axial da barra " $i "$, obtida das cargas constantes

IBC = Barra "i" obtida com força axial " $P_{i}$ " mais próxima da flambagem de Euler, produzido pelo " $\rho_{\max }$." $\operatorname{com} W=1$.

É importante lembrar que os elementos de barra definidos no processo são os elementos prismáticos do pórtico. Nos pontos de descontinuidade da estrutura serão definidos os nós, como ocorrem nas ligações entre pilares e traves de cobertura ( ou vigas de cobertura) e nas variações bruscas de seção transversal dos pilares dos edifícios industriais. As barras assim definidas, entre os nós da estrutura, não necessitarão de discretizações uma vez que o processo utiliza as funçōes de rigidez nas barras. Este processo favorece a economia de memória de computador, pois trabalha com número reduzido de elementos. Portanto, o parâmetro " $\rho$ " deve ser obtido com os comprimentos reais das barras em seus trechos prismáticos.

b) De posse da barra "IBC", mais próxima à flambagem de Euler, passa-se agora para a determinação do parâmetro "W" para a barra "IBC" para que esta barra atinja o limite de estabilidade. Este parâmetro será chamado agora de " $W_{E}$ ". Adotando " $\rho$ " unitário, em (2.27), tem-se:

$$
P_{c i}+W_{E} P_{v i}=P_{E i}
$$




$$
W_{E}=\frac{\left(P_{E i}-P_{c i}\right)}{P_{v i}}
$$

onde,

$$
\begin{aligned}
& \mathrm{W}_{\mathrm{E}}=\text { parâmetro das cargas vivas que levará a barra IBC até o limite de } \\
& \text { Euler }
\end{aligned}
$$

Nesta etapa, o limite de estabilidade do pórtico foi alcançado através da instabilidade da barra "IBC", por flexão no plano do pórtico. Esta determinação considerou barras bi-articuladas, nas condições de Euler, porém, como as barras do pórtico são ligadas rigidamente, o limite máximo do parâmetro " $\mathrm{W}_{\text {máx." }}$ será alcançado quando as barras forem consideradas bi-engastadas em ligações indeslocáveis, neste caso:

$$
\begin{aligned}
& P_{E_{\max }}=4 P_{E i} \\
& W_{\text {max }}=\frac{\left(4 P_{E i}-P_{c i}\right)}{P_{v i}} \\
& W_{\text {max }}=\left(3 P_{E i} / P_{v i}\right)+W_{E}
\end{aligned}
$$

onde,

$$
\begin{aligned}
& \mathrm{W}_{\max }= \text { Parâmetro máximo das cargas vivas que um pórtico pode } \\
& \text { suportar sem perder a estabilidade. }
\end{aligned}
$$

De posse do parâmetro máximo " $\mathrm{W}_{\max }$ ", a primeira verificação da estabilidade da estrutura será feita com o valor de "W" intermediário entre zero e o parâmetro máximo. $O$ processo, portanto, convergirá rapidamente pesquisando os intervalos: 


$$
W=\frac{(W A+W B)}{2}
$$

onde,

$$
\begin{aligned}
W A= & \text { Limite inferior do parâmetro das cargas vivas, inicialmente } \\
& \text { adotado igual a zero } \\
W B= & \text { Limite superior do parâmetro das cargas vivas, inicialmente } \\
& \text { adotado igual a } \mathrm{W}_{\max }
\end{aligned}
$$

Como o carregamento será sempre a soma das cargas constantes com as cargas vivas multiplicadas pelo parâmetro "W", este parâmetro será pesquisado sempre no intervalo compreendido entre um limite superior WB, para o qual a estrutura pode alcançar ou ultrapassar o limite de estabilidade e um limite inferior WA, para o qual a estrutura é considerada estável. Através do processo iterativo com aproximações sucessivas, pode-se alcançar rapidamente o parâmetro crítico "W $\mathrm{Wr}_{\mathrm{cr}}$, de instabilidade do pórtico.

Definido o carregamento inicial, inicia-se a fase de cálculo da matriz de rigidez em regime de segunda ordem. Com esta matriz, calculam-se os esforços axiais e analisa-se a convergência dos deslocamentos da estrutura, através do processo iterativo de aproximações sucessivas, já descrito nos itens anteriores. No caso de êxito na convergência, significa estrutura estável, logo altera-se o limite inferior "WA", para o valor atual de "W", mantendo "WB" inalterado. Repete-se 0 processo com 0 novo parâmetro intermediário entre os novos limites para determinar as novas forças axiais e os novos deslocamentos na estrutura. Caso não haja convergência no processo ou sequer a matriz de rigidez de estrutura possa ser decomposta, por Cholesky, isto significará estrutura instável. Logo, altera-se o limite superior "WB" para o valor atual de "W", mantendo "WA" inalterado. $O$ processo é novamente repetido buscando a igualdade entre os limites "WA" e "WB". O processo é interrompido quando além de satisfeitas as condições de convergência da matriz de rigidez, será verificada a tolerância do valor pesquisado, " $\mathrm{W}_{\mathrm{cr}}$ ", com: 


$$
\left(\frac{(W B-W A)}{W B}\right) \leq \text { TOL }
$$

onde,

TOL = Tolerância adotada no início da execução do programa, (sugerido $10^{-3}$ ).

A convergência satisfeita, com valores de "WA" e "WB" praticamente coincidentes significará que o parâmetro crítico máximo " $\mathrm{W}_{\mathrm{cr}}$ " foi encontrado. Neste caso, pode-se afirmar que a estrutura submetida ao carregamento majorado pelo parâmetro " $\mathrm{W}_{\mathrm{cr}}$ " nas cargas vivas terá alcançado o limite de estabilidade, ou seja, o carregamento crítico de instabilidade elástica por flexão do pórtico plano, foi atingido.

Para análise dos pilares que apresentam uma variação brusca de seção, formando dois trechos prismáticos, cada trecho poderá ser constituído de uma única barra, sem a necessidade de discretizaçōes ( ou divisões em várias barras ). O processo utiliza as funções de rigidez garantindo a configuração deformada da barra.

Com o carregamento crítico atingido no pórtico, é possivel comparar em cada barra a força crítica de Euler com a força crítica obtida do carregamento citado. Através desta relação é possivel conhecer o comportamento de cada elemento de barra no instante da instabilidade da estrutura. Os chamados comprimentos efetivos de flambagem de cada barra podem ser determinados multiplicando cada comprimento de barra pelo parâmetro " $\mathrm{K}$ ", definido como sendo a raiz quadrada da relação entre a força de Euler e a força crítica em cada barra do pórtico plano, no instante do carregamento crítico.

O programa de computador, Tipo I, desenvolvido utilizando o processo descrito até o momento, permite realizar alterações nas vinculaçōes, como por exemplo a ligação entre os pilares e a trave de cobertura, para possibilitar comparaçōes entre as posições deslocadas da estrutura em cada situação de carregamento crítico. 
É importante lembrar que a consideração das deformações por força cortante contribuem para complementar a precisão dos resultados, diminuindo as hipóteses simplificadoras embora muito pequenas.

O programa de computador, Tipo I, permite ainda comparar as máximas tensōes obtidas em cada elemento de barra, com a tensão limite de proporcionalidade do material. Esta comparação indica se o limite de estabilidade da estrutura ocorreu no regime elástico ou no regime inelástico do material. Portanto, o carregamento crítico da estrutura poderá ser alcançado ou pela tensão limite de proporcionalidade do material ou pelo limite de estabilidade por flexão da estrutura, no regime elástico. 


\section{CAPÍTULO III}

\section{CARREGAMENTO CRÍTICO DE INSTABILIDADE ELÁSTICA GERAL, DE PILARES DE SEÇÃO COMPOSTA VARIÁVEL, DE EDIFÍCIOS INDUSTRIAIS METÁLICOS}

\subsection{INTRODUÇÃO}

Como foi visto no capítulo anterior, a análise de instabilidade de pilares de edifícios industriais metálicos, é efetuada através do estudo do comportamento do pórtico transversal sob carregamento variável.

No presente capítulo, o pórtico transversal também será composto por trave em treliça e pilares de seção variável, porém com os pilares não mais formados por barras que só se deformam no plano do pórtico. Agora eles serão considerados como barras formadas por perfis metálicos, de seções abertas, tendo comportamento tridimensional.

Para a análise de barras constituídas de paredes delgadas de seções transversais abertas, poderia ser aplicada diretamente a teoria de barras longas desenvolvida por VLASSOV 32 . Entretanto, esta teoria só foi desenvolvida para barras com eixos alinhados, contrariando a concepção dos pilares com variação brusca de seção de edifícios industriais metálicos; Fig.IIl-1. Para analisar o presente problema, adotou-se 0 processo dos deslocamentos com a técnica de discretização de seção, desenvolvido por YAGUI 17-33-34.

O uso dessa técnica possibilita determinar, com relativa facilidade, o carregamento crítico dos pilares de seção variável compostos por perfis abertos e de paredes delgadas, acoplados à trave do telhado. A seguir este processo será exposto em suas linhas gerais. 


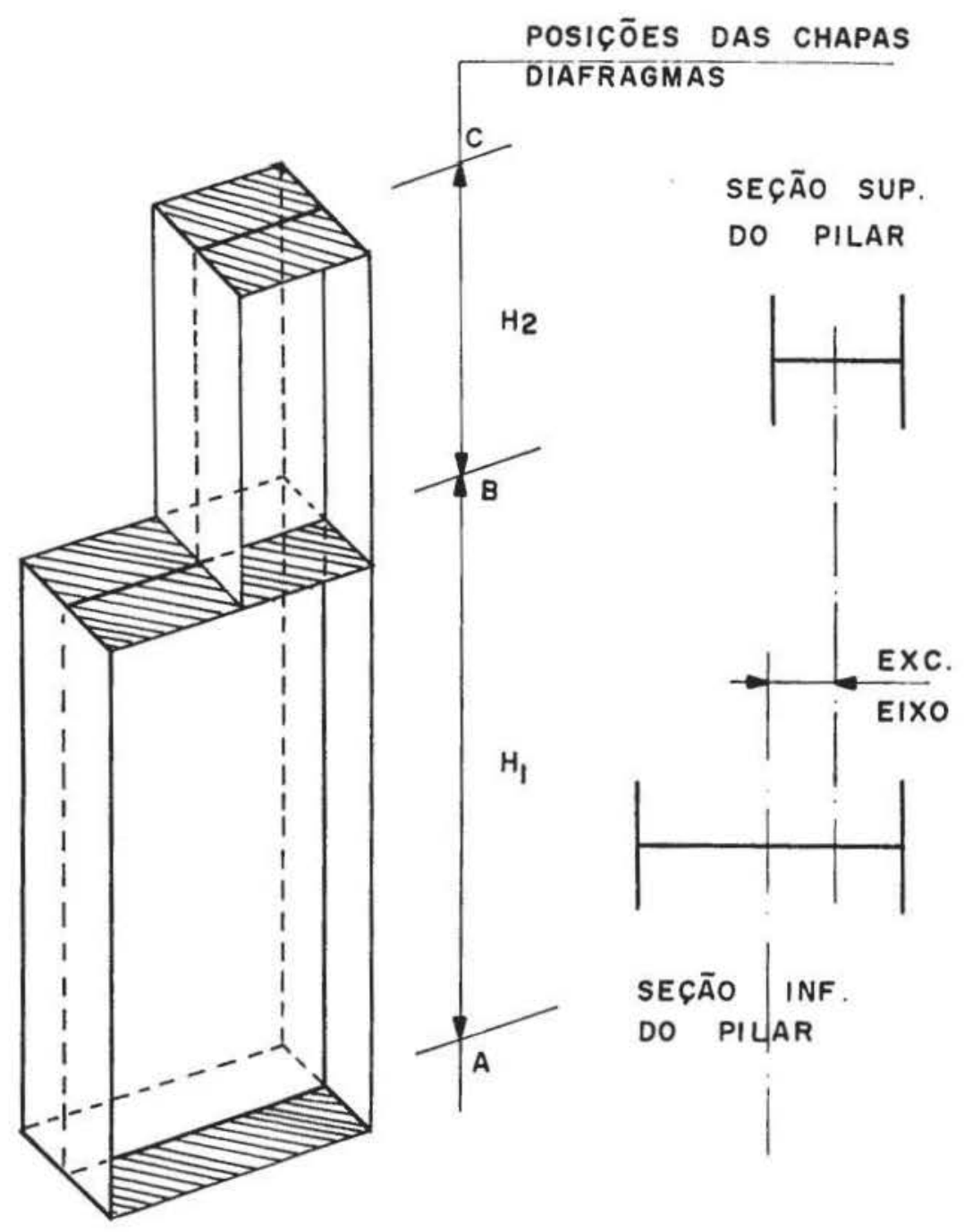

Figura III-1 Pilar com Variação Brusca de Seção Transversal do Tipo I, Utilizando Chapas Diafragmas nos Niveis A, B e C.

3.2 DISCRETIZAÇÃO DOS PILARES DE SEÇÃO VARIÁVEL COMPOSTOS POR PERFIS ABERTOS E DE PAREDES DELGADAS

Os pilares formados por perfis abertos e de paredes delgadas serão 
discretizados conforme ilustrado na Fig.III-2, para um perfil composto do Tipo I. O processo adotado consiste basicamente na discretização dos pilares, substituindo-se cada parede, constituinte do pilar, em painéis que por sua vez são divididos em tramos. Cada comprimento de tramo é definido compreendido entre dois níveis de diafragmas transversais dispostos ao longo do eixo longitudinal do pilar.

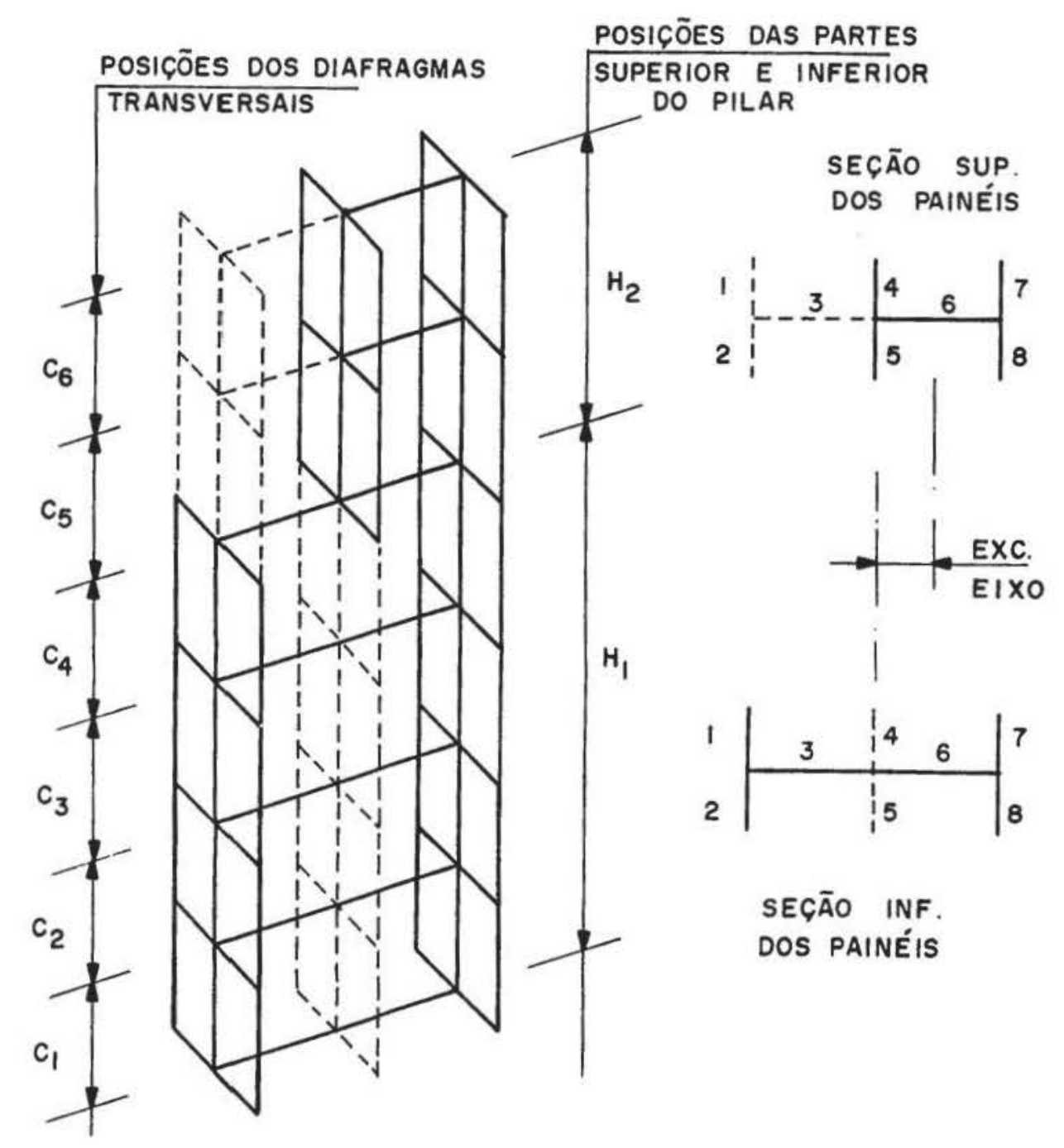

Figura III-2 Pilar Discretizado em Oito Painéis de Seis Tramos Cada Um 
Os painéis terão sempre o mesmo número de tramos $\theta$ as seçōes terão sempre o mesmo número de painéis. A variação geométrica da seção, com variação brusca, em que alguns dos painéis são interrompidos ao longo do eixo do pilar, pode ser realizada através da imposição de espessura igual a zero nos tramos em que os painéis deixam de participar da rigidez do pilar.

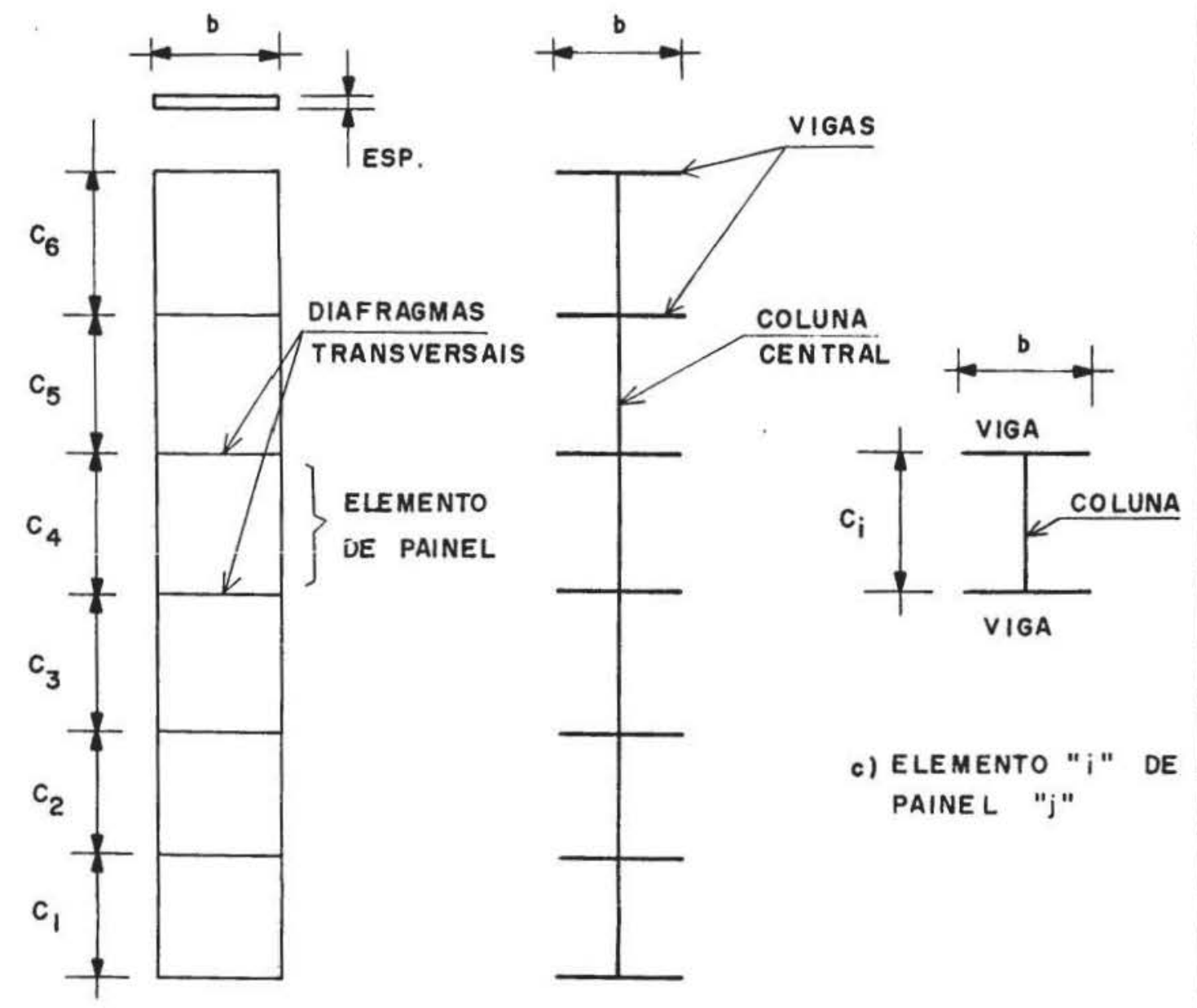

a) PAINEL " $j "$

b) PÓRTICO (PAREDE)

EQUIVALENTE

À PAREDE

Figura III-3 a) Painel "j " de um Perfil, Representando Uma Parede, Formado por Seis Elementos. b) Pórtico Equivalente à Parede, Formado por Vigas e Uma Coluna Central. c) Elemento de Painel. 
Os painéis de um perfil que representam as paredes, são constituídos de elementos de painel localizados em cada tramo, Fig. III-3. Estes painéis são substituídos por pórticos planos equivalentes, constituídos de vigas horizontais e uma coluna vertical central. As vigas são localizadas nos níveis dos diafragmas transversais.

A técnica de discretização de seção do pilar resume-se em substituir cada painel, proveniente de parede delgada do pilar, por um pórtico equivalente formado de elementos de painel.

\subsection{HIPÓTESES ADOTADAS NO PROCESSO}

Os perfis seguem as relações geométricas, de VLASSOV 32, nas seções transversais e nos comprimentos do pilar. Teoria de barras longas.

As relações entre as abas do perfil e suas espessuras, tanto para as mesas quanto para a alma, devem satisfazer a estabilidade local das paredes. Não é admitido distorções nas seções transversais.

\subsubsection{Painéis}

As paredes planas dos perfis componentes dos pilares, serão designados de painéis. Cada parede poderá ser considerada como painel individual ou subdividido em dois ou mais painéis coplanares adjacentes. Essa subdivisão é necessária sempre que uma parede é interceptada por outra, como ocorre no perfil do Tipo I, em que as abas são ligadas à alma.

Os painéis apresentam rigidez elástica, apenas no seu plano. A rigidez no plano transversal, é desprezada devido a sua pequena espessura.

A largura de cada painel deverá ser constante, porém sua espessura poderá variar bruscamente ao nível dos diafragmas.

A descontinuidade de um painel poderá ser considerada, através da adoção de espessura igual a zero. 
As únicas interações entre painéis ao longo de suas interseções, são as forças de cisalhamento longitudinais.

\subsubsection{Diafragmas}

Os diafragmas hipotéticos ou reais serão considerados indeformáveis em seu plano e flexíveis transversalmente. Desta forma, eles impedem as distorções nas seções transversais do pilar, nos pontos onde se localizam, porém, não impedem o seu empenamento, ( hipóteses da flexo-torção ).

As únicas interações que ocorrem entre os painéis verticais e os diafragmas horizontais são os esforços contidos nos planos horizontais ao longo das interseções desses elementos.

\subsubsection{Estrutura Equivalente}

Cada painel é substituído por um pórtico plano equivalente, Fig.III-3b, constituído por um conjunto de vigas horizontais, engastadas ao meio ao pilar central.

Essas vigas são consideradas como existentes nos niveis dos diafragmas transversais e terão rigidez infinita no plano do painel. Elas representam as seções transversais do referido painel, nas quais as deformações axiais se apresentam com variação linear.

Os tramos do pilar central do painel, compreendidos entre vigas consecutivas, terão as mesmas características elástico-geométricas do painel substituído.

Os pórticos planos são travados horizontalmente pelos diafragmas transversais e verticalmente pelos vínculos existentes nas extremidades das vigas concorrentes, de modo que somente forças verticais de interação sejam ai transmitidas.

Os diafragmas transversais, são exigidos nos locais onde possam existir variações brusca de espessura do painel ou até em caso de descontinuidade do mesmo. 
Os diafragmas transversais são necessários, também, nos locais onde são aplicadas as ações externas transversais ao pilar ou quando houver interesse em determinar deslocamentos nestas posições. A principal importância da existência dos diafragmas é de garantir o comportamento tridimensional da estrutura equivalente e, neste caso, devem satisfazer à relação entre o comprimento do tramo do pilar central com a largura do painel, Fig.III-4. Esta relação foi obtida para o presente estudo como forma de melhorar a precisão dos resultados obtidos no processo e encontram-se no ANEXO A.

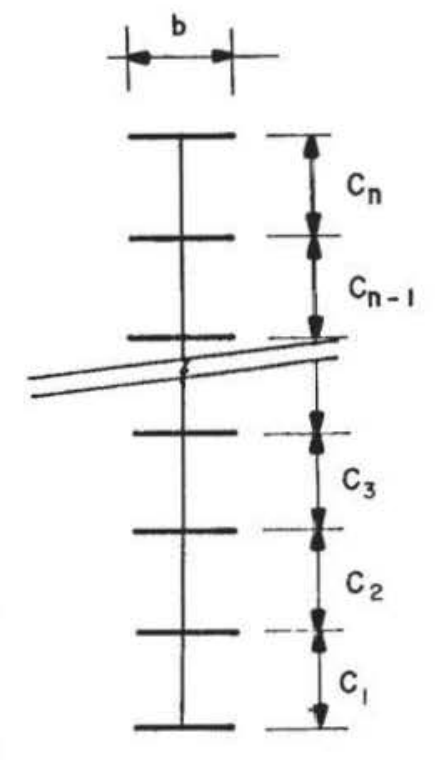

Recomendável para precisões de aproximadamente $1 \%$, no processo

$$
(\mathrm{ci} / \mathrm{b}) \leq 5
$$

Tolerância para precisões de aproximadamente $7 \%$, no processo

$$
5<(C / b) \leq 10
$$

Figura III-4 Relações entre Comprimento e Largura dos Tramos do Pilar Central do Pórtico Equivalente 
Para a estrutura equivalente formada por painéis de larguras diferentes, a determinação da relação, acima citada, deverá ser adotada pela média das larguras dos painéis ou pelo painel que apresentar o maior efeito de flexão ao longo do processo.

A estrutura tridimensional equivalente é, portanto, um sistema discreto constituído por um conjunto de pórticos, cada um correspondente a um painel, que por sua vez representa a parede ou parte dela do pilar considerado. Este conjunto de pórticos são interligados, nos níveis dos diafragmas transversais, pelas vigas horizontais concorrentes.

As forças de cisalhamento verticais, que entre paredes do perfil metálico, ocorrem de modo contínuo ao longo de suas interseções, ficam representadas pelas forças concentradas verticais, entre vigas concorrentes nos níveis dos diafragmas transversais.

\subsubsection{Ações}

Para o sistema estrutural equivalente, serão admitidas ações horizontais agindo nos planos dos diafragmas transversais, incluindo os momentos torçores. As ações verticais serão admitidas concentradas nas extremidades das vigas nos níveis dos diafragmas transversais.

Estas características não são exclusivas para pilares de edifícios industriais, podem ser aplicadas em qualquer pilar ou viga de perfil aberto $e$ de paredes delgadas.

\subsubsection{Vínculos Externos}

Os pilares dos edifícios industriais são, geralmente, engastados na base para fornecer à estrutura maior rigidez. Entretanto, podem ser considerados articulados ou até constituídos de vínculos elásticos, bastando para isto fornecer aos vínculos de apoio seus coeficientes de rigidez.

Para as vinculações de topo do pilar, há que se definir o tipo de análise a ser considerada. Para o estudo de pilares isolados, do resto da estrutura, pode-se considerar qualquer situação de vinculação: do tipo fixo; do tipo móvel ou até do tipo elástico. Para o estudo de pilares acoplados ao 
pórtico transversal, o topo de cada pilar terá vinculações incorporadas à trave em treliça, formando o sistema estrutural global do pórtico transversal.

No plano perpendicular ao do pórtico transversal, os vínculos externos serão do tipo fixo e, alternativamente, podem ser do tipo elástico cujas rigidezes serão fornecidas pelos contraventamentos dos pilares, adotados na concepção estrutural.

Os vínculos externos das estruturas discretizadas estão condicionados à existência de diafragmas transversais, pois possuem coordenadas horizontais e verticais capazes de transmitir esses efeitos para toda a estrutura discretizada equivalente.

\subsection{SISTEMAS DE REFERÊNCIA}

3.4.1 Sistema de Referência Global de Eixos para a Estrutura do Pórtico Transversal

Para referência da estrutura do pórtico transversal, será adotado um sistema global, dextrorso, com eixos " $\mathrm{X}_{G}$ ", " $\mathrm{Y}_{G}$ ", " $\mathrm{Z}_{G}$ " e origem " $\mathrm{O}_{G}$ " num ponto qualquer, no plano da base dos pilares. $O$ eixo " $\mathrm{x}_{G}$ ", vertical, será orientado de baixo para cima, da base para o topo dos pilares. O eixo " $\mathrm{y}_{\mathrm{G}}$ ", horizontal, será orientado da esquerda para a direita, do pilar da esquerda para o pilar da direita do pórtico transversal e paralelo ao plano da trave, Fig.III-5.

3.4.2 Sistema de Referência Local de Eixos para o Elemento de Barra "i", da trave.

Para referência do elemento de barra "i", será adotado um sistema local, dextrorso, com eixos " $x_{i}$ ", " $y_{i}$ ", " $z_{i}$ " e origem " $O_{i}$ " no nó inicial "j" da barra " $i$ ", no centro de gravidade da barra. O eixo " $y_{i}$ " será o próprio eixo da barra orientado do nó inicial "j" para o nó final " $k$ ". O eixo " $x_{i}$ " será orientado perpendicularmente ao eixo " $y_{i}$ " com início no nó "j". O ângulo " $\gamma_{i}$ ", formado entre o eixo " $\mathrm{y}_{\mathrm{G}}$ ", global da estrutura e o eixo " $\mathrm{y}_{i}$ ", local do elemento de barra, medido a partir do primeiro, no sentido anti-horário em relação ao 
eixo local " $z_{i}$ ", define a relação entre os sistemas de referência global e local, Fig.III-5.

3.4.3 Sistema de Referência Local de Eixos para o Painel "j", do Pilar Discretizado.

Para referência do painel "j", será adotado um sistema local, dextrorso, com eixos " $x_{j}$ ", " $y_{j}$ ", " $z_{j}$ " e origem " $\mathrm{O}_{j}$ " na base do painel e no ponto médio entre o nó inicial "ji" e o nó final "jk". O eixo " $x_{j}$ " terá a mesma orientação do eixo " $\mathrm{x}_{G}$ ", global. $O$ eixo " $y_{j}$ ", contido no plano do painel, será orientado do nó inicial "ji" para o nó final "jk" do painel "j". O eixo " $\mathrm{z}$ " será perpendicular ao plano do painel. $O$ angulo " $\gamma_{j}$ ", formado entre o eixo " $\mathrm{y}_{\mathrm{a}}$ ", global da estrutura e o eixo " $y_{j}$ ", local do painel, medido a partir do primeiro, no sentido do eixo " $\mathrm{X}_{\mathrm{G}}$ ", define a relação entre os sistemas de referência global e local, Fig.III-5.

\subsubsection{Sistema de Referência Local de Eixos para o Elemento "i" de} Painel "j", do Pilar Discretizado.

Para referência do elemento " $\mathrm{j}$ " do painel "j", será adotado um sistema local, dextrorso, com eixos " $\mathrm{x}_{i j}$ ", " $\mathrm{y}_{i \mathrm{i}}$ ", " $\mathrm{z}_{\mathrm{ij}}$ " e origem " $\mathrm{O}_{i j}$ " no centro de gravidade da seção transversal do painel, no plano do diafragma transversal, da base do tramo " $i$ ". $O$ eixo " $x_{i j}$ ", local, será coincidente com o eixo " $x_{j}$ ", local do painel e no mesmo sentido do eixo " $x_{G}$ ", global da estrutura. Os eixos " $y_{i j}$ " e " $z_{i j}$ " terão as mesmas direçōes e sentidos dos eixos " $y_{j}$ " e " $z_{j}$ " do painel, respectivamente, Fig.lll-5.

\subsubsection{Sistema de Referência Local de Eixos para o Pilar Discretizado.}

Para referência do pilar discretizado, será adotado um sistema local, dextrorso, com eixos "XPL" , "YPLL", "ZPL" e origem "OPIL" em um ponto qualquer da base do pilar, preferencialmente em um lugar geométrico do plano de simetria da seção transversal do pilar e coincidente com o plano da trave do pórtico transversal. Os eixos "XPL", "YPIL", "ZPIL", locais terão as mesmas orientações dos eixos " $\mathrm{x}_{G}$ ", " $\mathrm{y}_{G}$ ", " $\mathrm{z}_{G}$ ", globais, respectivamente, Fig.lll-5. 


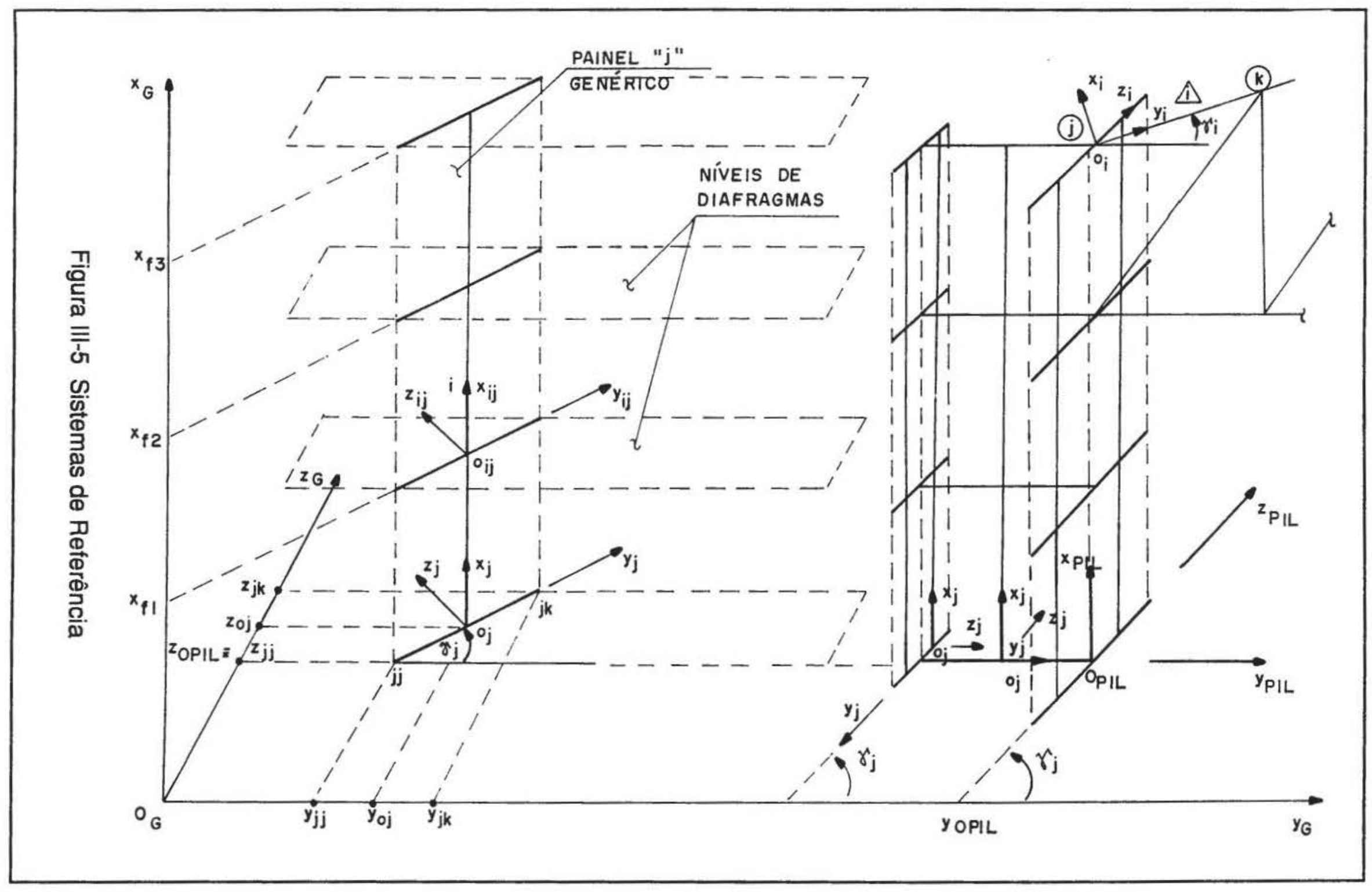




\subsection{MATRIZ DE RIGIDEZ DO ELEMENTO DE PAINEL}

Conforme as hipóteses adotadas, cada painel é substituído por um pórtico plano equivalente que representa a parede delgada do perfil metálico. Este pórtico plano é dividido em tramos constituídos, de elementos de painel, e serão representados pelo modelo mostrado na Fig.lli-6a, com seu sistema de coordenadas deslocamentos mostrado na Fig.lli-6b, caracterizando o comportamento do trecho discretizado da parede.

A matriz de rigidez do elemento de painel será constituída de coeficientes calculados considerando as deformações por força axial; por força cortante; por flexão e por torção, de forma simultânea através da análise de segunda ordem que considera a forma deformada do elemento, resultante dos esforços admitidos em suas extremidades.

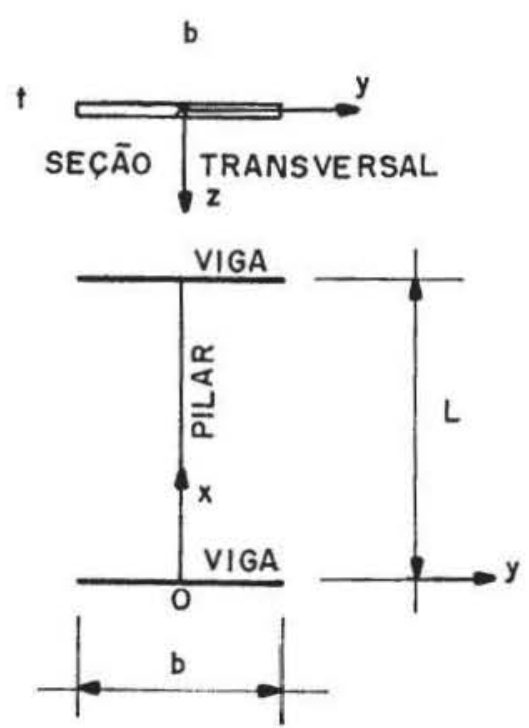

(a) modelo de elemento de painel

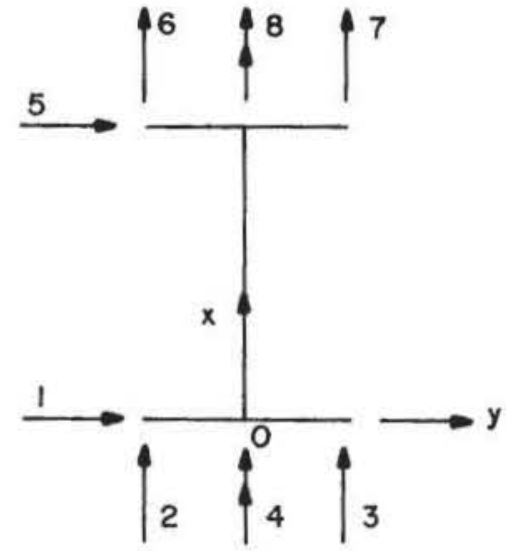

(b) coordenadas locais do elemento de painel

Figura III-6 Modelo de Elemento de Painel e Sistema de Coordenadas Deslocamentos 
As equações diferenciais, do sistema de equações que rege o problema, segundo VLASSOV ${ }^{32}$, tornam-se independentes devido a dupla simetria da seção "tb" e carga aplicada no centro de gravidade, coincidente com o centro de cisalhamento. Portanto, o sistema de equações lineares fica:

$$
\begin{aligned}
& E I_{z} v_{D}^{I V}+(P / a) v_{D}^{\prime \prime}=0 \\
& E I_{y} w_{D}^{I V}+(P / a) w_{D}^{\prime \prime}=0 \\
& E J_{w} \phi_{x}^{I V}+\left(P i_{D}^{2}-G J_{t}\right) \phi_{x}^{\prime \prime}=0
\end{aligned}
$$

onde,

$$
\begin{aligned}
& v_{D}=\text { deslocamento do centro de torção da seção na direção do eixo y } \\
& w_{D}=\text { deslocamento do centro de torção da seção na direção do eixo } z \\
& J_{w}=\text { momento setorial de inércia } \\
& \phi_{x}=\text { rotação da seção em torno do centro de torção } \\
& J_{t}=\text { momento de inércia à torção } \\
& i_{D}=\text { raio de giração polar em relação ao centro de torção }
\end{aligned}
$$

Como a seção considerada é retangular, o momento setorial de inércia "Jw" é nulo e pelas hipóteses adotadas de parede sem rigidez à flexão transversal e pelo fato de se considerar as derivadas dos deslocamentos transversais como desprezíveis, as equações ficam simplificadas e podem ser escritas como:

$$
E I_{Z} v_{D}^{\prime \prime}+(P / a) v_{D}=0
$$




$$
\left(G J_{t}+(-P) i_{D}^{2}\right) \phi_{x}=0
$$

Como pretende-se considerar a interação entre as deformaçōes por força axial; por força cortante; por flexão e por torção, as equações (3.2) e (3.3) apesar de serem independentes estarão sujeitas ao efeito da força normal; portanto, sujeitas ao efeito de segunda ordem.

A Fig.lll-7 mostra o comportamento do elemento de painel na posição deslocada e deformada sob a ação da força axial " $P$ " de forma análoga a um elemento de barra, visto no capítulo anterior, Fig.ll-2 e Fig.II-3, porém acrescido de duas coordenadas que representam os efeitos da torção.
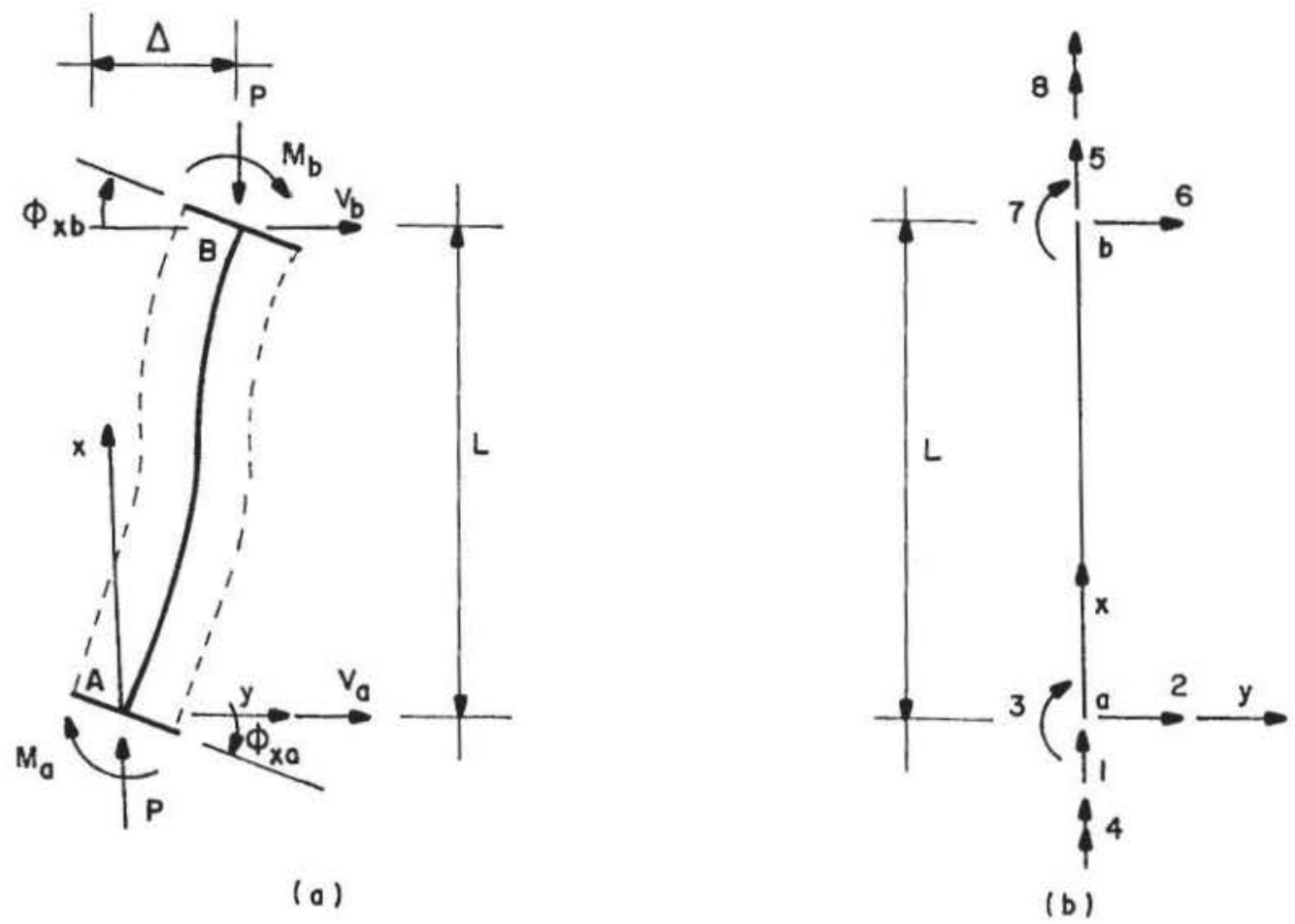

(b)

Figura III-7 Elemento de Painel na Posição Deslocada e Deformada e o Correspondente Sistema de Coordenadas Locais de Barra 
Os coeficientes de rigidez relativos à torção e representados pelas coordenadas 4 e 8, são obtidos da equação (3.3), observando que a força axial pode ser maior, menor ou igual a zero, portanto pode ser descrita como:

$$
\left(G J_{t}+(-P) i_{D}^{2}\right) \phi_{x}^{\prime}=M_{x B}
$$

onde,

$$
\begin{aligned}
& M_{X B}=\text { momento torçor em } B \\
& \phi_{X A} \text { e } \phi_{X B}=\text { rotações de torção nas extremidades A e B } \\
& M_{X B}=\frac{\left(\phi_{X B}-\phi_{X A}\right)}{L}\left(G J_{t}+(-P) i_{D}^{2}\right)
\end{aligned}
$$

Fazendo, $\left(\phi_{\mathrm{XB}}-\phi_{\mathrm{XA}}\right)=1$ como deslocamento relativo unitário, pode-se obter os coeficientes de rigidez das coordenadas 4 e 8 para $P>0 ; P<0$ e $\mathrm{P}=0$ :

Para,

$$
P=0 \rightarrow R_{44}=R_{88}=\frac{G J_{1}}{L} \equiv S_{6} \therefore R_{48}=R_{84}=-S_{6}
$$

Para,

$$
P>0 \rightarrow R_{44}=R_{88}=\frac{G J_{t}+P i_{D}^{2}}{L} \equiv S_{6} \therefore R_{48}=R_{84}=-S_{6}
$$


Para,

$$
P<0 \rightarrow R_{44}=R_{88}=\frac{G J_{t}+(-P) i_{0}^{2}}{L} \equiv S_{6} \therefore R_{48}=R_{84}=-S_{6}
$$

Os coeficientes de rigidez relativos à flexão, à força cortante e à força axial representadas pelas coordenadas $1,2,3,5,6$, 7 , são obtidos da equação (3.2) modificada devido a influência da força cortante, visto no capítulo anterior, pelas equaçöes (2.1), (2.3) e (2.5), portanto de forma análoga obtém-se a matriz de rigidez do elemento do painel de ordem $8 \times 8$ nas coordenadas de barra da mostrada na Fig.III-8 e Tab.III-1.

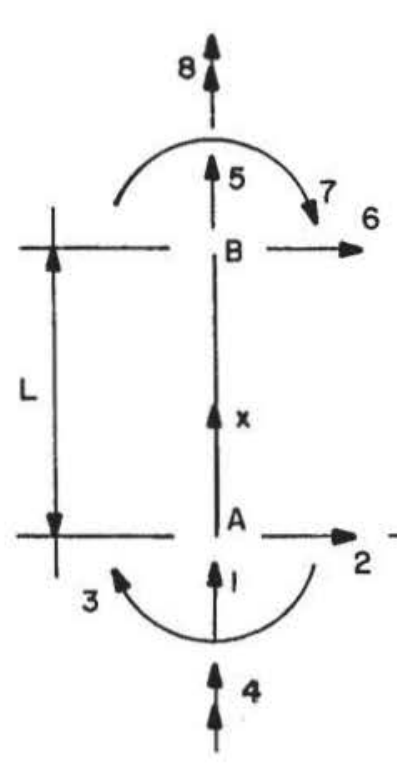

$$
\mathrm{S}_{\mathrm{K}}=\left[\begin{array}{cccccccc}
\mathrm{S}_{1} & 0 & 0 & 0 & -\mathrm{S}_{1} & 0 & 0 & 0 \\
0 & \mathrm{~S}_{2} & \mathrm{~S}_{3} & 0 & 0 & -\mathrm{S}_{2} & \mathrm{~S}_{3} & 0 \\
0 & \mathrm{~S}_{3} & \mathrm{~S}_{4} & 0 & 0 & -\mathrm{S}_{3} & \mathrm{~S}_{5} & 0 \\
0 & 0 & 0 & \mathrm{~S}_{6} & 0 & 0 & 0 & -\mathrm{S}_{6} \\
-\mathrm{S}_{1} & 0 & 0 & 0 & \mathrm{~S}_{1} & 0 & 0 & 0 \\
0 & -\mathrm{S}_{2} & -\mathrm{S}_{3} & 0 & 0 & \mathrm{~S}_{2} & -\mathrm{S}_{3} & 0 \\
0 & \mathrm{~S}_{3} & \mathrm{~S}_{5} & 0 & 0 & -\mathrm{S}_{3} & \mathrm{~S}_{4} & 0 \\
0 & 0 & 0 & -\mathrm{S}_{6} & 0 & 0 & 0 & \mathrm{~S}_{6}
\end{array}\right]
$$

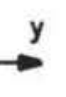

b

seção transversal - $\mathrm{t}$

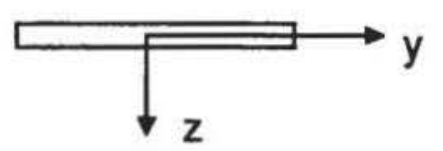

Figura III-8 Matriz de Rigidez do Elemento de Painel Sujeita às Funções de Rigidez, nas Coordenadas Locais do Elemento de Barra. 


\begin{tabular}{|c|c|c|c|}
\hline$S \backslash P$ & Compressáo $(P<0)$ & $(P=0)$ & Traçăo $(P>0)$ \\
\hline s1 & $\frac{E A_{x}}{L}$ & $\frac{E A_{x}}{L}$ & $\frac{E A_{x}}{L}$ \\
\hline S2 & $E I_{z} \frac{a^{2} \alpha^{3} \operatorname{sen} \alpha L}{\phi_{c}}$ & $\frac{12 \mathrm{EI}^{\prime}}{\mathrm{L}^{3}}$ & $E I_{z} \frac{a^{2} \alpha^{3} \operatorname{senh} \alpha L}{\phi_{t}}$ \\
\hline S3 & $E I_{z} \frac{a \alpha^{2}(1-\cos \alpha L)}{\phi_{0}}$ & $\frac{6 \mathrm{El}^{\prime}}{\mathrm{L}^{2}}$ & $E I_{z} \frac{a \alpha^{2}(\cosh \alpha L-1)}{\phi_{t}}$ \\
\hline 54 & $\mathrm{EI}_{2} \frac{\alpha(\operatorname{sen} \alpha \mathrm{L}-\mathrm{a} \alpha \mathrm{L} \cos \alpha \mathrm{L})}{\phi_{0}}$ & $(4+K) \frac{E I^{\prime}}{L}$ & $\mathrm{EI}_{\mathrm{z}} \frac{\alpha(\mathrm{a} \alpha \mathrm{L} \cosh \alpha \mathrm{L}-\operatorname{senh} \alpha \mathrm{L})}{\phi_{\mathrm{t}}}$ \\
\hline $\mathbf{S 5}$ & $E I_{z} \frac{\alpha(a \alpha L-\operatorname{sen} \alpha L)}{\phi_{c}}$ & $(2-K) \frac{E I^{\prime}}{L}$ & $E I_{z} \frac{\alpha(\operatorname{senh} \alpha L-a \alpha L)}{\phi_{t}}$ \\
\hline S6 & $\frac{G J_{t}+P i_{D}{ }^{2}}{L}$ & $\frac{G J_{t}}{L}$ & $\frac{G J_{t}+P i_{D}{ }^{2}}{L}$ \\
\hline & $\begin{array}{c}=2-2 \cos \alpha L-a \alpha L \text { sen } \alpha L \\
a=1+\frac{c f P}{G A_{x}} \\
\alpha=\sqrt{\frac{|P|}{a E I_{z}}} \\
c f=\text { fator de forma }\end{array}$ & $\begin{array}{l}A_{x}=t b \\
I_{z}=\frac{t b^{3}}{12} \\
J_{t}=C_{k} b t^{3} \\
I_{0}^{2}=\frac{I_{z}}{A_{x}}\end{array}$ & $\begin{array}{c}\phi_{t}=2-2 \cosh \alpha L+a \alpha L \operatorname{senh} \alpha L \\
I^{\prime}=\frac{1}{1+K} \\
K=\frac{12 c f E I_{z}}{G A_{x} L^{2}} \\
C_{k}=\frac{1}{3}\end{array}$ \\
\hline Tabe & $\begin{array}{l}\text { a III-1 Funções de Rigidez } \\
\text { entre Força Normal; }\end{array}$ & $\begin{array}{l}\text { Jara o Eleme } \\
\text { orça Cortant }\end{array}$ & $\begin{array}{l}\text { Ito de Painel com Interação } \\
\text {; Flexão g Torção. }\end{array}$ \\
\hline
\end{tabular}

Finalmente, para obter a matriz de rigidez do elemento de painel nas suas coordenadas, Fig.lll-6b, basta efetuar a transformação de coordenadas através da expressão ${ }^{(42)}$ : 


$$
\left[\mathrm{A}_{\mathrm{K}}\right]_{(8 \times 8)}=\left[\mathrm{b}_{\mathrm{P}}\right]_{(8 \times 8)}^{\mathrm{t}}\left[\mathrm{S}_{\mathrm{K}}\right]_{(8 \times 8)}\left[\mathrm{b}_{\mathrm{P}}\right]_{(8 \times \mathrm{B})}
$$

onde,
[A $]$ = matriz de rigidez do elemento de painel, de ordem $8 \times 8$, em suas coordenadas locais, Fig.III-9
[S $\left.\mathrm{S}_{\mathrm{K}}\right]=$ matriz de rigidez do elemento de painel de ordem $8 \times 8$, nas coordenadas do elemento de barra, Fig.III-8
$\left[b_{p}\right]=$ matriz de transformação, de ordem $8 \times 8$ que relaciona os deslocamentos das coordenadas do elemento de painel com os deslocamentos do elemento de barra

A matriz de rigidez do elemento do painel, em suas coordenadas fica determinada pela expressão (3.6) e mostrada na Fig.III-9.

A matriz de rigidez de um elemento de painel $\left[A_{K}\right]_{\mathrm{i}}$, relaciona o vetor dos esforços $\{F\}_{i}$ com o vetor dos deslocamentos $\{d\}_{i}$ nas suas coordenadas locais de extremidade. Portanto, a formulação matricial para o i-ésimo elemento de um painel "j", fica:

$\{F\}_{i_{(8 \times 1)}}^{\mathrm{i}}=\left[\mathrm{A}_{\mathrm{K}}\right]_{\mathrm{i}(\mathrm{x} \times 8)}^{\mathrm{i}}\{\mathrm{d}\}_{\mathrm{i}_{(8 \times 1)}}^{\mathrm{i}}$

onde,

$\{F\}_{i}^{i}=$ Vetor dos esforços, do elemento " $i$ " do painel " $j "$

$\left[A_{K}\right]_{i}^{i}=$ Matriz de rigidez, do elemento " $\mathrm{i}$ " do painel " $\mathrm{j}$ "

$\{d\}_{i}^{j}=$ Vetor dos deslocamentos, do elemento "i" do painel "j" 

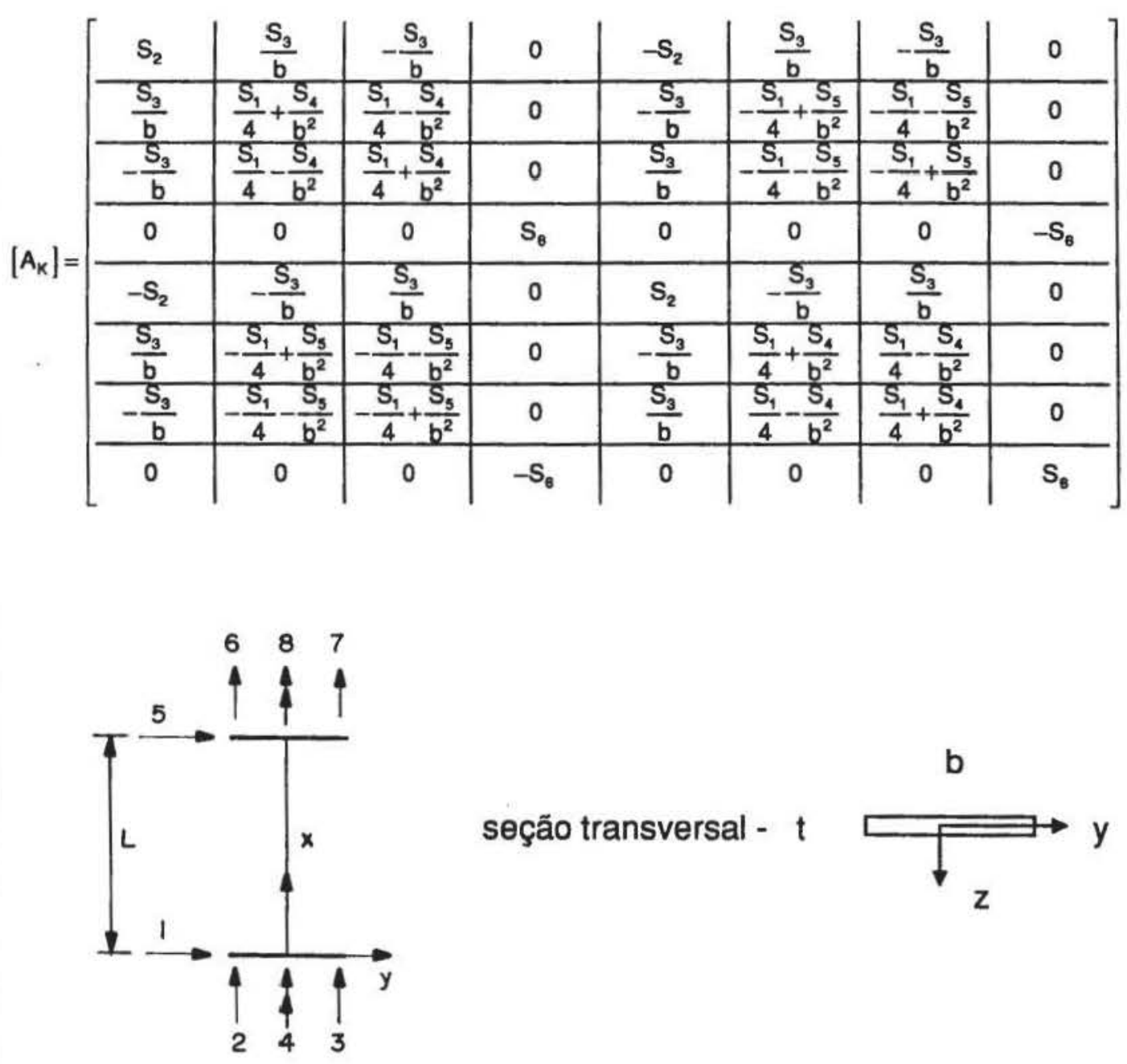

b

seção transversal - $t$

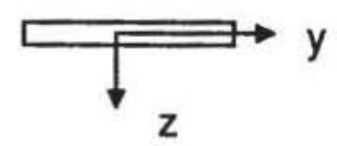

Figura III-9 Matriz de Rigidez do Elemento de Painel.

\subsection{MATRIZ DE RIGIDEZ DO PÓRTICO TRANSVERSAL}

A matriz de rigidez do pórtico transversal [S], relaciona o vetor das ações $\{\mathrm{A}\}$ com o vetor dos deslocamentos $\{\mathrm{V}\}$, nas " nt " coordenadas do sistema global, exemplificadas na Fig.III-10:

$$
\{A\}_{(n+x 1)}=[S]_{(n+x t)}\{V\}_{(n+x)}
$$




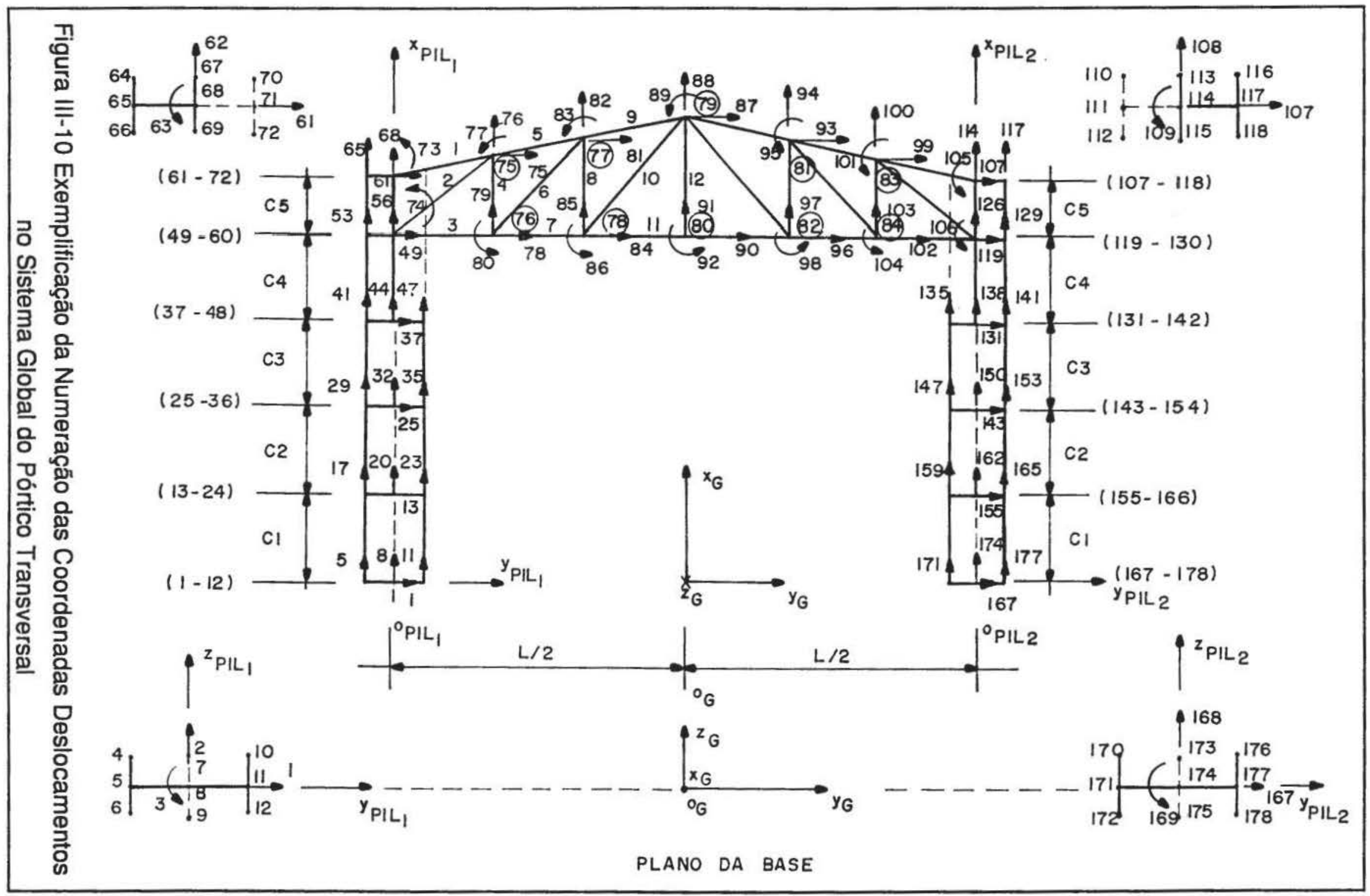


A matriz [S] é obtida somando-se as contribuiçöes dos elementos de painel que constituem os pilares e as contribuições dos elementos de barra que constituem a trave.

3.6.1 Contribuição dos elementos de painel do pilar da esquerda do pórtico transversal, denominado de " $\mathrm{P} 1$ "

Seja um painel genérico " $\mathrm{j}$ ", orientado, de extremidades "ij " $\mathrm{e}$ " jk ", conforme a Fig.lII-11 .

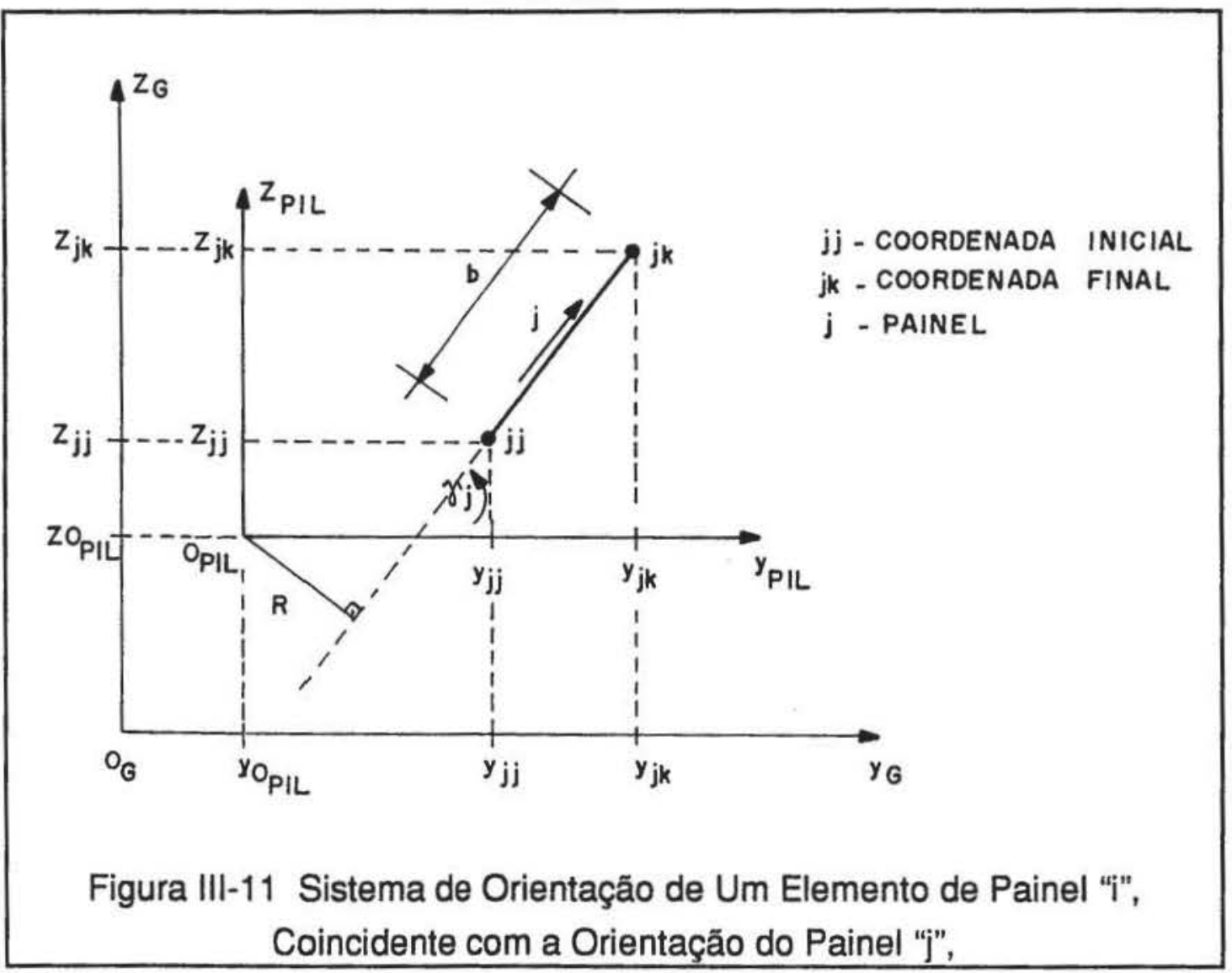

Conhecidas as coordenadas de suas extremidades, o comprimento " $b$ " e os componentes de orientação do vetor posição ficam definidos como:

$$
b=\left[\left(z_{j k}-z_{i j}\right)^{2}+\left(y_{j k}-y_{i j}\right)^{2}\right]^{1 / 2}
$$




$$
\begin{aligned}
& C=\cos \gamma_{1}=\frac{\left(y_{i k}-y_{i i}\right)}{b} \\
& S=\operatorname{sen} \gamma_{j}=\frac{\left(z_{j k}-z_{i j}\right)}{b} \\
& R=\left(y_{i j}-y_{O_{P I L}}\right) \operatorname{sen} \gamma_{i}-\left(z_{i j}-z_{O P I L}\right) \cos \gamma_{j}
\end{aligned}
$$

Seja uma seção transversal de pilar formada por painéis "j", ao nível do primeiro diafragma transversal, localizado na base do pilar, orientados e numerados conforme a Fig.III-12a. As coordenadas deslocamentos da seção no primeiro diafragma ficam orientadas conforme a Fig.lll-12b. As três primeiras coordenadas estão contidas no plano do diafragma e representam o deslocamento de corpo rígido da seção. A coordenada número 1 é positiva no sentido positivo do eixo global " $\mathrm{y}_{G}$ ". A coordenada número 2 é positiva no sentido positivo do eixo global " $_{G}$ " $A$ coordenada número 3 é positiva no sentido positivo do giro em torno do eixo global " $\mathrm{X}_{\mathrm{G}}$ ". As coordenadas seguintes, de número $4 \mathrm{em}$ diante, representam os deslocamentos longitudinais do pilar ao nível do diafragma considerado e também representam os empenamentos da seção. Estas coordenadas, verticais, são positivas no sentido positivo do eixo global " $x_{G}$ ". Portanto, 0 número de coordenadas deslocamentos em cada diafragma transversal de um pilar fica definido como "nd" coordenadas, sendo três coordenadas horizontais e "nd - 3" coordenadas verticais. A numeração das demais coordenadas deslocamentos de um pilar é feita considerando, a numeração dos diafragmas transversais, da base para 0 topo do pilar. Finalmente, 0 número total de coordenadas deslocamentos de um pilar é "nd $x \mathrm{nf}$ ", o número de diafragmas multiplicado pelo número de coordenadas em cada diafragma transversal. A rigidez à torção do pilar é considerada através da coordenada tipo 3 em cada diafragma transversal e a rigidez à flexão, à força cortante e à força normal do pilar são consideradas através das demais coordenadas. 


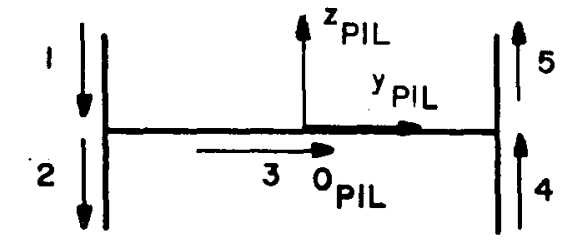

(a)

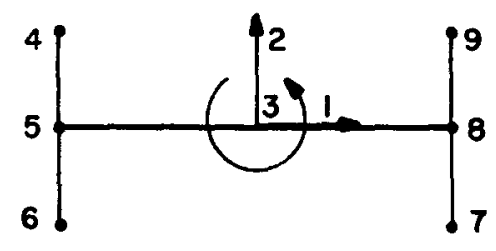

(b) numeração e orientação

dos painéis numeração das coordenadas

deslocamentos do $1^{\circ}$ diafragma

Figura III-12 Coordenadas Deslocamentos do Primeiro Diafragma Transversal de Um Pilar Discretizado Formado por Painéis

Seja " $\mathrm{i}$ " um elemento genérico, do pilar " $P 1$ ", contido no painel " $\mathrm{j}$ " e espaço(tramo) " $c_{i}$ ". Chamando $\left[A_{k}\right]$ a matriz de rigidez deste elemento, a contribuição de todos os elementos " $\mathrm{i}$ " na matriz de rigidez do sistema do pórtico transversal pode ser obtida pela expressão ${ }^{(40)}$ :

$[S]_{(n t \times n t)}=\sum_{j=1}^{n p 1} \sum_{i=1}^{n C_{1}}[T]_{i}^{T_{(n 1 \times 8)}}\left[A_{K}\right]_{i(8 \times 8)}^{j}[T]_{(8 \times n t)}^{j}$

onde, 
nt = número total de coordenadas da estrutura do pórtico transversal, no sistema global

$n e_{1}=$ número de elementos de painel em "P1", ne $e_{1}=n c_{1} \times n p_{1}$

$n p_{1}=$ número de painéis do pilar "P1"

$\mathrm{nc}_{1}$ = número de espaços(tramos) entre diafragmas, "nf 1 - 1", em "P1"

$\mathrm{nf}_{1}$ = número de diafragmas transversais, em "P1"

i = elemento genérico do painel "j" e espaço(tramo) " $c_{i}$ "

$[T]_{(B \times n t)}^{j}=$ submatriz de ordem $8 \times \mathrm{nt}$, correspondente ao elemento "i" do painel "j", da matriz de transformação [T], que relaciona os deslocamentos da estrutura do pórtico transversal "V", com os deslocamentos dos elementos de painel " $d_{1}$ ", do pilar "P1", (estrutura desmontada):

$\left\{\begin{array}{c}\left\{\mathrm{d}_{1}\right\}_{1} \\ \left\{\mathrm{~d}_{1}\right\}_{2} \\ \vdots \\ \left\{\mathrm{d}_{1}\right\}_{\mathrm{ne}}\end{array}\right\}=\left[\begin{array}{l}{[\mathrm{T}]_{1}} \\ {[\mathrm{~T}]_{2}} \\ \vdots \\ {[\mathrm{T}]_{\mathrm{n} \mathrm{\theta}_{1}}}\end{array}\right] \cdot\{\mathrm{V}\}_{(\mathrm{n} \times 1)}$

onde,

$\left\{d_{1}\right\}_{i}=$ Vetor deslocamento do elemento de painel "i", do pilar "P1", de ordem $8 \times 1$, nas coordenadas locais do elemento

$[\mathrm{T}]_{\mathrm{i}}^{\mathrm{T}}=$ Matriz transposta de $[\mathrm{T}]_{\mathrm{i}}^{\mathrm{i}}$

$\left[A_{K}\right]_{i}^{j}=$ Matriz de rigidez do elemento genérico " $i "$, do painel genérico " $j$ ", no espaço " $c_{i}$ " entre diafragmas

[S] = Matriz de rigidez pórtico transversal, de ordem nt $\times \mathrm{nt}$, nas coordenadas globais

$\{V\}=$ Vetor deslocamento da estrutura do pórtico transversal, de ordem nt $\times 1$, nas coordenadas globais 
A submatriz de transformação $[T]_{i}^{i}$ de um elemento genérico " $i$ " de um painel genérico " $\mathrm{j}$ " fica definida como:

$$
\begin{aligned}
& {[\mathrm{T}]_{i}^{i}=\left[\begin{array}{ccccccccc|cccccccc|c}
\ldots & C & S & R & \ldots & 0 & \ldots & 0 & \ldots & 0 & 0 & 0 & \ldots & 0 & \ldots & 0 & \ldots & \mathrm{r}_{1} \\
\ldots & 0 & 0 & 0 & \ldots & 1 & \ldots & 0 & \ldots & 0 & 0 & 0 & \ldots & 0 & \ldots & 0 & \ldots & \mathrm{r}_{2} \\
\ldots & 0 & 0 & 0 & \ldots & 0 & \ldots & 1 & \ldots & 0 & 0 & 0 & \ldots & 0 & \ldots & 0 & \ldots & r_{3} \\
\ldots & 0 & 0 & 1 & \ldots & 0 & \ldots & 0 & \ldots & 0 & 0 & 0 & \ldots & 0 & \ldots & 0 & \ldots & r_{3} \\
\ldots & 0 & 0 & 0 & \ldots & 0 & \ldots & 0 & \ldots & C & S & R & \ldots & 0 & \ldots & 0 & \ldots & r_{4} \\
\ldots & 0 & 0 & 0 & \ldots & 0 & \ldots & 0 & \ldots & 0 & 0 & 0 & \ldots & 1 & \ldots & 0 & \ldots & r_{5} \\
\ldots & 0 & 0 & 0 & \ldots & 0 & \ldots & 0 & \ldots & 0 & 0 & 0 & \ldots & 0 & \ldots & 1 & \ldots & r_{8} \\
\ldots & 0 & 0 & 0 & \ldots & 0 & \ldots & 0 & \ldots & 0 & 0 & 1 & \ldots & 0 & \ldots & 0 & \ldots & r_{7} \\
r_{8}
\end{array}\right.}
\end{aligned}
$$

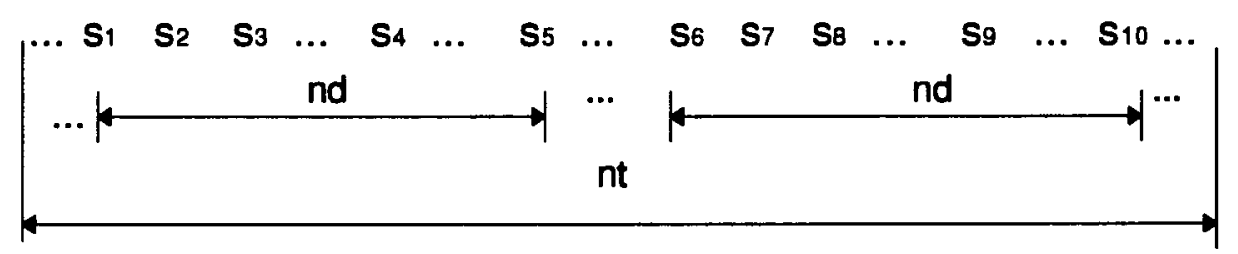

Figura III-13 Submatriz de Transformação de Ordem $8 \times$ nt, Obtida de Parte da Matriz de Transformação [T]

A submatriz $[T]_{i}^{j}$, de ordem " $8 \times n t$ ", terá a numeração das colunas correspondente a posição do elemento de painel no pilar. Os elementos de painel do pilar são numerados por tramos para cada painel. Inicialmente todo o primeiro painel, depois todos o segundo painel e assim por diante. Os números das colunas da submatriz do elemento "i", contido no espaço ou tramo "ci" , do painel "j" que tem orientação do nó inicial "ji" e nó final "jk", será:

$$
\begin{aligned}
& s 1=\left(c_{i}-1\right) \times n d+1 \\
& s 2=s 1+1 \\
& s 3=s 2+1
\end{aligned}
$$




$$
\begin{aligned}
& s 4=\left(c_{i}-1\right) \times n d+j j \\
& s 5=\left(c_{i}-1\right) \times n d+j k \\
& s 6=\left(c_{i}-1\right) \times n d+n d+1 \\
& s 7=s 6+1 \\
& s 8=s 7+1 \\
& s 9=(c i-1) \times n d+n d+j j \\
& s 10=(c i-1) \times n d+n d+j k
\end{aligned}
$$

onde,

nd = número de coordenadas deslocamentos em cada diafragma transversal do pilar

jj = número do nó inicial do painel "j", ao nível do primeiro diafragma localizado na base do pilar, correspondente às coordenadas verticais

jk = número do nó final do painel "j", ao nível do primeiro diafragma localizado na base do pilar, correspondente às coordenadas verticais

$c_{i}$ = número do tramo ou espaço considerado entre dois diafragmas transversais, a numeração é sempre feita da base do pilar para o topo

A numeração das linhas da submatriz de transformação $[T]_{i}^{j}$, da Fig.IIl-13, correspondente ao elemento "i"do painel "j" do pilar "P1", será:

$$
\begin{aligned}
& r_{1}=8(i-1)+1 \\
& r_{2}=r_{1}+1
\end{aligned}
$$

sucessivamente, de um em um até,

$r_{8}=r_{1}+8$ 
O pilar da esquerda "P1", do pórtico transversal, contribuirá com " $8 \mathrm{x}$ $n_{1}{ }_{1}$ linhas da matriz de transformação, correspondente às "nd $x$ nf $_{1}$ " primeiras linhas e colunas da matriz de rigidez [ $S$ ], da estrutura.

3.6.2 Contribuição dos elementos de barra que constituem a trave do pórtico transversal

Seja um elemento de barra genérico " i ", plano, orientado pelo sistema de referência local de barra, contido no plano " $x_{G}$ ", " $y_{G}$ " do sistema de referência global " $x_{G}$ ", " $y_{G}$ " $e$ " $z_{G}$ " conforme a Fig.III-5. Todos os elementos de barra, planos que representam a trave do pórtico transversal estão contidos no plano dos painéis que representam o plano de simetria das seções transversais dos pilares.

Chamando [ $\mathrm{S}_{\mathrm{KG}}$ ] a matriz de rigidez deste elemento, visto no Capítulo anterior, a contribuição de todos os elementos " $i$ " na matriz de rigidez do sistema do pórtico transversal pode ser obtida pela expressão ${ }^{(40)}$ :

$[S]_{(n t \times n t)}=\sum_{i=1}^{n b}[b]_{i_{(n+6)}^{\top}}^{\top}\left[S_{K B}\right]_{i(6 \times 6)}[b]_{i(6 \times n t)}$

onde,

$\mathrm{nb}=$ número de elementos de barra, na trave

$i=$ elemento genérico de barra

$[b]_{j}=$ submatriz de ordem $6 \times n$ t, correspondente ao elemento " $\mathrm{i}$ ", da matriz de transformação [b], que relaciona os deslocamentos da estrutura do pórtico transversal "V", com os deslocamentos dos elementos de barra da trave " $d_{T R}$ ", ( estrutura desmontada ):

$\left\{\begin{array}{c}\left\{\mathrm{d}_{\mathrm{TR}}\right\}_{1} \\ \left\{\mathrm{~d}_{\mathrm{TR}}\right\}_{2} \\ \vdots \\ \left\{\mathrm{d}_{\mathrm{TR}}\right\}_{\mathrm{no}}\end{array}\right\}=\left[\begin{array}{c}{[\mathrm{b}]_{1}} \\ {[\mathrm{~b}]_{2}} \\ \vdots \\ {[\mathrm{b}]_{\mathrm{nb}}}\end{array}\right] \cdot\{\mathrm{V}\}_{(\mathrm{nt} \times 1)}$ 
onde,

$\left\{d_{T R}\right\}_{i}=$ Vetor dos deslocamentos do elemento de barra "i", da trave, de ordem $6 \times 1$, nas coordenadas locais do elemento

$[\mathrm{b}]_{\mathrm{i}}^{\top}=$ Matriz transposta de $[\mathrm{b}]_{\mathrm{i}}$

$\left[S_{K B}\right]_{i}=$ matriz de rigidez do elemento genérico de barra "i", da trave do pórtico transversal, de ordem $6 \times 6$, nas coordenadas locais

[S] = matriz de rigidez da estrutura do pórtico transversal, de ordem $\mathrm{nt} \mathrm{x}$ t, nas coordenadas globais

A submatriz de transformação $[\mathrm{b}]_{i}^{\top}$ de um elemento genérico de barra " $\mathrm{i}$ "da trave do pórtico transversal fica definida como:

$$
\begin{aligned}
& {[\mathrm{b}]_{i}=\left[\begin{array}{ccccccccc|c}
\ldots & \cos \gamma & \operatorname{sen} \gamma & 0 & \ldots & 0 & 0 & 0 & \ldots \\
\ldots & -\operatorname{sen} \gamma & \cos \gamma & 0 & \ldots & 0 & 0 & 0 & \ldots & r_{1} \\
\ldots & 0 & 0 & 1 & \ldots & 0 & 0 & 0 & \ldots & r_{2} \\
\ldots & 0 & 0 & 0 & \ldots & \cos \gamma & \operatorname{sen} \gamma & 0 & \ldots & r_{3} \\
r_{4} \\
\ldots & 0 & 0 & 0 & \ldots & -\operatorname{sen} \gamma & \cos \gamma & 0 & \ldots & r_{5} \\
\ldots & 0 & 0 & 0 & \ldots & 0 & 0 & 1 & \ldots
\end{array}\right] \mathrm{r}_{6}} \\
& \begin{array}{lllllllll}
\ldots & S_{1} & S_{2} & S_{3} & \ldots & S_{4} & S_{5} & S_{6} & \ldots
\end{array}
\end{aligned}
$$

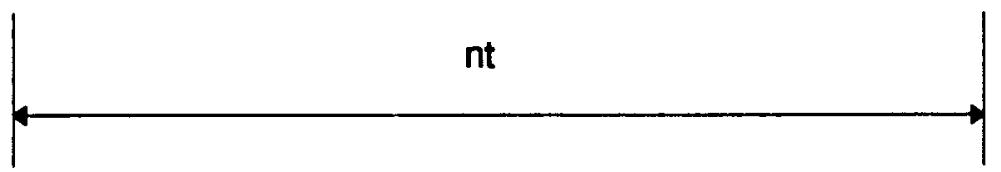

Figura III-14 Submatriz de Transformação de Ordem 6xnt, Obtida de Parte da Matriz de Transformação [b] 
A submatriz $[\mathrm{b}]_{1}$, de ordem "6 $\times \mathrm{nt}$ ", terá a numeração das colunas correspondente a posição do elemento de barra " $i$ ". As barras são divididas em três tipos:

a) barras intermediárias da trave,

$$
\begin{aligned}
& s 1=3 \times n j-(2 \times \mathrm{Np} 1)-2-\mathrm{nml} \\
& \mathrm{s} 2=\mathrm{s} 1+1 \\
& \mathrm{~s} 3=\mathrm{s} 2+1 \\
& \mathrm{~s} 4=3 \times \mathrm{nk}-(2 \times \mathrm{Np} 1)-2-\mathrm{nml} \\
& \mathrm{s} 5=\mathrm{s} 4+1 \\
& \mathrm{~s} 6=\mathrm{s} 5+1
\end{aligned}
$$

b) barras de extremidade esquerda da trave, ligadas ao pilar da esquerda:

$$
\begin{aligned}
& s 1=n c f 1 \\
& s 2=n j \\
& s 3=n c m l \\
& s 4=3 \times n k-(2 \times N p 1)-2-n m l \\
& s 5=s 4+1 \\
& s 6=s 5+1
\end{aligned}
$$

c) barras de extremidade direita da trave, ligadas ao pilar da direita:

$$
s 1=3 \times n j-(2 \times N p 1)-2-n m l
$$




$$
\begin{aligned}
& s 2=s 1+1 \\
& s 3=s 2+1 \\
& s 4=n c f 1 \\
& s 5=n k \\
& s 6=n c m l
\end{aligned}
$$

onde,

nj = número do nó inicial do elemento de barra "i"

nk = número do nó final do elemento de barra "i"

ncf1 = número da coordenada horizontal, Tipo 1, do diafragma considerado, no eixo global " $y_{G}$ "

$\mathrm{ncml}=$ número da coordenada momento de extremidade da barra conectada ao pilar

Np1 = número total de coordenadas deslocamentos do pilar da esquerda, $\mathrm{nf}_{1} \times \mathrm{nd}$

$\mathrm{nml}$ = número de nós da trave conectados aos pilares do pórtico transversal

nnos = número de nós da trave, do pórtico transversal

A numeração das linhas da submatriz de transformaçăo $[b]_{i}$, da Fig.III-14, correspondente ao elemento "i", da trave, será:

$$
\begin{aligned}
& r_{1}=\left(8 \times n e_{1}\right)+6(i-1)+1 \\
& r_{2}=r_{1}+1
\end{aligned}
$$

sucessivamente, de um em um até,

$r_{6}=r_{1}+6$ 
A trave do pórtico transversal, contribuirá com " 6 x nb" linhas da matriz de transformação

3.6.3 Contribuição dos elementos de painel do pilar da direita do pórtico transversal, denominado de " $\mathrm{P2}$ "

Analogamente ao item 3.6.1, a contribuição dos elementos de painel do pilar da direita do pórtico transversal pode ser obtida pela expressão ${ }^{(40)}$ :

$[S]_{(n t \times n t)}=\sum_{j=1}^{n p_{2}} \sum_{i=1}^{n c_{2}}[T]_{i(n+\times 8)}^{j^{T}}\left[A_{K}\right]_{i(8 \times 8)}^{j}[T]_{i(8 \times n t)}^{j}$

onde,

$\mathrm{ne}_{2}=$ número de elementos de painel em "P2", $n e_{2}=n c_{2} \times n p_{2}$

$\mathrm{np}_{2}$ = número de painéis do pilar "P2"

$\mathrm{nc}_{2}$ = número de espaços entre diafragmas, " $\mathrm{nf}$ - 1", em "P2"

$\mathrm{nf}_{2}$ = número de diafragmas transversais, em "P2"

$[T]_{i(8 \times n)}^{j}=$ submatriz de ordem $8 \times n t$, Fig.IIl-13, correspondente ao elemento "i" do painel "j", da matriz de transformação [T], que relaciona os deslocamentos da estrutura do pórtico transversal " $V$ ", com os deslocamentos dos elementos " $d_{2}$ " de painel, do pilar "P2", (estrutura desmontada):

$$
\left\{\begin{array}{c}
\left\{d_{2}\right\}_{1} \\
\left\{d_{2}\right\}_{2} \\
\vdots \\
\left\{d_{2}\right\}_{n \theta_{2}}
\end{array}\right\}=\left[\begin{array}{l}
{[T]_{1}} \\
{[T]_{2}} \\
\vdots \\
{[T]_{n \theta_{2}}}
\end{array}\right] \cdot\{V\}_{(n+\times 1)}
$$


$\left\{d_{2}\right\}_{i}=$ Vetor deslocamento do elemento de painel "i", do pilar "P2", de ordem $8 \times 1$, nas coordenadas locais do elemento

$[\mathrm{T}]_{\mathrm{i}}^{\mathrm{j}^{\top}}=$ Matriz transposta de $[\mathrm{T}]_{\mathrm{i}}^{\mathrm{i}}$

$\left[A_{K}\right]_{i}^{j}=$ Matriz de rigidez do elemento genérico "i" do painel genérico " j " no espaço " $c_{i}$ " entre diafragmas

[S] = Matriz de rigidez pórtico transversal, de ordem nt $\times \mathrm{nt}$, nas coordenadas globais

$\{\mathrm{V}\}=$ Vetor deslocamento da estrutura do pórtico transversal, de ordem $n t \times 1$, nas coordenadas globais

A submatriz de transformação $[T]_{i}^{i}$ de um elemento genérico " $i$ " de um painel genérico ".j" fica definida analogamente ao pilar da esquerda Fig.III-13.

A submatriz $[T]_{i}^{i}$, de ordem " $8 \times n$ nt", terá a numeração das colunas correspondente a posição do elemento de painel no pilar. Os elementos de painel do pilar são numerados por tramos para cada painel. Inicialmente todo o primeiro painel, depois todos o segundo painel e assim por diante. Os números das colunas da submatriz do elemento "i", contido no espaço ou tramo "ci" , do painel "j" que tem orientação do nó inicial "ji" e nó final "jk", será:

$$
\begin{aligned}
& s 1=\left(n c_{2}-c_{i}\right) n d+n t a b+1 \\
& s 2=s 1+1 \\
& s 3=s 2+1 \\
& s 4=\left(n c_{2}-c_{i}\right) n d+n t a b+j j \\
& s 5=\left(n c_{2}-c_{i}\right) n d+n t a b+j k \\
& s 6=\left(n c_{2}-c_{i}\right) n d+n d+n t a b+1 \\
& s 7=s 6+1 \\
& s 8=s 7+1
\end{aligned}
$$




$$
\begin{aligned}
& s 9=\left(n c_{2}-c i\right) n d+n d+n t a b+j j \\
& s 10=\left(n c_{2}-c i\right) n d+n d+n t a b+j k
\end{aligned}
$$

ntab = número de coordenadas deslocamentos acumuladas do pilar "P1" e da trave, excluindo as coordenadas do pilar "P2", definido por:

$$
\mathrm{ntab}=\mathrm{Np} 1+(3 \times \mathrm{nnos})-(2 \times \mathrm{nml})
$$

A numeração das linhas da submatriz de transformação $[T]_{i}^{j}$, Fig.lll13 , correspondente ao elemento " $i$ " do painel "j" do pilar "P2", será:

$$
\begin{aligned}
& r_{1}=\left(8 \times n e_{1}\right)+(6 \times n b)+8\left(n e_{2}-i\right)+1 \\
& r_{2}=r_{1}+1
\end{aligned}
$$

sucessivamente, de um em um até,

$$
r_{8}=r_{1}+8
$$

O pilar da esquerda "P2", do pórtico transversal, contribuirá com " $8 \mathrm{x}$ $n e_{2}$ " linhas da matriz de transformação, correspondente às " $n d x \mathrm{nf}_{2}$ " últimas linhas e colunas da matriz de rigidez [ $S$ ], da estrutura.

O número total de coordenadas deslocamentos do pórtico transversal "nt" será, portanto:

$$
n t=n d x n f_{1}+(3 \times n n o s)-(2 \times n m l)+n d x n f_{2}
$$

\subsubsection{Contribuição dos vínculos elásticos}

Após a obtenção da matriz de rigidez [S], deve-se levar em conta a contribuição dos vínculos elásticos que possam existir no pilar. Esta contribuição é feita nos respectivos coeficientes da diagonal principal da 
matriz [S], correspondentes às coordenadas dos vínculos do sistema global da estrutural do pórtico transversal.

\subsection{DETERMINAÇÃO DO CARREGAMENTO CRÍTICO}

\subsubsection{Cálculo dos Esforços e Deslocamentos}

A formulação matricial (3.8), obtida através do processo dos deslocamentos, permite determinar os deslocamentos nas coordenadas globais a partir de sua matriz de rigidez e de um carregamento nas mesmas coordenadas. Com esses deslocamentos, pode-se determinar os esforços $\theta$ deslocamentos nas coordenadas locais. Porém, como se trata de matrizes que consideram os efeitos das forças normais no cálculo de seus coeficientes, há necessidade de utilização do processo iterativo com aproximações sucessivas para resolver o problema.

\subsubsection{Processo Iterativo de Aproximações Sucessivas}

A técnica utilizada é a mesma já descrita em detalhes no capítulo anterior, item 2.6. Em resumo, a técnica consiste em avaliar os deslocamentos da estrutura produzidos por um determinado carregamento, inicialmente sem $o$ efeito das forças normais e posteriormente considerando os seus efeitos. A estrutura é calculada sucessivas vezes até que haja convergência nos valores dos deslocamentos, mediante uma tolerância previamente fornecida.

\subsubsection{Carregamento Crítico de Instabilidade Geral}

Como foi descrito no capítulo anterior, item 2.7, uma estrutura será considerada estável sob um certo carregamento se sua matriz de rigidez for definida positiva. Neste caso, todos os deslocamentos da estrutura serão determinados; porém, se este carregamento levar a estrutura a uma situação de instabilidade, a matriz de rigidez da estrutura deixará de ser definida positiva e sequer haverá possibilidade de solução do sistema de equações. Portanto, os deslocamentos tornar-se-ão indeterminados. 
O carregamento crítico de instabilidade de uma estrutura será considerado definido quando após sucessivos aumentos no carregamento da estrutura, a rigidez for se degenerando até que o determinante de sua matriz de rigidez se torne nulo, indicando o surgimento do menor auto-valor igual a zero.

Para a estrutura do edifício industrial com ponte rolante, submetida às ações permanentes e às ações variáveis, o carregamento da estrutura será definido através de dois grupos distintos de ações: o primeiro será mantido constante e será chamado de carregamento das cargas constantes, constituído das ações permanentes da estrutura e das ações devidas ao vento, apesar de ser este um vento variável. O segundo grupo será chamado de carregamento das cargas vivas, constituído apenas pelas ações da ponte rolante. $O$ carregamento das cargas vivas será afetado por um parâmetro " $W$ " que será incrementado até que o conjunto do carregamento total da estrutura atinja o crítico de instabilidade. Neste caso, o parâmetro relacionado com este carregamento crítico, será chamado de parâmetro crítico " $W_{C R}$ ".

Pode-se alterar os grupos de carregamentos das cargas constantes e cargas vivas, dependendo da análise da estrutura que se deseja obter para o carregamento crítico de instabilidade do pilar mais carregado do pórtico transversal do edifício industrial.

A obtenção do parâmetro crítico " $W_{C R}$ ", segue a mesma rotina já apresentada no capítulo anterior, item 2.8. Para o cálculo do parâmetro " $W_{C R}$ " será necessário também analisar o limite das tensões envolvidas.

Determinada a matriz de rigidez do sistema (do pilar discretizado) ou do sistema global, com os coeficientes não afetados pelos efeitos das forças normais, serão calculados os esforços internos provocados pelo carregamento das cargas constantes e pelo carregamento das cargas vivas com parâmetro unitário.

A máxima tensão normal dentre todas aquelas das seçóes transversais das paredes constituintes dos pilares metálicos é calculada, através das tensões normais parciais, na mesma seção, provocadas pelas cargas constantes " $\sigma_{c}$ " e pelas cargas vivas " $\sigma_{v 1}$ ", com parâmetro unitário. Será chamado de " $\sigma_{p}$ " a tensão limite de proporcionalidade do material. No caso em questão, refere-se ao tipo de aço previamente definido. 
O parâmetro " $W_{\max }$ " será, portanto, calculado como segue:

$$
\begin{aligned}
& \sigma_{\max }=\mathrm{W}_{\max } \sigma_{\mathrm{v} 1}+\sigma_{\mathrm{c}}, \quad \mathrm{p} / \sigma_{\max } \leq \sigma_{\mathrm{p}} \rightarrow \\
& \mathrm{W}_{\max }=\frac{\left(\sigma_{\mathrm{p}}-\sigma_{\mathrm{c}}\right)}{\sigma_{\mathrm{v} 1}}
\end{aligned}
$$

Com a expressão (3.68), pode-se garantir que a pesquisa do parâmetro crítico, faz-se-á sempre no regime elástico do material.

Quando a estrutura é analisada com elemento na forma tridimensional, como no caso dos pilares discretizados, há casos especiais de geometrias em que quando carregadas além do parâmetro crítico de instabilidade, a matriz de rigidez da estrutura retoma a condição de ser definida positiva. Este fato, deve-se a uma nova situação de instabilidade de estrutura que não mais interessa à análise. Portanto, em casos de dúvidas quanto ao valor " $W_{C R}$ " encontrado, repete-se o processo alternando o valor inicial de " $W_{\max }$ " para uma seqüência decimal de pesquisa do parâmetro crítico, ou seja, em dez intervalos de " $W_{\max }$ " acompanhando 0 comportamento dos deslocamentos para analisar possíveis anomalias no processo. Esta operação consumirá um tempo de programação muito maior, porém garantirá a confiabilidade dos resultados encontrados.

O processo apresentado tem a vantagem de analisar os pilares de um pórtico transversal de um edifício industrial em comportamento tridimensional, interligados pela trave de cobertura, contida no plano do pórtico transversal, em comportamento plano. Os contraventamentos do topo do pilar no plano perpendicular ao do pórtico transversal, garantem a indeslocabilidade dos apoios da trave nesse plano. A principal funçăo da trave, portanto, é de interligação dos pilares, apenas no plano do pórtico, transmitindo $o$ efeito das rigidezes pelas ligações trave-pilar. 


\section{CAPÍTULO IV}

\section{FLUXOGRAMA DAS PROGRAMAÇÕES PARA COMPUTADOR}

\subsection{CONSIDERAÇÕES GERAIS}

As determinações dos parâmetros críticos de instabilidade, para os carregamentos, tanto do pórtico plano formado por elementos de barra como para pórtico transversal com pilares discretizados, foram possíveis através do desenvolvimento de dois programas. Estes, foram elaborados em Linguagem FORTRAN-77 V.5.0, em dupla precisão, com o intuito de determinar as capacidades máximas de carregamentos nas estruturas ao atingirem os limites de suas estabilidades.

Os programas foram separados em dois tipos: o primeiro determina o parâmetro crítico "Wcr", para o pórtico plano constituído apenas de elementos de barra; o segundo determina o parâmetro crítico " $\mathrm{Wcr}$ ", para o pórtico transversal constituído de pilares discretizados, tendo comportamento tridimensional. Para ambos os programas, foram utilizadas análises de estruturas em regime de segunda ordem, adotando o processo iterativo de aproximações sucessivas, como forma de resolver os sistemas de equações não lineares, em termos de forças axiais nos elementos.

Os programas foram montados em sub-rotinas que facilitam a separação das etapas de cálculo além de propiciarem melhor entendimento do processo.

A seguir, são ilustrados os fluxogramas dos programas Tipo I e Tipo II, com intuito de melhorar o entendimento dos processos utilizados nos programas. 


\subsection{FLUXOGRAMAS RESUMIDOS DAS PROGRAMAÇÕES}

4.2.1 Carregamento crítico de instabilidade elástica por flexão de pórticos planos - programa Tipo I (PORTCRI7.FOR)

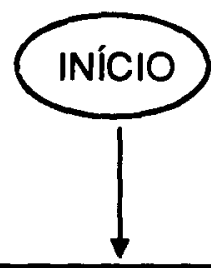

IDENTIFICAÇÃO DOS ARQUIVOS DE ENTRADA E SAÍDA NO DISCO, (FILES). CONDIÇÕES SOBRE CONSIDERAÇÃO DA FORÇA CORTANTE. DEFINIÇĀO DA TOLERÂNCIA NA CONVERGÉNCIA DO PROÇESSO,TOL(\%).

CARACTERÍSTICAS ELÁSTICO-GEOMÉTRICAS DO PÓRTICO PLANO, CONSTITUÍDO DE ELEMENTOS DE BARRA, (READ 1); (READ 2); (READ 3). CONDIÇÕES DE VINCULAÇÕES EXTERNAS, (READ 4). CARGAS VIVAS E CARGAS CONSTANTES, (READ 5).

CARACTERÍ́STICAS ELÁSTICO-GEOMÉTRICAS DO PÓRTICO PLANO, CONSTITUÍDO DE ELEMENTOS DE BARRA, (READ 1); (READ 2); (READ 3). CONDIÇŌES DE VINCULAÇÕES EXTERNAS, (READ 4). CARGAS VIVAS E CARGAS CONSTANTES, (READ 5).

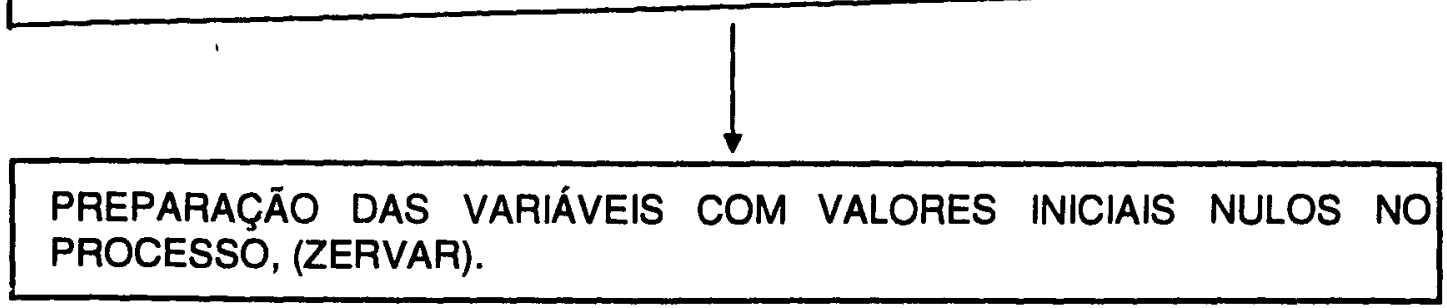

PROCESSO, (ZERVAR)

MONTAGEM DAS MATRIZES DE RIGIDEZ DOS ELEMENTOS DE BARRA, NAS COORDENADAS DO SISTEMA [ $\left.\mathrm{S}_{\mathrm{KBG}}\right]$, (RIGBAR). OBS: MATRIZES COM "P" = 0, EM REGIME DE PRIMEIRA ORDEM. 
MONTAGEM DA MATRIZ DE RIGIDEZ DO SISTEMA [S $\mathrm{S}_{\mathrm{KG}}$, (SISTEM).

OBS: MATRIZ EM REGIME DE PRIMEIRA ORDEM, $\quad$ "P" $=0$.

DESLOCAMENTOS DO SISTEMA PROVOCADOS PELAS CARGAS VIVAS, COM PARÂMETRO UNITÁRIO, "W" = 1. $\left\{A_{\phi V}\right\}=\left[S_{K G}\right]\left\{D_{v}\right\},(D E C O M)$; (SOLVE), EM REGIME DE PRIMEIRA ORDEM.

ESFORÇOS $\left\{F_{\mathrm{v}}\right\}_{i} E$ DESLOCAMENTOS $\left\{D_{\mathrm{LV}}\right\}_{i}$ DOS ELEMENTOS DE BARRA, PROVOCADOS PELAS CARGAS VIVAS COM "W" = 1, (ESFOR). OBS: EM ESPECIAL AS FORÇAS AXIAIS " $P_{\mathrm{v}}$ " $\neq 0$, EM REGIME PRIMEIRA ORDEM.

REMONTAGEM DA MATRIZ DE RIGIDEZ DO SISTEMA [S $\mathrm{SG}_{\mathrm{KG}}$, (SISTEM), POIS FOI ALTERADA NA ETAPA ANTERIOR. "P" = 0. OBS: MATRIZ EM REGIME DE PRIMEIRA ORDEM.

DESLOCAMENTOS DO SISTEMA PROVOCADOS PELAS CARGAS CONSTANTES, (DECOM); (SOLVE) $\left\{A_{\phi c}\right\}=\left[S_{K G}\right]\left\{D_{c}\right\}$, EM REGIME DE PRIMEIRA ORDEM. 


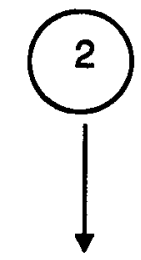

ESFORÇOS $\left\{F_{C}\right\}_{i} E$ DESLOCAMENTOS $\left\{D_{L C}\right\}_{i}$ DOS ELEMENTOS DE BARRA, PROVOCADOS PELAS CARGAS CONSTANTES, (ESFOR).

OBS: EM ESPECIAL AS FORÇAS AXIAIS, "Pc" $\neq 0$, EM REGIME DE PRIMEIRA ORDEM.

ESFORÇOS AXIAIS NAS BARRAS " $P_{\mathrm{v}}$ " $E$ " $P_{\mathrm{c}}$ ". DESLOCAMENTOS DO SISTEMA "D," E "Do". (WRITE 1); (WRITE 4), EM REGIME DE PRIMEIRA ORDEM.

PARÂMETRO INICIAL "W", MULTIPLICADOR DAS CARGAS VIVAS. $P_{i}=P_{C i}$ $+W P_{V_{i}} ; \quad W_{\max }=\left(3 P_{E} / P_{V}\right)+W_{E} ; W=(A+B) / 2 . \quad O B S: A_{I N I C}=0, B_{I N I C}=$ $W_{\max }\left(\right.$ PARAMW). $W_{\max }=W_{1} p /$ ESTABILIDADE E $W_{\max }=W_{2} p /$ TENSÃO COM $W_{\max } \leq W_{1}$ OU $W_{2}$

(115)

INCREMENTO DAS CARGAS VIVAS, (INCREMW)

$\left\{A_{\phi_{w}}\right\}=\left\{A_{\phi_{v}}\right\} * W+\left\{A_{\phi_{c}}\right\}$, CONJUNTO DO CARREGAMENTO

$\left\{P_{\mathrm{w}}\right\}=\left\{\mathrm{P}_{\mathrm{v}}\right\} * \mathrm{~W}+\left\{\mathrm{P}_{\mathrm{w}}\right\}$, ESFORÇOS AXIAIS, DO CARREGAMENTOS

$\left\{D_{w}\right\}=\left\{D_{v}\right\} * W+\left\{D_{c}\right\}$, DESLOCAMENTO DO SISTEMA, DO CARREGAMENTO

10

$\longrightarrow$

MONTAGEM DAS MATRIZES DE RIGIDEZ DOS ELEMENTOS DE BARRA, [S $\left.\mathrm{S}_{\mathrm{KB}}\right]$ ] AFETADAS PELAS FORÇAS AXIAIS $\left\{\mathrm{P}_{\mathrm{w}}\right\}$, (RIGBAR). OBS: MATRIZES COM "P" $\neq 0$, EM REGIME DE SEGUNDA ORDEM. 
MONTAGEM DA MATRIZ DE RIGIDEZ DO SISTEMA [S $\mathrm{S}_{\mathrm{KG}}$ AFETADA PELAS FORÇAS AXIAIS $\left\{P_{W}\right\}$, (SISTEM). OBS: MATRIZ EM REGIME DE SEGUNDA ORDEM. "P" $\neq 0$.

DECOMPOSIÇÃO DA MATRIZ [S $\mathrm{S}_{K G}$ ], POR CHOLESKY. VERIFICA SE A MATRIZ É DEFINIDA POSITIVA. DEF. POS. $\rightarrow \mathbb{I N}=0$; SE NÃO DEF. POS. $\rightarrow \mathbb{I N}=-1$ (DECOM).

(130)

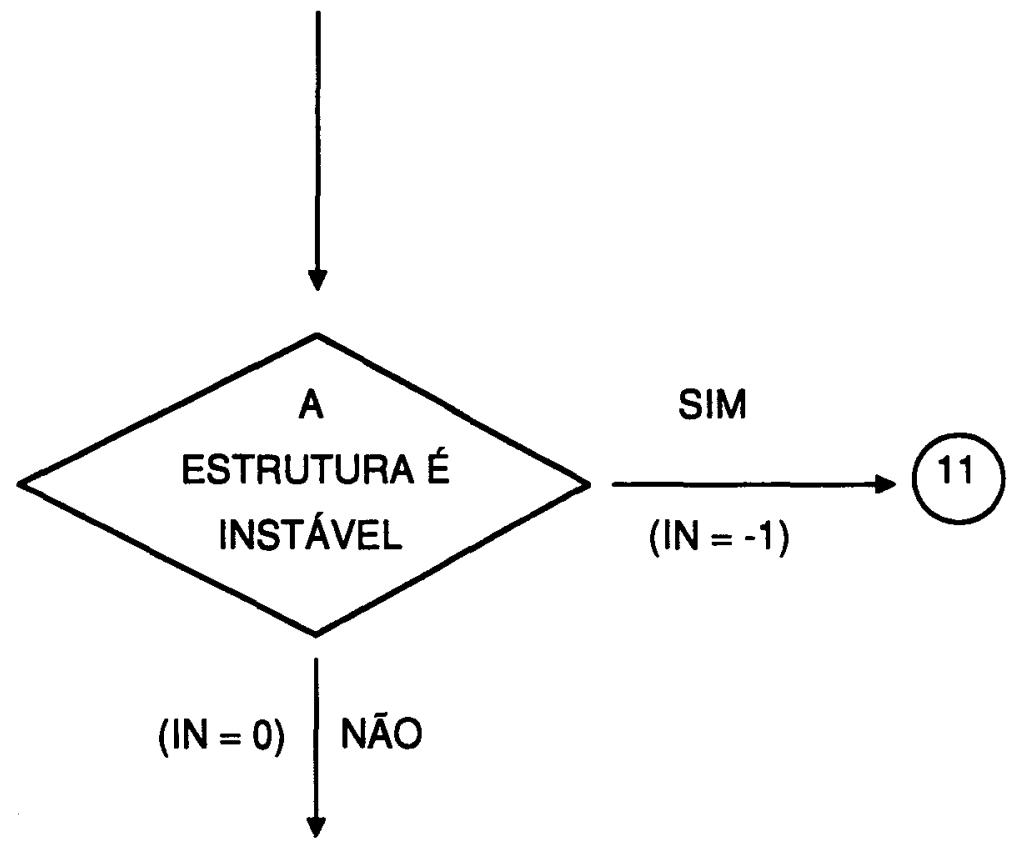

DESLOCAMENTOS DO SISTEMA $\left\{D_{\mathrm{w}_{2}}\right\}$ PROVOCADOS PELAS AÇÓES DO CARREGAMENTO $\left\{A_{\phi w}\right\},(S O L V E) .\left\{A_{\phi w}\right\}=\left[S_{\mathrm{KG}}\right]\left\{D_{w_{2}}\right\}$, EM REGIME DE SEGUNDA ORDEM.

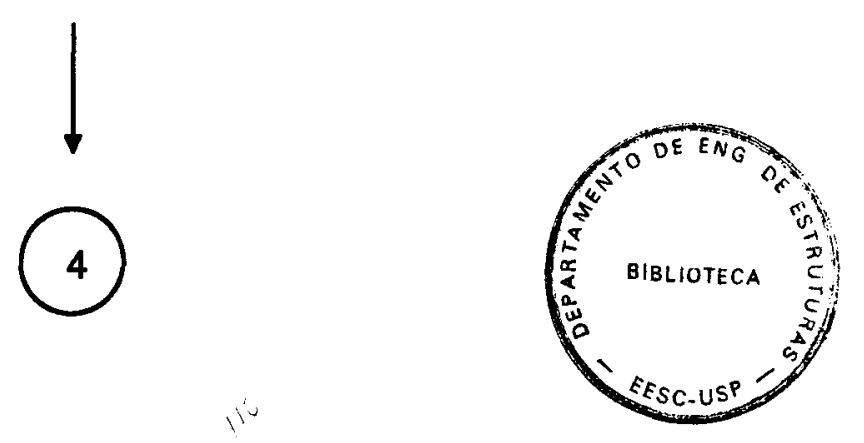




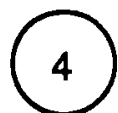

1

NOVOS ESFORÇOS AXIAIS PARA O MESMO CARREGAMENTO PARA OS NOVOS EFEITOS AXIAIS NA MATRIZ DE RIGIDEZ, " $P_{w}$ " (ESFOR).

COMPARAÇÃO DOS DESLOCAMENTOS DO SISTEMA $\left\{\mathrm{D}_{\mathrm{w}_{2}}\right\}$ COM $\left\{\mathrm{D}_{\mathrm{w}}\right\}$ PARA O MESMO CARREGAMENTO. VERIFICAÇÃO DA CONVERGÊNCIA DOS DESLOCAMENTOS; (CICLOS).

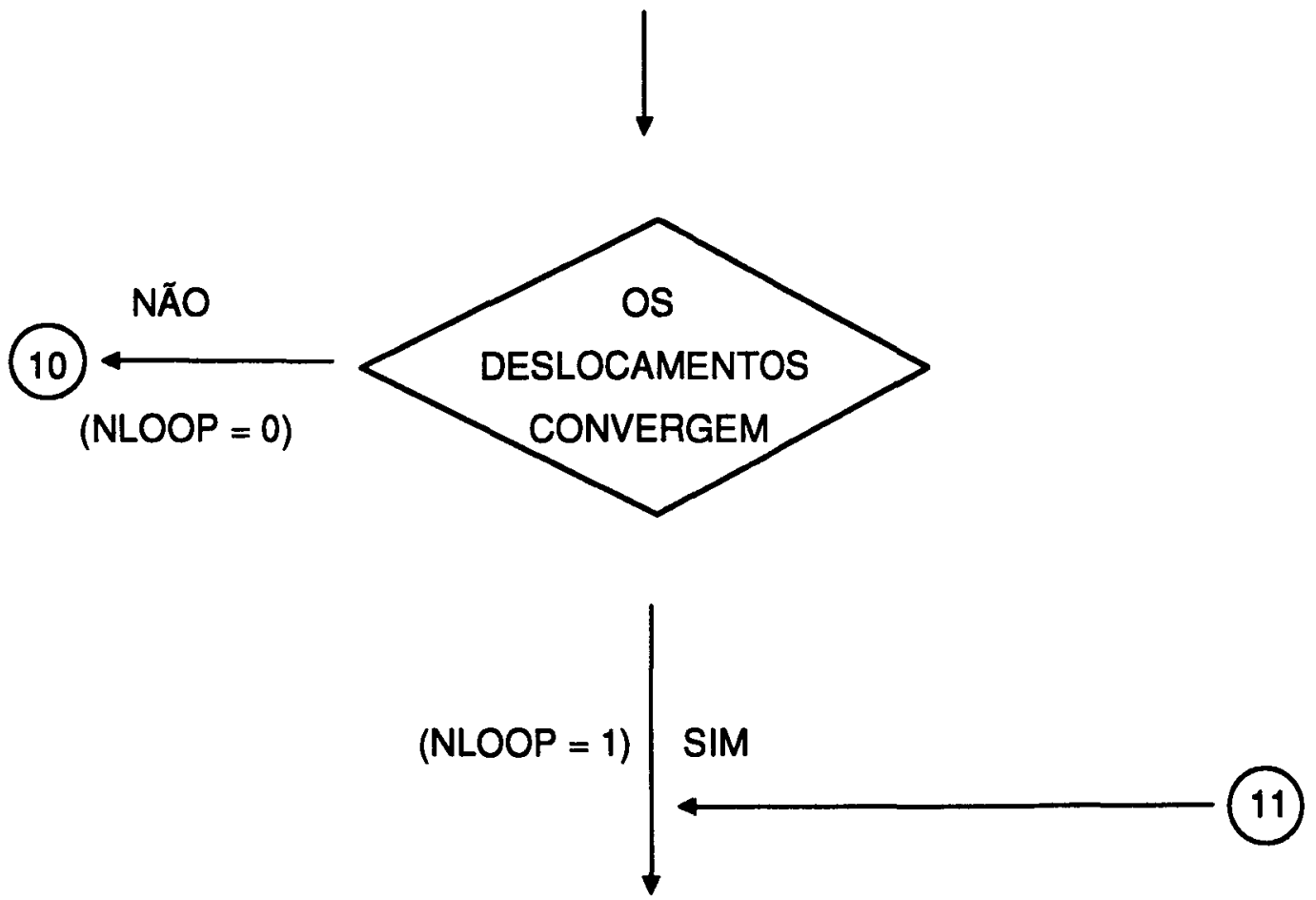

(160)

TROCA DOS LIMITES DE PESQUISA DO PARÂMETRO MULTIPLICADOR DAS CARGAS VIVAS. PARA IN = -1, ESTRUTURA INSTÁVEL FAZ-SE $B=$ W OU PARA IN $=0$, ESTRUTURA ESTÁVEL FAZ-SE $A=W$. CALCULA-SE NOVO $W=(A+B) / 2$, (LIMITES).

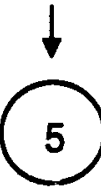


CALCULA A DIFERENÇA ENTRE OS LIMITES DE PESQUISA DO PARÂMETRO "W" COMPARANDO COM TOL (\%): SE SIM $\rightarrow$ IND $=-1$, SE $\mathrm{NA} O \rightarrow \mathbb{N D}=+1$, (TOLER).

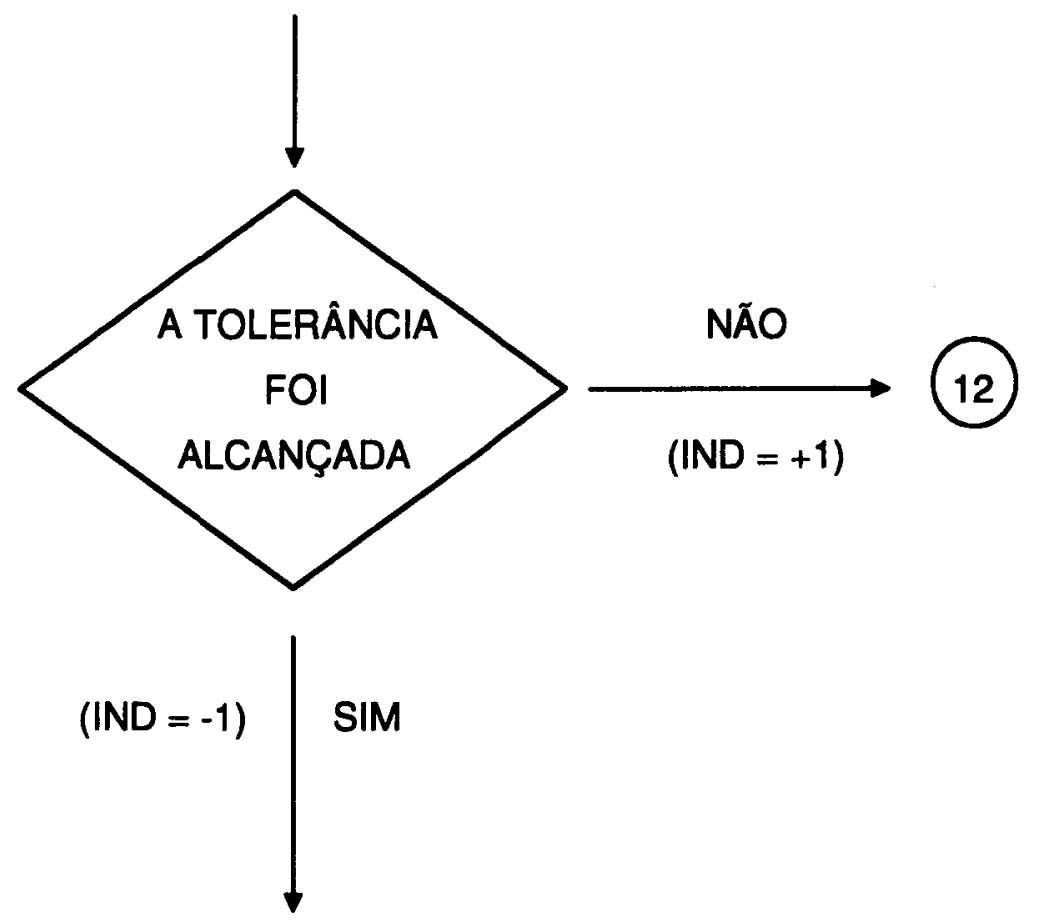

O VALOR DO PARÂMETRO CRÍTICO " $W_{C R}$ " FOI ENCONTRADO. IMPRIME O VALOR, (WRITE WCR). 
4.2.2 Carregamento crítico de instabilidade geral, no regime elástico para estruturas com elementos discretizados e elementos de barra - programa tipo II (CARCRITF.FOR)

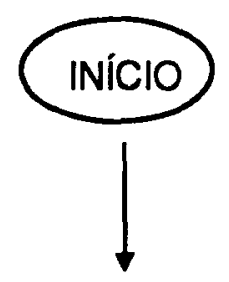

IDENTIFICAÇÃO DOS ARQUIVOS DE ENTRADA E SAÍDA NO DISCO, (FILESCR).

DEFINIÇÃO DA TOLERÂNCIA NA CONVERGÊNCIA DO PROCESSO TOL $(\%)$.

CARACTERÍSTICAS ELÁSTICO-GEOMÉTRICAS DO PÓRTICO TRANSVERSAL, CONSTITUÍDO DE ELEMENTOS DE BARRA NA TRAVE E ELEMENTOS DE PAINEL NOS PILARES DISCRETIZADOS (READICR); (READ1); (READ2CR); (READ2);. CONDIÇÕES DE VINCULAÇŌES; CARGAS VIVAS E CARGAS CONSTANTES, (READ3CR); (READ3).

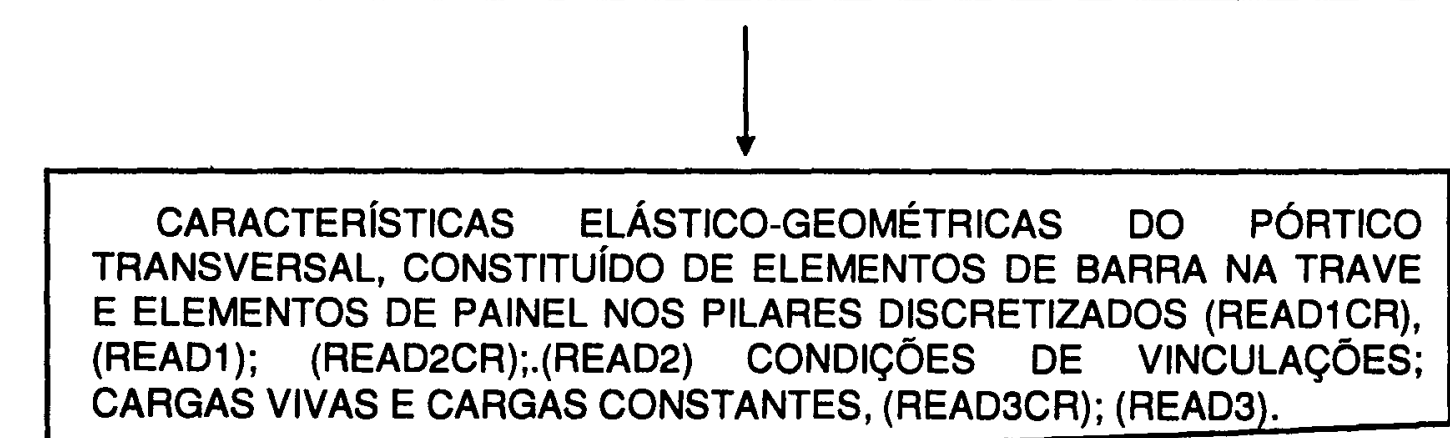

(READ1); (READ2CR);:(READ2) CONDIÇÕES DE VINCULAÇŌES;

CARGAS VIVAS E CARGAS CONSTANTES, (READ3CR); (READ3).

PREPARAÇĀO DAS VARIÁVEIS COM VALORES INICIAIS NULOS NO PROCESSO, (ZERVARCR). 
$\downarrow$

MONTAGEM DAS MATRIZES DE RIGIDEZ DOS ELEMENTOS DOS PAINÉIS DISCRETIZADOS DOS PILARES [S $]_{K}$, (MEMBRO).

OBS: MATRIZES COM "P" = 0, EM REGIME DE PRIMEIRA ORDEM.

$\downarrow$

MONTAGEM DAS MATRIZES DE RIGIDEZ DOS PILARES, [S] QUE CONTRIBUIRÃO PARA A MONTAGEM DA MATRIZ DE RIDIGEZ DO PORTICO TRANSVERSAL [SIST], (SISTG).

OBS: MATRIZES COM "P" = 0, EM REGIME DE PRIMEIRA ORDEM.

$\downarrow$

MONTAGEM DA MATRIZ DE RIGIDEZ DO SISTEMA DO PORTICO TRANSVERSAL [SISG], FORMADA PELA CONTRIBUIÇĀO DAS MATRIZES [S]; DOS PILARES, E DAS MATRIZES DE RIGIDEZ DOS ELEMENTOS DE BARRA DA TRAVE [S $\left.\mathbf{S}_{\mathrm{KBG}}\right]_{i}$, (SISTG); (RIGBAR).

OBS: MATRIZ COM "P" = 0, EM PRIMEIRA ORDEM.

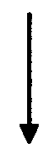

DESLOCAMENTOS DO SISTEMA GLOBAL PROVOCADOS PELAS CARGAS CONSTANTES, (DECOM); (SOLVE), EM REGIME DE PRIMEIRA ORDEM. $\left\{A_{c}\right\}=[S I S G]\left\{V_{c}\right\}$

ORCA AXIAL "Pc" NOS ELEMENTOS, PROVOCADOS PELAS CARGAS CONSTANTES. (FORÇA P); (FORCAPTR), EM REGIME DE PRIMEIRA ORDEM. 


\section{(2)}

$\downarrow$

ESFORÇOS E TENSÓES NAS SEÇÓES DOS PAINÉIS PROVOCADOS PELAS CARGAS CONSTANTES, (ESFTEN).

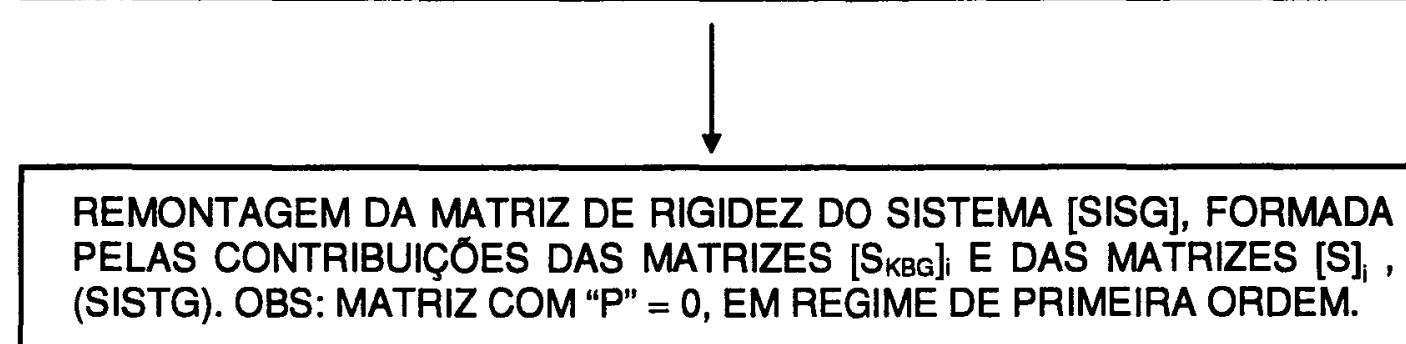

DESLOCAMENTO DO SISTEMA GLOBAL PROVOCADOS PELAS CARGAS VIVAS, COM PARÂMETRO UNITÁRIO, "W" = 1, (DECOM); (SOLVE), EM REGIME DE PRIMEIRA ORDEM. $\left\{A_{v}\right\}=[S I S G]\left\{V_{v}\right\}$.

FORÇA AXIAL "Pv" NOS ELEMENTOS, PROVOCADOS PELAS CARGAS VIVAS, COM PARÂMETRO UNITÁRIO, "W" = 1, (FORÇA P); (FORCAPTR), EM PRIMEIRA ORDEM.

ESFORÇOS E TENSÓES NAS SEÇÓES DOS PAINÉIS PROVOCADOS PELAS CARGAS VIVAS, COM "W"=1, (ESFTEN). 


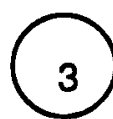

1

PARÂMETRO INICIAL "W", MULTIPLICADOR DAS CARGAS VIVAS. " $\sigma_{\mathrm{p}}$ " (DO MATERIAL FORNECIDO). $W_{\max }=\left(\sigma_{p}-\sigma_{C}\right) / \sigma_{v} \cdot W=(A+B) / 2$.

OBS: $A_{\text {INIC }}=0 ; \quad B_{\text {INIC }}=W_{\text {MAX, }}$ (PARAMCR).

(210)

INCREMENTO DAS CARGAS VIVAS. (INCREMCR)

$\{A\}=\left\{A_{P}\right\}+W\left\{A_{v}\right\}$, CONJUNTO DO CARREGAMENTO

$\{P\}=\left\{P_{c}\right\}+W\left\{P_{v}\right\}$, ESFORÇOS AXIAIS DO CARREGAMENTO

$\{D\}=\left\{V_{c}\right\}+W\left\{V_{v}\right\}, D E S L O C A M E N T O S$ DO SISTEMA DO CARREGAMENTO

(10)

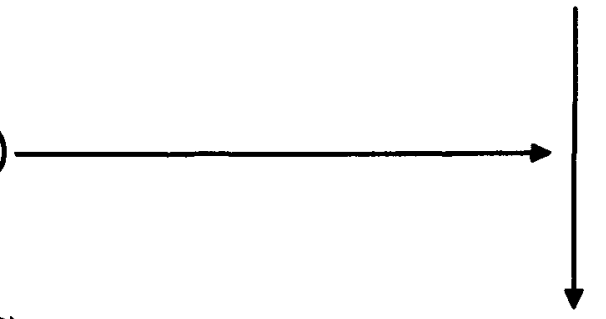

(300)

MONTAGEM DAS MATRIZES DE RIGIDEZ DOS ELEMENTOS DE PAINEL, AFETADAS PELAS FORÇAS AXIAIS, EM REGIME DE SEGUNDA ORDEM. MONTAGEM DAS MATRIZES DE RIGIDEZ DOS ELEMENTOS DE BARRA DA TRAVE, EM REGIME DE SEGUNDA ORDEM (MEMBRO);(RIGBAR).

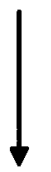

MONTAGEM DAS MATRIZES DE RIGIDEZ DOS PILARES [S] DISCRETIZADOS EM REGIME DE SEGUNDA ORDEM QUE CONTRIBUIRAM PARA A MONTAGEM DA MATRIZ DE RIGIDEZ DO PORTICO TRANSVERSAL. 


\section{4}

1

MONTAGEM DA MATRIZ DE RIGIDEZ DO SISTEMA DO PÓRTICO TRANSVERSAL [SISG], FORMADA PELA CONTRIBUIÇĀO DAS MATRIZES [SKBG], EM SEGUNDA ORDEM E DAS MATRIZES [S], EM REGIME DE SEGUNDA ORDEM, (SISTG).

DECOMPOSIÇÃO DA MATRIZ [SISG], POR CHOLESKY. VERIFICA SE A MATRIZ É DEFINIDA POSITIVA. SE DEF. POS. $\rightarrow \mathbb{I N}=0$. SE NÃO DEF. POS. $\rightarrow \mathbb{N}=-1$ (DECOM)

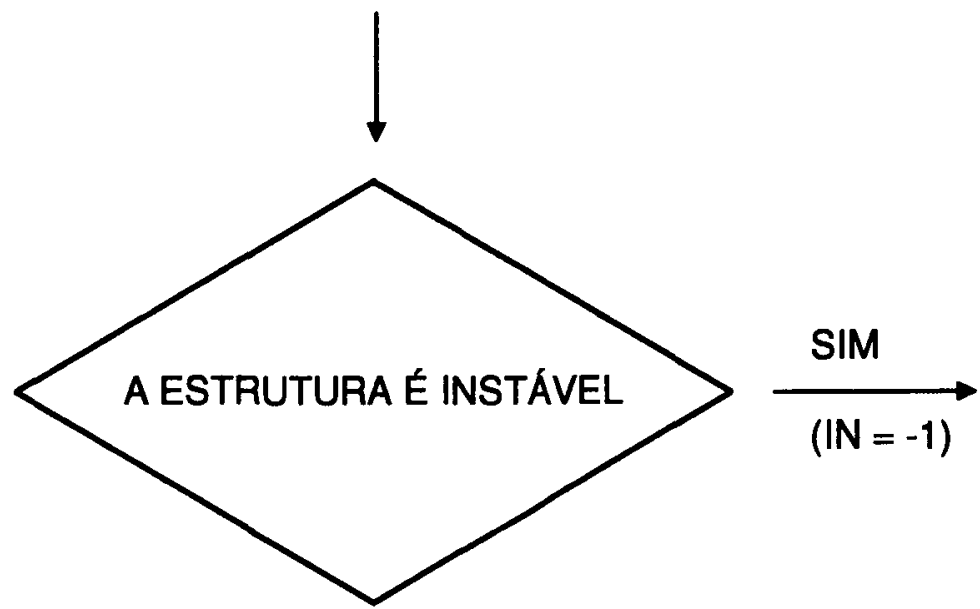

DESLOCAMENTO DO SISTEMA GLOBAL \{V\} PROVOCADOS PELAS AÇOES DO CARREGAMENTO \{A\}, (SOLVE).

$\{A\}=[S I S G]\{V\}, E M$ REGIMES DE SEGUNDA ORDEM. 
COMPARAÇÃO DOS DESLOCAMENTOS DO SISTEMA \{V\} COM \{D\} PARA O MESMO CARREGAMENTO. VERIFICAÇÃO DA CONVERGÊNCIA DOS DESLOCAMENTOS, (CONVERGCR).

NOVA FORÇA AXIAL "P", DOS ELEMENTOS.

(FORCAP); (FORCAPTR)

PI MESMO CARREG .

1

(10)

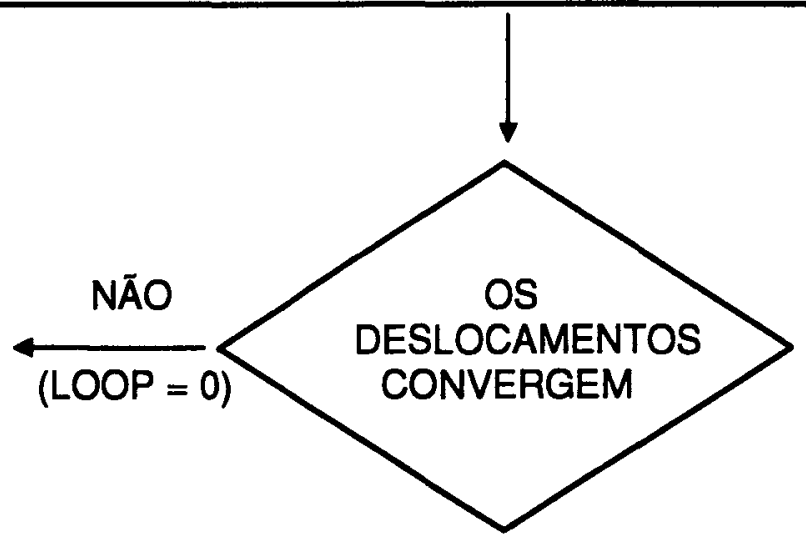

(350)

TROCA DOS LIMITES DE PESQUISA DO PARÂMETRO MULTIPLICADOR DAS CARGAS VIVAS. PARA IN = -1, ESTRUTURA INSTÁVEL FAZ-SE $B=$ W OU PARA IN $=0$, ESTRUTURA ESTÁVEL FAZ-SE $A=W$. CALCULA-SE NOVO $W=(A+B) / 2$, (LIMITSCR $)$.

CALCULA A DIFERENÇA ENTRE OS LIMITES, DE PESQUISA DO PARÂMETRO "W" COMPARANDO COM, TOL (\%). SE SIM $\rightarrow$ IND $=-1$, SE $N A ̄ O \rightarrow I N D=1$, (TOLER). 


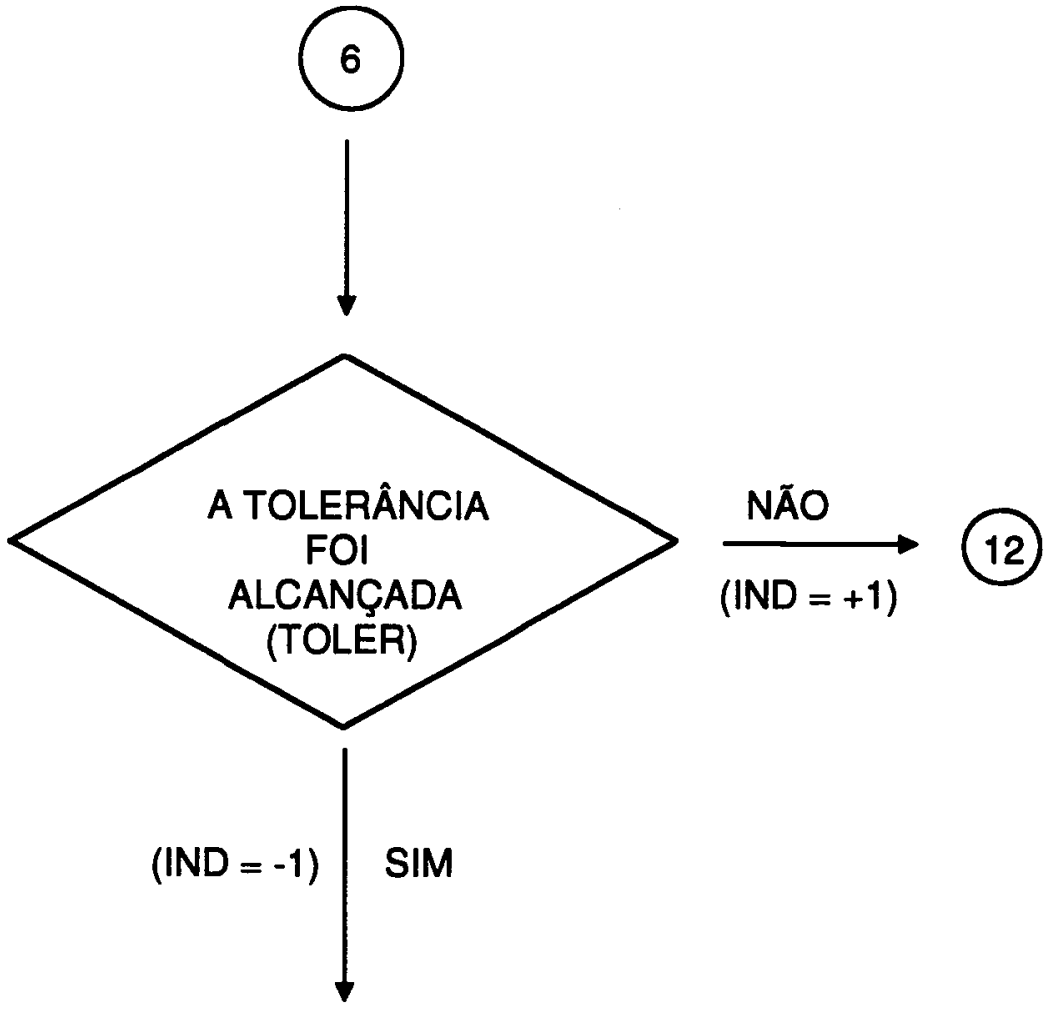

O VALOR DO PARÂMETRO CRITICO "WCr" FOI ENCONTRADO. IMPRIME VALOR. (WRITEWCR).

ESFORÇOS E TENSÓES NOS ELEMENTOS DE PAINEL. (ESFTEN).

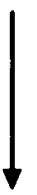

ESFORÇOS E TENSÓES NOS ELEMENTOS DE PAINEL. (WRITE 2). 


\section{CAPÍtULO V}

\section{EXEMPLOS NUMÉRICOS E COMPARAÇÕES DE RESULTADOS}

\subsection{INTRODUÇĀO}

Os programas para computador, descritos no capítulo IV, foram utilizados na solução de uma série de problemas relativos à determinação de parâmetros críticos " $\mathrm{W}_{\mathrm{cr}}$ ", na análise de instabilidade de pilares de edifícios industriais metálicos.

Os exemplos numéricos foram separados em dois tipos: no primeiro, utilizando o programa tipo $I$, os exemplos de pilares constituídos de elementos de barras foram analisados inicialmente de forma isolada e posteriormente de forma integrada ao pórtico plano transversal e todos os resultados comparados com os de outros autores; no segundo, utilizando o programa tipo II, os exemplos de pilares na forma tridimensional, foram analisados de forma comparativa com a análise anterior; com expressōes teóricas de cálculos de instabilidade e com o programa de computador ANSYS V-5.2.

As análises são realizadas não somente através de resultados obtidos dos parâmetros críticos de instabilidade dos pilares, mas também através das tensões limites de proporcionalidade do material que garantam a análise no regime elástico da estrutura definidas nas hipóteses adotadas nos programas. 


\subsection{EXEMPLO NUMÉRICO 1}

Neste primeiro exemplo, será mostrada a forma convencional de análise de um pilar de edifício industrial quanto a sua estabilidade, apenas no plano do pórtico transversal.

De acordo com a AISE $^{2}$ o pilar submetido a esforços combinados, de compressão e de flexão, devem ser verificados em sua estabilidade através da expressão de interação (1.1), sempre que a tensão normal atuante " $\mathrm{f}_{\mathrm{a}}$ " for $15 \%$ maior que a tensão admissivel " $F_{\mathrm{a}}$ ". Para o caso particular de análise de barras submetidas à força de compressão normal e flexão apenas no plano do pórtico, a expressão citada fica:

$$
\frac{f_{a}}{F_{a}}+\frac{C_{m x} f_{b x}}{\left(1-\frac{f_{a}}{F^{\prime}{ }_{e x}}\right) F_{b x}} \leq 1.0
$$

O primeiro termo da expressão, verifica a possibilidade de ocorrência da chamada flambagem de Euler no plano do pórtico. O segundo termo, verifica o aumento da tensão de flexão majorada pelo efeito de segunda ordem devido ao efeito da compressão normal.

O termo " $\mathrm{F}_{\mathrm{a}}$ " que representa a tensão admissível de compressão no pilar depende do índice de esbeltez " $\mathrm{KI} / \mathrm{r}_{\mathrm{x}}$ " e "Kly / $\mathrm{r}_{\mathrm{y}}$ " para ser obtido, através das curvas de flambagem da AISC ${ }^{49}$. O termo " $F_{\text {ex }}$ " depende do índice de esbeltez " $\mathrm{Kl} \mathrm{x}_{\mathrm{x}} / \mathrm{r}_{\mathrm{x}}$ ", apenas no plano do momento de segunda ordem provocado pela força axial do pilar.

A clássica questão, portanto, fica em como obter o comprimento efetivo de flambagem "Kl " do pilar do edifício industrial que tem como principal característica uma variação brusca de seção ao nível da viga de rolamento, no plano do pórtico. A obtenção de "Kly", no plano perpendicular fica definida pela posição dos contraventamentos, garantindo a estabilidade nessa direção. 
A análise convencional, portanto, utiliza o conceito do comprimento efetivo do pilar isolado com carregamento máximo em ambos os pilares do pórtico transversal, provocando a instabilidade simultânea.

A Fig.V-1, mostra a estrutura de um edifício industrial analisado por FISHER $^{7}$ (pag. 156), seguindo as recomendações da AISE ${ }^{2}$.

$$
\begin{aligned}
& P_{2}=50^{k} \text { (incluindo impacto) }(222,4 \mathrm{kN}) \\
& P_{H}=3,4^{k}(15,1 \mathrm{kN}) \\
& P_{1}=31^{k}(137,9 \mathrm{kN})
\end{aligned}
$$

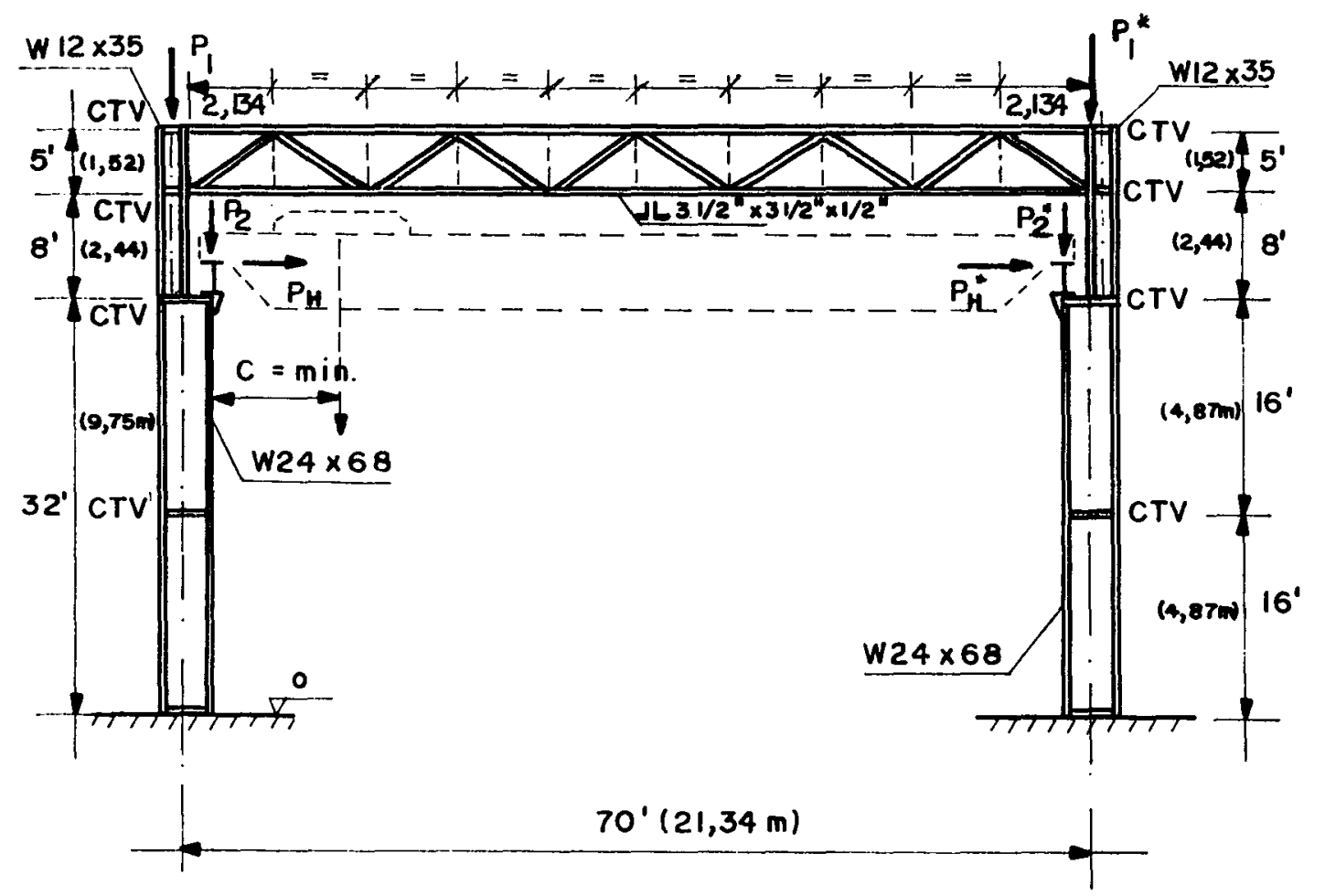

Figura V-1 Estrutura do Edifício Industrial 
A Fig.V-2, mostra os modelos do pilar isolado para efetuar a análise. $O$ carregamento é representado pelas ações $P_{1}, P_{2}$ e $P_{H}$ obtidas admitindo a máxima carga da ponte rolante o mais próximo desse pilar, já considerados os impactos.

Os vínculos do pilar isolado, são considerados de duas formas: a) com engastamento na base e engastamento-móvel no topo; b) com engastamento na base e articulação fixa no topo.

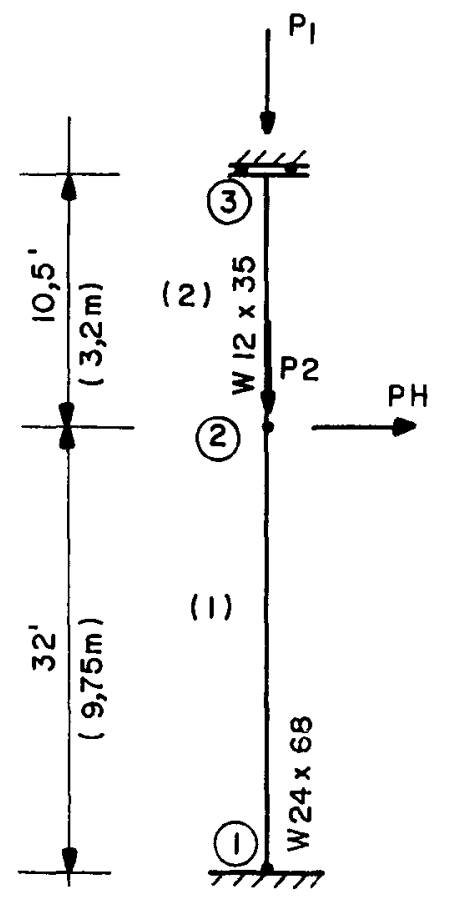

(a)

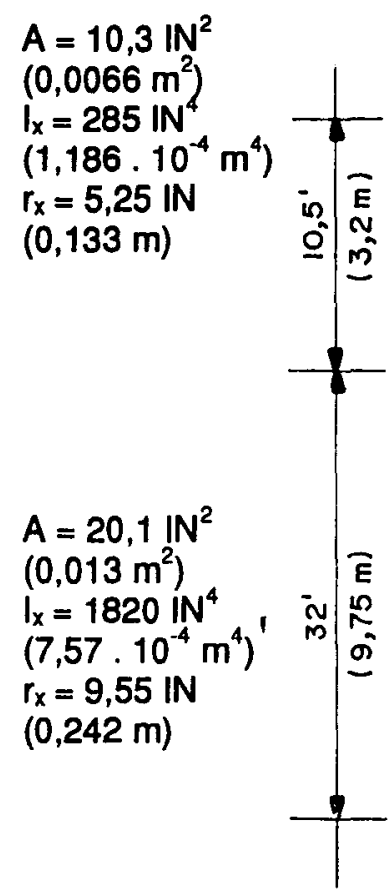

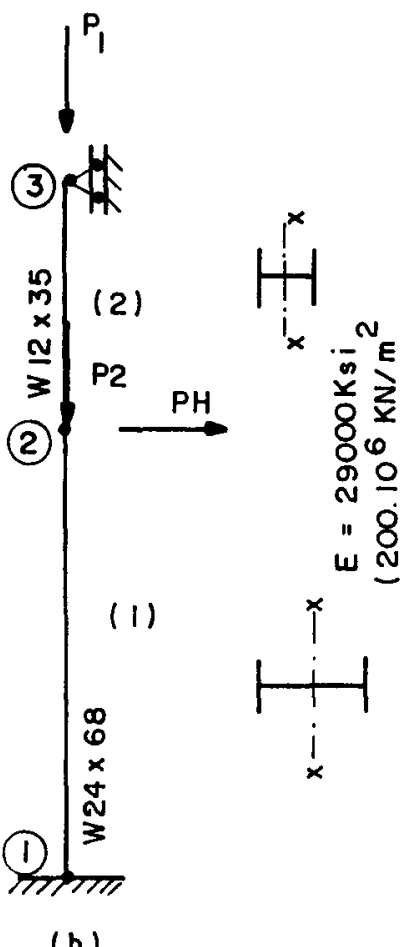

(b)

Figura V-2 Modelagem dos Pilares Isolados do Edifício Industrial do Exemplo1 
Utilizando o programa do tipo $\mathrm{I}$, do presente trabalho, com carregamento constituído apenas por cargas vivas para as ações $P_{1}, P_{2} \theta$ $P_{H}$, foram obtidos os parâmetros críticos de instabilidade " $W_{c r}$ ", nos seguintes casos:

a) Para o pilar da Fig. V-2a, $W_{\mathrm{cr}}=13,7084 \mathrm{com}$ forças normais, $F_{\mathrm{INF}}=-$ $1110,35^{k}$ e $F_{\text {SUP }}=-424,94^{k}$. Com estes resultados, foram determinados os comprimentos efetivos de flambagem para as partes inferior e superior do pilar, no plano do pórtico.

$$
\begin{aligned}
& \mathrm{K}=\sqrt{\frac{\mathrm{P}_{E}}{\mathrm{P}_{\mathrm{CR}}}} \rightarrow \mathrm{K}=\sqrt{\frac{\mathrm{F}_{\mathrm{E}}}{\mathrm{F}_{\mathrm{CR}}}} \\
& \mathrm{K}_{\mathrm{INF}}^{2}=\frac{\pi^{2} \cdot 29000 \cdot 1820}{(32 \cdot 12)^{2} \cdot 1110,33} \rightarrow \mathrm{K}_{\mathrm{INF}}=1,7837 \mathrm{ft} \\
& \mathrm{KL}_{\text {INF }}=1,7837 * 32 \rightarrow \mathrm{KL}_{\mathrm{INF}} 57,08 \mathrm{ft}
\end{aligned}
$$

Analogamente,

$$
\mathrm{K}_{\text {SUP }}=3,477 \rightarrow \mathrm{KL}_{\text {SUP }}=36,51 \mathrm{ft}
$$

b) Para o pilar da Fig. V-2b, foi obtido $W_{c r}=41,5678$ com forças normais $F_{I N F}=-3366,89^{k}$ e $F_{\text {SUP }}=-1288,56^{k}$. Com estes resultados, foram determinados analogamente os comprimentos efetivos de flambagem.

$$
\begin{aligned}
& K_{\text {INF }}=1,0243 \rightarrow \mathrm{L}_{\text {INF }}=32,778 \mathrm{ft} \\
& \mathrm{K}_{\text {SUP }}=1,9968 \rightarrow \mathrm{LL}_{\text {SUP }}=20,96 \mathrm{ft}
\end{aligned}
$$


Os resultados acima foram obtidos sem a consideração da deformação por cortante, a título de se obter resultados com os mesmos critérios de outros autores. Portanto, repetindo os dois casos anteriores, agora considerando 0 efeito da cortante, obtém-se:

$$
\begin{aligned}
& \text { para o tipoa, } \mathrm{F}_{\mathrm{INF}}=-1097,18^{\mathrm{k}} \rightarrow \mathrm{K}_{\mathrm{INF}}=1,794 \rightarrow \mathrm{KL}_{\mathrm{INF}}=57,41 \mathrm{ft} \\
& \mathrm{W}_{\mathrm{cr}}=13,545 ; \quad F_{\text {SUP }}=-419,91^{\mathrm{k}} \rightarrow \mathrm{K}_{\text {SUP }}=3,50 \rightarrow \mathrm{KL}_{\text {SUP }}=36,57 \mathrm{ft} \\
& \text { para o tipo } \underline{b}, F_{\text {INF }}=-3263,82^{k} \rightarrow K_{I N F}=1,04 \rightarrow \mathrm{KL}_{\mathrm{INF}}=33,28 \mathrm{ft} \\
& \mathrm{W}_{\mathrm{cr}}=40,293 ; \quad \mathrm{F}_{\text {SUP }}=-1247,12^{\mathrm{k}} \rightarrow \mathrm{K}_{\text {SUP }}=2,03 \rightarrow \mathrm{KL}_{\text {SUP }}=21,32 \mathrm{ft}
\end{aligned}
$$

A mesma estrutura foi analisada por FISHER $^{7-11}$, utilizando apenas 0 tipo a , lançando mão das equações diferenciais de ANDERSON ${ }^{9}$, e utilizando programação para obter as raízes da equação característica do caso apresentado.

Os resultados obtidos por FISHER ${ }^{7-11}$, foram:

$$
\begin{aligned}
& \mathrm{K}_{\mathrm{S}}=3,48 \rightarrow \mathrm{KL}_{\mathrm{S}}=36,51 \mathrm{ft} \\
& \mathrm{K}_{\mathrm{i}}=1,78 \rightarrow \mathrm{KL}_{\mathrm{i}}=57,08 \mathrm{ft}
\end{aligned}
$$

Foi realizada também uma tentativa de análise da estrutura através das tabelas da AISE ${ }^{2}$, porém sem sucesso, uma vez que as tabelas são muito limitadas na relação $P_{1} / P_{2}=0,25$ e em nosso exemplo, $P_{1} / P_{2}=0,62$ impossibilitando sua utilização.

Finalmente, utilizando as tabelas de AGRAWAL ${ }^{12}$, foram obtidos novos valores dos comprimentos efetivos de flambagem, apesar das dificuldades de enquadrar-se nas relações apresentadas, (AGRAWAL ${ }^{12}$ pag. 98 e 99): 
para o tipo a $, \mathrm{K}_{\mathrm{S}}=0,791 \rightarrow \mathrm{KL}_{\mathrm{s}}=33,62 \mathrm{ft}$

$$
\mathrm{K}_{\mathrm{i}}=1,319 \rightarrow \mathrm{KL}_{\mathrm{i}}=56,06 \mathrm{ft}
$$

para o tipo $\underline{\mathrm{b}}, \mathrm{K}_{\mathrm{s}}=0,5355 \rightarrow \mathrm{KL}_{\mathrm{s}}=22,76 \mathrm{ft}$

$$
K_{i}=0,906 \rightarrow K_{i}=38,51 \mathrm{ft}
$$

$\mathrm{Na}$ Tabela V-1, foram reunidos os resultados do exemplo numérico 1 obtidos através dos processos e autores, já citados, para as hipóteses adotadas:

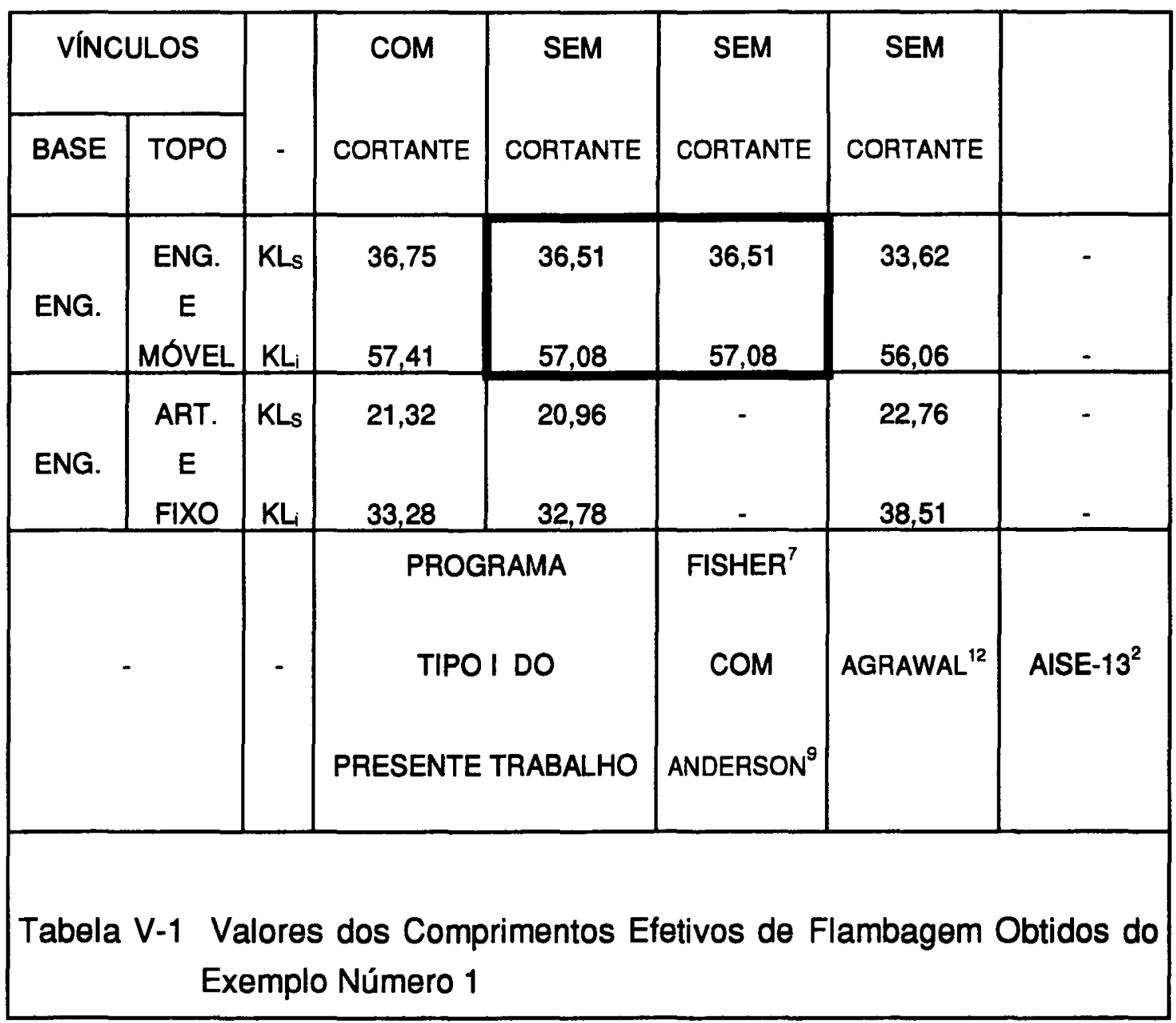


Analisando os resultados da tabela V-1, pode-se concluir:

a) As diferenças encontradas nos resultados, considerando o efeito da força cortante, não foram significativas uma vez que os pilares não estão submetidos a grandes forças transversais, porém é importante salientar 0 aspecto de garantir maior precisão no processo proposto.

b) Os resultados do programa tipo I, sem considerar o efeito da força cortante, coincidem rigorosamente com os resultados obtidos por FISHER $^{7}$ que utilizou as equaçóes diferenciais exatas de ANDERSON ${ }^{9}$, para os casos de pilares isolados. Portanto, seus resultados são também considerados exatos, dentro das hipóteses apresentadas. Neste caso, podese afirmar que o presente programa tipo I fornece resultados muito precisos, pois utiliza as funções de rigidez e controla a precisão dos resultados adotando rígida tolerância de $10^{-4}$ para a convergência do processo. Estas convergências ocorreram em apenas três iteraçōes para cada análise de carregamento do presente exemplo numérico.

c) A utilização de tabelas, como da $\operatorname{AISE}^{2}$ e de AGRAWAL ${ }^{12}$, não permitem atender às necessidades dos projetistas, pois é muito comum a situação em que o pilar do edifício industrial nāo se enquadra nas referidas tabelas e, quando são possíveis suas utilizações, nem sempre enquadramse perfeitamente às relações solicitadas por elas. Consequentemente os resultados podem apresentar grandes variações.

d) Esta análise de pilar isolado do pórtico transversal não retrata a realidade do comportamento real dos pilares dos edifícios industriais pois os vínculos são teóricos e admitidos perfeitos, apesar de ser a forma mais utilizada nos dias atuais.

e) Para as condições de normas que utilizam coeficientes de majorações das ações, como no caso da $\operatorname{LRFD}^{50}$ e da $A B N T^{51}$, as ações devem ser majoradas e combinadas para cada situação de trabalho da estrutura antes de determinar os comprimentos efetivos de flambagem, através do programa. Desta forma, os parâmetros de flambagem obtidos podem ser aplicados nas expressões de interação das referidas normas, separadamente para cada situação de trabalho da estrutura sob vários carregamentos. Esta recomendação é indispensável tendo em vista que o processo utiliza não linearidade geométrica e portanto não valendo a superposição dos efeitos. 


\subsection{EXEMPLO NUMÉRICO 2}

Neste segundo exemplo, será mostrada a análise de um pilar de edifício industrial, integrado ao pórtico transversal.

Esta análise, comparada com a anterior, diverge apenas na determinação dos comprimentos efetivos de flambagem das partes superior e inferior dos pilares no plano do pórtico, pois neste caso, todo o pórtico será analisado com seus vínculos contínuos e com as ações devidas à ponte rolante carregando os pilares de forma diferenciada.

$\mathrm{Na}$ Fig.V-3, é mostrada a estrutura de um edifício industrial analisado por FRASER ${ }^{18}$ (pag. 29), "Turbine House at Liddell Power Station, New South Wales, Australia".

FRASER ${ }^{18}$, determinou os comprimentos efetivos de flambagem das partes superior e inferior do pilar mais carregado, utilizando para esta análise de instabilidade do pórtico o processo dos elementos finitos de barras planas, obtendo os seguintes resultados:

$$
\begin{aligned}
& \left.\begin{array}{l}
K_{\mathrm{S}}=4,566 \rightarrow \mathrm{KL}_{\mathrm{s}}=63,93 \mathrm{~m} \\
\mathrm{~K}_{\mathrm{i}}=1,466 \rightarrow \mathrm{KL}_{i}=29,31 \mathrm{~m}
\end{array}\right\} \text { pelo programa de FRASER }{ }^{18} \\
& \left.\begin{array}{l}
\mathrm{K}_{\mathrm{S}}=4,75 \rightarrow \mathrm{KL}_{\mathrm{s}}=66,5 \mathrm{~m} \\
\mathrm{~K}_{\mathrm{i}}=1,52 \rightarrow \mathrm{KL}_{\mathrm{i}}=30,5 \mathrm{~m}
\end{array}\right\} \text { pelas tabelas de FRASER }{ }^{18}
\end{aligned}
$$

Os resultados encontrados utilizando o processo de FRASER ${ }^{18}$, demonstram precisão apenas quando obtidos pelo seu programa pois os resultados obtidos pelas suas tabelas demonstram alguma imprecisão, 0 que já era de se esperar. 


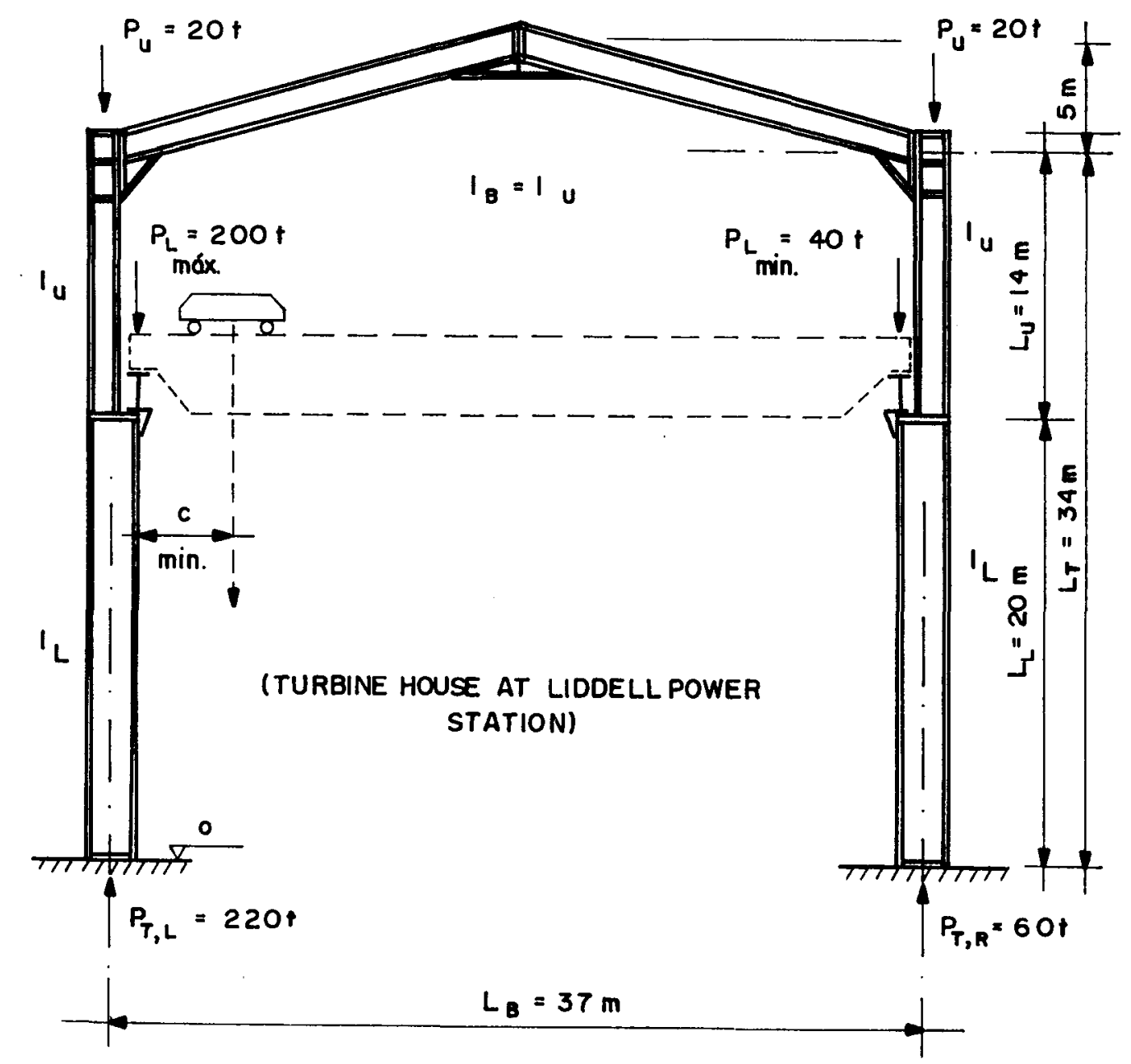

(u)

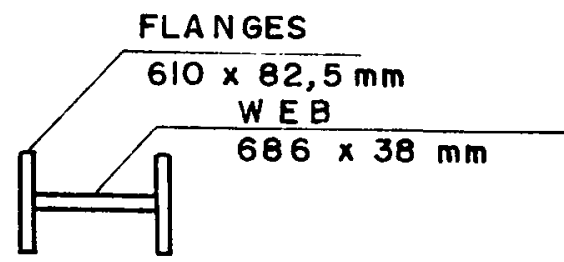

$$
\begin{aligned}
& E=200 \cdot 10^{6} \mathrm{kN} / \mathrm{m}^{2} \\
& \left(2 \cdot 10^{7}-t / \mathrm{m}^{2}\right) \\
& I_{u}=0,016 \mathrm{~m}^{4} \\
& A_{u}=0,1267 \mathrm{~m}^{2} \\
& I_{L}=0,037 \mathrm{~m}^{4} \\
& A_{L}=0,1412 \mathrm{~m}^{2}
\end{aligned}
$$

Figura V-3 Estrutura do Edifício Industrial 
Utilizando o programa tipo $I$, do presente trabalho, considerando o carregamento constituído apenas por cargas vivas, para as ações $P_{\mathbf{U}} \in P_{L}$, com o pórtico completo, carregando os pilares de forma diferenciada, podese obter o parâmetro crítico de instabilidade " $W_{\mathrm{cr}}$ ". A modelagem do pórtico, Fig.V-4, é representada por seis elementos de barra e ações diferenciadas de acordo com a posiçăo mais desfavorável da carga da ponte rolante. Os resultados obtidos foram:

$$
\begin{aligned}
& W_{c r}=35,8976, \quad F_{1 W}=-7994,84 t, \quad F_{2 W}=-817,33 t \\
& F_{5 W}=-618,17 t, \quad F_{6 W}=-2053,67 t
\end{aligned}
$$

Com estes resultados, obtém-se:

$$
\begin{aligned}
& \mathrm{K}_{1}=1,51 \rightarrow \mathrm{KL}_{1}=30,2 \mathrm{~m} ; \quad \mathrm{K}_{2}=4,44 \rightarrow \mathrm{KL}_{2}=62,16 \mathrm{~m} \\
& \mathrm{~K}_{5}=5,11 \rightarrow \mathrm{KL}_{5}=71,5 \mathrm{~m} ; \quad \mathrm{K}_{6}=2,98 \rightarrow \mathrm{KL}_{6}=59,6 \mathrm{~m}
\end{aligned}
$$

Analisando os resultados do programa de FRASER ${ }^{18}$, utilizando 0 processo dos elementos finitos de barras planas, e o programa tipo I do presente trabalho, utilizando o processo matricial com as funções de rigidez, observa-se que os valores estão muito próximos. Portanto, garantindo a confiabilidade do programa proposto.

Para o melhor entendimento da análise do pilar integrado ao pórtico, foi montada a Tabela V-2, mostrando as diferentes formas de obtenção dos parâmetros " $W_{c r}$ ", para o exemplo numérico número 2 , com o programa tipo I. 


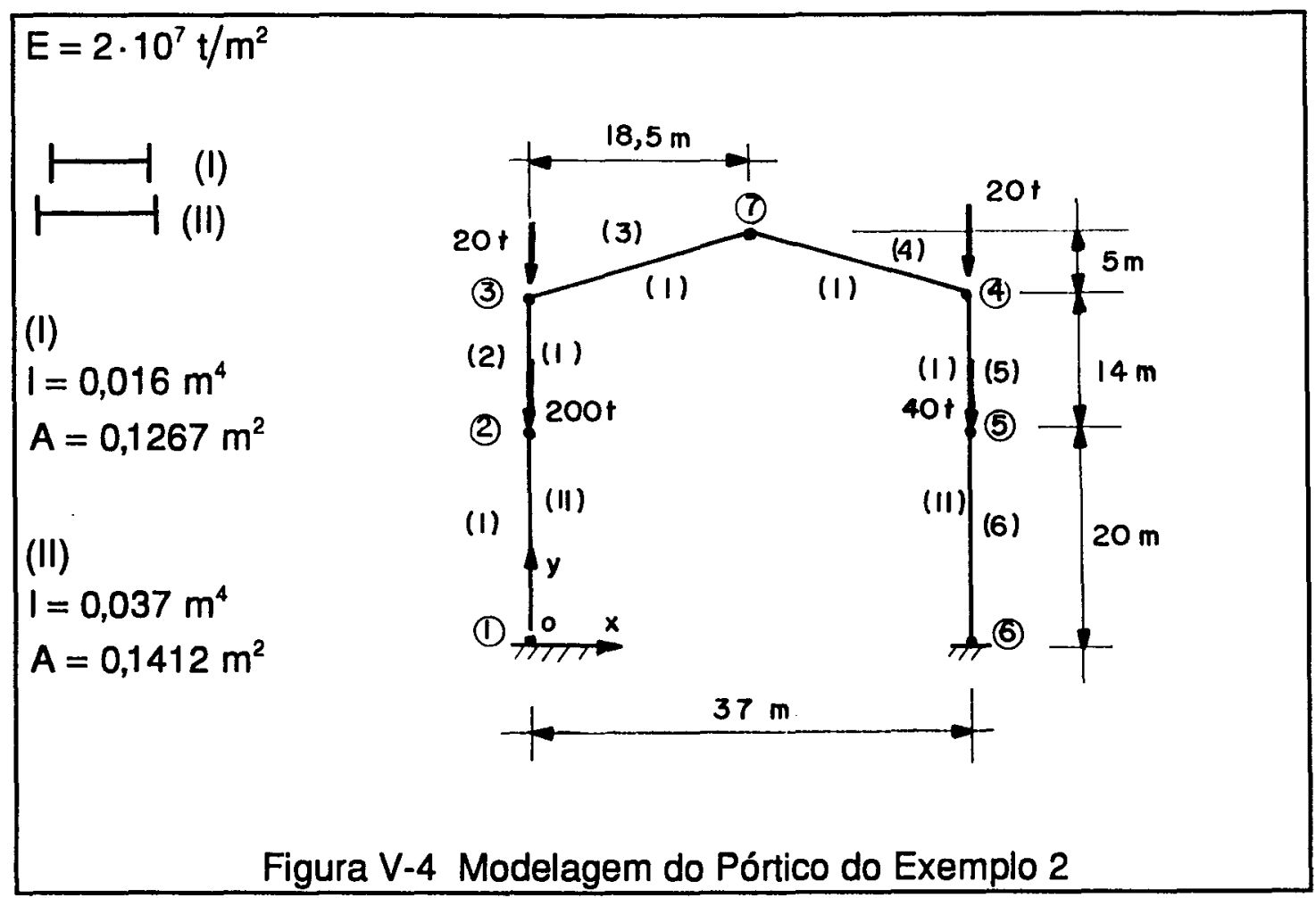

\begin{tabular}{|c|c|c|c|c|c|c|}
\hline Exemplo & & & & IV & V & - \\
\hline 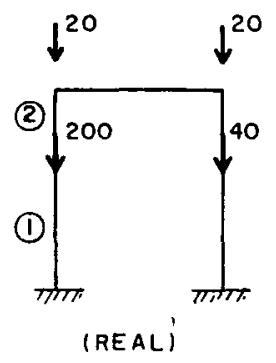 & 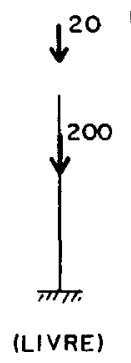 & $\downarrow_{\pi m+m}^{\downarrow^{20}}$ & 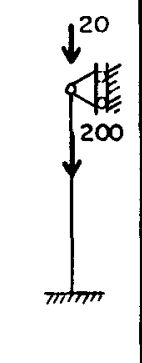 & $\downarrow_{\downarrow_{\pi}^{200}}^{\downarrow^{20}} \downarrow_{\pi}^{200}$ & $\underbrace{\downarrow^{20}}_{\downarrow_{m}^{200}} \downarrow_{\pi+m}^{\downarrow_{m}^{20}}$ & - \\
\hline 35,90 & 18,17 & 28,94 & 87,82 & 25,98 & 25,23 & Wer \\
\hline 1,511 & 2,138 & 1,693 & 0,972 & 1,786 & 1,814 & $\mathrm{~K}_{1}$ \\
\hline 4,44 & 6,660 & 5,275 & 3,030 & 5,567 & 5,651 & $\mathrm{~K}_{2}$ \\
\hline 0,707 & 1,00 & 0,792 & 0,455 & 0,835 & 0,848 & $K_{1}=2,138$ \\
\hline 1,976 & 1,00 & 1,593 & 4,833 & 1,43 & 1,388 & $W_{a / 18,17}$ \\
\hline Representações & $\begin{array}{l}\downarrow^{20} \\
\downarrow_{m+m}^{200} \\
\alpha_{A}=0 \\
\alpha_{T}=0\end{array}$ & $\prod_{\substack{\downarrow^{20} \\
\downarrow_{A}=1,593 \\
\alpha_{T}=0}}^{\substack{\downarrow^{20} \\
\alpha_{4}}}$ & $\underbrace{200}_{\substack{\downarrow^{20} \\
\downarrow^{200} \\
\alpha_{\mathrm{A}}=0 \\
\alpha_{\mathrm{T}=4,833}}}$ & $\underbrace{200}_{\substack{\prod^{2} \\
\downarrow_{\mathrm{A}}=1,43 \\
\alpha_{T}=0}}$ & $\sum_{\substack{\downarrow_{m}^{20} \\
\alpha_{A}=0 \\
\alpha_{T}=1,388}}^{200}$ & - \\
\hline
\end{tabular}


A tabela V-2 apresenta na primeira coluna o pórtico transversal completo com o carregamento diferenciado nos pilares. $O$ valor indicado na linha de " $W_{C R}$ " representa o parâmetro crítico de instabilidade do pórtico sob este carregamento. $O$ valor indicado na linha de " $K_{1}$ " representa a constante multiplicadora do comprimento da parte inferior do pilar, mais carregado do pórtico, para a obtenção do comprimento efetivo de flambagem. $O$ valor indicado na linha de " $\mathrm{K}_{2}$ " representa a constante multiplicadora do comprimento da parte superior do pilar, mais carregado do pórtico, para obtenção do comprimento efetivo de flambagem. $O$ valor indicado na linha " $K_{1} / 2,138$ " representa a relação entre a constante " $K_{1}$ " do pilar rigidamente ligado ao pórtico transversal e a constante " $\mathrm{K}_{1}$ " obtido do pilar considerado isolado com engastamento na base e livre no topo. $O$ valor indicado na linha " $W_{C R} / 18,17$ " representa a relação entre o parâmetro de instabilidade " $W_{C R}$ " do pilar rigidamente ligado ao pórtico transversal e o parâmetro " $W_{C R}$ " obtido do pilar considerado isolado com engastamento na base e livre no topo. As análises são efetuadas para pilar isolado tipo I, na segunda coluna; pilar isolado tipo II, na terceira coluna; pilar isolado tipo III, na quarta coluna; pilar rigidamente ligado ao pórtico com carregamentos iguais nos pilares, quinta coluna $\theta$ pilar ligado articuladamente no topo pórtico transversal com carregamento diferenciado nos pilares, na sexta coluna. Na última linha são ilustradas as representações dos vínculos dos pilares de forma a obter a comparação dos cinco tipos de pilares. Os valores das constantes " $\alpha_{T}$ e $\alpha_{R}$ " representam 0 aumento da rigidez do pilar exercidos pelos vínculos elásticos que estão representados em relação ao pilar isolado.

Analisando os resultados da Tabela V-2, conclui-se:

a) Esta análise do pórtico transversal considera a rigidez da ligação do topo do pilar com o elemento estrutural de cobertura e a rigidez do pilar menos carregado agindo em favor do pilar mais carregado. A interpretação dos dois efeitos pode ser dada através da análise do pilar isolado (I), recebendo a contribuição da rigidez elástica (IV), devido a ligação pilartrave, com pilares igualmente carregados e recebendo a contribuição da rigidez elástica $(\mathrm{V})$ devido à diferença das açōes entre os pilares sem a rigidez da ligaçăo pilar-trave, desta forma: 


$$
\begin{aligned}
& W_{c r}=35,90=18,17 \cdot 1,976 \\
& W_{c r}=35,90 \cong 18,17 \cdot 1,43 \cdot 1,388 \\
& \text { (I) (IV) (V) }
\end{aligned}
$$

Para o presente exemplo numérico, a ligaçáo pilar-trave contribui para 0 aumento de $43 \%$ no parâmetro crítico do pótico e a contribuição do pilar menos carregado contribui para o aumento de $38,8 \%$ para o parâmetro crítico do pórtico. Portanto, os dois efeitos contribuem simultaneamente em $98 \%$ no aumento do parâmetro crítico do pórtico em relação ao pilar isolado sem nenhum vínculo na ligação de topo.

b) Comparando com a análise anterior, observa-se através da Tabela $\mathrm{V}-2$, que a falta da análise de conjunto do pórtico em relação a análise isolada do pilar (II) ou (III) com vínculos hipotéticos, pode fornecer valores muito discrepantes comparados com o comportamento real da estrutura aporticada.

c) Considerando que os resultados do programa tipo I, do presente trabalho são considerados precisos, a análise do pórtico transversal com as vinculaçōes contínuas, pode fornecer o parâmetro crítico " $\mathrm{W}_{\mathrm{cr}}$ " e os comprimentos efetivos de flambagem para a utilização das expressōes da AISE ${ }^{2}$. Desta forma, melhora-se a análise através do comportamento completo do pórtico plano.

d) A utilização de ábacos para parâmetros de flambagem de pórticos, que consideram as rigidezes de vigas e pilares de pórticos múltiplos fornecidos por várias normas, é inviável na maioria dos casos de pilares de edifícios industriais, pois esses ábacos só valem para vigas e pilares totalmente prismáticos $e$ igualmente carregados com instabilidade simultânea, no regime elástico. Portanto, a presente análise considerando 0 pórtico completo com a utilização do proposto programa, atende as necessidades de obtenção dos comprimentos efetivos de forma precisa e com pouco gasto computacional.

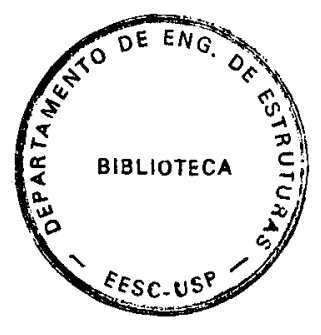




\subsection{EXEMPLO NUMÉRICO 3}

A fim de comprovar a validade do processo proposto para a determinação do carregamento crítico de instabilidade geral, de pilares de edifícios industriais constituídos de seçōes transversais abertas, tendo comportamento tridimensional, será considerada uma estrutura formada por chapas de aço de $0,4 \mathrm{~cm}$ de espessura, apresentando o perfil em forma de I com as dimensões e características geométricas indicadas na Fig.V-5.

Será suposto que o elemento estrutura seja engastado em uma extremidade e livre na outra, carregado na extremidade livre por uma ação concentrada posicionada exatamente no centro de gravidade da seção transversal, para determinar o valor do momento crítico de instabilidade geral através da obtenção da força crítica.

Para discretizar as seções, os diafragmas transversais foram colocados nas duas extremidades e espaçados em $45 \mathrm{~cm}$, ao longo do eixo longitudinal com a relação $\mathrm{c} / \mathrm{b}=2,25$ para a alma e com a relação $\mathrm{c} / \mathrm{b}=9,0$ para a mesa do perfil. A estrutura é , então, discretizada em cinco painéis com as coordenadas deslocamentos da estrutura discretizada mostrada na Fig.V-5. Os vínculos rígidos de apoio ocorrerăo no primeiro diafragma através das coordenadas de 1 a 9 , representando o engastamento. Todas as demais coordenadas ficarão livres para deformação, lembrando que em cada diafragma, as coordenadas 1,2 e 3 representam movimentos de corpo rígido da seção transversal e as coordenadas de 4 a 9 representam movimentos axiais, sendo possivel analisar os empenamentos da seção através deles. A única ação concentrada do problema está posicionada no décimo primeiro diafragma, na coordenada vertical 2, portanto, para 0 sistema a ação estará agindo na coordenada 92 e com sinal negativo por estar na posição contrária ao sistema de referência. Desta forma, a estrutura fica representada por nove coordenadas deslocamentos em cada diafragma e noventa e nove coordenadas deslocamentos no sistema. 

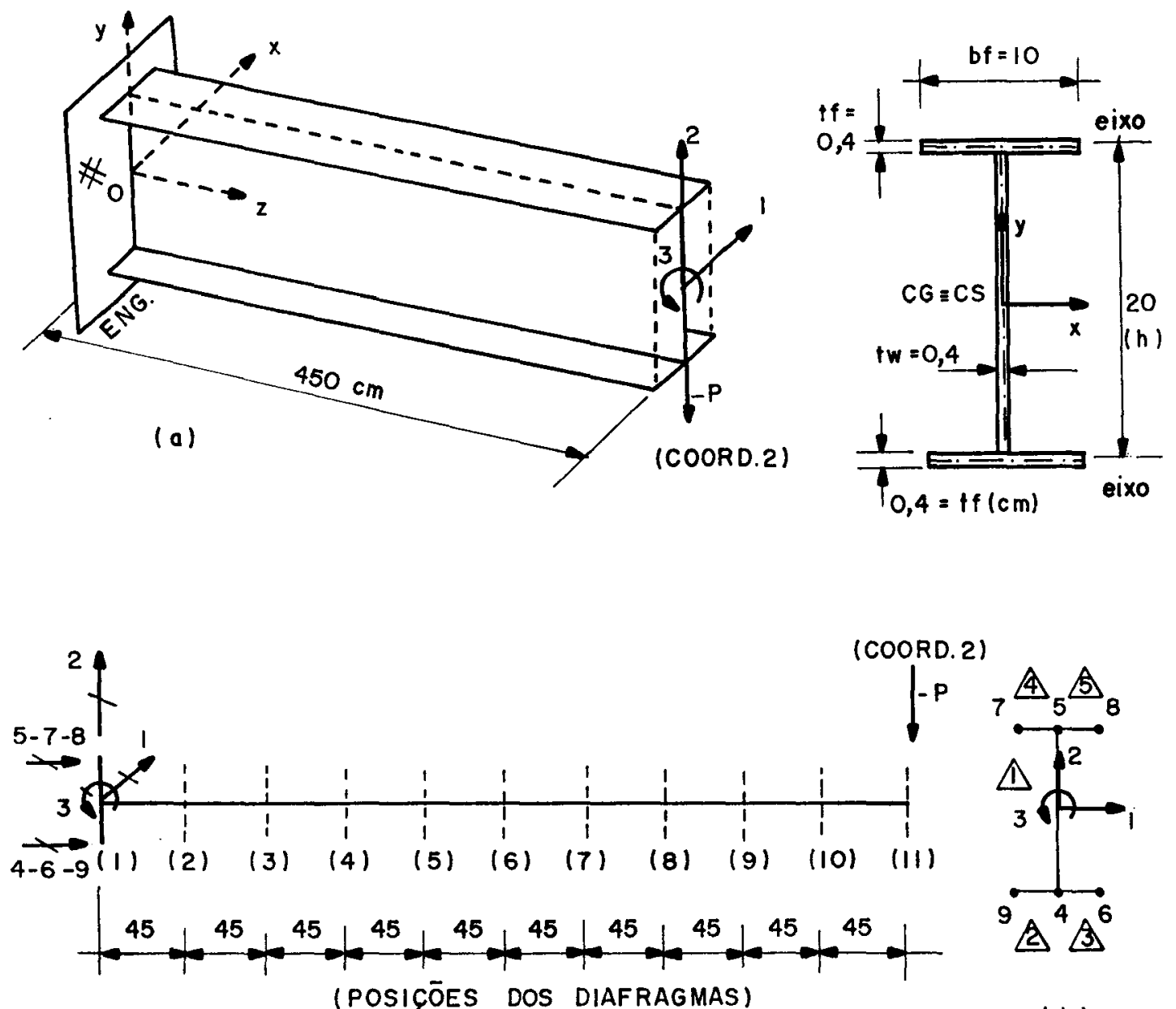

$$
\begin{array}{ll}
E=21000 \mathrm{kN} / \mathrm{cm}^{2} & ; I_{x}=1051 \mathrm{~cm}^{4} \\
G=E / 2,6 & ; I_{y}=66,77 \mathrm{~cm}^{4} \\
A=15,84 \mathrm{~cm}^{2} & W_{x}=105,10 \mathrm{~cm}^{3}
\end{array}
$$

Figura V-5 a) Características Geométricas; b) Sistema de Coordenadas Deslocamentos e Posições dos Diafragmas para Discretização

Aplicando o processo apresentado, determinou-se 0 valor do parâmetro crítico igual a 3,2636 utilizando tolerância de $0,01 \%$ e com limite de proporcionalidade igual a $25 \mathrm{kN} / \mathrm{cm}^{2}$. Obtendo-se também a tensão máxima igual a $13,97 \mathrm{kN} / \mathrm{cm}^{2}$ e $\mathrm{M}_{\max }=1468,62 \mathrm{kN} . \mathrm{cm}$.

Utilizando novamente $\circ$ programa para $\sigma_{p}=12,5 \mathrm{kN} / \mathrm{cm}^{2} \rightarrow$ $\rightarrow P_{\mathrm{cr}}=3,0475 \mathrm{kN}$ com a mesma tolerância. 
Os resultados obtidos foram verificados analiticamente, através da fórmula ${ }^{(25)}$ :

$$
M_{c r}=\frac{\pi}{(K L)} \sqrt{E \cdot I_{y} \cdot G \cdot J_{T}} \cdot \sqrt{1+W^{2}}
$$

onde,

$$
W=\frac{\pi}{(K L)} \sqrt{\frac{E \cdot C_{W}}{G \cdot J_{T}}}
$$

segundo $\mathrm{CHEN}^{25}, \mathrm{pg} .339$, adota-se

$$
K=0,8 \rightarrow W=1,250
$$

segundo VLASSOV ${ }^{32}$, adota-se

$$
\mathrm{K}=0,783 \rightarrow \mathrm{W}=1,277 \text { (adotado) }
$$

Para perfil $I \rightarrow C_{W}=\frac{t_{f} \cdot b_{f}^{3} \cdot h^{2}}{24} \quad \therefore \quad C_{W}=\frac{0,4 \cdot 10^{3} \cdot 20^{2}}{24}=6666,67$

$$
\text { para } d=h+t_{f}, \quad J_{T}=\frac{2 \cdot b_{f} \cdot t_{f}^{3}+\left(d-2 t_{f}\right) t_{W}^{3}}{3} \quad \therefore \quad J_{T}=0,8448
$$

Para os termos definidos $\rightarrow M_{c r}=1414,54 \mathrm{kN} \cdot \mathrm{cm}$

Portanto, $P_{c r}=\frac{M_{c r}}{450} \rightarrow P_{c r}=3,143 \mathrm{kN}$

(supondo regime totalmente elástico). 
Comparando com o resultado do programa tipo II proposto, a diferença ficou na ordem de $3,695 \%$.

Apesar da análise apresentar resultados muito próximos, observa-se 0 fato de que as expressões analíticas, para este caso, não serem exatas necessitando de parâmetros de ajuste em suas soluções. Portanto, necessitando de uma análise numérica mais sofisticada como, por exemplo - programa ANSYS, para garantir a potencialidade do processo de discretização apresentado. Esta nova análise, utilizando o programa ANSYS, será apresentada no próximo exemplo numérico.

\subsection{EXEMPLO NÚMERO 4}

Utilizando o exemplo número 3 , será realizada uma análise complementar comparando os resultados obtidos no processo proposto e os resultados obtidos pelo programa ANSYS. O perfil do tipo I, formado por chapas, será desdobrado em vários exemplos variando as espessuras das chapas, desde as mais finas até as mais grossas, com o objetivo de variar as características geométricas como $\circ$ " $\mathrm{J}_{T}$ " momento de inércia à torção $e$ "Jw" momento setorial de inércia.

Para o processo proposto, a modelagem da viga foi mantida, ou seja, a discretização ao longo do eixo longitudinal foi efetuada em dez partes. A seção transversal do perfil foi representada em cinco painéis. Portanto, a viga ficou discretizada em cinquenta elementos de painel. As espessuras das chapas de alma e de mesa foram mantidas constantes e definidas sete exemplos diferentes para as seguintes espessuras: $0.4 \mathrm{~cm} ; 0.6 \mathrm{~cm} ; 0.8 \mathrm{~cm}$; $1.0 \mathrm{~cm} ; 1.2 \mathrm{~cm} ; 1.4 \mathrm{~cm} ; \theta 1.6 \mathrm{~cm}$.

A modelagem da viga para a utilização do programa ANSYS teve como elemento escolhido o "SHELL63". Este elemento de casca é composto de quatro nós com seis graus de liberdade para cada um, possibilitando a análise dentro e fora de seu plano, inclusive sob o aspecto da estabilidade. A discretização ao longo do eixo longitudinal foi efetuada em quarenta $e$ cinco partes, a alma foi dividida em quatro partes e ambas as mesas foram divididas em duas partes totalizando trezentos e sessenta elementos de 
casca para a discretização total da referida viga. As espessuras dos elementos de casca também seguiram as mesmas variações já mencionadas produzindo sete exemplos diferentes. Esta modelagem foi exaustivamente testada para garantir a precisão dos resultados, com todos os elementos medindo $5,0 \mathrm{~cm}$ por $10,0 \mathrm{~cm}$.

As análises de instabilidade utilizando o programa ANSYS foram efetuadas através de duas formas distintas: "Eigenvalue Buckling Analysis", utilizando teoria de segunda ordem com ponto de bifurcação e "Nonlinear Buckling Analysis", utilizando teoria de terceira ordem para grandes deslocamentos utilizando a não linearidade geometricamente exata.

As Fig.V-6, ilustra a viga discretizada em elementos de casca, pelo programa ANSYS, e a Fig.V-7 ilustra a posição da ação unitária localizada no centro de gravidade da viga, na extremidade do balanço.

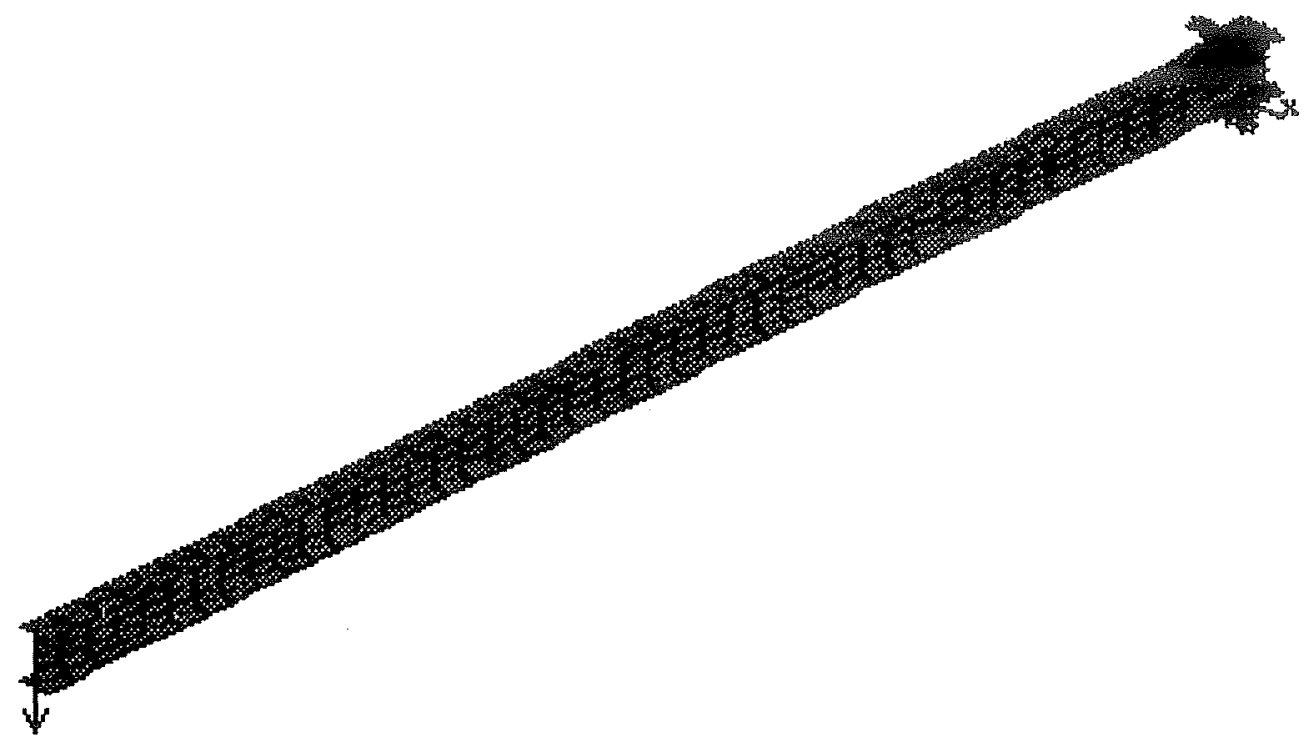

Figura V-6 Modelagem da Viga em Balanço, Feita pelo ANSYS 


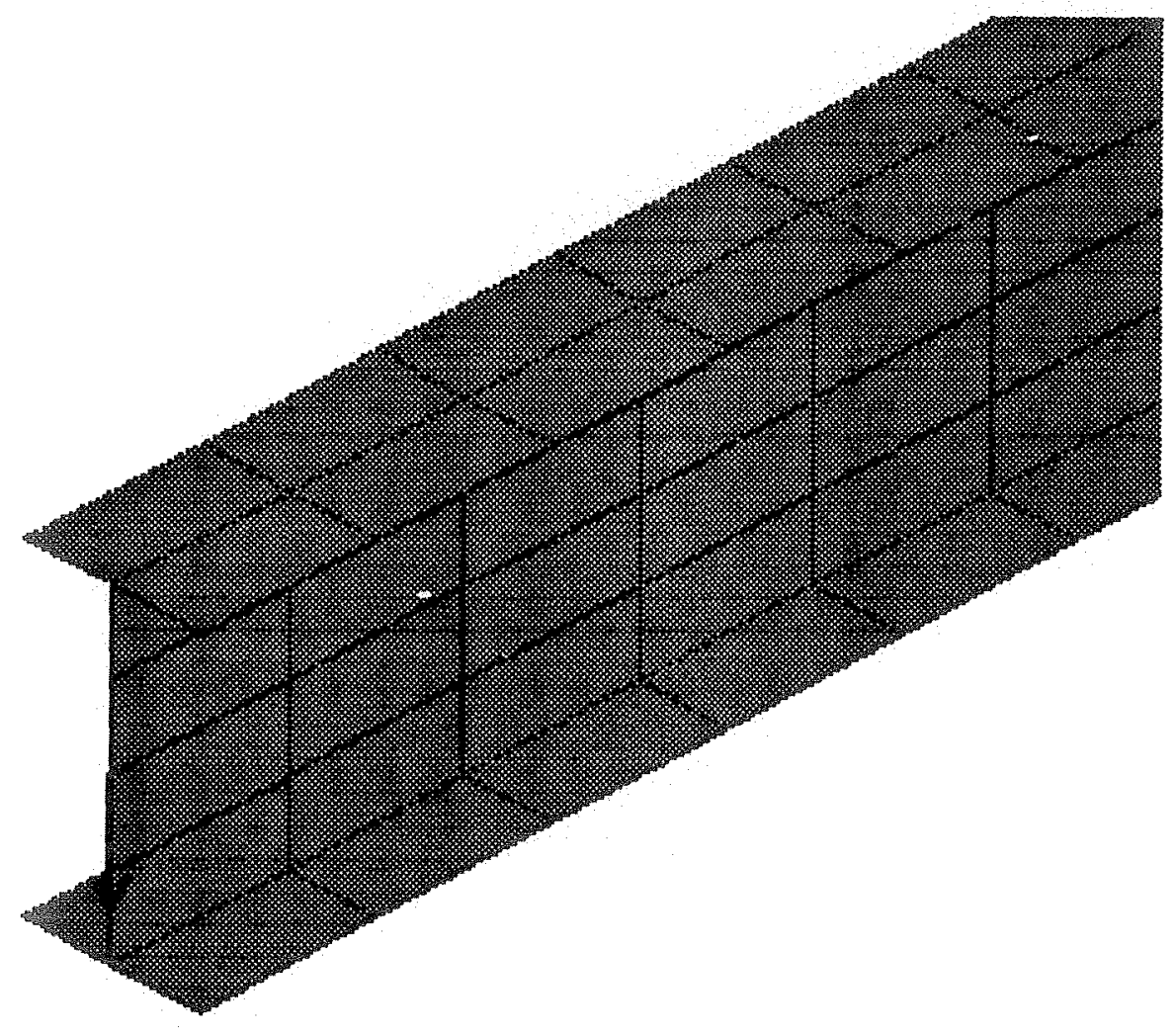

Figura V-7 Vista Ampliada da Modelagem da Viga em Balanço com Ação Unitária Aplicada no CG da Seção da Extremidade Livre

Os processamentos foram realizados, inicialmente, através da análise chamada "Eigenvalue Buckling Analysis", para todas as espessuras já citadas. Os resultados foram lançados na Tab.V-3 e no diagrama da Fig.V-8. Posteriormente, os processamentos foram realizados através das análises mais complexas e demoradas, chamadas "Nonlinear Buckling Analysis", também para todos os casos citados. Os resultados obtidos confirmaram todos os resultados da análise anterior, realizada pelo programa ANSYS, com a diferença de que esta última análise teve a capacidade de medir uma reserva de resistência pós-flambagem para os casos analisados. 


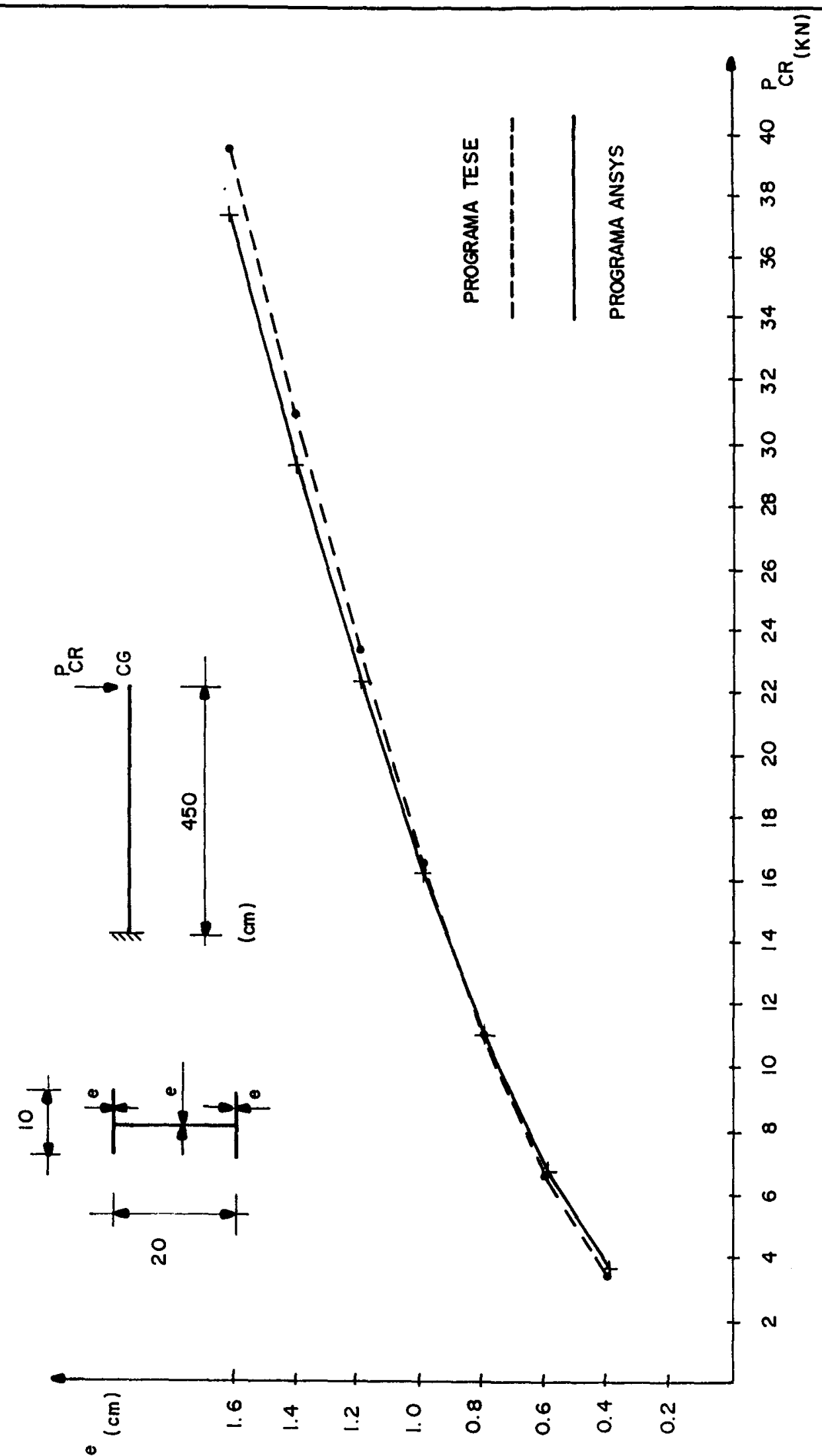

Figura V-8 Diagramas dos Resultados de "P $P_{C R} \times$ e" para a Viga do Exemplo Número 4, Comparando o Programa Proposto com o Programa ANSYS 


\begin{tabular}{|c|c|c|}
\hline $\begin{array}{c}\text { Espessura } \\
\mathbf{t}_{\mathbf{f}}=\mathbf{t}_{\mathbf{w}}=\mathbf{e}\end{array}$ & $\begin{array}{c}\text { Programa } \\
\text { ANSYs }\end{array}$ & $\begin{array}{c}\text { Programa } \\
\text { proposto }\end{array}$ \\
\hline & & \\
\hline 0.4 & 3.5885 & 3.2636 \\
\hline 0.6 & 6.8263 & 6.5832 \\
\hline 0.8 & 10.9681 & 11.0211 \\
\hline 1.0 & 16.0621 & 16.5682 \\
\hline 1.2 & 22.1396 & 23.2092 \\
\hline 1.4 & 29.2244 & 30.9202 \\
\hline 1.6 & 37.3391 & 39.6715 \\
\hline & & \\
\hline
\end{tabular}

Tabela V-3 Resultados comparativos " $P_{C R} \times$ e" do Exemplo Número 4

Os resultados demonstraram que apesar de existirem diferenças, principalmente para os casos de espessuras muito finas ou de espessuras muito grossas, evidenciam que o processo proposto consegue produzir bons resultados, para os casos analisados.

Fica evidente que o programa ANSYS, com mais recursos consegue produzir resultados mais precisos, porém necessitando de muitos elementos com muitos graus de liberdade para sua finalidade. Neste caso, a comparação deve ser feita, também levando-se em consideração que o custo de processamento para realizar a análise não linear é muito grande e que a análise em teoria de segunda ordem ainda é muito útil para análises de estabilidade. Em casos mais complexos, a análise não linearmente exata pode indicar qual o grau de segurança que se pode atingir em relação aos processos utilizando auto-valores e auto-vetores.

Para o exemplo analisado, que foi subdividido em sete casos, a análise de terceira ordem apenas referendou a análise de segunda ordem, 
ambas realizadas pelo programa ANSYS, que por sua vez também foram comparadas com o processo proposto.

\subsection{EXEMPLO NÚMERO 5}

Utilizando o exemplo número 3, será agora acrescentada uma ação unitária de compressão, distribuída na seção transversal, na extremidade livre do elemento estrutural, para obtenção de ações combinadas.

As açōes foram colocadas no diafragma número onze, através das coordenadas de quatro a nove. Tanto a açăo unitária transversal como a ação unitária normal serão consideradas como cargas vivas e serão incrementadas no processo.

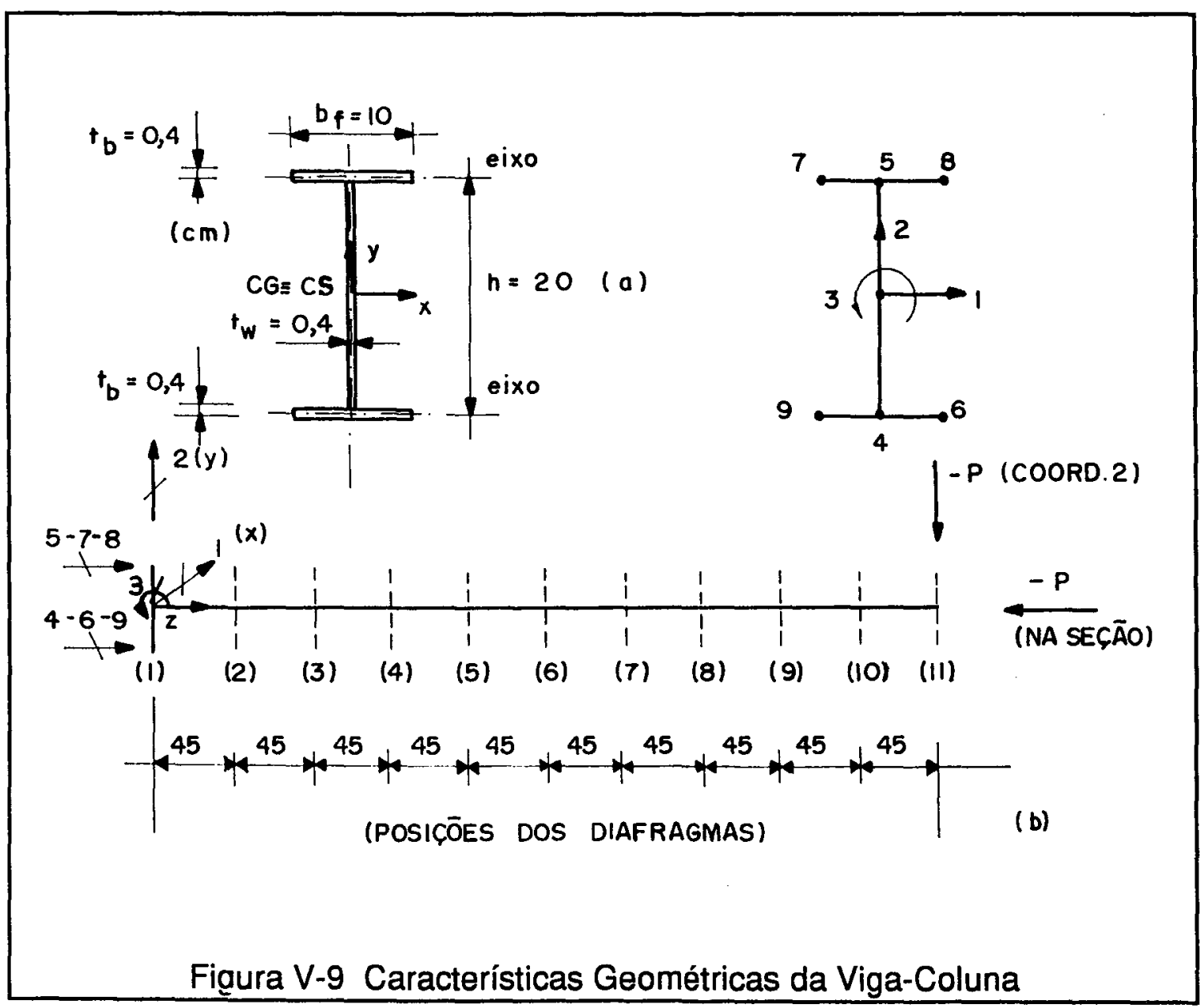


Para distribuir uniformemente a ação unitária na seção transversal, o carregamento no diafragma onze fica: coord. $\underline{1}=$ zero, coord. $\underline{2}=-1,0$, coord. $\underline{3}=$ zero, coord. $\underline{4}=-0,3737$, coord. $\underline{5}=-0,3737$, coord. $\underline{6}=-0,063$, coord. $\underline{7}=-0,063$, coord. $\underline{8}=-0,063$ e coord. $\underline{9}=-0,063$.

Aplicando o processo apresentado, determinou-se o valor do parâmetro crítico igual a 3,00173, utilizando tolerância de $0,1 \%$ e $\sigma_{\mathrm{p}}=12,5 \mathrm{kN} / \mathrm{cm}^{2}$. Utilizando agora o programa para, $\sigma_{\mathrm{p}}=25 \mathrm{kN} / \mathrm{cm}^{2} \rightarrow \mathrm{P}_{\mathrm{cr}}=3,06 \mathrm{kN}$.

Utilizando a modelagem do exemplo 4, para a análise através do programa ANSYS, com o carregamento proposto neste exemplo, resultou 0 valor do parâmetro crítico de instabilidade igual a 3,3189 KN. Este valor, não muito próximo do obtido pelo processo proposto, já era de se esperar pois foi analisado apesar para espessura muito fina.

Estes valores são verificados analiticamente através das expressões de interação da AISC $\left(1.6\right.$ - 1a) ${ }^{49}$, sem levar em consideração os coeficientes de segurança, como apresentados a seguir:

$\frac{f_{a}}{F_{a}}+\frac{f_{b} \cdot C_{M}}{F_{b}\left(1-\frac{f_{a}}{F_{\theta x}}\right)} \leq 1$, já citada em ${ }^{(1)}$, porém de forma tridimensional.

Considerando $\mathrm{W}_{\mathrm{cr}}=3,06$ para as ações transversal e axial,

$f_{a}=\frac{P}{S}=\frac{3,06}{15,84}=0,1932 \mathrm{kN} / \mathrm{cm}^{2} ; f_{b}=\frac{M}{W}=\frac{3,06 \cdot 450}{105,1}=13,10 \mathrm{kN} / \mathrm{cm}^{2}$

$\left.\begin{array}{l}r_{x}=8,1456 ; \lambda_{x}=110,489 ; F_{a x}=16,9778 \mathrm{kN} / \mathrm{cm}^{2} \\ r_{y}=2,053 ; \lambda_{y}=438,38 ; F_{a y}=1,078 \mathrm{kN} / \mathrm{cm}^{2}\end{array}\right\}$ no regime elástico

$F_{b}=\frac{M_{c r}}{W}=\frac{1414,54}{105,1}=13,459 \mathrm{kN} / \mathrm{cm}^{2}$ (obtido no exemplo 3) 
$C_{M}=0,85$ para elementos deslocáveis.

$F_{e x}=F_{a x}=16,9778 \mathrm{kN} / \mathrm{cm}^{2}$

Substituindo na expressão (1):

$$
\begin{aligned}
& \frac{0,1932}{1,078}+\frac{13,10}{13,459} *\left[\frac{0,85}{1-\left(\frac{0,1932}{16,9778}\right)}\right]= \\
& =0,1792+0,97330(0,8598)=1,0165 \geq 1,(1,65 \%)
\end{aligned}
$$

Analiticamente, verifica-se um valor muito próximo ao proposto, com diferença de $1,65 \%$, porém, deve-se salientar que isto acontece sempre que a ação de flexão é preponderante à ação de compressão, pois o valor de " $\mathrm{C}_{\mathrm{M}}$ " adotado igual a 0,85 conforme recomendação de vários autores, se altera de acordo com a relação entre a flexão e a compressão normal.

Estes dois últimos exemplos serviram para mostrar que para 0 carregamento crítico das estruturas são considerados os perfis de forma tridimensional, com seus efeitos de flexão, de torção e de flexo-torção.

A verificação da resistência e estabilidade de elementos estruturais submetidos a esforços combinados de flexão e de força normal, pode ser realizada através do carregamento crítico de instabilidade geral, proposto com o programa tipo II. Esta análise poderá ser feita desde que a estrutura esteja no regime elástico e para garantir esta hipótese o programa solicita a tensão limite de proporcionalidade do material.

O uso do programa proposto só não analisa as condiçōes de estabilidade local das chapas, ou seja, flambagem de alma e flambagem de mesa dos perfis. Portanto, é admitido relações de aba e espessura no perfil utilizado, suficientes para garantir este tipo de estabilidade. 


\subsection{EXEMPLO NUMÉRICO 6}

Com a finalidade de aplicar todos os conceitos apresentados até o momento, será mostrado neste exemplo numérico a verificação da estabilidade do pilar mais carregado de um edifício industrial, utilizando o programa de carregamento crítico de instabilidade geral, para pórtico constituído de trave em treliça e pilares de seção composta variável ao nível da viga de rolamento. Será admitida a tensão limite de proporcionalidade para o aço igual a $12,5 \mathrm{kN} / \mathrm{cm}^{2}$ e, a título de análise comparativa será também admitida hipoteticamente com $250 \mathrm{kN} / \mathrm{cm}^{2}$.

A estrutura escolhida para esta análise será a mesma do exemplo número 1, Fig. V-1, efetuando a análise de forma completa. Os resultados são analisados comparativamente utilizando ambos os programas, do tipo II e também do tipo I, segundo os modelos da Fig.V-10.

As características das seções transversais são apresentadas na Fig.V-11. Inicialmente os pilares serão constituídos com as seçōes 1 e 2 e posteriormente serão constituídos com as seções 1 e 3.

As barras da treliça de cobertura foram consideradas constituídas de perfis em dupla cantoneira de abas iguais: 3 1⁄2" $\times 31 \frac{1}{2}$ " $\times 1 / 2$ ", com área da seção transversal igual a $41,94 \mathrm{~cm}^{2}$.

Será suposto que os pilares serăo engastados na base, através dos impedimentos aos deslocamentos de todas as coordenadas dos diafragmas das bases. Os carregamentos ocorrerão aos niveis dos diafragmas 11, 12 , 14 e 16, Fig.V-10. Para o pilar da esquerda, $P_{1 E} / 2$ ocorrerá no diafragma 16 e 14, ambos na coordenada 8 da referência local no sentido negativo; $P_{2 E}$ ocorrerá no diafragma 11 na coordenada 11 da referência local no sentido negativo e $P_{H E}$ ocorrerá no diafragma 12 na coordenada 1 da referência local no sentido positivo. Para o pilar da direita as ações ocorrerão nos mesmos níveis dos diafragmas do pilar da esquerda e nos mesmos números de coordenadas de referência local. As ações foram consideradas como cargas vivas no processo. 

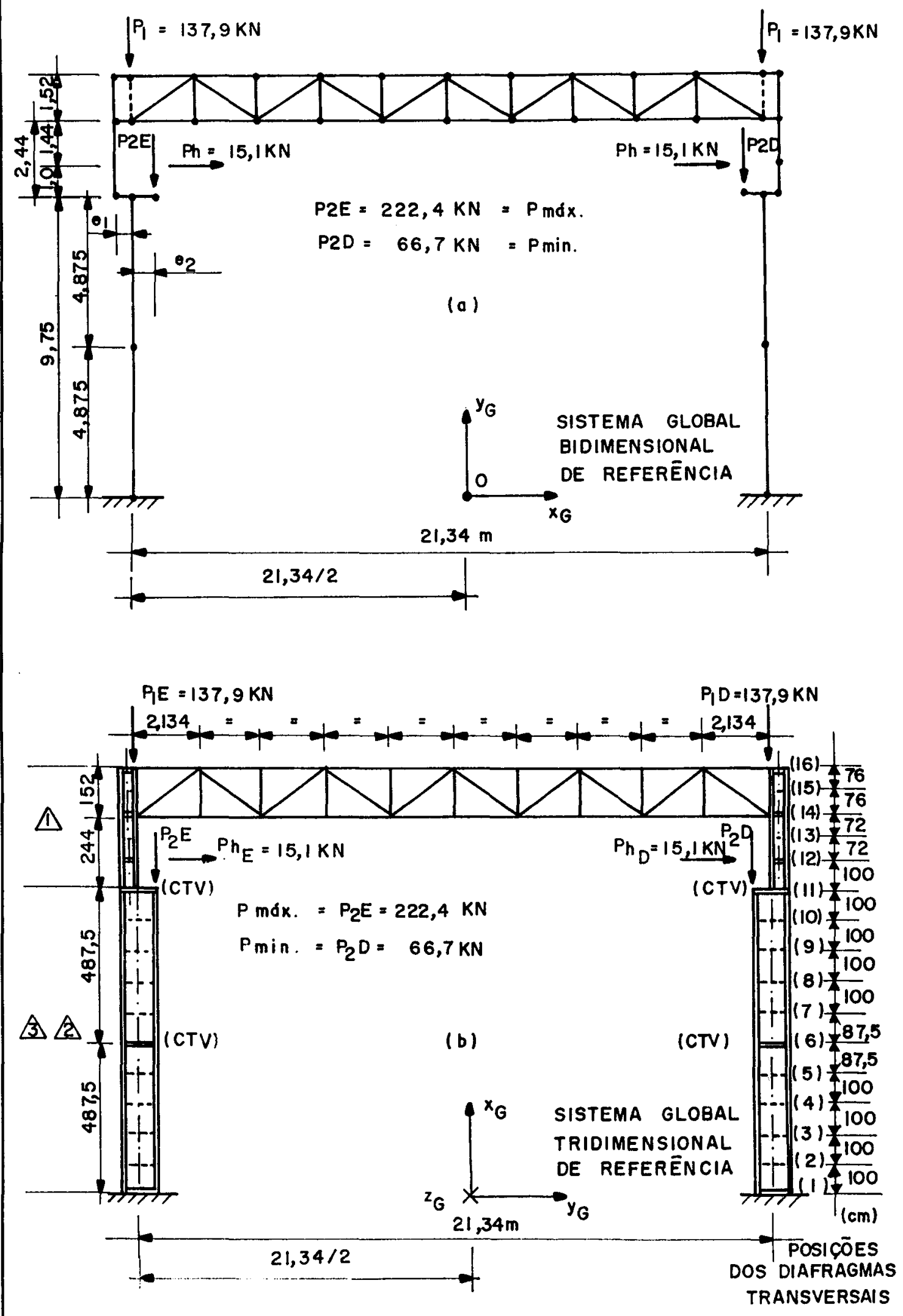

Figura V-10 Modelos Estruturais para Análise 


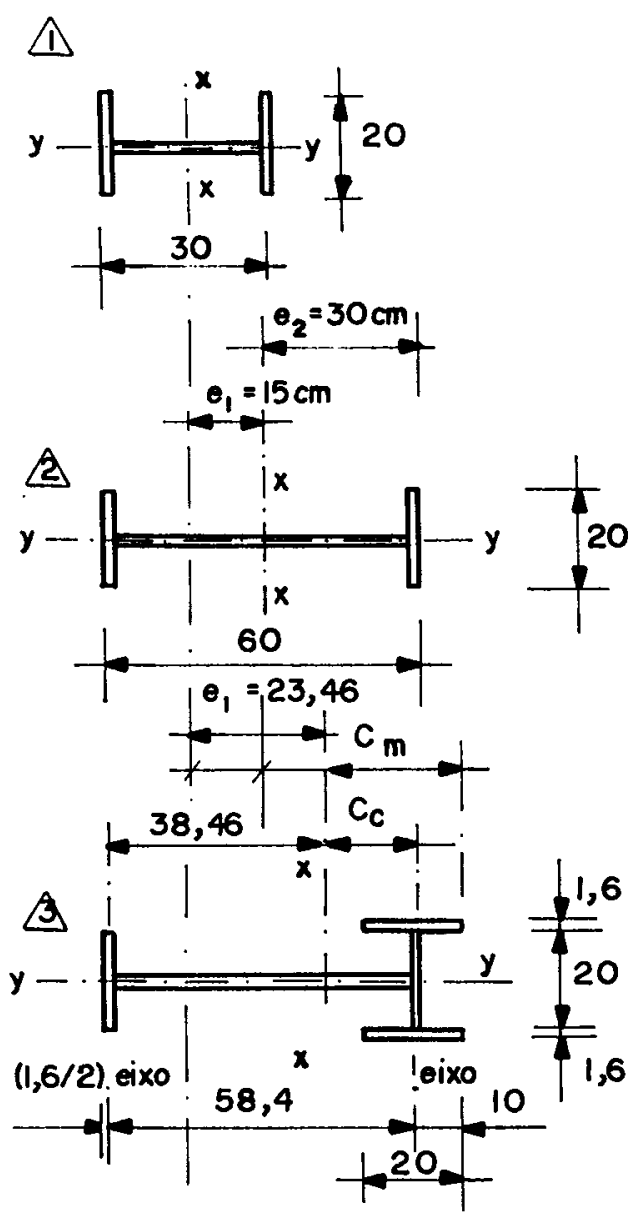

$$
\begin{array}{ll}
A=90,8 \mathrm{~cm}^{2} & \mathrm{I}_{x}=14522 \mathrm{~cm}^{4} \\
\mathrm{bf}=20,0 \mathrm{~cm} & \mathrm{r}_{x}=12,65 \mathrm{~cm} \\
\mathrm{tf}=1,6 \mathrm{~cm} & S_{x}=968,13 \mathrm{~cm}^{3} \\
\mathrm{~h}_{W}=26,8 \mathrm{~cm} & \mathrm{I}_{y}=2135,6 \mathrm{~cm}^{4} \\
d=30,0 \mathrm{~cm} & \mathrm{r}_{y}=4,85 \mathrm{~cm} \\
\mathrm{t}_{W}=1,0 \mathrm{~cm} & S_{y}=213,56 \mathrm{~cm}^{3}
\end{array}
$$

$A=137,8 \mathrm{~cm}^{2} \quad I_{x}=74435 \mathrm{~cm}^{4}$

$b f=20,0 \mathrm{~cm} \quad r_{x}=23,24 \mathrm{~cm}$

$\mathrm{tf}=1,6 \mathrm{~cm}$

$S_{x}=2481,17 \mathrm{~cm}^{3}$

$h_{w}=56,8 \mathrm{~cm}$

$r_{T}=4,92 \mathrm{~cm}$

$d=60,0 \mathrm{~cm}$

$\mathrm{l}_{\mathrm{y}}=2143,7 \mathrm{~cm}^{4}$

I $w=1,3 \mathrm{~cm}$

$r_{y}=3,96 \mathrm{~cm}$

$S_{y}=214,37 \mathrm{~cm}^{3}$

$\begin{array}{ll}A=201,84 \mathrm{~cm}^{2} & I_{x}=114795,43 \mathrm{~cm}^{4} \\ C_{m}=29,94 \mathrm{~cm} & S_{x}=3840,20 \mathrm{~cm}^{3} \\ C c=19,94 \mathrm{~cm} & I_{y}=9623,31 \mathrm{~cm}^{4} \\ r_{x}=23,87 \mathrm{~cm} & S_{y}=829,60 \mathrm{~cm}^{3} \\ r_{T}=9,053 \mathrm{~cm} & r_{y}=6,91 \mathrm{~cm}\end{array}$
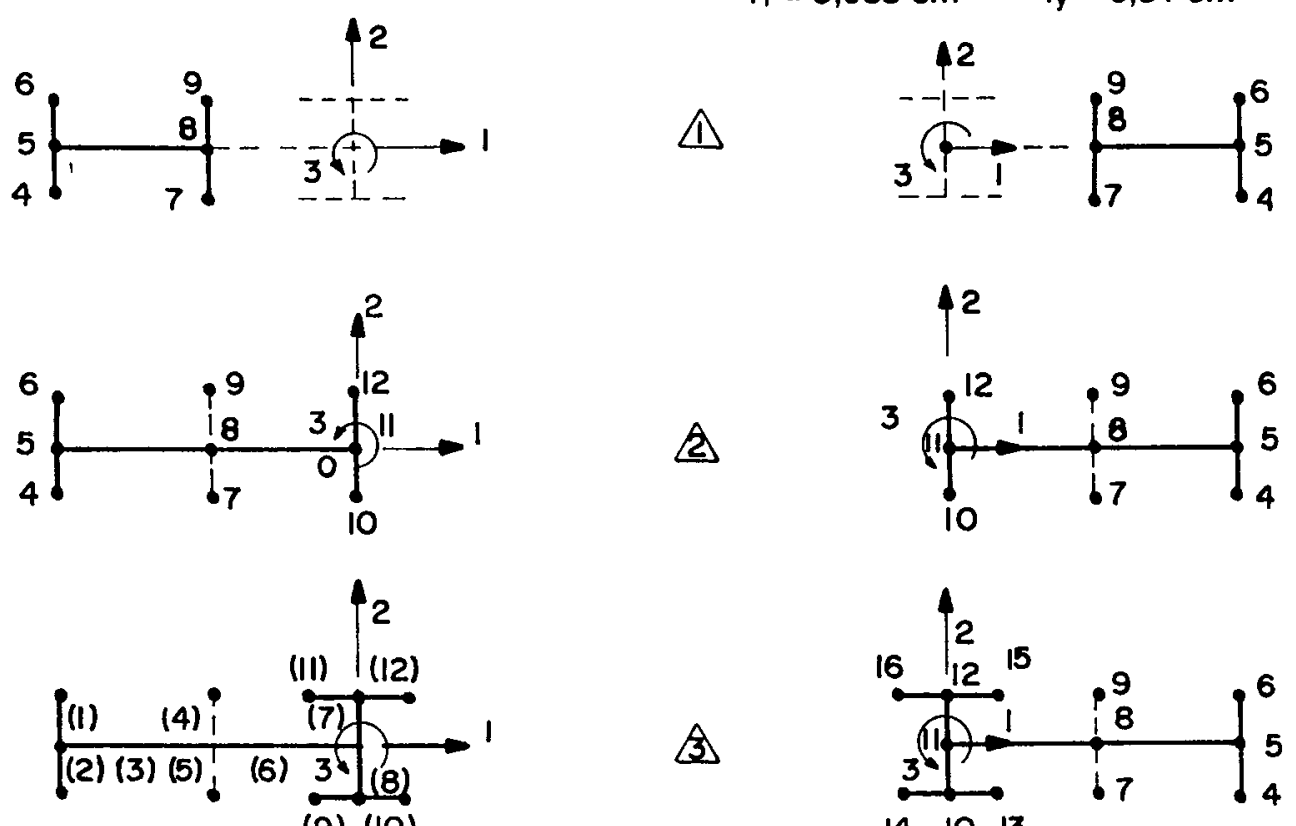

11

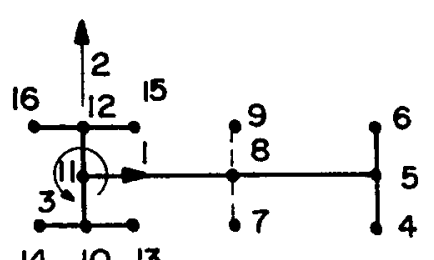

(9) $(10)$

$14 \quad 10 \quad 13$

Figura V-11 Características Geométricas das Seções Transversais e Sistema de Coordenadas Locais para o Exemplo Numérico 6 
Os espaçamentos dos diafragmas transversais seguirão as relações de $c / b_{\max }=3,33$ para as almas e $c / b_{\max }=10$ para as mesas dos pertis. Os pilares foram discretizados em doze painéis em todas as seçōes transversais. A variação brusca da seção é obtida impondo espessura igual a zero para os segmentos de painéis que se deseja eliminar. Portanto, a numeração das coordenadas locais dos diafragmas deve seguir a mesma ordem do primeiro ao último diafragma para cada pilar. 0 programa trabalhará com todos os segmentos dos painéis, porém as rigidezes dos segmentos eliminados serão eliminadas na matriz de rigidez do sistema, sem que este fato incorra na singularização da matriz.

Os vínculos rígidos ocorrerão tanto nas bases dos pilares, diafragma 1 , como nos pontos de contraventamentos da estrutura, diafragmas $6,11,12$, 14 e 16. Estes vínculos rígidos agirão nas coordenadas 1, 2 e 3 para 0 diafragma 1 pois representam a rigidez ao deslocamento da seção transversal, como corpo rígido e agirão nas coordenadas 2 e 3 para os diafragmas restantes de contraventamentos. Como forma alternativa da análise vínculos elásticos podem ser impostos nas coordenadas 2 e 3 , dos diafragmas contraventados.

Aplicando o processo proposto, determinou-se os seguintes valores para estas análises de instabilidade:

a) Pórtico com pilares de seções 1 e 2 considerado plano, ou seja, considerado com contenção lateral contínua, programa tipo I, utilizando $\mathrm{cf}=1,867$.

$$
\begin{aligned}
& \sigma_{\mathrm{p}}=250 \mathrm{kN} / \mathrm{cm}^{2} \rightarrow \mathrm{W}_{\mathrm{cr}}=15,6587 \\
& \sigma_{\mathrm{p}}=12,5 \mathrm{kN} / \mathrm{cm}^{2} \rightarrow \mathrm{W}_{\mathrm{cr}}=1,5906
\end{aligned}
$$

b) Pórtico com pilares de seçōes 1 e 3 considerado plano, ou seja, considerado com contenção lateral contínua, programa tipo I, utilizando $\mathrm{cf}=2,733$.

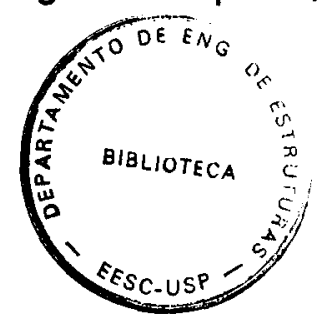


$\sigma_{\mathrm{p}}=250 \mathrm{kN} / \mathrm{cm}^{2} \rightarrow \mathrm{W}_{\mathrm{cr}}=22,2591$

$\sigma_{\mathrm{P}}=12,5 \mathrm{kN} / \mathrm{cm}^{2} \rightarrow \mathrm{W}_{\mathrm{cr}}=2,2407$

c) Pórtico com pilares de seção 1 e 2 discretizados, tridimensionais, com contenção lateral em todos os diafragmas, programa tipo II.

$\sigma_{\mathrm{P}}=250 \mathrm{kN} / \mathrm{cm}^{2} \rightarrow \mathrm{W}_{\mathrm{cr}}=8,7853$

$\sigma_{\mathrm{P}}=12,5 \mathrm{kN} / \mathrm{cm}^{2} \rightarrow \mathrm{W}_{\mathrm{cr}}=1,6708$

d) Pórtico com pilares de seção 1 e 2 discretizados, tridimensionais, com contenção lateral apenas nos contraventamentos, diafragmas 16 , $14,12,11,6$ e 1, programa tipo II.

$\sigma_{\mathrm{p}}=250 \mathrm{kN} / \mathrm{cm}^{2} \rightarrow \mathrm{W}_{\mathrm{cr}}=7,352$

$\sigma_{\mathrm{p}}=12,5 \mathrm{kN} / \mathrm{cm}^{2} \rightarrow \mathrm{W}_{\mathrm{cr}}=1,6708$

e) Pórtico com pilares de seção 1 e 3 discretizados, tridimensionais, com contenção lateral em todos os diafragmas, programa tipo II.

$\sigma_{\mathrm{P}}=250 \mathrm{kN} / \mathrm{cm}^{2} \rightarrow \mathrm{W}_{\mathrm{cr}}=20,047$

$\sigma_{\mathrm{P}}=12,5 \mathrm{kN} / \mathrm{cm}^{2} \rightarrow \mathrm{W}_{\mathrm{cr}}=2,3516$ 
f) Pórtico com pilares de seção 1 e 3 discretizados, tridimensionais, com contenção lateral apenas nos contraventamentos, diafragmas 16 , $14,12,11,6$ e 1 , programa tipo II.

$$
\begin{aligned}
& \sigma_{\mathrm{P}}=250 \mathrm{kN} / \mathrm{cm}^{2} \rightarrow W_{\mathrm{cr}}=15,90 \\
& \sigma_{\mathrm{P}}=12,5 \mathrm{kN} / \mathrm{cm}^{2} \rightarrow W_{\mathrm{cr}}=2,3516
\end{aligned}
$$

Com estes resultados, verifica-se a importância do aumento da rigidez na seção 3 comparada com a seção 2 no plano perpendicular ao plano do pórtico. As diferenças entre os resultados do programa tipo I com o programa tipo II são menores para a seção 3, pois apresenta maior rigidez à torção na seção.

Com esta análise, pode-se garantir qual o carregamento máximo da estrutura através do parâmetro crítico $W_{\text {cr }}$. Através do carregamento imposto, os programas analisam a estabilidade da estrutura, indicando qual parâmetro multiplicador do carregamento fará a estrutura atingir seu limite de estabilidade. Portanto, para parâmetros menores do que o valor unitário significa que o carregamento inicialmente imposto já levaria a estrutura a uma situação de instabilidade e em caso contrário, para parâmetro maiores do que o valor unitário, significa que o carregamento inicial imposto poderia ser majorado até alcançar a instabilidade. Neste caso, é importante a utilização da tensão limite de proporcionalidade para que a estrutura também seja verificada em sua resistência no regime elástico do material.

Os resultados dos itens a) e b) são utilizados nos casos em que as estruturas são verificadas em sua estabilidade através das fórmulas de interação das normas, através do conceito do comprimento efetivo de flambagem. $E$ com $o$ intuito de manter a estrutura no regime elástico do material, pode-se utilizar a tensão limite de proporcionalidade no processo.

Os resultados dos itens c), d), e) e f) mostram que a análise de instabilidade pode ser realizada de forma global através do processo proposto. A análise dos pilares discretizados considera seçōes abertas de paredes delgadas na forma tridimensional. A variação brusca de seção acarreta alteração no comportamento do pilar, visto que esta variação 
provoca variação dos eixos longitudinais, consequentemente alterando os esforços de flexo-torção nas seções. As aplicações das ações ocorrem em pontos de coordenadas discretas, contribuindo também para alteração dos esforços nas seções. 


\section{CAPÍtULO VI}

\section{CONCLUSÕES E CONSIDERAÇÕES FINAIS}

Para análise de instabilidade de pilares isolados de edifícios industriais, seguindo as recomendações da AISE ${ }^{2}$, pode-se constatar as dificuldades em se obter os comprimentos efetivos de flambagem de pilar no plano do pórtico transversal, através das tabelas disponíveis na própria publicação da AISE $^{2}$ como em outras publicações citadas no capítulo 5 . Para esta finalidade, é proposto no presente trabalho o processo do carregamento crítico de instabilidade elástica por flexão de pilares de edifícios industriais, programa tipo I, capaz de determinar os parâmetros de instabilidade do pilar considerado isolado. A análise é feita com muita precisão e seus resultados são considerados exatos, quando comparados com o processo analítico de Anderson \& Woodward ${ }^{9}$, sob as hipóteses adotadas mostradas no capítulo 5 , dispensando 0 uso de tabelas normalmente incompletas.

A análise de instabilidade de pilares agora integrados ao pórtico transversal, apresenta-se como uma forma mais rigorosa de verificação da estrutura e revela valores discrepantes se comparados com a análise de pilar isolado. O programa tipo I fornece parâmetros críticos de elementos de barras planas, podendo ser utilizado também em pórticos constituídos de elementos treliçados na cobertura ou até de pilares também treliçados. As análises podem ser realizadas considerando o efeito da força cortante, apesar desse efeito não apresentar variações significativas no parâmetro crítico, para edifícios industriais menos carregados.

Para análise convencional de verificação da estabilidade de um pilar de edifício industrial através do conceito do comprimento efetivo indicado pelas normas, o programa tipo I apresenta-se como ferramenta bastante eficiente para tal finalidade, considerando a estrutura como um todo incluindo todas as ações de cada carregamento. 
As análises foram realizadas sempre no regime elástico do material, porém, há de se ressaltar a importância de complementar este trabalho para - regime inelástico ( não linearidade física do material). Os exemplos apresentados, obtidos de artigos de vários autores, colocaram em evidência a forma convencional de obtenção dos parâmetros de estabilidade em meio elástico para utilizá-los em dimensionamentos independente do regime do material. Este procedimento leva a uma imprecisão dos resultados. Portanto, nos casos de análise em regime elástico em que os materiais não corresponderem aos regimes considerados, os perfis devem ser alterados para coerência e precisão dos resultados ou efetuar novamente a análise corrigindo o módulo de elasticidade tangente do material. Os exemplos apresentados neste trabalho, tiveram sempre a preocupação de esclarecer que o limite de proporcionalidade do material era teoricamente mais alto que - real, possibilitando trabalhar no regime elástico e consequentemente compará-los com os resultados dos artigos existentes. Fica, portanto, a extrema necessidade de complementação do trabalho para o regime inelástico do material. Assim, a análise do pórtico plano poderá ser realizada em teoria de segunda ordem com a não linearidade geométrica da estrutura e a não linearidade física do material produzindo dimensionamentos mais adequados baseados na análise global de estabilidade da estrutura como um todo.

Uma das limitações do processo é de não fornecer os modos de flambagem, pois fornece apenas o carregamento crítico (carga crítica), através da singularização da matriz de rigidez da estrutura e não pelo cálculo dos auto-valores e auto-vetores. Apenas em casos de carregamento de segunda espécie é possível fornecer os deslocamentos dos nós na eminência da instabilidade da estrutura, estimando o modo deslocado da estrutura.

O processo apresentado baseado em teoria de segunda ordem, com pequenos deslocamentos, só consegue fornecer o limite de carregamento da estrutura do pórtico sem dar informações a respeito do comportamento pós-flambagem. Para ser possivel a análise do comportamento pósflambagem é necessário utilizar programas mais complexos, em teoria de terceira ordem, com grandes deslocamentos em análise não linearmente exata. Esta análise mais sofisticada apenas contempla a análise de segurança da estrutura pois informa se a estrutura apresenta reservas de 
resistência ou falta de resistência pós-flambagem quando comparada com a teoria clássica.

Outra forma de análise de instabilidade de pilar de edifício industrial, apresentado neste trabalho, consiste em considerá-lo de forma tridimensional, com a finalidade de obter os efeitos de flexo-torção de forma mais direta e precisa sem ter que recorrer às expressões de interações indicadas em normas técnicas que dependendo dos perfis adotados nos pilares, podem apresentar grandes variaçōes nos resultados. $O$ processo proposto de carregamento crítico de instabilidade geral de pilares discretizados de edifícios industriais, apesar de ser um processo aproximado, conduz a bons resultados, pois o pilar integra o pórtico transversal e a análise de instabilidade da estrutura é feita de forma mais rigorosa considerando o comportamento global da estrutura.

Este processo tem a vantagem de colocar a origem dos eixos da seção transversal do pilar em lugar aleatório da seção, facilitando a modelagem do processo discreto, permitindo trabalhar com grandes mudanças na seçăo transversal que naturalmente altera a posição dos eixos principais de inércia, ao longo do eixo longitudinal do pilar, como é o caso dos pilares dos edifício industrial.

O aumento da capacidade do carregamento crítico do pilar mais carregado, quando acoplado ao pórtico transversal, é explicado em função da matriz de rigidez global só atingir sua singularidade quando ambos os pilares, tanto o mais carregado quanto o menos carregado esgotarem simultaneamente suas capacidades de carregamento, tornando todo 0 sistema global instável.

Este processo, possibilita também integrar vínculos elásticos no pilar discretizado com o objetivo de simular, com maior precisão, a ação dos contraventamentos que normalmente são constituídos de perfis metálicos muito deformáveis.

As análises apresentadas ocorreram em regime de segunda ordem, com a não linearidade geométrica da estrutura, totalmente no regime elástico. No exemplo número 4, foi utilizado o programa ANSYS para análise do comportamento pós-flambagem de uma viga em balanço com uma carga centrada no CG da extremidade livre. Os resultados mostraram uma reserva de resistência pós-flambagem. Portanto, o carregamento crítico 
dos casos analisados, no referido exemplo, foram confirmados tanto em teoria de segunda ordem quanto em teoria de terceira ordem. Estes resultados foram praticamente os mesmos encontrados pela análise do processo proposto. Desta forma, dentro das hipóteses adotadas, o processo proposto apresenta-se bastante satisfatório com a vantagem de trabalhar com menos elementos que normalmente se utilizam em elementos finitos.

O escopo deste trabalho manteve a não linearidade geométrica em teoria de segunda ordem na obtenção do carregamento crítico pela singularização da matriz de rigidez da estrutura. Portanto, os modos de flambagem só podem ser estimados e não obtidos.

O carregamento crítico de uma estrutura depende não só da geometria da estrutura como também da situação de carregamento com ações verticais e horizontais, com ou sem majorações das açōes. A análise é feita para cada situação de trabalho da estrutura com todas as ações inviabilizando a montagem de tabelas sem que haja grandes simplificações em suas montagens. Portanto, recomenda-se o uso de programas para esta finalidade tendo em vista a complexidade do problema.

Os perfis utilizados nos exemplos numéricos foram constituídos de chapas comerciais soldadas, prevalecendo as geometrias que melhor atenderam às solicitações dos problemas estruturais analisados. Em alguns exemplos, os perfis apresentaram formas e espessuras não convencionais, pois foram baseados em artigos internacionais de estruturas especiais.

Os processos propostos neste trabalho apresentam a vantagem de utilizar menos elementos e menos memória de computação comparando com o processo dos elementos finitos. Apesar de também ser um processo aproximado atende às necessidades previstas no escopo deste trabalho com menor tempo de processamento.

Através das análises efetuadas pelo programa ANSYS, constatou-se a dificuldade em trabalhar com modelagem de grandes estruturas, principalmente para análise não linearmente exata. $O$ tempo de processamento é muito grande e o custo elevado se utilizado para fins comerciais. A análise em segunda ordem, utilizando o processo proposto, apresenta vantagens quanto a simplicidade de modelagem com menor tempo de processamento, apresentando bons resultados para obtenção de parâmetros críticos de instabilidade. 
Outra vantagem do processo de discretização de seção proposto é de permitir considerar a excentricidade do apoio da viga de rolamento em relação ao pilar. Esta excentricidade ocorre no plano perpendicular ao do pórtico transversal, devido a imperfeições de montagem da estrutura, pois, a viga de rolamento não fica exatamente no eixo de simetria da seção transversal do pilar. Desta forma, esta ação excêntrica provoca o bimomento na seção e consequentemente o esforço de flexo-torção. A maioria dos calculistas dispensam este efeito pela dificuldade em considerá-lo. $O$ processo proposto considera facilmente este efeito, bastando para este fim, modificar a modelagem do pilar criando mais um painel próximo da ação aplicada criando novas coordenadas no sistema.

O processo de discretização de seção pode facilitar um futuro estudo da não linearidade física dos elementos estruturais. A discretização em elementos de painel de seção retangular pode facilitar o controle do módulo de elasticidade tangente em todas as regiões desejadas da seção transversal e em qualquer ponto do elemento estrutural. 


\title{
ANEXO A \\ ESTUDO DA DISTRIBUIÇÃO DE DIAFRAGMAS TRANSVERSAIS
}

\begin{abstract}
A precisão dos resultados obtidos no processo de discretização de seção, depende de uma relação que compara os comprimentos dos tramos de cada painel com suas respectivas larguras.

O estudo foi efetuado analisando inicialmente painéis isolados $\theta$ posteriormente painéis associados de forma coplanar representando uma parede de perfil metálico, ou painéis associados que representam a constituição total do perfil.

O estudo foi baseado predominantemente nos efeitos de flexão, nos elementos estruturais discretizados, analisando os deslocamentos mediante carregamento imposto, como também, seus carregamentos críticos.

A seguir, são ilustrados alguns exemplos do estudo que deram origem às relações, já citadas na Fig.III-4, do capítulo três:
\end{abstract}


a) viga em balanço formada por painéis coplanares, para obtenção dos deslocamentos

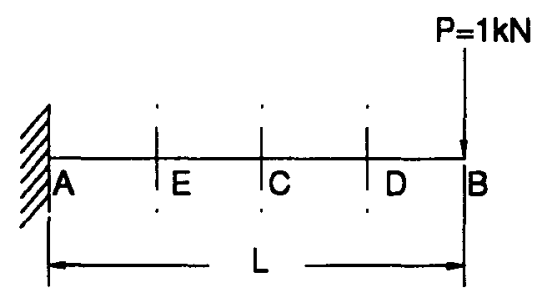

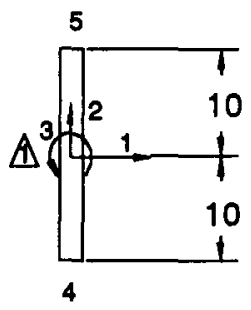

(l)

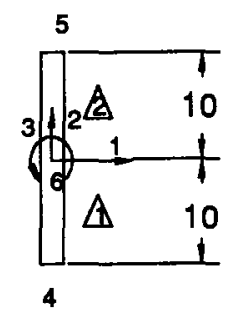

(II)

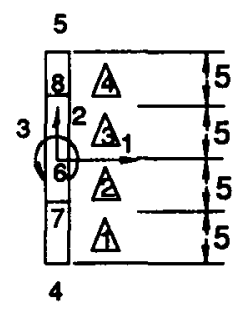

(III)

$$
\begin{aligned}
& E=21000 \mathrm{KN} / \mathrm{cm}^{2} \\
& G=8077 \mathrm{KN} / \mathrm{cm}^{2} \\
& t=0,4 \mathrm{~cm} \\
& S=8 \mathrm{~cm}^{2} \\
& I_{1}=266,67 \mathrm{~cm}^{4}
\end{aligned}
$$$$
\mathrm{I}_{2}=0,11 \mathrm{~cm}^{4}
$$$$
\mathrm{L}=450 \mathrm{~cm}
$$$$
M_{\mathrm{s}}=20 \mathrm{~cm}^{3}
$$$$
i_{0}^{2}=33,35 \mathrm{~cm}^{2}
$$$$
J_{t}=0,427 \mathrm{~cm}^{4}
$$

$$
\begin{array}{ll}
M_{A}=450 \mathrm{KN} \cdot \mathrm{cm} \quad, & \sigma_{A, \max }=\frac{450 \cdot 10}{266,67}=16,875 \mathrm{KN} / \mathrm{cm}^{2} \\
M_{C}=225 \mathrm{KN} \cdot \mathrm{cm} \quad, & \sigma_{C, \max }=\frac{225 \cdot 10}{266,67}=8,437 \mathrm{KN} / \mathrm{cm}^{2}
\end{array}
$$$$
Q_{A}=Q_{C}=1 \mathrm{KN} \quad, \quad \tau_{A=C}=\frac{1 \cdot 20}{0,4 \cdot 266,67}=0,1875 \mathrm{KN} / \mathrm{cm}^{2}
$$$$
f_{B}=\frac{1 \cdot 450^{3}}{3 \cdot 21000 \cdot 266,67}=5,424 \mathrm{~cm}
$$$$
f_{c}=\frac{5 \cdot 450^{3}}{48 \cdot 21000 \cdot 266,67}=1,695 \mathrm{~cm}
$$ 


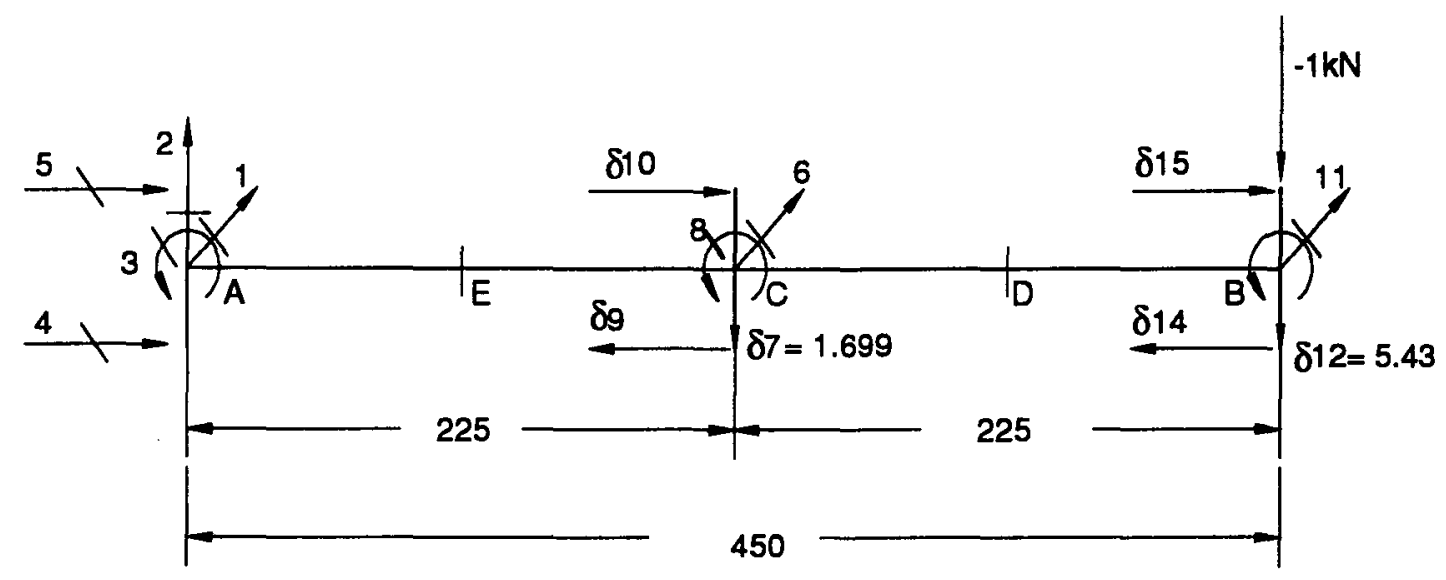

\section{TES 41.DAT}

Tipo (I) - Painel isolado, tendo comportamento de viga com três diafragmas

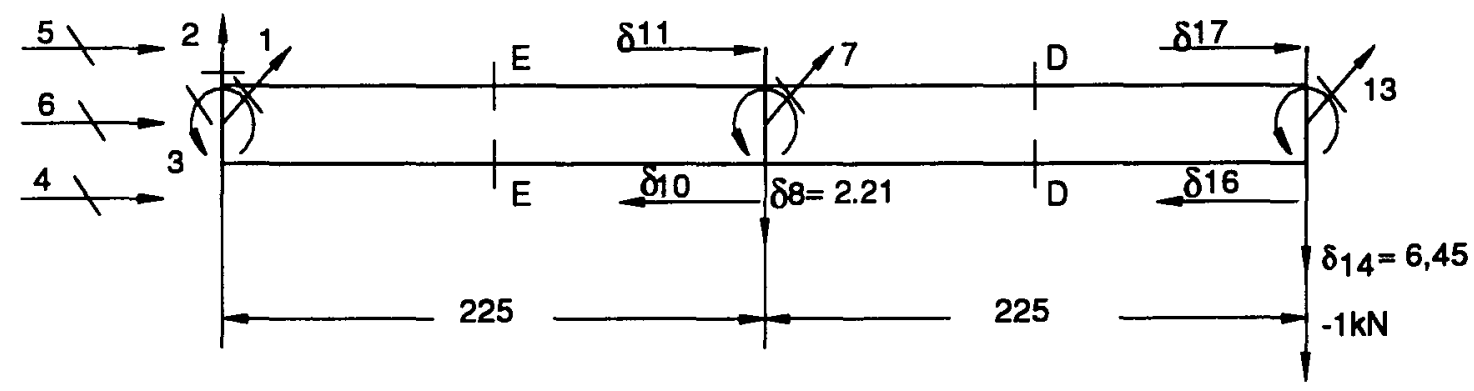

\section{TES 42.DAT}

Tipo (II) - $c / b=22,5$. Três diafragmas - painel duplo

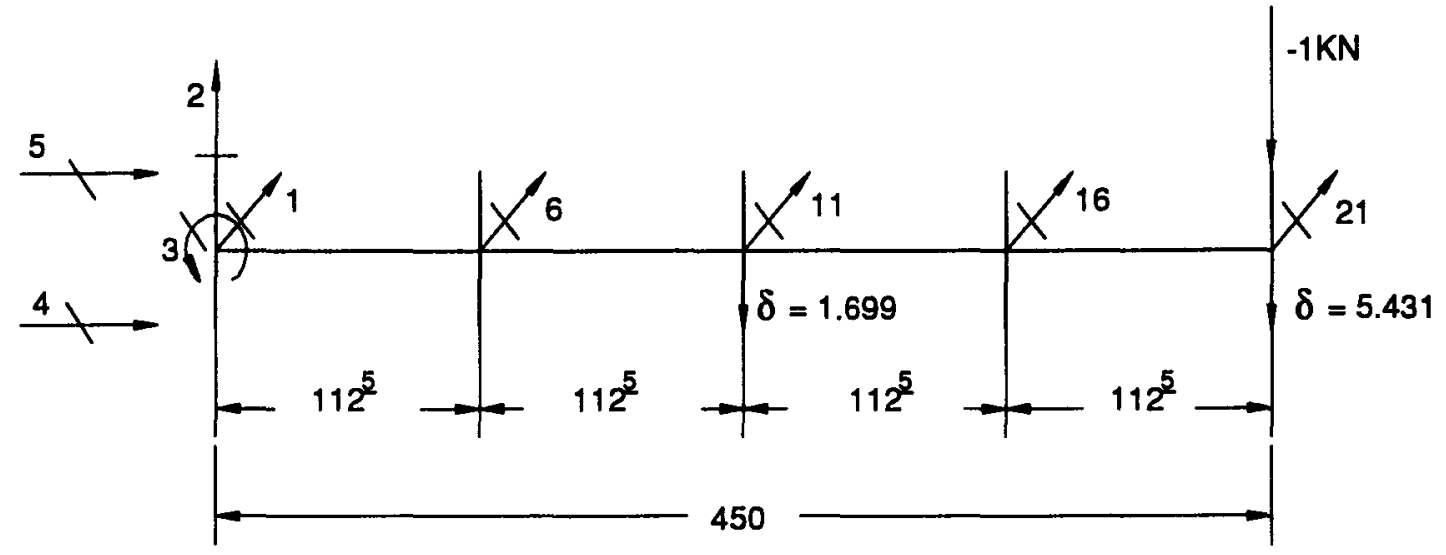

\section{TES 43.DAT}

Tipo (I) - Painel isolado, tendo comportamento de viga com cinco diafragmas 


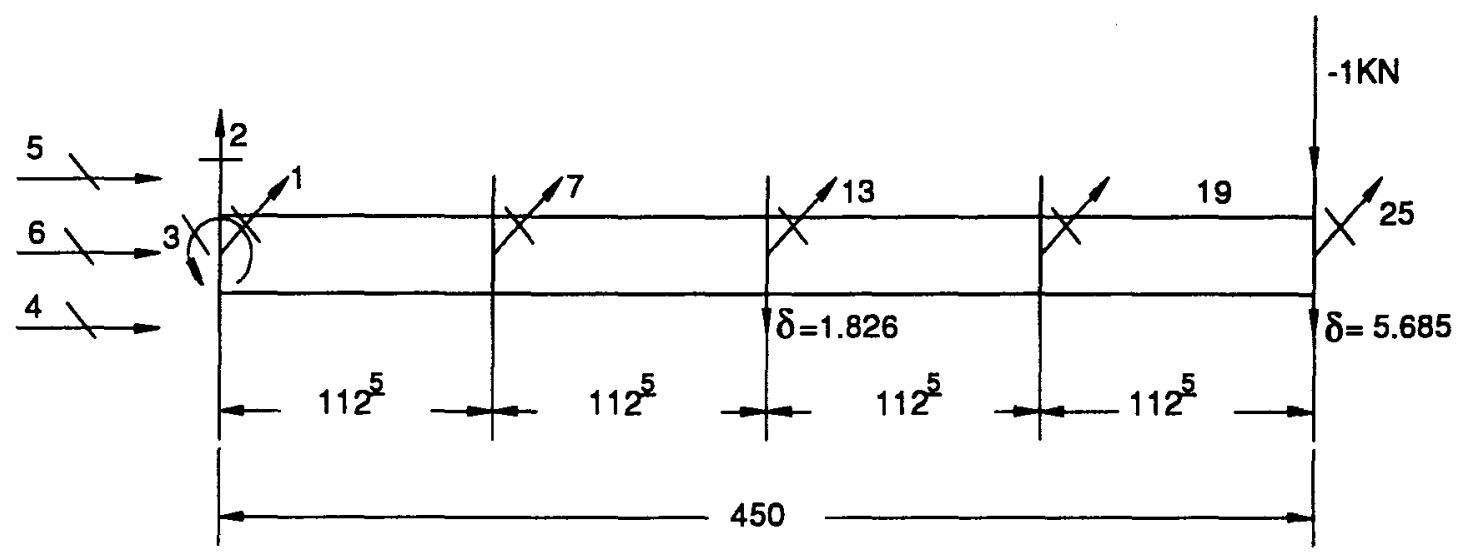

TES 44.DAT

Tipo (II) - $c / b=11,25$. Cinco diafragmas - painel duplo

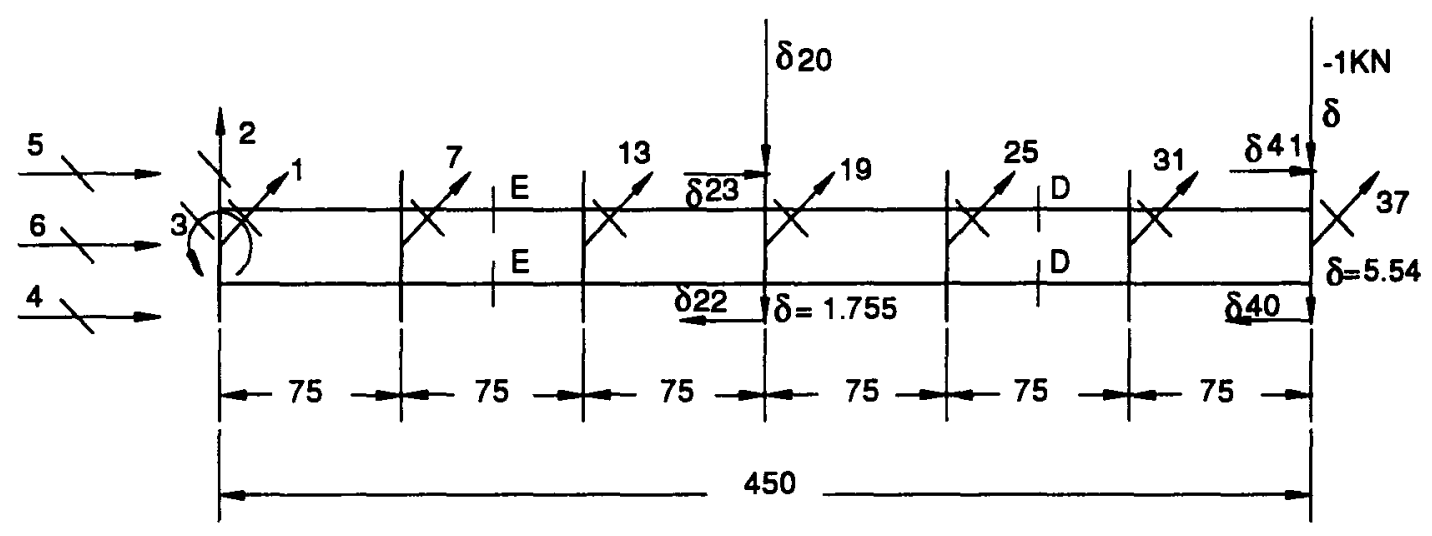

TES 47.DAT

Tipo (II) - $c / b=7,5$. Sete diafragmas - painel duplo

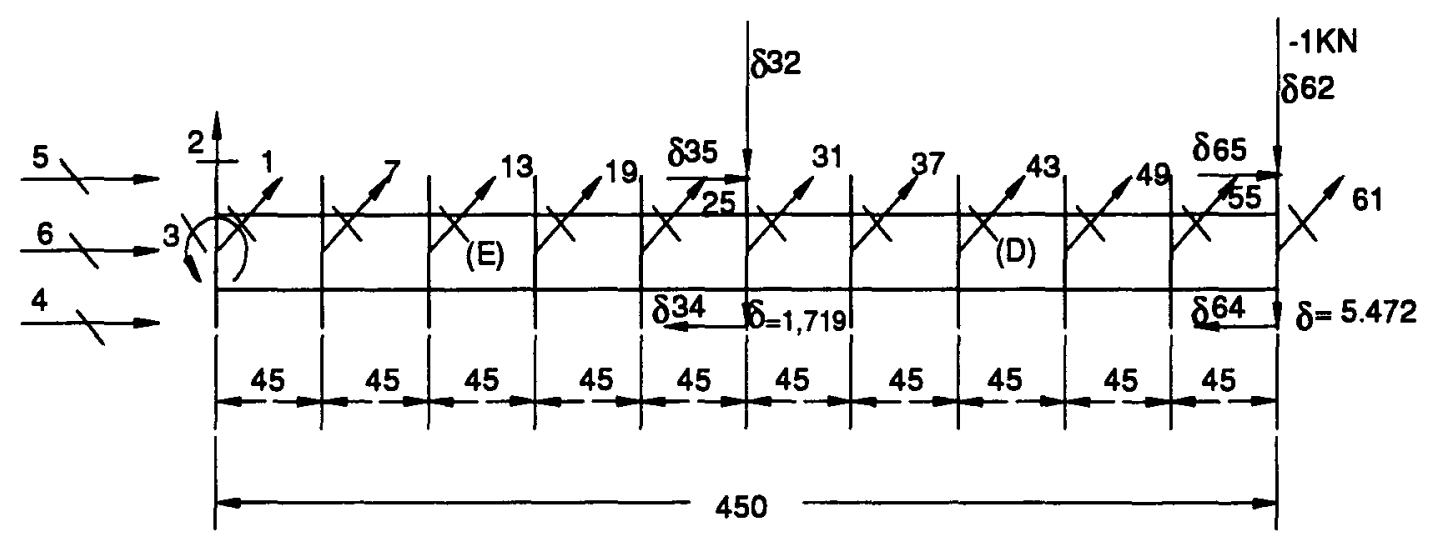

TES 48.DAT

Tipo (II) - $\mathrm{c} / \mathrm{b}=4,5$. Onze diafragmas - painel duplo 


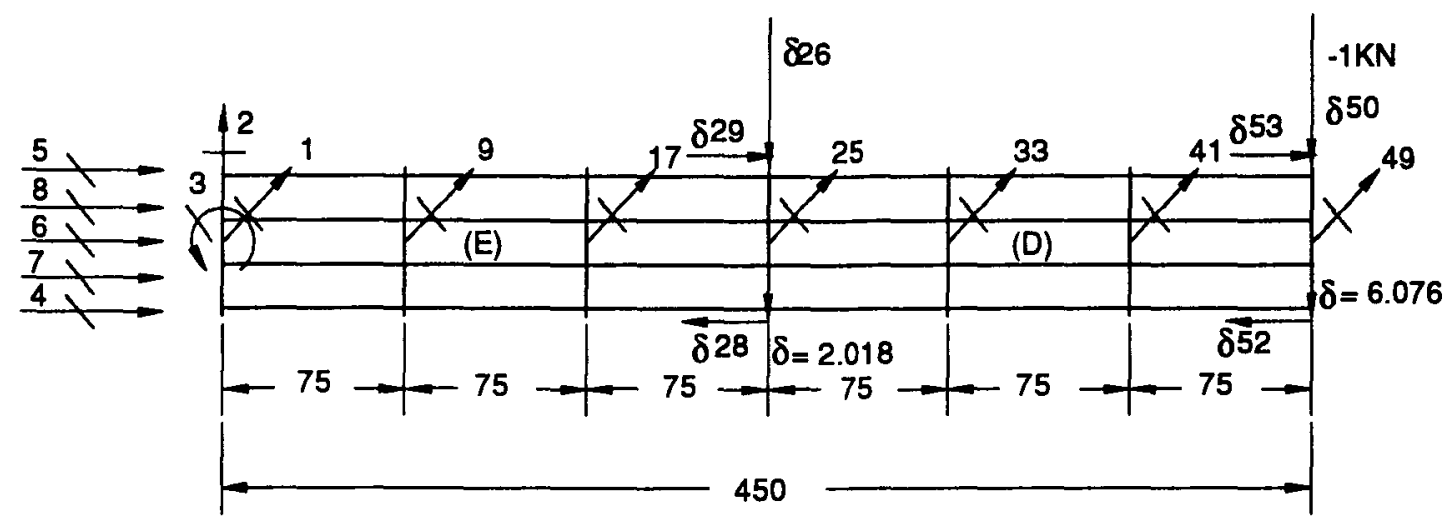

TES 49.DAT

Tipo (III) $-\mathrm{c} / \mathrm{b}=15$

Sete diafragmas - painel quádruplo

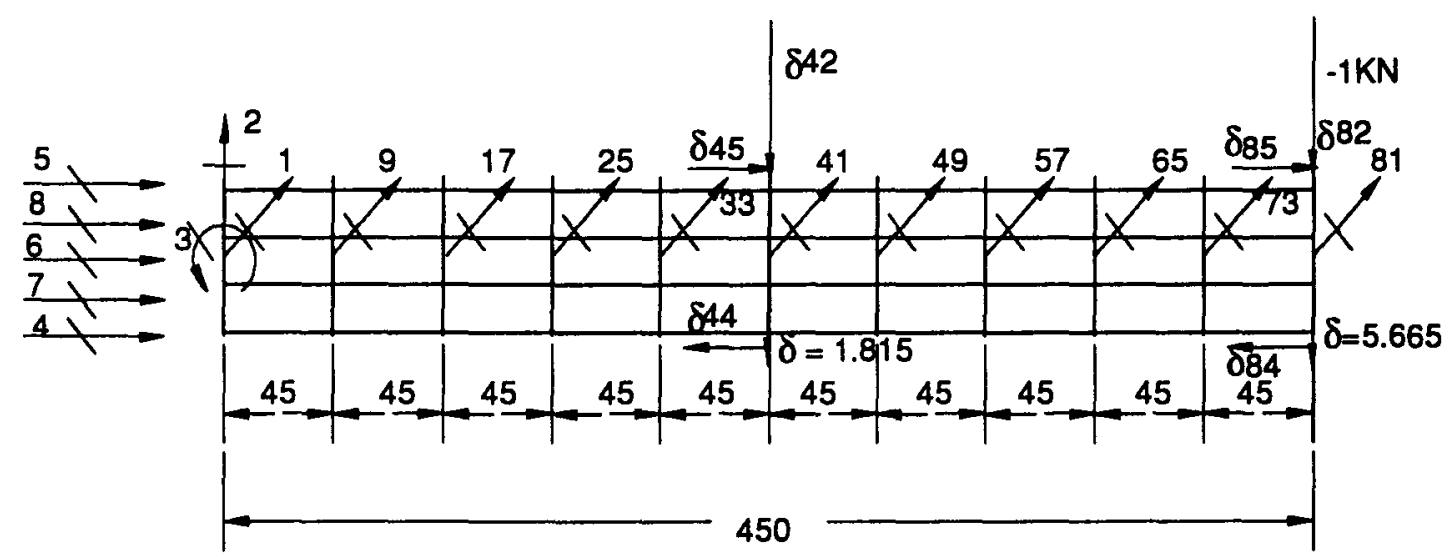

TES 50.DAT

Tipo (III) $-\mathrm{c} / \mathrm{b}=9$

Onze diafragmas - painel quádruplo 
Painéis submetidos à flexão, $\mathrm{c} / \mathrm{b} \leq 10$ (precisão de aproximadamente $7,5 \%) ; c / b \leq 5$ (precisão de aproximadamente $1 \%$ ).

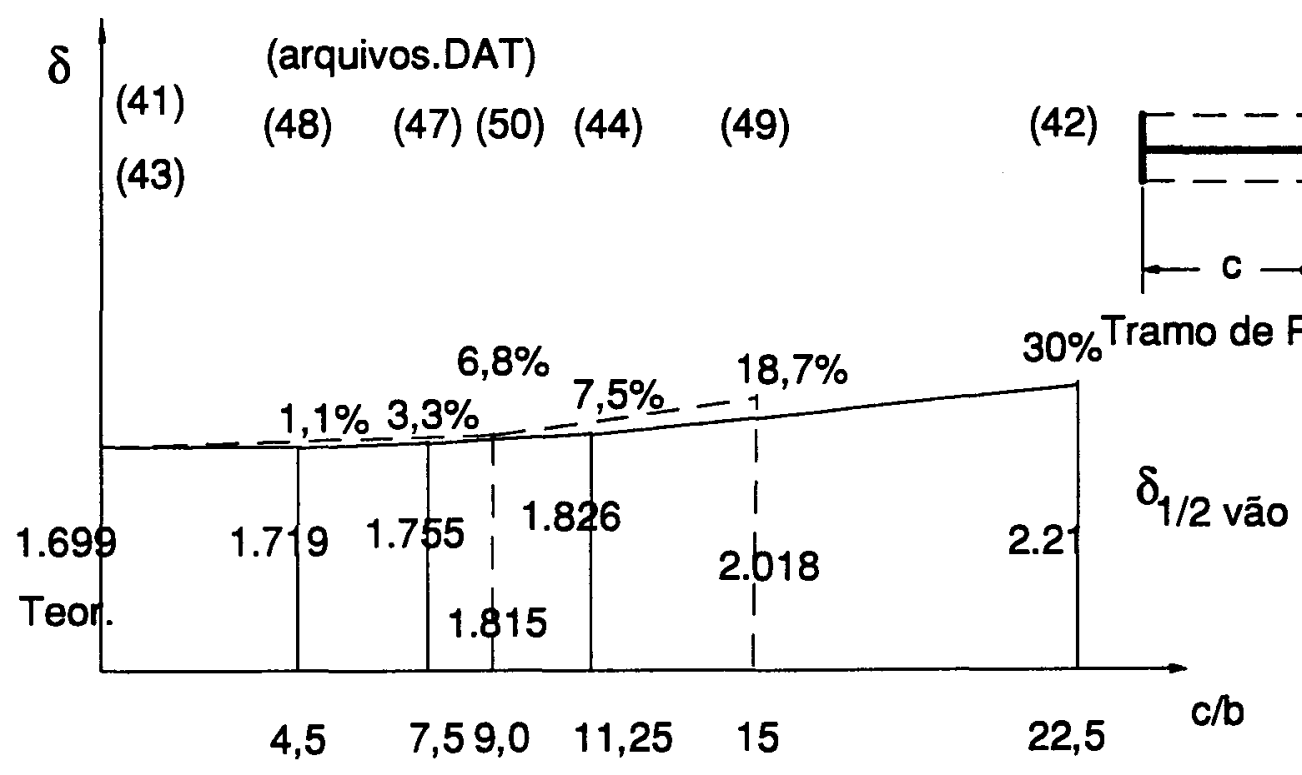
(l)
(II)
(II) (III) (II)
(III)
(II)

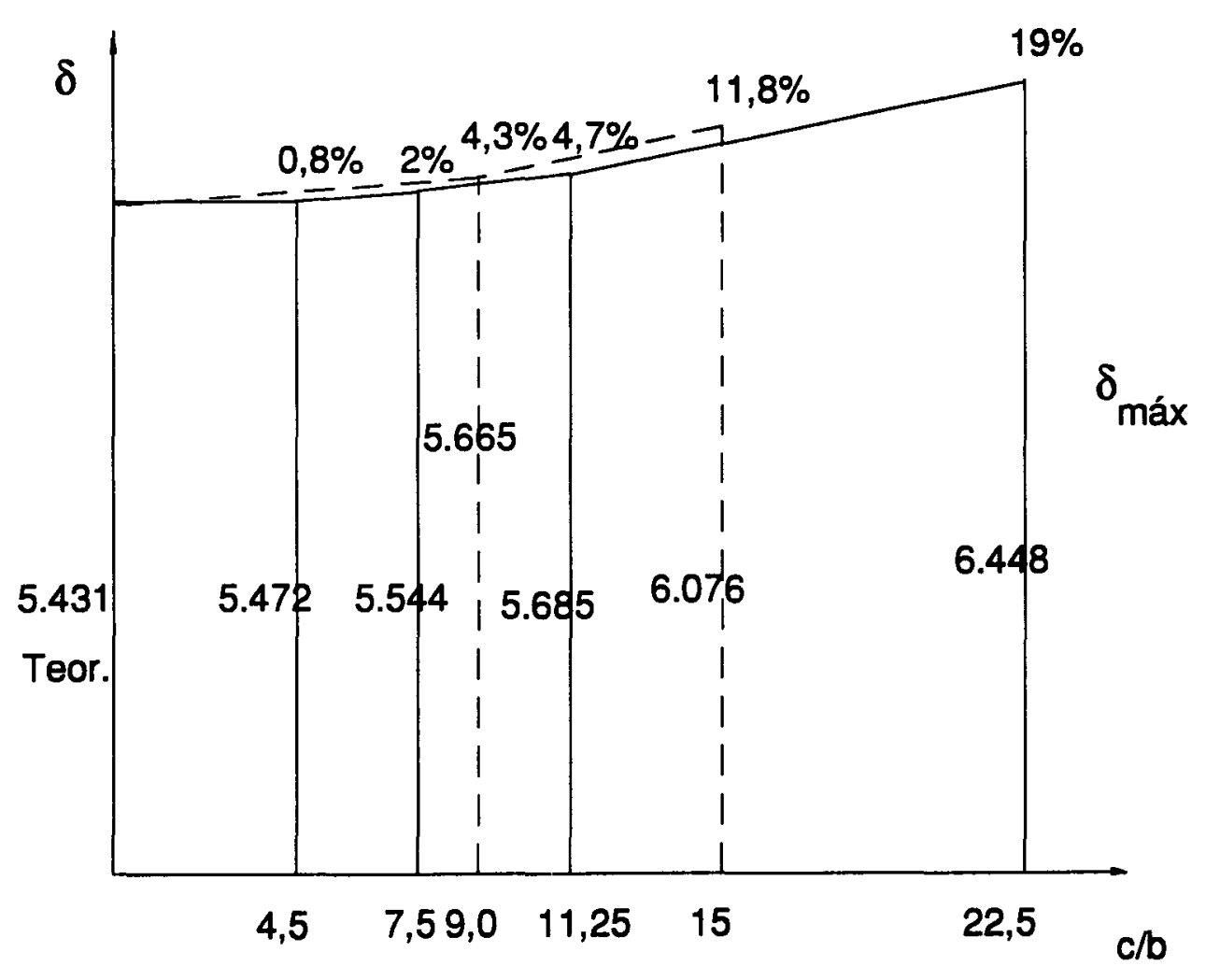

Legenda :

Tipo III ; Tipo II 
b) viga em balanço do item a), para obtenção do carregamento crítico no plano de maior inércia, pois o painel isolado só trabalha neste plano.

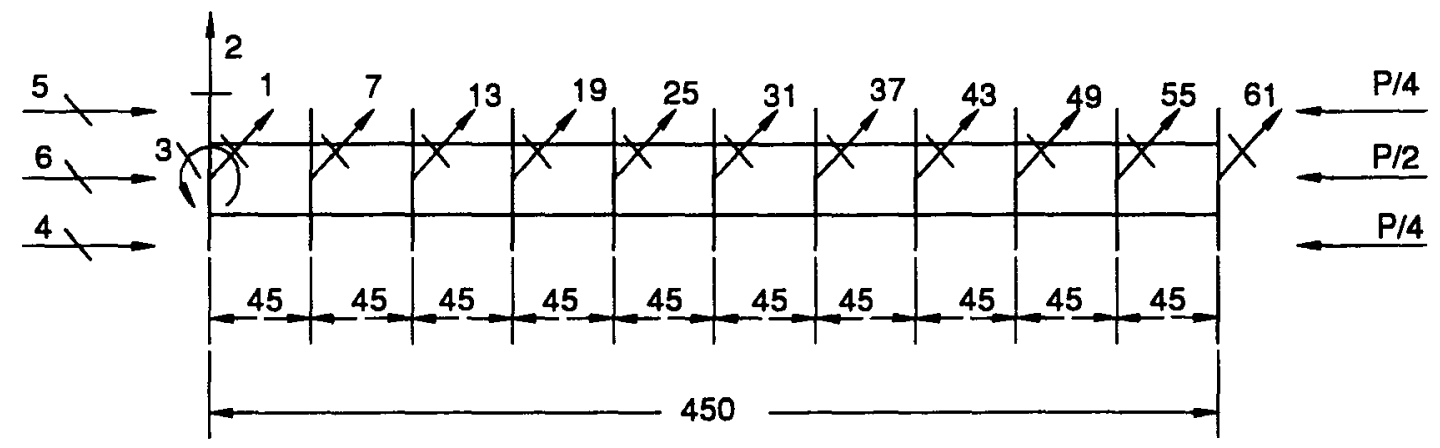

TES 51A.DAT - ENG.-LIVRE

Tipo (II) - $\mathrm{c} / \mathrm{b}=4,5(1,1 \%)$

$W_{\text {cr }}=67,87(0,538 \%)$

(FLB- para flexão)

$W_{\text {leor }}=68,235$

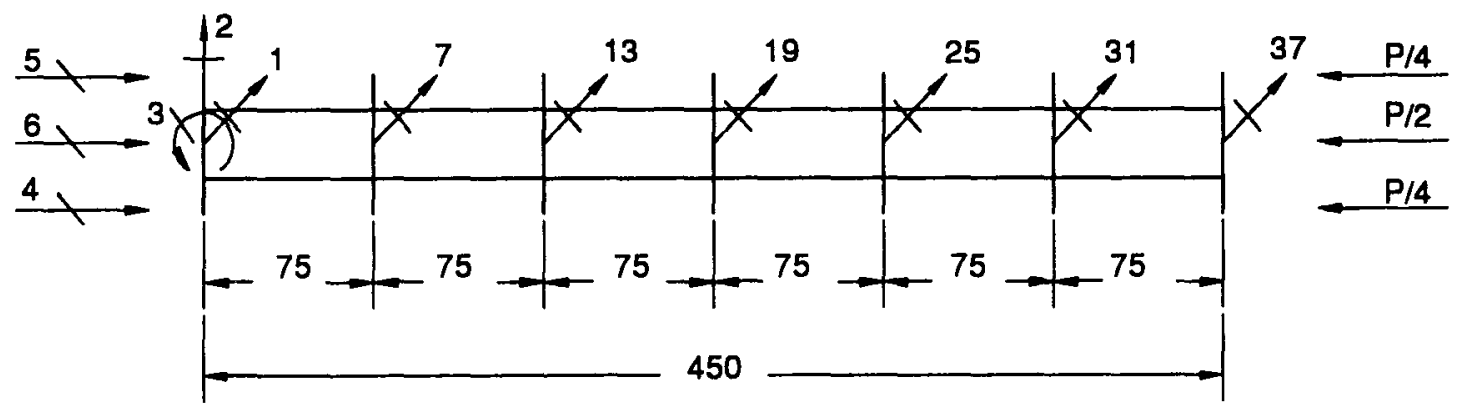

TES 51.DAT - ENG.-LIVRE

Tipo (II) - $\mathrm{c} / \mathrm{b}=7,5(3,3 \%)$

$W_{c r}=66,89(2 \%)$

TEÓRICO: 68,235 
c) viga simplesmente apoiada, formada por painéis coplanares, para obtenção do carregamento crítico

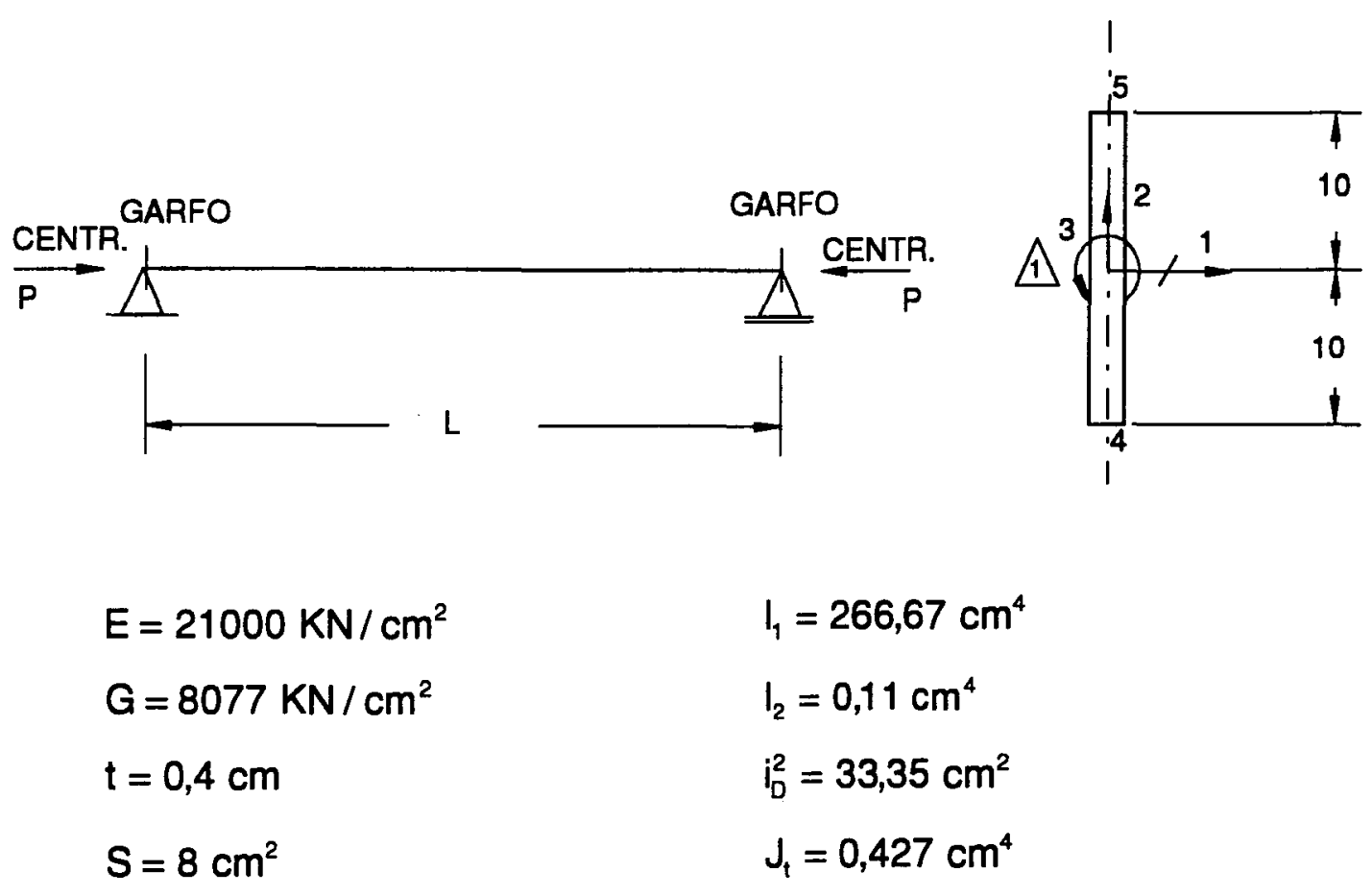

OBS.: restrições em $1 \therefore$ só será considerado liberdade em $\underline{2}$ e $\underline{3}$

- Carga centrada - Problema de 1를 Espécie - Valores teóricos:

$$
\begin{aligned}
& L=100 \therefore P_{W_{2}}=5527 \mathrm{KN} ; P_{\phi 3}=\underline{\underline{102,43 \mathrm{KN}}} \text { (FLB - Torção) }
\end{aligned}
$$

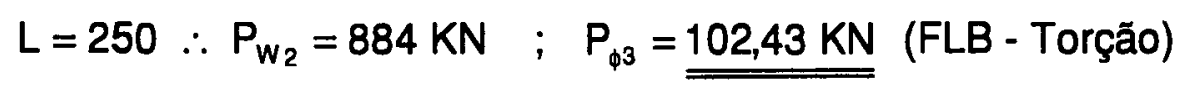

$$
\begin{aligned}
& L=450 \therefore P_{w_{2}}=273 \mathrm{KN} ; P_{\phi 3}=102,43 \mathrm{KN} \text { (FLB - Torção) } \\
& L=735 \therefore P_{W_{2}}=\underline{\underline{102,3 \mathrm{KN}}} ; P_{\phi 3}=\underline{\underline{102,4 \mathrm{KN}}} \text { (FLB - simultânea flexão e } \\
& \text { torção) }
\end{aligned}
$$

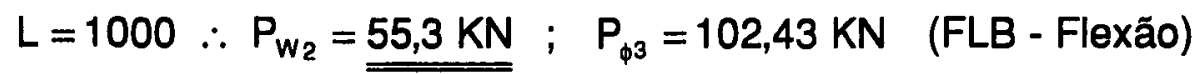




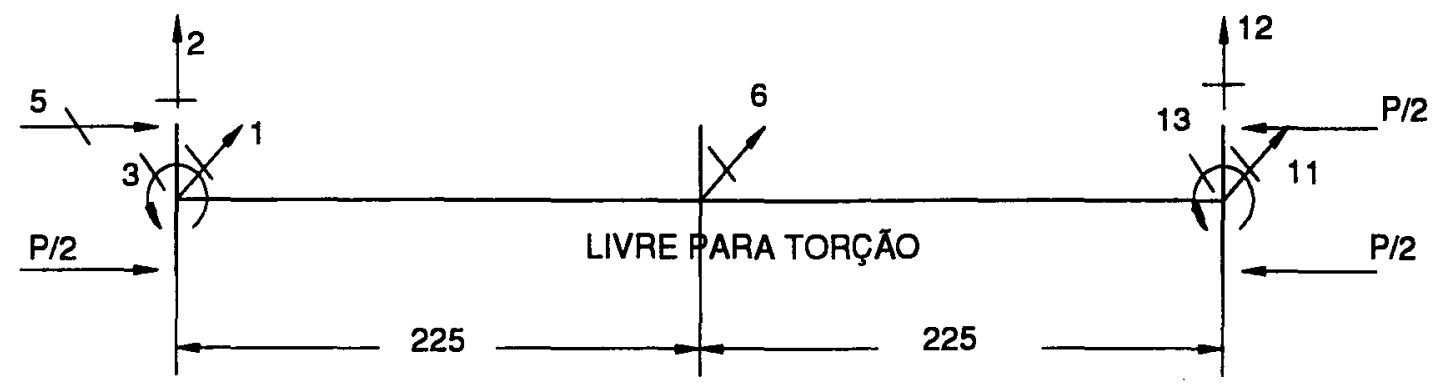

TES 19.DAT

$W_{c r(0,1 \%)}=101,12$. FLB - Torção

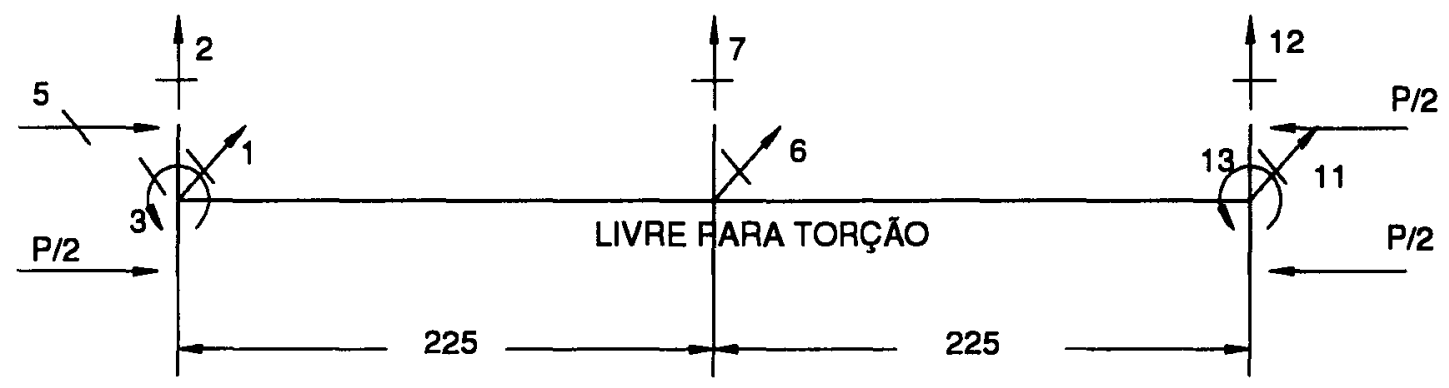

TES 19A.DAT

$W_{\text {cr(0,1\%) }}=101,12$. FLB - Torção

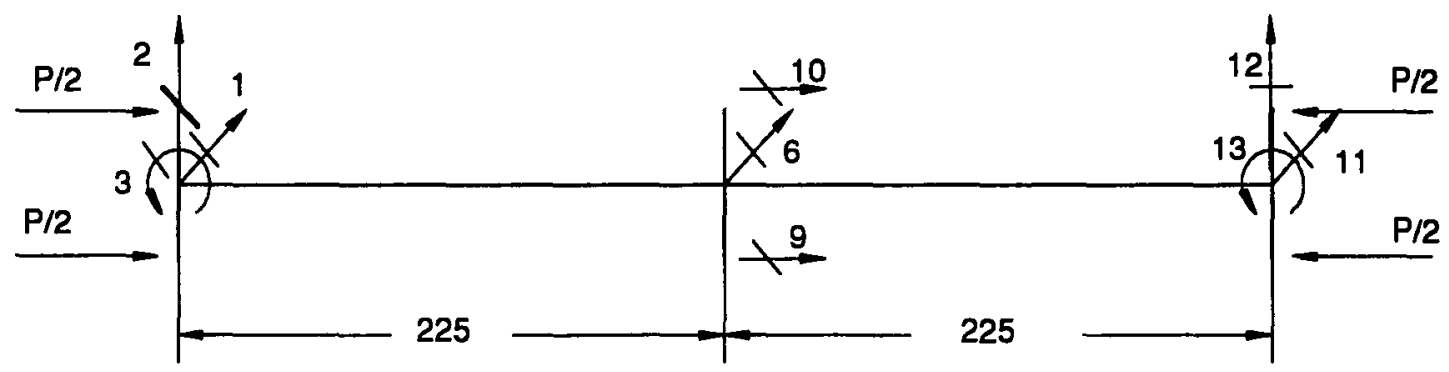

\section{TES 23.DAT}

$W_{c r(0,1 \%)}=101,12$. FLB - Torção

Obs: TES 19A.DAT e TES23.DAT são variações de TES 19.DAT na aplicação das restrições dos vínculos.

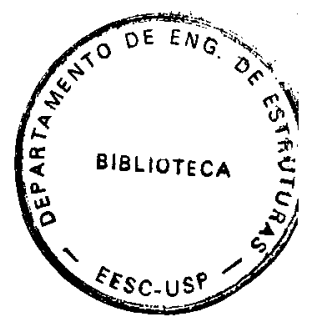




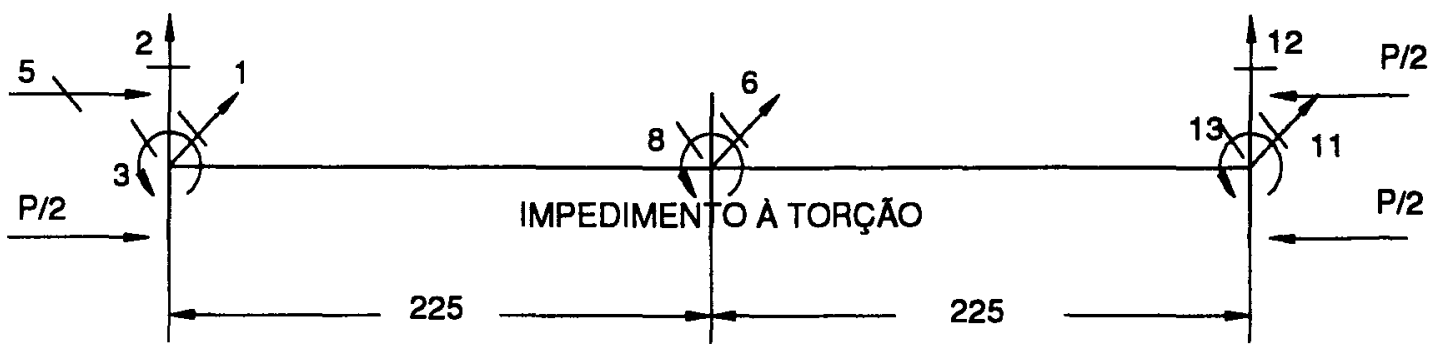

\section{TES 24.DAT}

$W_{c r(2 \%)}=270,31 . \quad$ FLB - Flexão

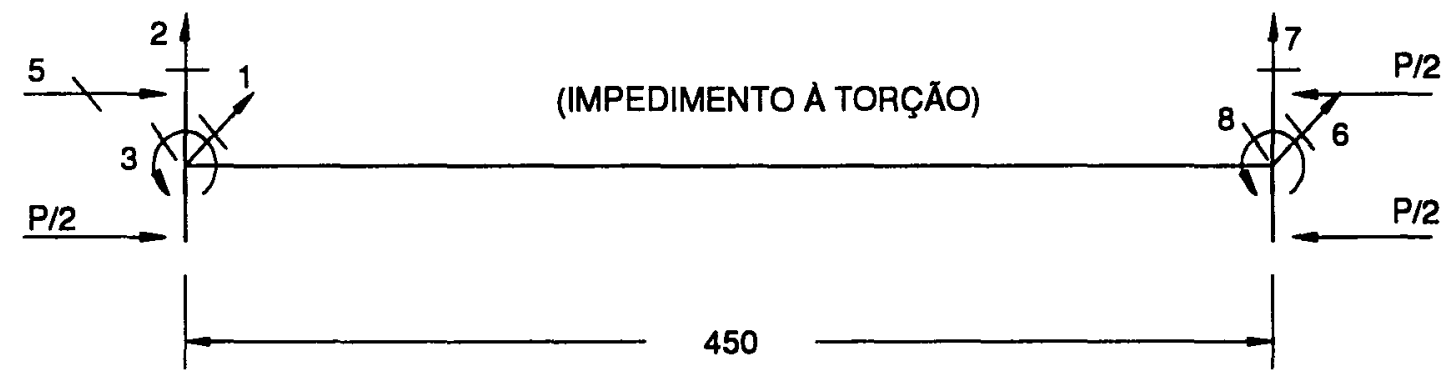

\section{TES 25.DAT}

$W_{c r(2 \%)}=270,31 . \quad$ FLB - Flexão.

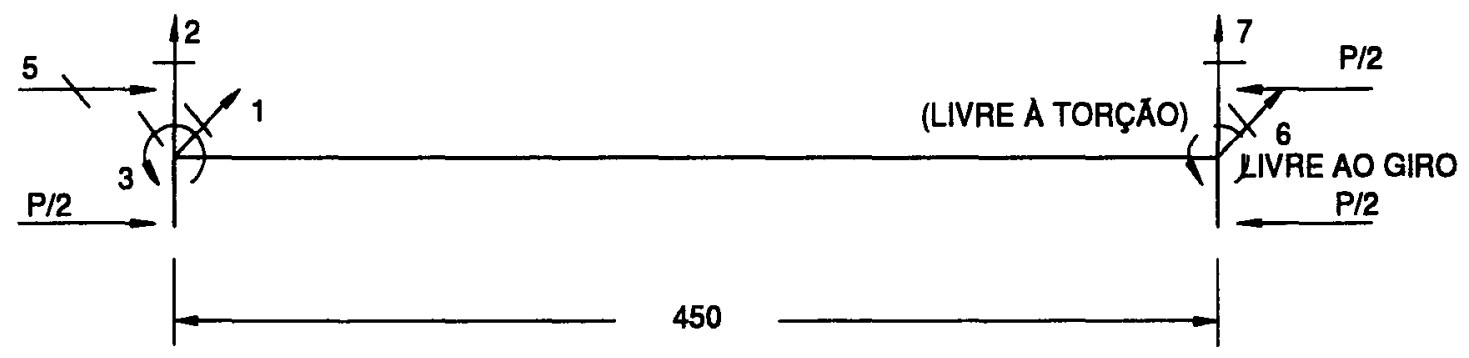

TES 26.DAT

$W_{\operatorname{cr}(0,1 \%)}=101,12 . \quad W_{(2 \%)}=100,78 . \quad$ FLB - Torção 


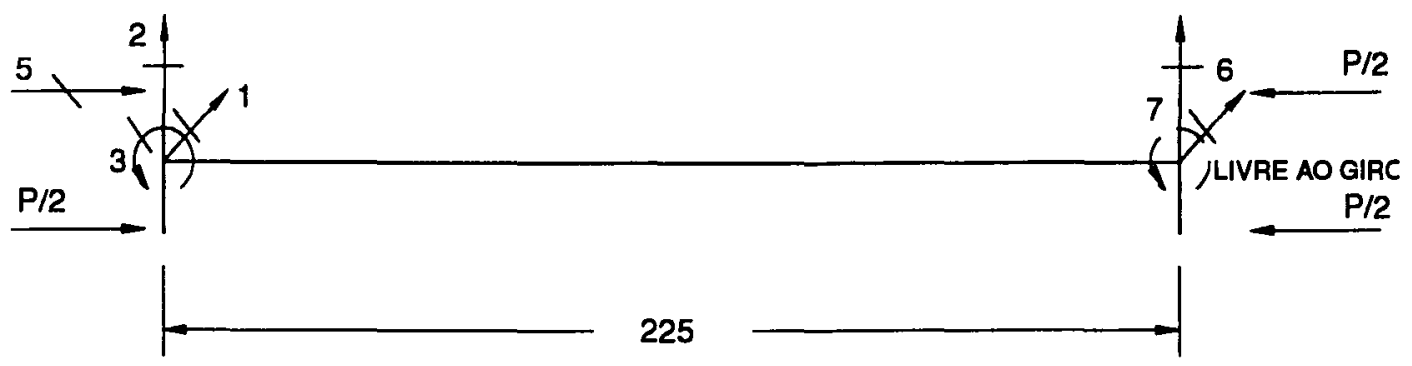

\section{TES 27.DAT}

$W_{c r(2 \%)}=100,78 . \quad$ FLB - Torção.

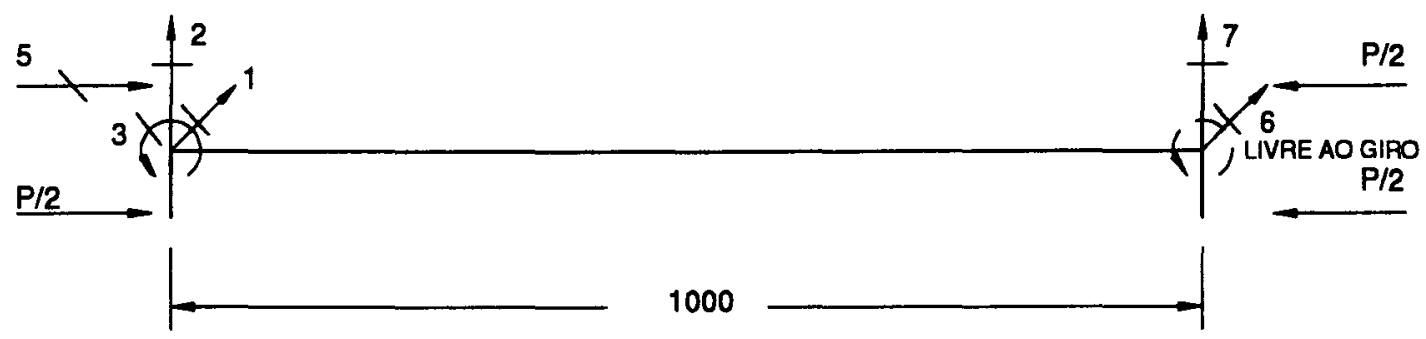

\section{TES 28.DAT}

$W_{\text {cr(2\%) }}=55,08 . \quad$ FLB - Flexão

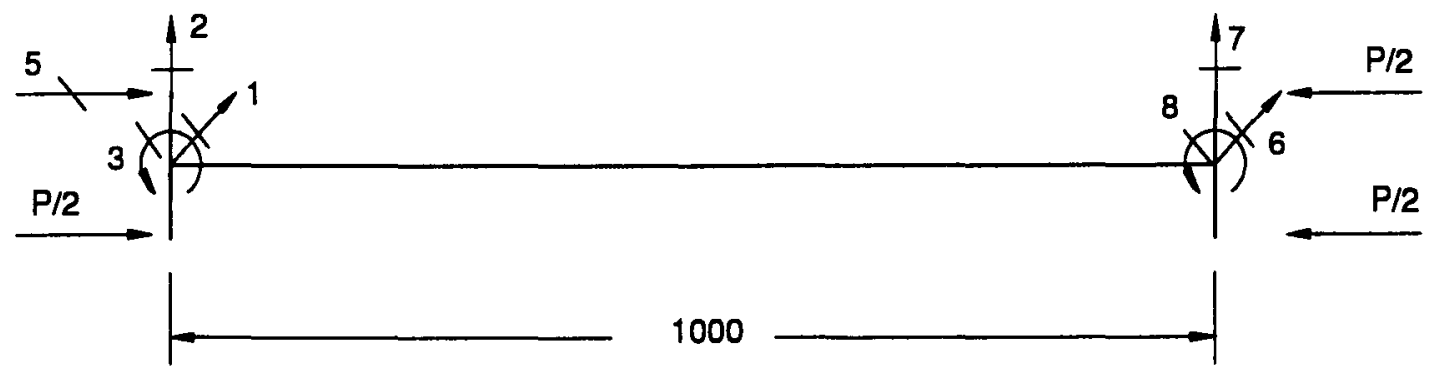

TES 28A.DAT

$W_{\text {cr(2\%) }}=55,08 . \quad$ FLB - Flexão 


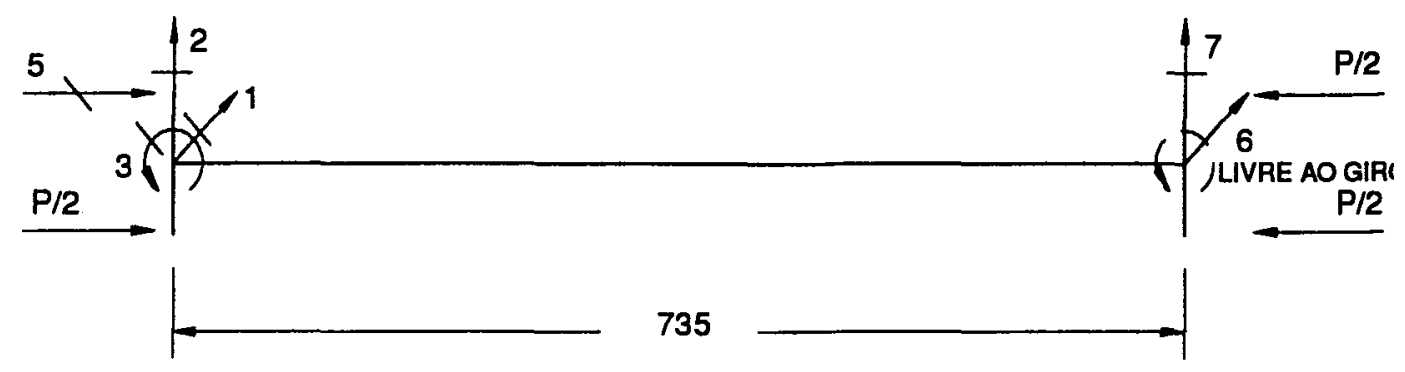

TES 29.DAT

$W_{c(2 \%)}=100,78 . \quad$ FLB - Fle/Tor

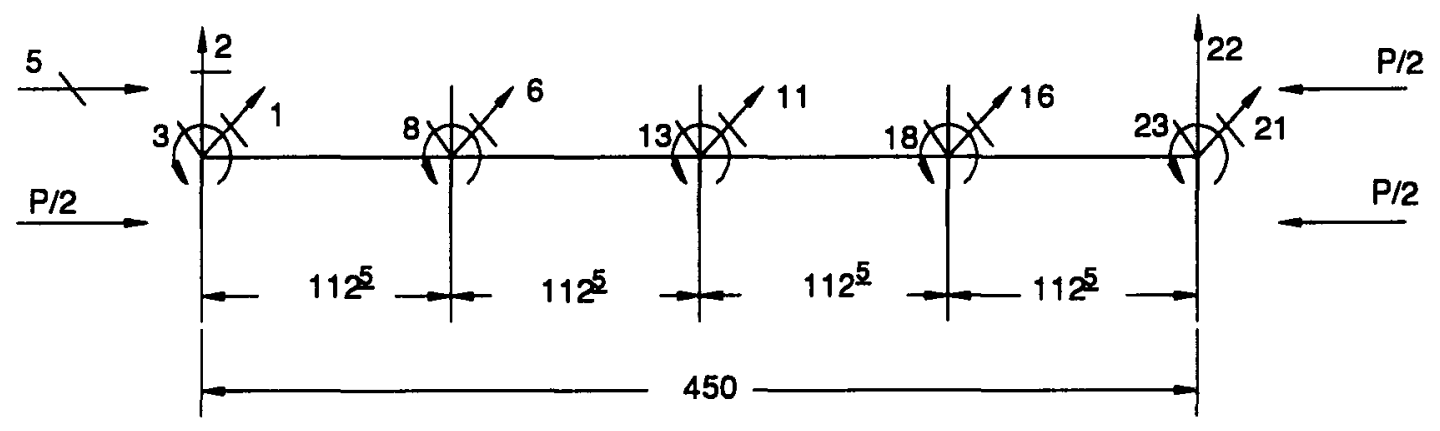

TES 31.DAT

$W_{c r(2 \%)}=270,31 . \quad$ FLB - Flexão

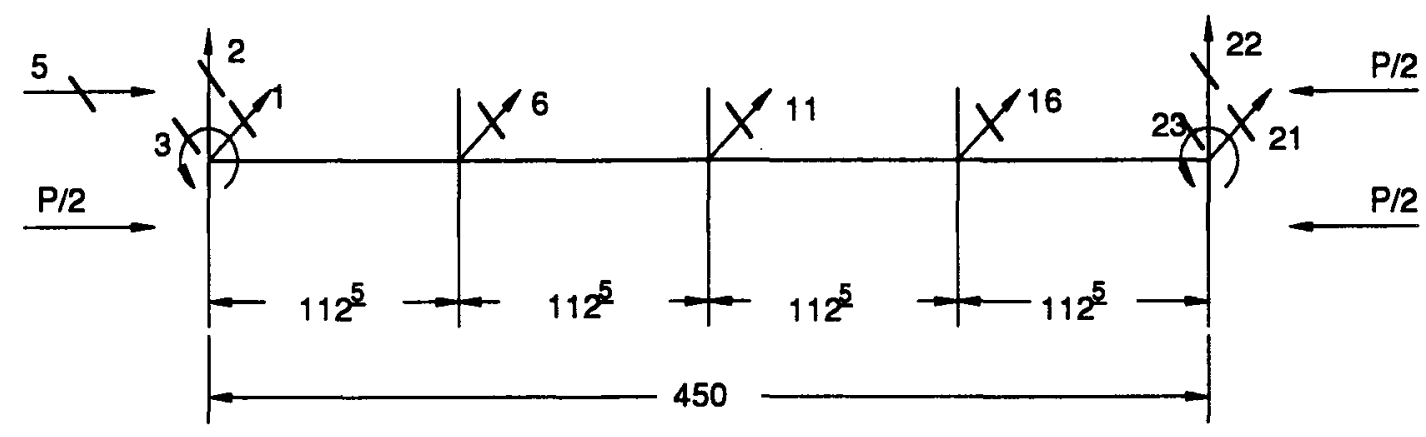

TES 30.DAT

$W_{c r(2 \%)}=100,78 . \quad$ FLB - Torção $\quad W_{(0,1 \%)}=101,12$ 


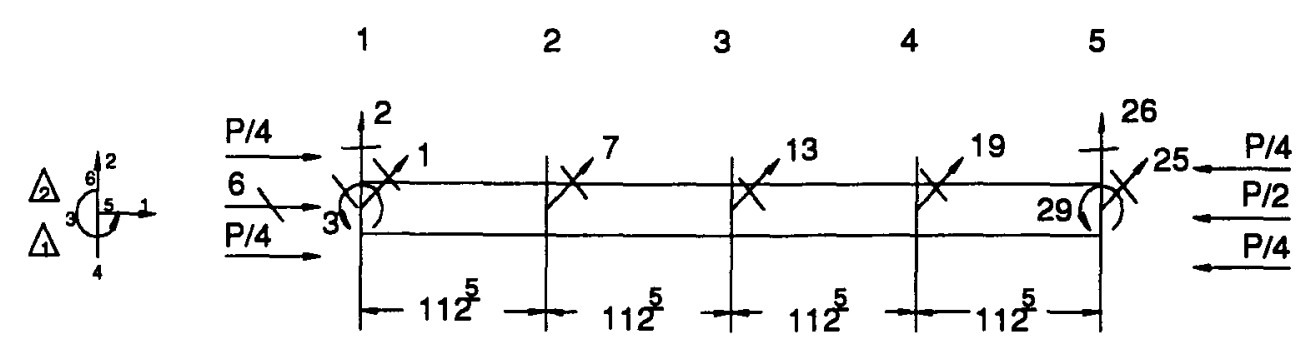

\section{TES 20.DAT}

$W_{c r}=236,00 . \quad c / b=11,25(7,5 \%) \quad$ Dif. $=13,5 \%$.

(FLB - Flexão)

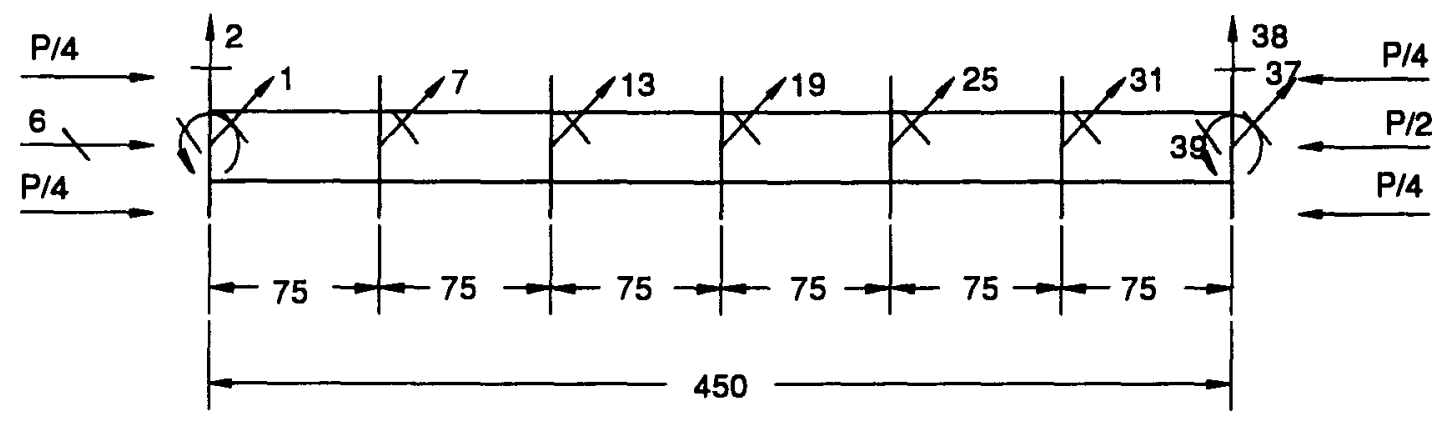

\section{TES 21.DAT}

$\mathrm{W}_{\mathrm{cr}}=255,86 . \quad \mathrm{c} / \mathrm{b}=7,5(3,3 \%) . \quad \mathrm{DIF} .=6,24 \% \quad$ (FLB - Flexão)

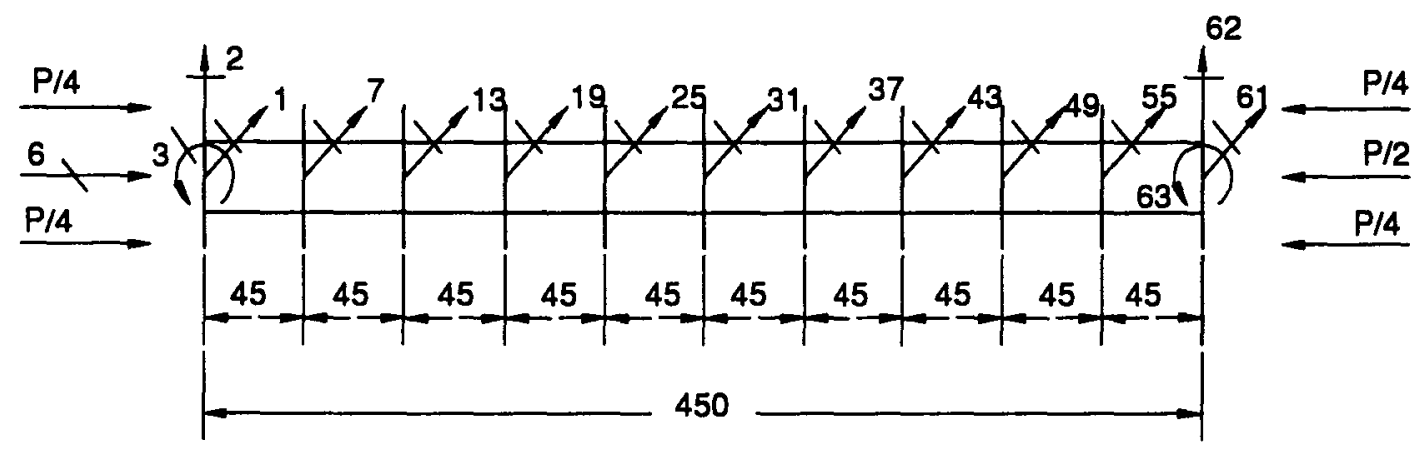

TES 20A.DAT - BI-ARTICULADO

$W_{c r}=263,89 . \quad c / b=4,5(1,1 \%) . \quad$ Dif. $=3,33 \% \quad$ (FLB - Flexão) 


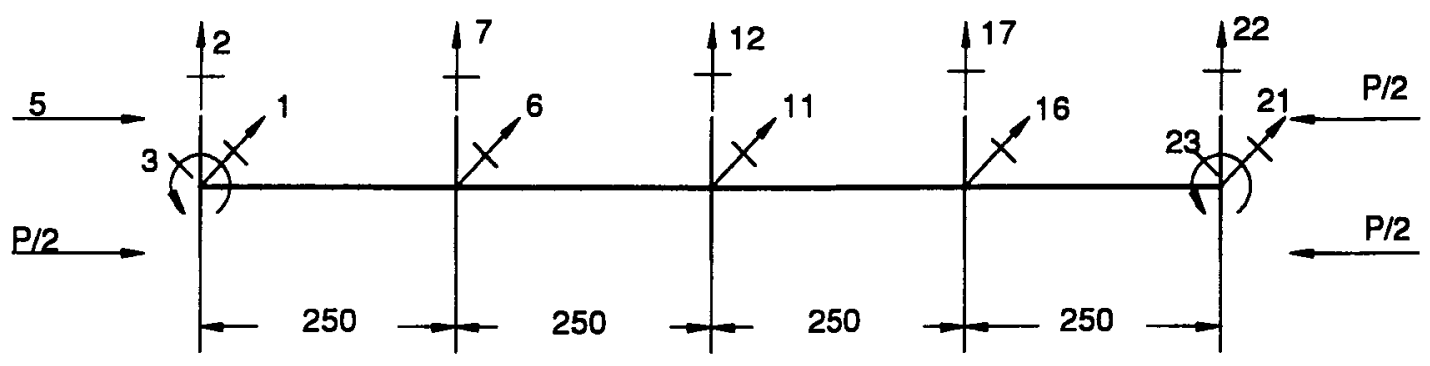

TES 34.DAT

$W_{\text {cr(2\%) }}=100,78 . \quad$ FLB - Torção Dif. $=1,6 \%$

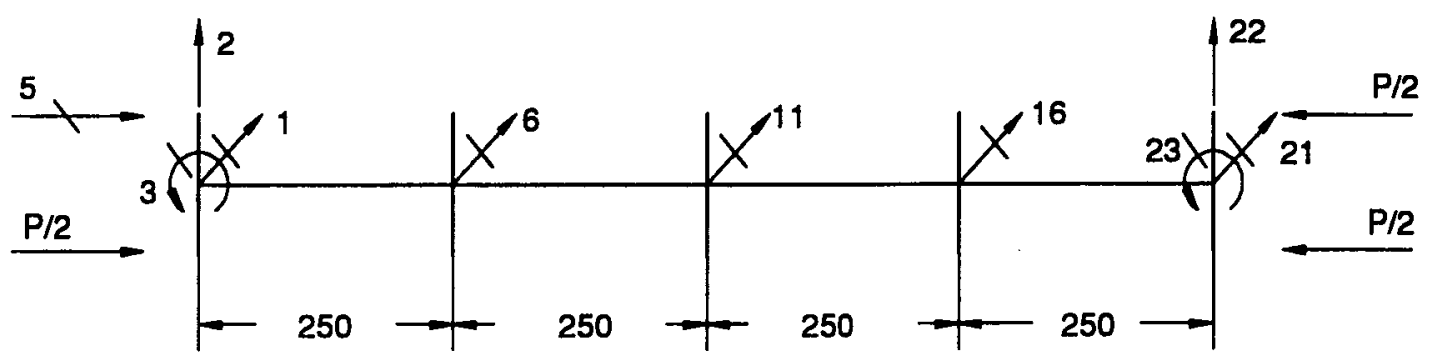

TES 32.DAT

$W_{\text {cr(2\%) }}=55,08$. FLB - Flexão Dif. $=0,4 \%$

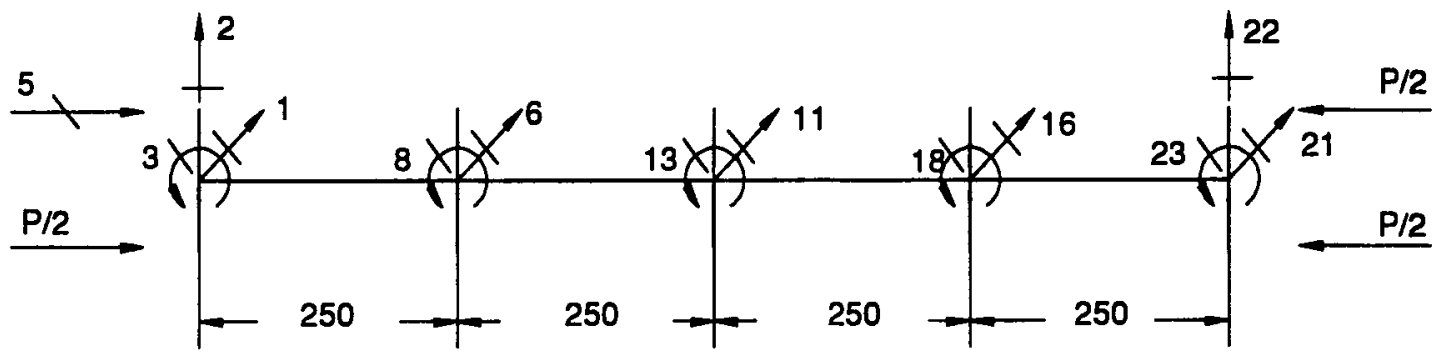

TES 33.DAT

$W_{\text {cr(2\%) }}=55,08 . \quad$ FLB - Flexão $\quad$ Dif. $=0,4 \%$ 


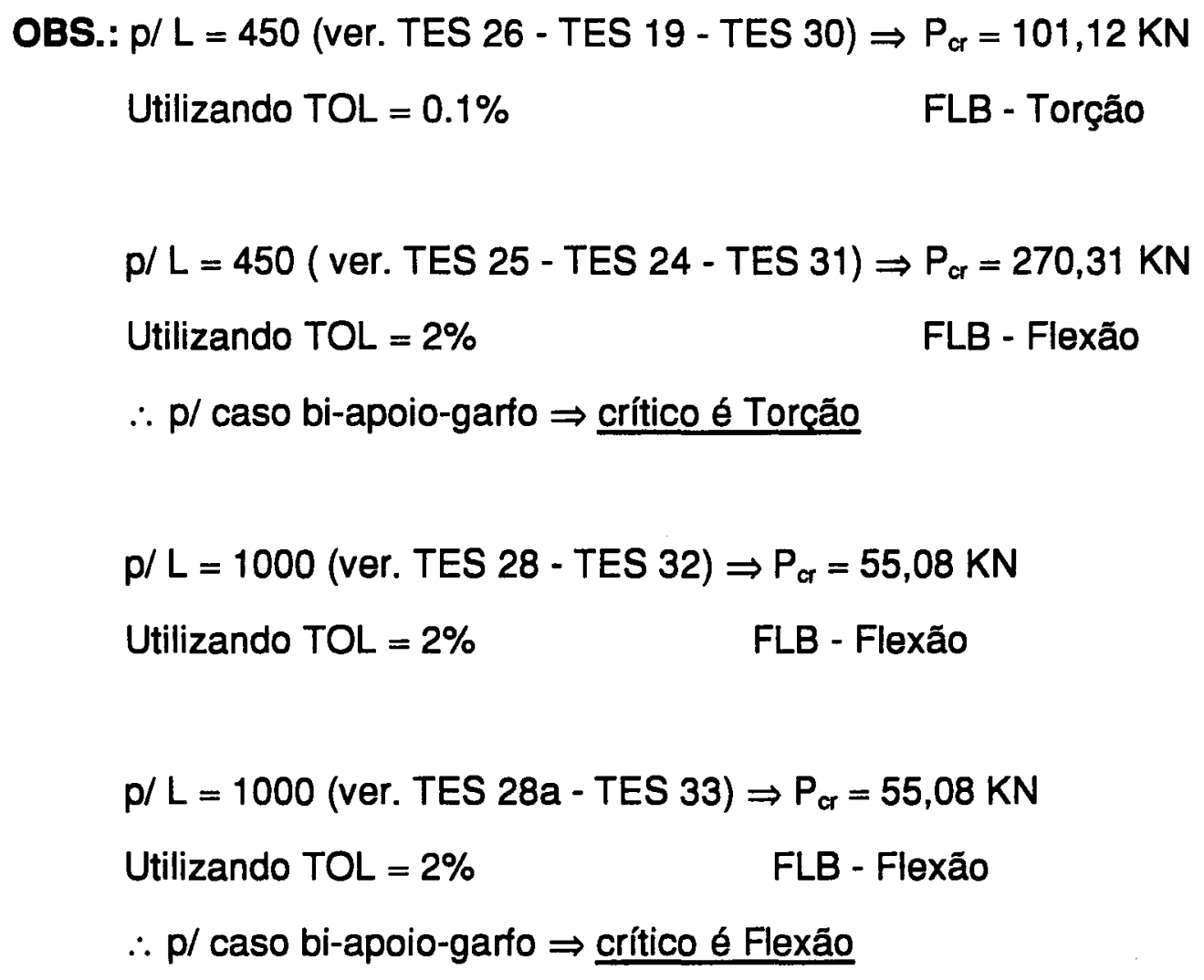


d) viga em balanço, formada por painéis que constituem o perfil metálico, para obtenção dos deslocamentos

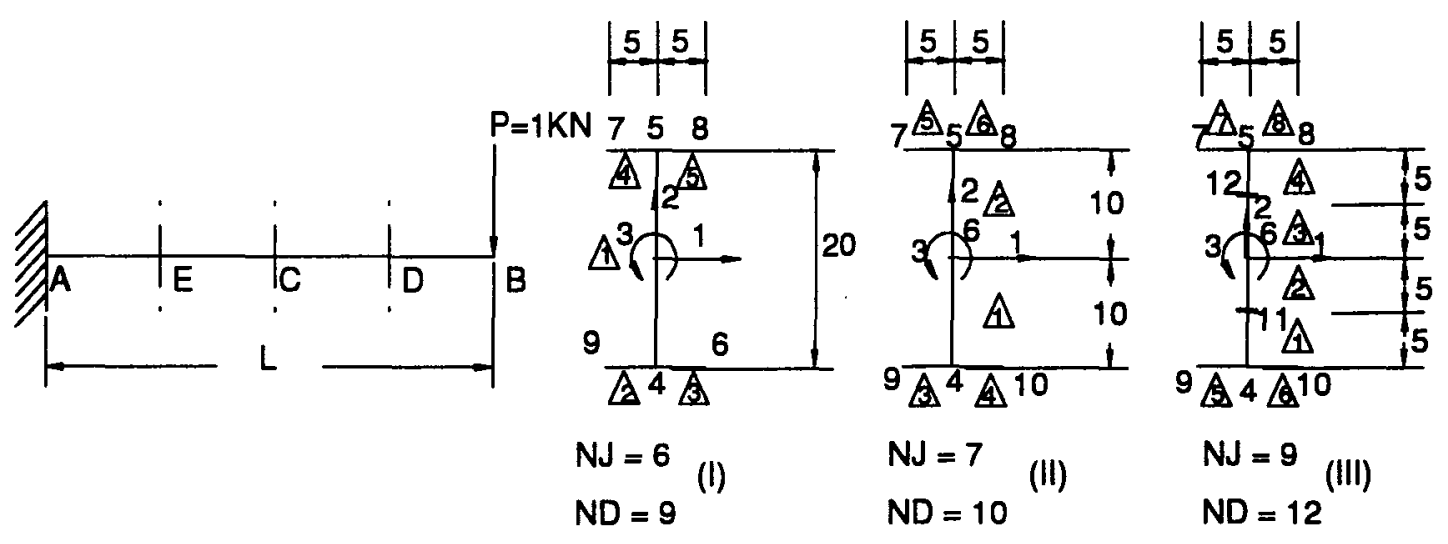

$$
\begin{array}{ll}
E=21000 \mathrm{KN} / \mathrm{cm}^{2} & M_{A}=450 \mathrm{KN} \cdot \mathrm{cm} \\
\mathrm{G}=8077 \mathrm{KN} / \mathrm{cm}^{2} & M_{\mathrm{C}}=225 \mathrm{KN} / \mathrm{cm} \\
\mathrm{t}=0,4 \mathrm{~cm} & \mathrm{i}_{\mathrm{D}}^{2}=70,57 \mathrm{~cm}^{2} \\
\mathrm{~S}=15,84 \mathrm{~cm}^{2} & \mathrm{~J}_{\mathrm{t}}=0,8533 \mathrm{~cm}^{4} \\
\mathrm{I}_{1}=1051,0 \mathrm{~cm}^{4} & \sigma_{\mathrm{A}, \max }=\frac{450 \cdot 10}{1051}=4,28 \mathrm{KN} / \mathrm{cm}^{2} \\
\mathrm{I}_{2}=66,77 \mathrm{~cm}^{4} & \sigma_{\mathrm{C}, \max }=\frac{225 \cdot 10}{1051}=2,14 \mathrm{KN} / \mathrm{cm}^{2}
\end{array}
$$

$\delta_{\mathrm{B}}=\frac{1 \cdot 450^{3}}{3 \cdot 21000 \cdot 1051}$

$\delta_{\mathrm{B}}=1,376 \mathrm{~cm}$

$\delta_{c}=\frac{5 \cdot 450^{3}}{48 \cdot 21000 \cdot 1051}$

$\delta_{\mathrm{c}}=0,430 \mathrm{~cm}$ 


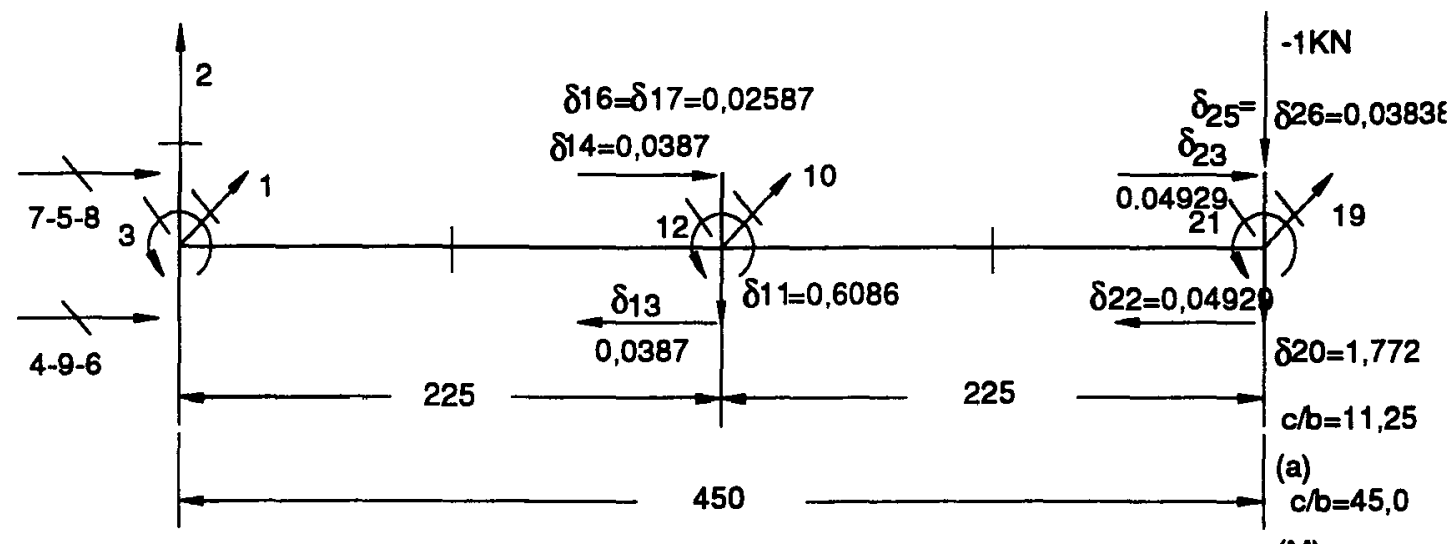

TES 52.DAT

(Tipo I)

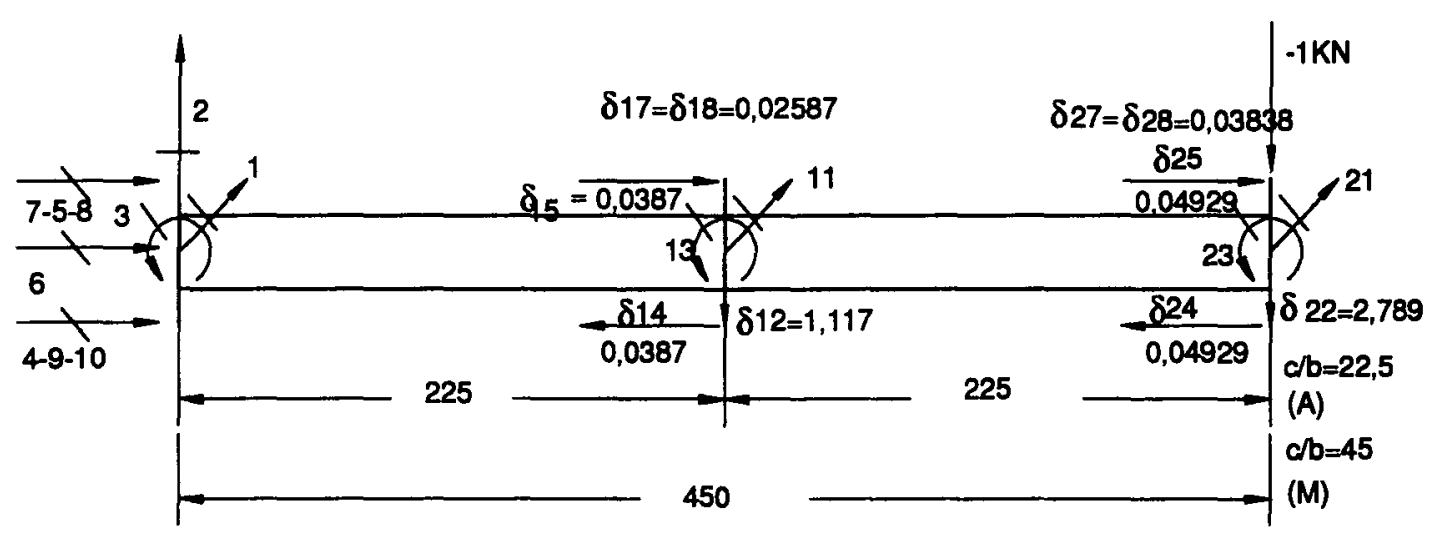

TES 53.DAT

(Tipo II)

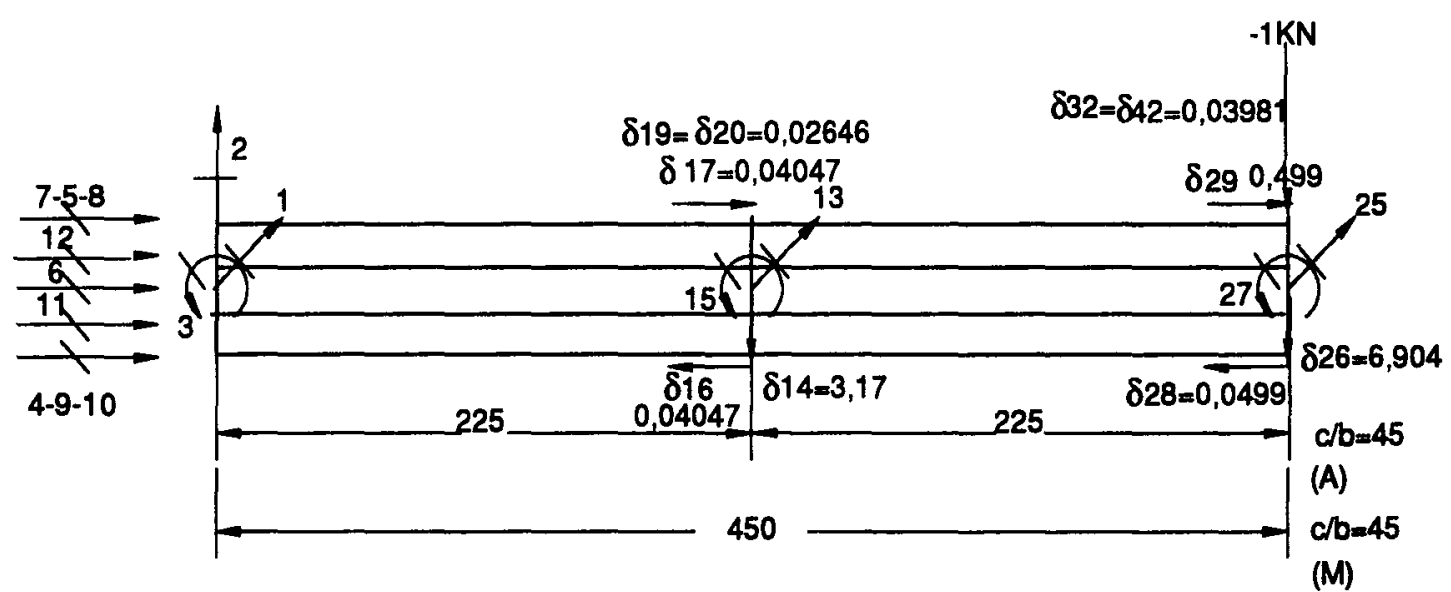

TES 54.DAT

(Tipo III) 


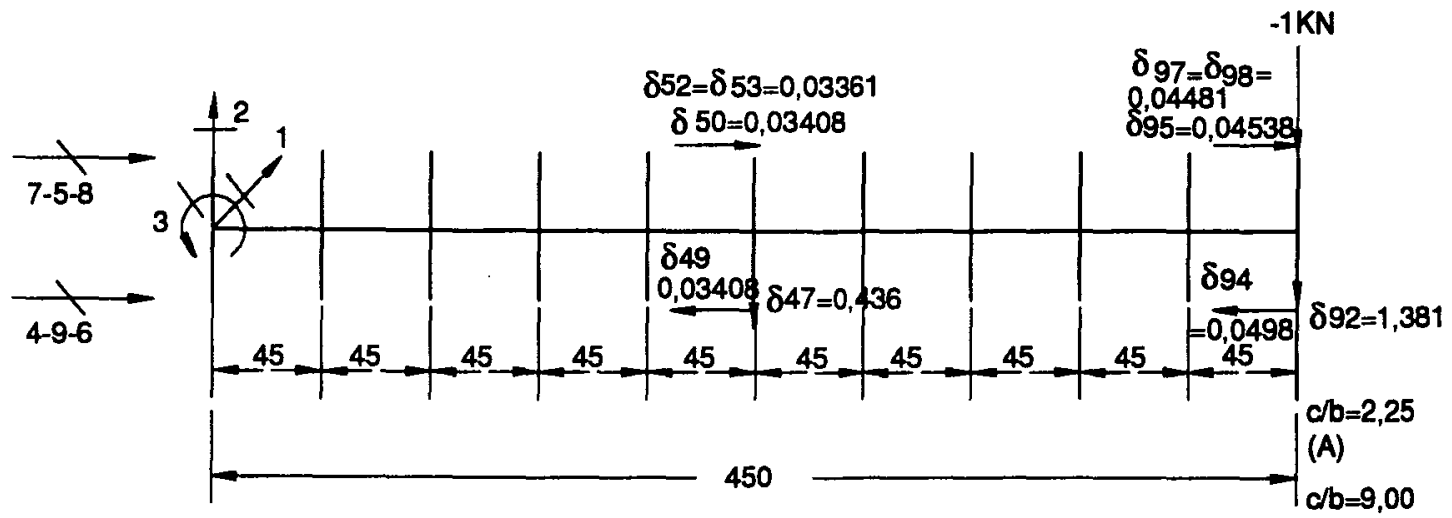

TES 55.DAT

(M)

(Tipo I)

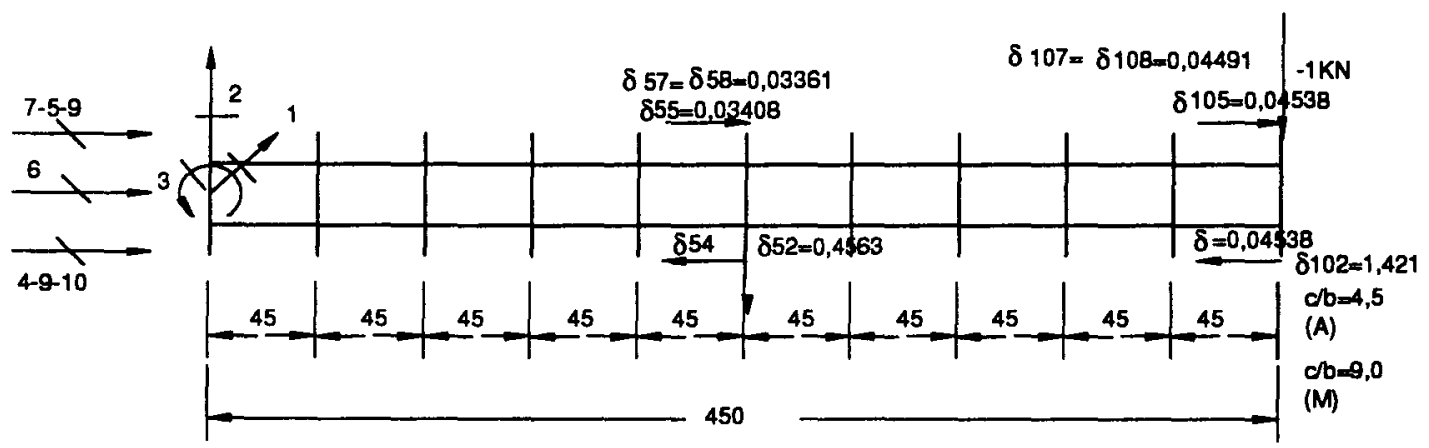

TES 56.DAT

(Tipo II)

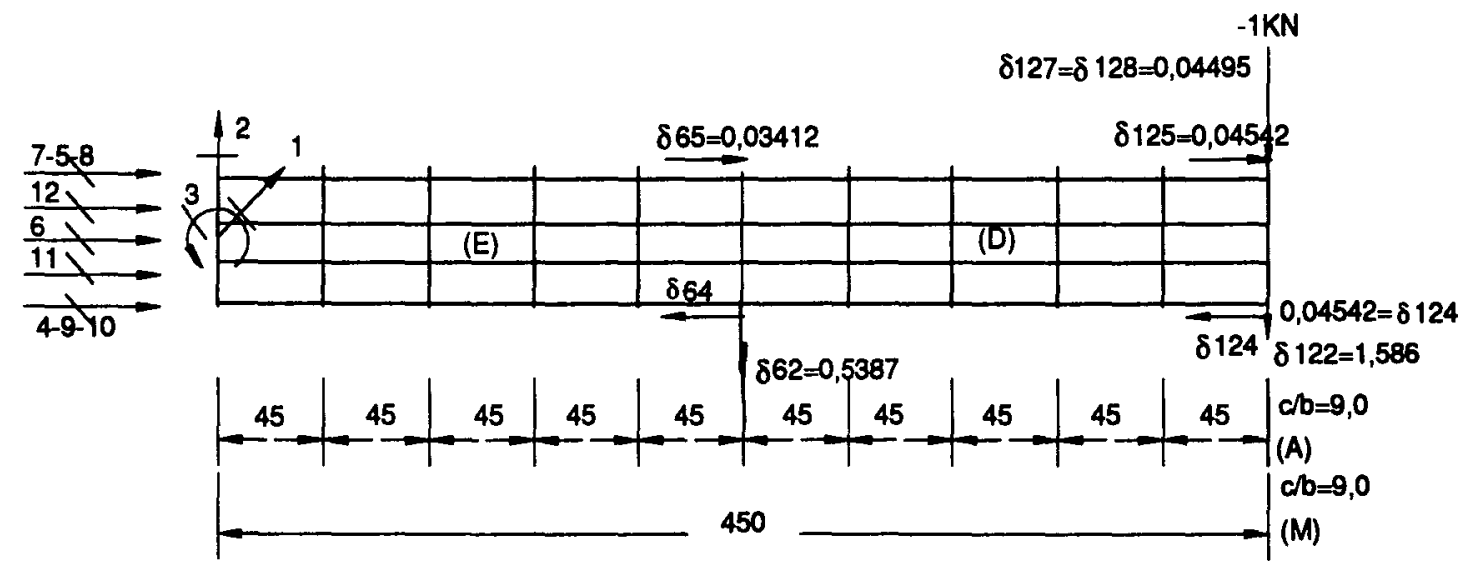

\section{TES 57.DAT}

(Tipo III) 
Resultados obtidos com perfil do tipo I, em viga em balanço com carga concentrada transversal ao eixo longitudinal aplicada na extremidade livre.

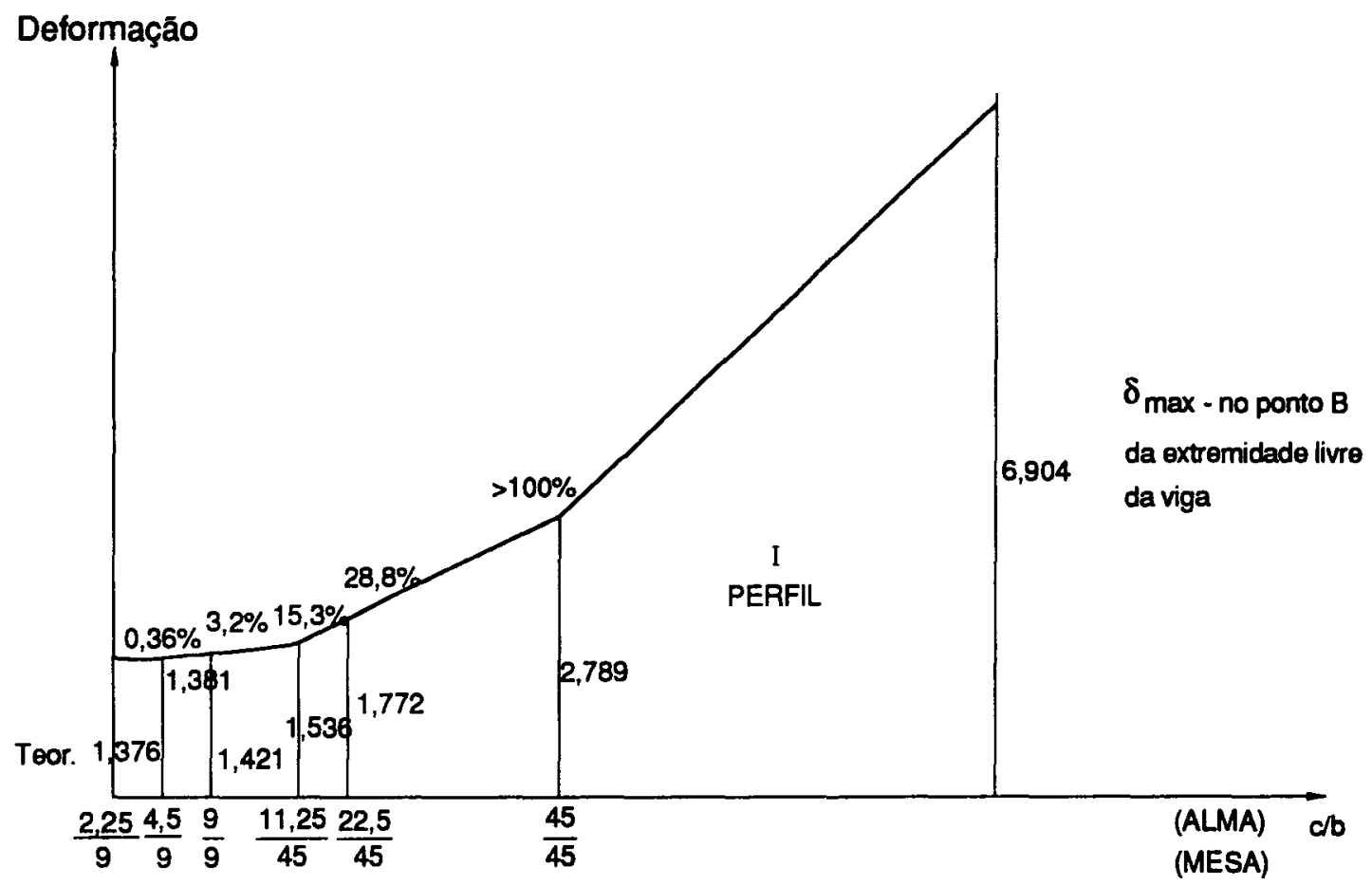

$c / b$ - Relação entre espaçamentos de diafragmas transversais e a largura do painel analisado 
e) viga em balanço, formada por painéis que constituem o perfil metálico, para obtenção do carregamento crítico
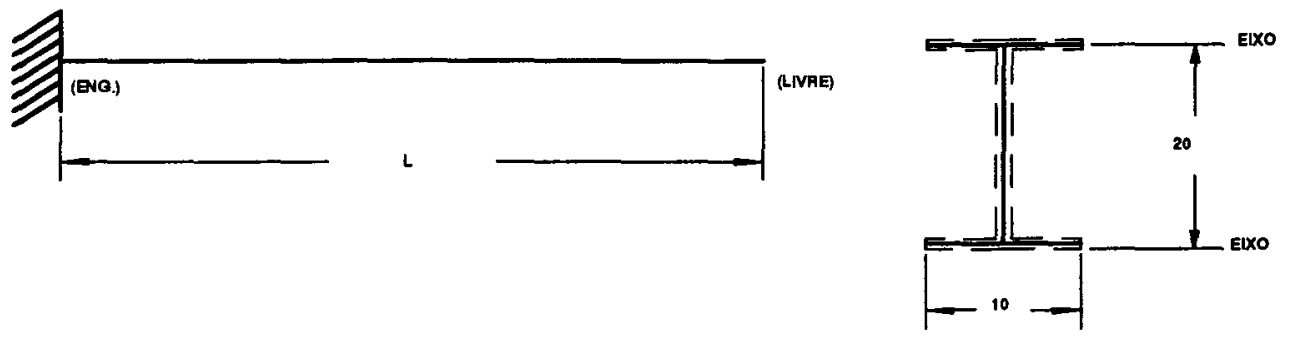

$\mathrm{E}=21000 \mathrm{KN} / \mathrm{cm}^{2} \quad \mathrm{I}_{2}=66,77 \mathrm{~cm}^{4}$

$\mathrm{G}=8077 \mathrm{KN} / \mathrm{cm}^{2} \quad \mathrm{~L}=450 \mathrm{~cm}$

$\mathrm{t}=0,4 \mathrm{~cm} \quad \mathrm{C}_{\mathrm{w}}=\mathrm{J}_{\mathrm{w}}=6666,67 \mathrm{~cm}^{6}$

$S=15,84 \mathrm{~cm}^{2} \quad i_{0}^{2}=70,57 \mathrm{~cm}^{2}$

$\mathrm{I}_{1}=1051,0 \mathrm{~cm}^{4} \quad J_{t}=0,8448 \mathrm{~cm}^{4}$

$11^{\circ}$ CASO: para $1^{a}$ espécie carga centrada de compressão

$P_{\text {cr1-1,10x. }}=\frac{\pi^{2} \cdot E \cdot I_{1}}{(2 \cdot 450)^{2}}=268,92 \mathrm{KN} ; \quad P_{\text {crp, torc. }}=\frac{G J_{T}}{i_{D}^{2}}=96,69 \mathrm{KN}$

$P_{\text {er2-2,110x. }}=\frac{\pi^{2} \cdot E \cdot I_{2}}{(2 \cdot 450)^{2}}=17,09 \mathrm{KN}$

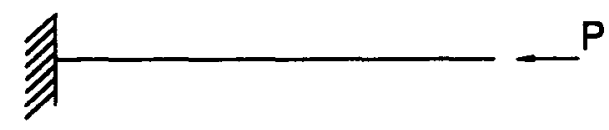

$2^{\circ}$ CASO: para $2^{2}$ espécie momento puro na extremidade livre

$$
\begin{aligned}
& M_{\mathrm{er}}=\frac{\pi}{\mathrm{L}} \sqrt{E I_{\mathrm{y}} \mathrm{GJ} J_{\mathrm{T}}} \cdot \sqrt{1+\mathrm{W}^{2}} \text {; } \\
& W=\frac{\pi}{L} \sqrt{\frac{E C_{W}}{G J_{T}}} \quad ; \quad W=0,995 \quad \therefore \quad M_{c r}=963,32 \mathrm{KN} \cdot \mathrm{cm} \\
& P_{c r}=M_{c r} / 20=48,165 \mathrm{KN}
\end{aligned}
$$


$3^{\circ}$ CASO: Para $2^{\mathrm{a}}$ espécie, carga transversal concentrada na extremidade livre, no CG e CC.

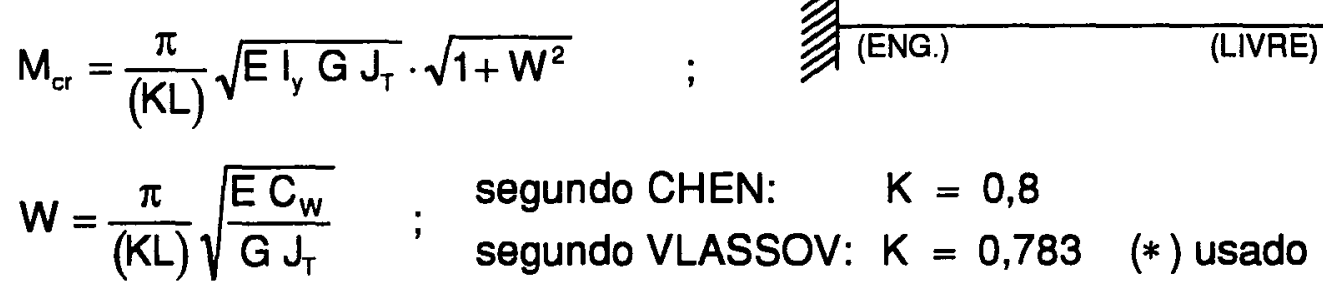

$$
\begin{array}{ll}
W=1,277 \quad \therefore \quad & M_{c r}=1414,85 \mathrm{KN} \cdot \mathrm{cm} \\
& P_{c r}=M_{c r} / L=3,144 \mathrm{KN}
\end{array}
$$

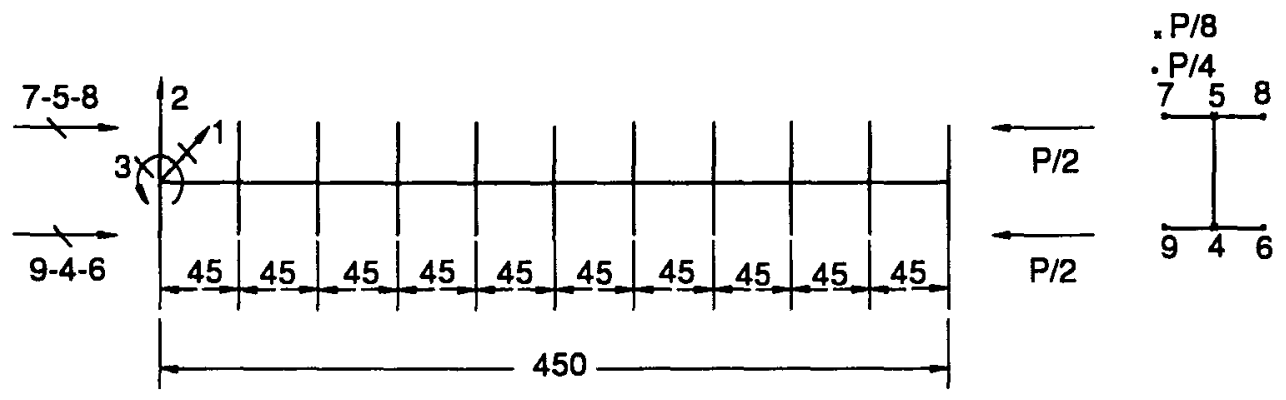

\section{TES 58}

(Tipo I)

$W_{c r}=16,95 . \quad c / b_{A}=2,25 . \quad c / b_{M}=9,00$

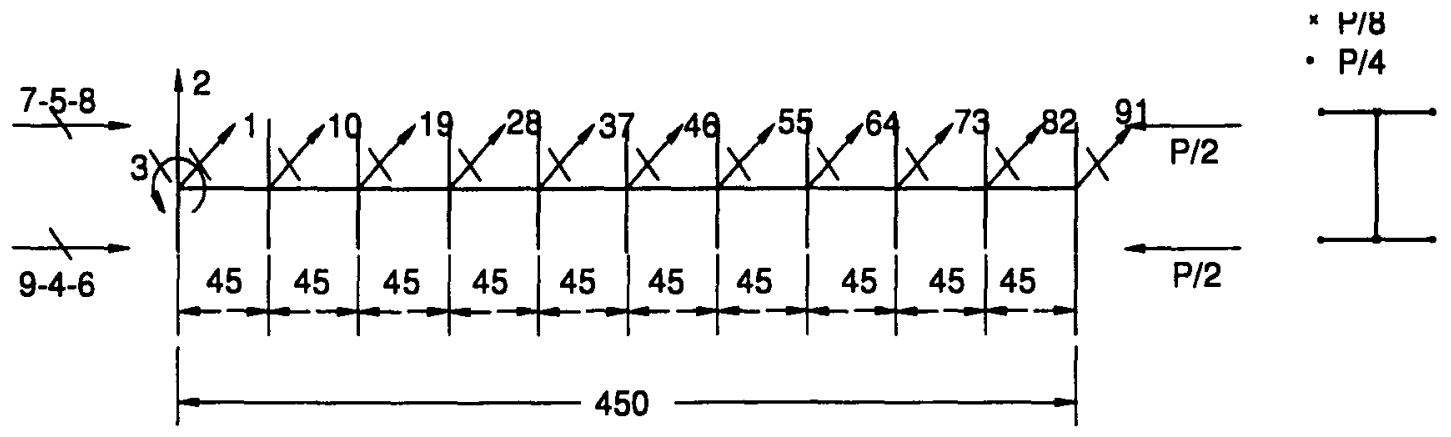

TES 59

(Tipo I)

$W_{c r}=112,05 . \quad c / b_{A}=2,25 . \quad c / b_{M}=9,00$ 


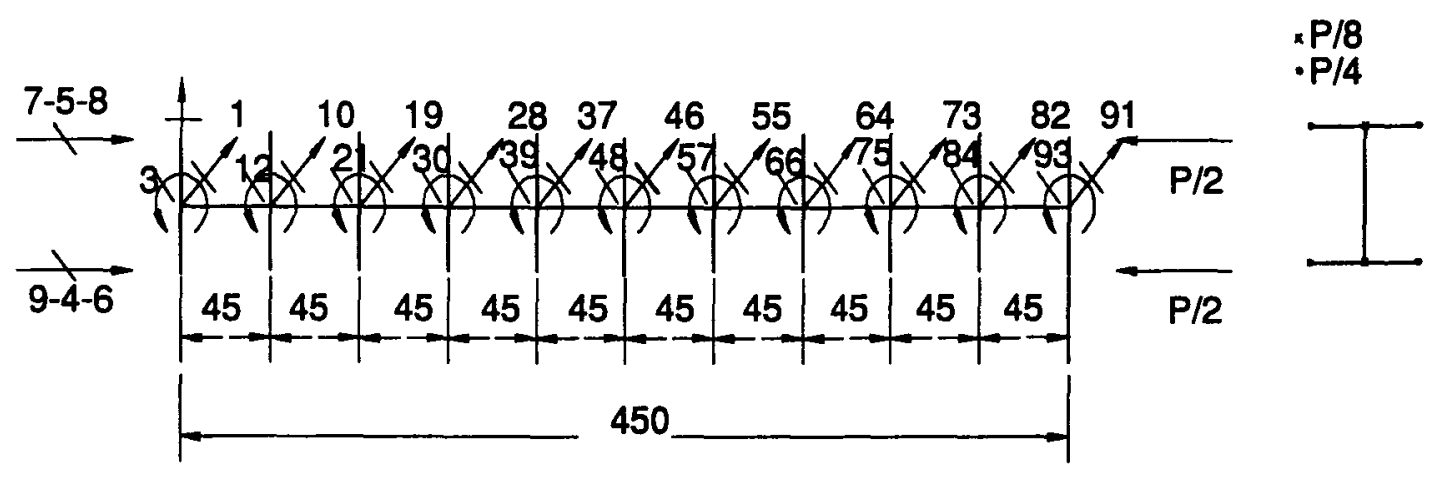

TES 60

(Tipo I)

$W_{c r}=267,39 . \quad c / b_{A}=2,25 . \quad c / b_{M}=9,00$

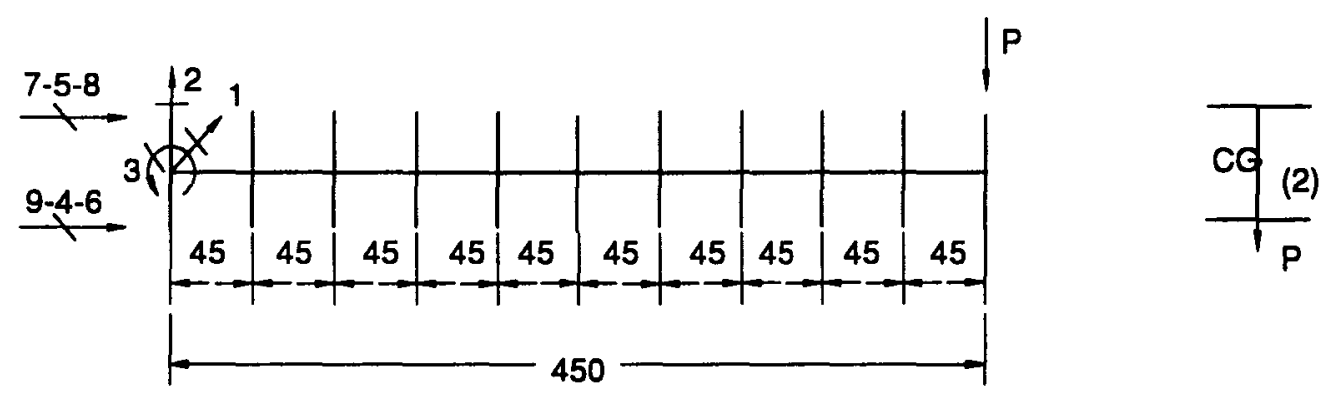

\section{TES 61}

(Tipo I)

$W_{c r}=3,245(2 \%) . \quad c / b_{A}=2,25 . \quad c / b_{M}=9,00$

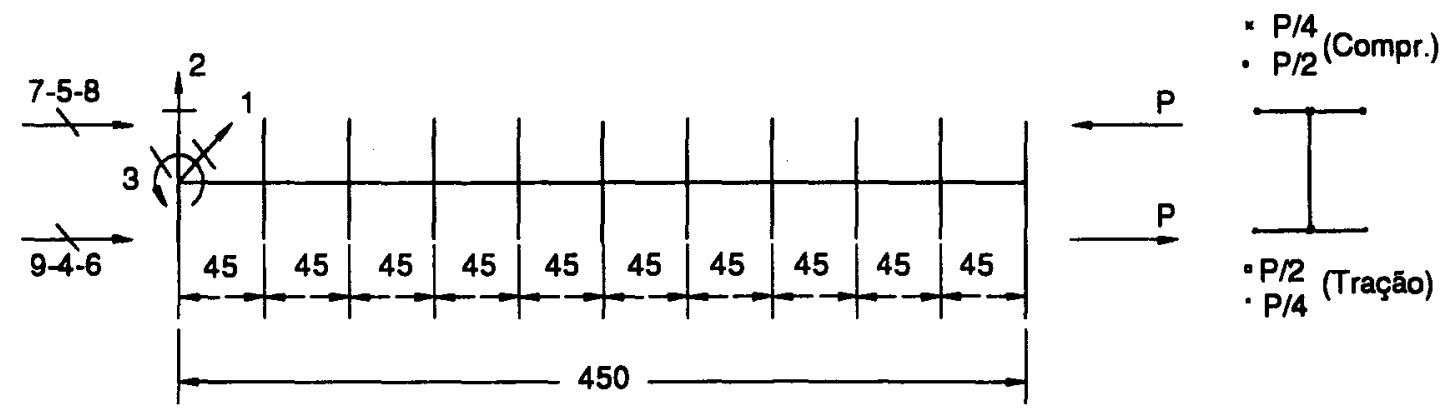

TES 62

(Tipo I)

$W_{c r}=50,72 . \quad c / b_{A}=2,25 . \quad c / b_{M}=9,00$ 


\section{REFERÊNCIAS BIBLIOGRÁFICAS}

1) AMERICAN INSTITUTE OF STEEL CONSTRUCTION, "Specification for the Design, Fabrication and Erection of Steel Buildings", AISC, Chicago, IL, 1978.

2) ASSOCIATION OF IRON AND STEEL ENGINEERS, "Guide for the Design and Construction of Mill Buildings", AISE Technical Reporter N.13, Pittsburgh, PA, 1979, 117p.

3) MURRAY, J.J. \& GRAHAM, T.C., "The Design of Mill Buildings", Iron and Steel Engineer, Vol. 34, N.2, p.159-172, 1957.

4) HUANG, H.C., "The Design of Mill Buildings Columns", Iron and Steel Engineer, Vol. 45, N.3, p.97-109, 1968.

5) HUANG, H.C., "Determination of Slenderness Ratios for Design of Heavy Mill Buildings Stepped Columns", Iron and Steel Engineer, Vol. 45, N.11, p.123-134, 1968.

6) GALAMBOS, T.V., "Guide to Stability Design Criteria for Metal Structures", Structural Stability Research Concil, 4th ed., John Wiley, 1988, 786p.

7) FISHER, J.M. \& BUETTNER, D.R., "Light \& Heavy Industrial Buildings", AISC-American Institute of Steel Construction, Chicago, IL, 1979, $185 p$.

8) YURA, J.A., "The Effective Length of Columns in Unbraced Frames", Engineering Journal - AISC, Vol. 8, N.2, p.37-42, 1971. 
9) ANDERSON, J.P. \& WOODWARD, J.H., "Calculation of Effective Lengths and Effective Slenderness Ratios of Stepped Columns", Engineering Journal - AISC, Vol. 9, N.4, p.157-166, 1972.

10) BAKOTA, J.F., "Mill Building Design Procedure", Engineering Journal AISC, N.4/4, p.130-7, 1977.

11) FISHER, J.M., "One Enginner's Opinion", Engineering Journal - AISC, N.1/4, p.14-8, 1980.

12) AGRAWAL, K.M. \& STAFIEJ, A.P., "Calculation of Effective Lengths of Stepped Columns", Engineering Journal - AISC, Vol.4, N. 4/4, p.96105, 1980.

13) MOORE, W.E. II, "A Programmable Solution for Stepped Crane Columns", Engineering Journal - AISC, Vol. 23, N.2/4, p.55-8, 1986.

14) CATIGLIONI, C.A., "Stepped Columns: A Simplified Design Method", Engineering Journal - AlSC, Vol.23, N.1/4, p.1-8, 1986.

15) VILAS, H.K., "Mill Building Frame Analysis: Distribuition of Lateral Loads", Engineering Journal - AISC, Vol.24, N.3/4, p.101-112, 1987.

16) FRASER, D.J., "Uniform Pin-Based Crane Columns, Effective Lengths", Engineering Journal - AISC, Vol.26, N.2/4, p.61-5, 1989.

17) YAGUI, T., "Critical Loading of Tall Core-Supported Structures", Computer \& Structures, Vol.36, N.2, p.223-235, 1990.

18) FRASER, D.J. \& BRIDGE, R.Q., "Buckling of Stepped Crane Columns", Journal Construction Steel Research, Vol.16, N.1, p.23-38, 1990. 
19) FRASER. D.J., "The In-Plane Stability of a Frame Containing Pin-Based Stepped Columns", Engineering Journal - AISC, Vol.27, N.2/4, p.49$53,1990$.

20) SMITH, C.V. Jr., "On Inelastic Column Buckling", Engineering Journal AISC, Vol.13, N.3/4, p.86-8, 1976.

21) BARNES, W.D. \& MANGELSDORF, C.P., "Allowable Axial Stresses in Segmented Columns", Engineering Journal - AISC, N.1/4, p.11-7, 1979.

22) SALMON, C.G. \& JOHNSON, J.E., "Steel Structures: Design and Behavior", 2nd ed., Harper \& How, N.Y., 1980, 1007p.

23) WHITE, D.W. \& HAJJAR, J.F., "Aplication of Second - Order Elastic Analysis in LRFD: Research To Pratice", Engineering Journal - AISC, N.4/4, p.133-148, 1991.

24) CHEN, W.F. \& LUI, E.M., "Stability Design Criteria for Steel Members and Frames in the United States", Journal Constructional Steel Research, Vo.5, p.31-74, 1985.

25) CHEN, W.F. \& LUI, E.M., "Structural Stability: Theory and Implementation", Elsevier, N.Y., 1987, 489p.

26) GALAMBOS, T.V., "Structural Members and Frames", Prentice-Hall, N.J., 1968, 373p.

27) BLEICH, F., "Buckling Strength of Metal Structures", McGraw-Hill, N.J., 1952, 508p. 
28) HORNE, M.R. \& MERCHANT, W., "The Stability of Frames", Pergamon Press Ltd., London, 1965, 179p.

29) TIMOSHENKO, S.P. \& GERE, J.M., "Theory of Elastic Stability", 2nd. ed., McGraw-Hill, N.Y, 1961, 541pp.

30) McGUIRE, W., "Steel Structures", N.J., 1968, 1112p.

31) MUKHANOV, K., "Estruturas Metálicas", Mir, Moscou, 1976, 520p. (Traduz. para português por ASRYANTZ, 1980).

32) VLASSOV, B.Z., "Pièces Longues En Voiles Minces", 10a. ed., Eyrolles, Paris, 1962, 655p.

33) YAGUI, T., "Estruturas Constituídas de Paredes Delgadas com Diafragmas Transversais", Tese de Doutorado, EESC-USP, S. Carlos, 1971, 138p.

34) YAGUI, T., "Análise de Estruturas de Edifícios Constituídas de Núcleo de Concreto Armado e Pilares ou Pendurais de Aço: Carregamento Crítico de Instabilidade Geral", Tese de Livre Docência, UNICAMPFaculdade de Engenharia de Limeira, 1978, 115p.

35) ANTUNES, H.M.C.C., "Carregamento Crítico de Instabilidade Geral para Estruturas Tridimensionais de Edifícios Altos", Tese de Doutorado, EESC-USP, São Carlos, 1978, 160p.

36) FIGUEIREDO, R.G. "Sobre a Instabilidade Elástica de Pórticos Tridimensionais de Edifícios", Tese de Doutorado, EESC-USP, São Carlos, 1976, 160p. 
37) RACHID, M., "Instabilidade de Barras de Seção Delgada", Tese de Doutorado, EESC-USP, São Carlos, 1975, 119p.

38) MORI, D.D., "Flexo-Torção de 1a e e 2a. Ordem: Automação do Cálculo", Dissertação de Mestrado, EESC-USP, 1978, 174p.

39) PALERMO Jr., L., "Esforços de Flexão e Flexo-Torcão em Teoria de Segunda Ordem: Automação de Cálculo", Dissertação de Mestrado, EESC-USP, São Carlos, 1985, 151p.

40) RUBISTEIN, M.F., "Matrix Computer Analysis of Structures", PrenticeHall, N.J., 1966, 402p.

41) GERE, J.M. \& WEVER, W.Jr., "Análise de Estruturas Reticuladas", Guanabara, R.J., 1987.

42) WEVER, W.Jr., "Computer Programs for Structural Analysis", Van. Nostrand, 1967, 300p.

43) JENNINGS, A., "Matrix Computation for Engineers and Scientists", A. Wiley, 1977. (Reimpr. 1978).

44) RACHID, M. \& MORI, D.D., "Instabilidade: Conceitos-Aplicação na Flambagem por Flexão", Publicação 049/89, EESC-USP, São Carlos, 1989, 130p.

45) MORI, D.D., "Flexo-Torção: Barras com Seção Transversal Aberta e Paredes Delgadas", Publicação 42/88, EESC-USP, São Carlos, 1988, $133 p$. 
46) RACHID, M. \& MORI, D.D., "Instabilidade: Flambagem de Barras de Seção Delgada por Torção e Flexão", Publicação 056/93, EESC-USP, São Carlos, 1993, 166p.

47) MORI, D.D., "Os Núcleos Estruturais e a Não Linearidade Geométrica na Análise de Estruturas Tridimensionais de Edifícios Altos", Tese de Doutorado, EESC-USP, São Carlos, 1992, 195p.

48) SERRA, J.L.F.A., "Contribuição ao Estudo de Núcleos Resistêntes de Concreto Armado", Tese de Doutorado, EESC-USP, São Carlos, 1994, 128p.

49) AMERICAN INSTITUTE OF STEEL CONSTRUCTION, "Manual of Steel Construction: Allowable Stress Design", AISC, 9a. ed., Chicago, IL, 1989.

50) AMERICAN INSTITUTE OF STEEL CONSTRUCTION, "Load and Resistence Factor Design: Specification for Structural Steel Buildings", AISC, 1a. ed., Chicago, IL, 1986.

51) ASSOCIAÇÃO BRASILEIRA DE NORMAS TÉCNICAS, "Projeto e Execução de Estruturas de Aço de Edifícios: Método dos Estados Limites", ABNT, 2a. ed., RJ, 1986.

52) GOLUB, G.H. \& VAN LOAN, C.F., "Matrix Computations", 2a. ed., John Hop Kings, Baltimor, 1990, 642p.

53) YAGUI, T., "Estruturas Metálicas dos Edifícios Industriais", Publicaçāo 23/87, FEL-UNICAMP, Limeira, 1987, 52p.

54) BELLEl, I.H., "Edifícios Industriais em Aço", Pini, Săo Paulo, 1994, 493p. 
55) FRUCHTENGARTEN, J., "Sobre a Estabilidade de Perfis de Seção Aberta", Tese de Doutorado, EPUSP, São Paulo,1995, 245p

56) PIMENTA, P.M. \& YOJO, T., "Geometrically Exact Analysis of Spacial Frames, With Consideration of Torsion Warping", XIV CILAMCE Congresso Ibero Latino Americano sobre Métodos Computacionais para Engenharia, Anais, São Paulo, 1993. 